Metodologia para mapeamento de informações não estruturadas descritas em laudos médicos para uma representação atributo-valor 



\title{
Metodologia para mapeamento de informações não estruturadas descritas em laudos médicos para uma representação atributo-valor ${ }^{1}$
}

\author{
Daniel de Faveri Honorato
}

Orientadora: Prof ${ }^{a} \operatorname{Dr}^{a}$ Maria Carolina Monard

Dissertação apresentada ao Instituto de Ciências Matemáticas e de Computação - ICMC-USP, como parte dos requisitos para obtenção do título de Mestre em Ciências de Computação e Matemática Computacional.

\section{USP - São Carlos março/2008}

\footnotetext{
${ }^{1}$ Trabalho realizado com auxílio da Fundação Parque Tecnológico Itaipu e CNPq.
} 



\section{Dedicatória}

A meu pai Antonio Salvato Honorato, in memoriam, por ter-me ensinado, com seus exemplos e suas palavras, o amor a Deus, o serviço ao próximo e a dedicação ao estudo e ao trabalho. A minha família e a todos aqueles que contribuíram para minha formação até 



\section{Agradecimentos}

A minha orientadora Maria Carolina Monard pela dedicação e paciência na orientação deste trabalho. Agradeço por ela ter sido minha orientadora e a cada dia aprendo coisas que vou guardar para minha vida.

A minhã mãe e ao meu irmão, pelo apoio incondicional em todos os momentos. São pessoas maravilhosas que sempre estão me encorajando para enfrentar os problemas e compartilhar com elas a alegria das minhas conquistas.

Aos amigos e mestres Huei e Paulo Wu, que foram meus primeiros orientadores. Agradeço pela amizade, longas conversas no LABI e por terem me apresentado ao mundo da pesquisa. Agradeço por todos ensinamentos que me proporcionam. Também ao amigo do LABI, Renato Bobsin Machado, pela amizade.

Aos amigos e colegas do LABIC, Ronaldo, Takashi, Richardson, Eduardo S., Quiles, Katti, Rafael G., Andres, André, Ana, Magaly, Bruno F., Rodrigo C., Márcio e Tiago, pelos momentos juntos, a "hora do cafezinho", que tornaram meu dia-a-dia mais agradável.

Aos amigos da república "StaffSushi", Takashi, Mauro Miazaki, Ronaldo, Sidney Sato e Márcio Miazaki pelos vários momentos de lazer e companheirismo.

Ao Ronaldo pelas dicas do $\mathrm{LT}_{\mathrm{E}} \mathrm{X}$ e discussões a respeito do trabalho e ao Caneca pelo auxílio no PreTexT.

A Thaíne, pela pessoa especial que é e pela compreensão e paciência em todos os momentos.

A Fundação Parque Tecnológico Itaipu - FPTI pela bolsa no primeiro ano do mestrado e ao CNPq pela bolsa no segundo ano do mestrado.

Aos funcionários do ICMC, sempre prestativos, em especial as garotas da pós-graduação Ana Paula, Beth e Laura.

A todos do LABI e do LABIC que me apoiaram no momento mais difícil da minha vida. 



\section{Resumo}

Devido à facilidade com que informações biomédicas em língua natural são registras e armazenadas no formato digital, a recuperação de informações a partir de registros de pacientes nesse formato não estruturado apresenta diversos problemas a serem solucionados. Assim, a extração de informações estruturadas (por exemplo, no formato atributo-valor) a partir de registros não estruturados é um importante problema de pesquisa. Além disso, a representação de registros médicos não estruturados no formato atributo-valor, permite a aplicação de uma grande variedade de métodos de extração de padrões. Para mapear registros médicos não estruturados no formato atributo-valor, propomos uma metodologia que pode ser utilizada para automaticamente (ou semi-automaticamente, com a ajuda de um especialista do domínio) mapear informações médicas de interesse armazenadas nos registros médicos e descritas em linguagem natural em um formato estruturado. Essa metodologia foi implementada em um sistema computacional chamado TP-DISCOVER, o qual gera uma tabela no formato atributo-valor a partir de um conjunto de registros de pacientes (documentos). De modo a identificar entidades importantes no conjunto de documentos, assim como relacionamentos significantes entre essas entidades, propomos uma abordagem de extração de terminologia híbrida (lingüística/estatística) a qual seleciona palavras e frases que aparecem com freqüência acima de um dado limiar por meio da aplicação de medidas estatísticas. A idéia geral dessa abordagem híbrida de extração de terminologia é que documentos especializados são caracterizados por repetir o uso de certas unidades léxicas ou construções morfo-sintáticas. Nosso objetivo é reduzir o esforço despendido na modelagem manual por meio da observação de regularidades no texto e o mapeamento dessas regularidades como nomes de atributos na representação atributo-valor. A metodologia proposta foi avaliada realizando a estruturação automática de uma coleção de 6000 documentos com informações de resultados de exames de Endoscopia Digestiva Alta descritos em língua natural. Os resultados experimentais, os quais podem ser considerados os piores resultados, uma vez que esses resultados poderiam ser muito melhores caso a metodologia for utilizada semi-automaticamente junto com um especialista do domínio, mostram que a metodologia proposta é adequada e permite reduzir o tempo usado pelo especialista para analisar grande quantidade de registros médicos. 



\section{Abstract}

The information retrieval from text stored in computer-based patient records is an important open-ended research problem, as the ease in which biomedical information recorded and stored in digital form grows. Thus, means to extract structured information (for example, in the so-called attribute-value format) from free-text records is an important research endeavor. Furthermore, by representing the free-text records in the attribute-value format, available pattern extraction methods can be directly applied. To map free-text medical records into the attribute-value format, we propose a methodology that can be used to automatically (or semi-automatically, with the help of a medical expert) map the important medical information stored in patient records which are described in natural language into an structured format. This methodology has been implemented in a computational system called TP-DISCOVER, which generates a database in the attribute-value format from a set of patient records (documents). In order to identify important entities in the set of documents, as well as significant relations among these entities, we propose a hybrid linguistic/statistical terminology extraction approach which filters out words and phrases that appear with a frequency higher than a given threshold by applying statistical measures. The underlying assumption of this hybrid approach to terminology extraction is that specialized documents are characterized by repeated use of certain lexical units or morpho-syntactic constructions. Our goal is to reduce the effort spent in manual modelling by observing regularities in the texts and by mapping them into suitable attribute names in the attribute-value representation format. The proposed methodology was evaluated to automatically structure a collection of 6000 documents which contains High Digestive Endoscopies exams' results described in natural language. The experimental results, all of which can be considered lower bound results as they would greatly improve in case the methodology is applied semi-automatically together with a medical expert, show that the proposed methodology is suitable to reduce the medical expert workload in analysing large amounts of medical records. 

Esta dissertação foi preparada com o formatador de textos $\mathrm{ET}_{\mathrm{E}} \mathrm{X}$. Foi utilizado um estilo (style) desenvolvido por Ronaldo Cristiano Prati. O sistema de citações de referências bibliográficas utiliza o padrão Apalike do sistema Bibtex.

Algumas palavras utilizadas neste trabalho não foram traduzidas da língua inglesa para a portuguesa por serem amplamente conhecidas e difundidas na comunidade acadêmica. 



\section{Sumário}

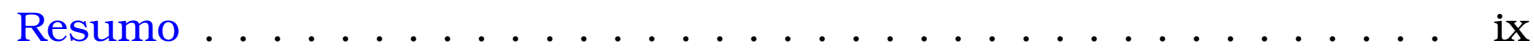

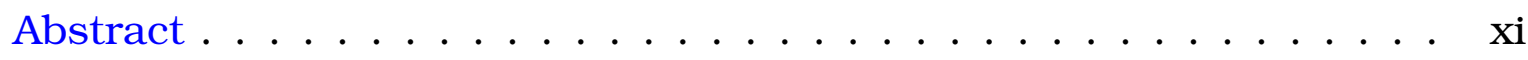

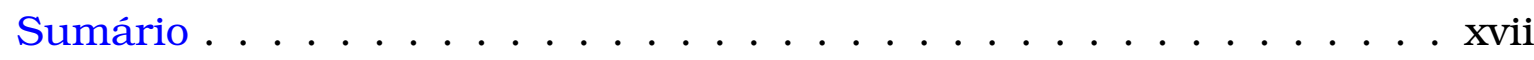

Lista de Figuras . . . . . . . . . . . . . . xxi

Lista de Tabelas . . . . . . . . . . . . . . . . . . xxvi

Lista de Algoritmos . . . . . . . . . . . . . . . . . xxvii

Lista de Abreviaturas . . . . . . . . . . . . . . . . xxix

1 Introdução 1

1.1 Principais Objetivos do Trabalho . . . . . . . . . . . 9

1.2 Organização do Trabalho . . . . . . . . . . . . . . 10

2 Pré-processamento $\quad 11$

2.1 Considerações Iniciais . . . . . . . . . . . . . . . . . . 11

2.2 Mineração de Textos . . . . . . . . . . . . . . . . . . . 11

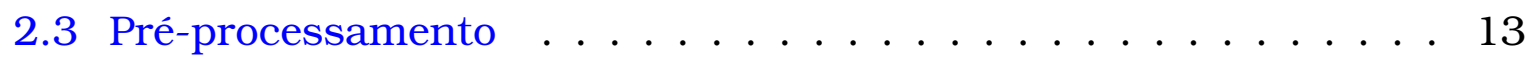

2.3.1 Representação dos Documentos . . . . . . . . . . . . 13

2.3 .2 Valores dos Atributos . . . . . . . . . . . . . . . 14

2.3.3 Redução de Dimensionalidade . . . . . . . . . . . . 15

2.3.4 Outras Abordagens para Identificação de Atributos . . . . . 16

2.4 Trabalhos Relacionados . . . . . . . . . . . . . . . . . 18

2.5 Considerações Finais . . . . . . . . . . . . . . . . . . . 19

3 Extração de Terminologia $\quad 21$

3.1 Considerações Iniciais . . . . . . . . . . . . . . . . . . 21

3.2 Abordagem Lingüística . . . . . . . . . . . . . . . 24

3.3 Abordagem Estatística . . . . . . . . . . . . . . 25

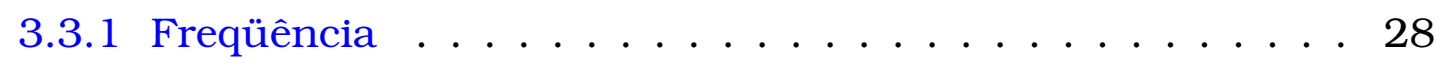

3.3 .2 Informação Mútua . . . . . . . . . . . . . 28 
3.3.3 Log-likelihood . . . . . . . . . . . . . . . . . . . . 29

3.3 .4 Dice . . . . . . . . . . . . . . . . . . 29

3.4 Abordagem Híbrida . . . . . . . . . . . . . 30

3.5 Avaliação . . . . . . . . . . . . . . . . . 30

3.6 Considerações Finais . . . . . . . . . . . . . . . . . 31

4 Visão Geral da Metodologia 33

4.1 Considerações Iniciais . . . . . . . . . . . . . . . . . . . 33

4.2 Metodologia Proposta . . . . . . . . . . . . . . . . 34

4.2.1 Fase 1 - Pré-processamento . . . . . . . . . . . 34

4.2.2 Fase 2 - Extração de Terminologia . . . . . . . . . . . . 35

4.2.3 Fase 3 - Identificação de Atributos . . . . . . . . . . 36

4.2.4 Fase 4 - Construção do Dicionário . . . . . . . . . . . . . 39

4.2.5 Fase 5 - Construção da Tabela Atributo-valor . . . . . . . 39

4.3 Considerações Finais . . . . . . . . . . . . . . . 41

5 Metodologia Desenvolvida 43

5.1 Considerações Iniciais . . . . . . . . . . . . . . . . . . 43

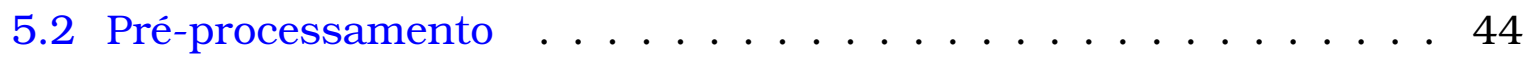

5.2 .1 Preparação do Corpus . . . . . . . . . . . . . . . . . 45

5.2.2 Construção do Conjunto de Frases Únicas . . . . . . . . . . 46

5.2 .3 Remoção de Stopwords . . . . . . . . . . . . . . . . . . 48

5.2.4 Transformação para Minúsculo . . . . . . . . . . . 49

5.2 .5 Correção Ortográfica . . . . . . . . . . . . . . . . . . . 49

5.2 .6 Normalização . . . . . . . . . . . . . . . . . . . . 52

5.2.6.1 Aplicação de Substituições . . . . . . . . . . . . 53

5.2.6.2 Aplicação de Lematização . . . . . . . . . . . . . . 55

5.3 Extração de Terminologia . . . . . . . . . . . . . . . 56

5.3.1 Etiquetação dos Documentos . . . . . . . . . . . . 58

5.3 .2 Definição de Máscaras . . . . . . . . . . . . . . . . . 61

5.3.3 Extração de Termos dos Documentos . . . . . . . . . . . . . 62

5.3.4 Aplicação de Heurísticas . . . . . . . . . . . . . . . . 64

5.4 Identificação de Atributos . . . . . . . . . . . . . . . . . 68

5.4.1 Definição de Termos raiz . . . . . . . . . . . . . 69

5.4 .2 Geração de Árvores . . . . . . . . . . . . . . . . . 70

5.4 .3 Definição de Atributos . . . . . . . . . . . . . . . . 73

5.5 Construção do Dicionário . . . . . . . . . . . . . . . . . 74

5.6 Construção da Tabela Atributo-valor . . . . . . . . . . . . 75

5.7 Considerações Finais . . . . . . . . . . . . . 76 
6 Avaliação Experimental $\quad 79$

6.1 Descrição do Conjunto de Laudos . . . . . . . . . . . . . . . 79

6.2 Configurações dos Experimentos . . . . . . . . . . . 80

6.3 Resultados - Seção de Esôfago . . . . . . . . . . . . . . . . . . . 84

6.3.1 Aspecto Quantitativo . . . . . . . . . . . . . 84

6.3 .2 Aspecto Qualitativo . . . . . . . . . . . . . 93

6.4 Resultados - Seção de Estômago . . . . . . . . . . . . . . 96

6.4.1 Aspecto Quantitativo . . . . . . . . . . . . . . 96

6.4 .2 Aspecto Qualitativo . . . . . . . . . . . 103

6.5 Considerações Finais . . . . . . . . . . . . . 105

7 Conclusões 107

7.1 Contribuições . . . . . . . . . . . . . . . 108

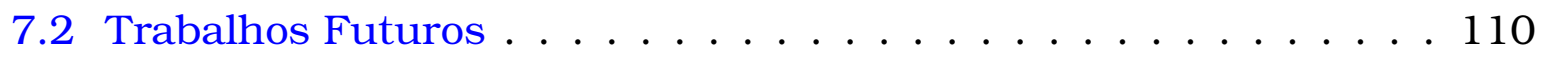

$\begin{array}{ll}\text { Referências } & 118\end{array}$

A Resultados do Processamento da Seção de Esôfago 119

B Resultados do Processamento da Seção de Estômago 133 
Xviii 


\section{Lista de Figuras}

1.1 Tipos de estruturação de documentos . . . . . . . . . 2

1.2 Tipos de laudos . . . . . . . . . . . . . . . 6

1.3 Laudo estruturado de Andrologia . . . . . . . . . . . . 7

1.4 Laudo semi-estruturado de Endoscopia Digestiva Alta . . . . . 8

2.1 Processo de mineração de textos . . . . . . . . . . . . . . . 12

4.1 Fases da metodologia . . . . . . . . . . . . . . 34

4.2 Extração de terminologia . . . . . . . . . . . . . . . 35

4.3 Geração de árvores a partir dos termos identificados . . . . . . . 37

4.4 Exemplo de árvore gerada a partir do termo raiz terço distal 38

4.5 Árvore gerada . . . . . . . . . . . . . . . . . . 38

5.1 Metodologia desenvolvida . . . . . . . . . . . . . . . 44

5.2 Divisão das seções do laudo de Endoscopia Digestiva Alta . . . . 45

5.3 Exemplo de geração do CFU . . . . . . . . . . . . . . 46

5.4 Exemplo do arquivo do $\mathrm{CFU} \ldots \ldots \ldots$

5.5 Exemplo do arquivo de estatística do CFU . . . . . . . . . . 48

5.6 Exemplo do arquivo de stopwords . . . . . . . . . . . . . . . 49

5.7 Exemplo do arquivo de correção de termos incorretos . . . . . . 52

5.8 Exemplo do arquivo de substituição . . . . . . . . . . . . . . 54

5.9 Processo de aplicação das substituições . . . . . . . . . . 55

5.10 Metodologia para extração de termos . . . . . . . . . . . 58

5.11 Geração e análise do CFU etiquetado . . . . . . . . . . . . . . 59

5.12 Aplicação do algoritmo de correção de etiquetas . . . . . . . . . 59

5.13 Exemplo do arquivo de correção de etiquetas . . . . . . . . 60

5.14 Processo de etiquetação do conjunto de documentos . . . . . . . 60

5.15 Exemplos de frases extraídas de um laudo . . . . . . . . . . . 61

5.16 Exemplos de frases etiquetadas extraídas de um laudo . . . . . 61 
5.17 Processo de extração de termos . . . . . . . . . . . . . 62

5.18 Termo raiz da árvore . . . . . . . . . . . . . . . . 70

5.19 Filho do termo raiz . . . . . . . . . . . . . . 71

5.20 Filho do termo mucoso . . . . . . . . . . . . . 71

5.21 Arquivo correspondente a árvore gerada a partir dos termos lago e cardia . . . . . . . . . . . . . . 72

5.22 Árvore gerada a partir do termo lago . . . . . . . . . . 73

5.23 Árvore gerada a partir do termo cardia . . . . . . . . . . . 73

5.24 Arquivo com os comandos do GRAPHVIZ gerado a partir da descrição XML do termo lago . . . . . . . . . . . . . . . . 73

5.25 Árvore gerada a partir do termo mucosa fundo . . . . . . . . . 74

5.26 Exemplo da tabela atributo-valor $\ldots \ldots \ldots \ldots \ldots$

6.1 Laudo de EDA . . . . . . . . . . . . . . . . 80

6.2 Divisão dos laudos . . . . . . . . . . . . . . . . 80

6.3 Configuração dos experimentos . . . . . . . . . . 83

6.4 Relação entre número de termos raiz e número de atributos gerados utilizando limiar igual a 0\% - seção de esôfago . . . . . 87

6.5 Taxa de atributos considerados utilizando limiar igual a 5\% seção de esôfago . . . . . . . . . . . . . . . . . 88

6.6 Taxa de atributos considerados utilizando limiar igual a $10 \%-$ seção de esôfago . . . . . . . . . . . . . . . 88

6.7 Taxa de atributos considerados utilizando limiar igual a $20 \%-$ seção de esôfago . . . . . . . . . . . . . . . . . . 89

6.8 Garbage correspondente ao experimento Exp1, usando 4009 frases do conjunto Te - seção de esôfago . . . . . . . . . . . 91

6.9 Garbage correspondente ao experimento Exp2, usando 4011 frases do conjunto Te - seção de esôfago . . . . . . . . . . . 91

6.10 Garbage correspondente ao experimento Exp3, usando 3998 frases do conjunto Te - seção de esôfago . . . . . . . . . . . 92

6.11 Garbage correspondente ao experimento Exp4, usando 4013 frases do conjunto Te - seção de esôfago . . . . . . . . . . . . 9 92

6.12 Precisão e recall para o experimento Exp1 - seção de esôfago . . 94

6.13 Precisão e recall para o experimento Exp2 - seção de esôfago . . 94

6.14 Precisão e recall para o experimento Exp3 - seção de esôfago . . 95

6.15 Precisão e recall para o experimento Exp4 - seção de esôfago . . 95

6.16 Relação entre número de termos raiz e número de atributos gerados utilizando limiar igual a $0 \% \ldots$. . . . . . . . 98 
6.17 Taxa de atributos considerados utilizando limiar igual a 5\% seção de estômago . . . . . . . . . . . . . . . . . . . 999

6.18 Taxa de atributos considerados utilizando limiar igual a $10 \%$ seção de estômago . . . . . . . . . . . . . . . . . . . 99

6.19 Taxa de atributos considerados utilizando limiar igual a $20 \%-$ seção de estômago . . . . . . . . . . . . . . . . . . . 999

6.20 Garbage correspondente ao experimento Exp1, usando 7966 frases do conjunto Te - seção de estômago . . . . . . . . . . . 102

6.21 Garbage correspondente ao experimento Exp2, usando 7971 frases do conjunto Te - seção de estômago . . . . . . . . . . . 102

6.22 Garbage correspondente ao experimento Exp3, usando 8003 frases do conjunto Te - seção de estômago . . . . . . . . . . . 102

6.23 Garbage correspondente ao experimento Exp4, usando 7961 frases do conjunto Te - seção de estômago . . . . . . . . . . . 103

6.24 Precisão e recall para o experimento Exp1 - seção de estômago . 103

6.25 Precisão e recall para o experimento Exp2 - seção de estômago . 104

6.26 Precisão e recall para o experimento Exp3 - seção de estômago . 104

6.27 Precisão e recall para o experimento Exp4 - seção de estômago . 105 


\section{Lista de Tabelas}

2.1 Representação atributo-valor de um conjunto de documentos . 14

3.1 Padrões sintáticos . . . . . . . . . . . . . . . . . 24

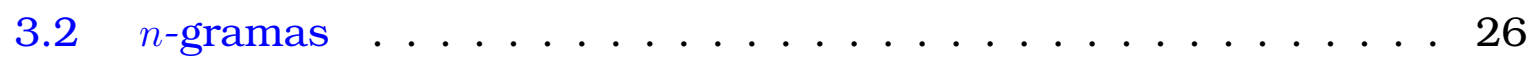

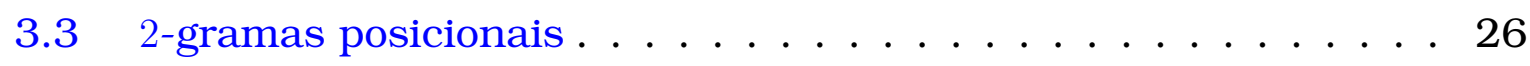

3.4 Tabela de contingência para 2 -gramas . . . . . . . . . 27

4.1 Exemplos de frases e freqüências de ocorrência . . . . . . . . . 37

4.2 Estrutura das frases . . . . . . . . . . . . . . 37

4.3 Tabela atributo-valor gerada . . . . . . . . . . . . 40

5.1 Lista de unigramas . . . . . . . . . . . . . . . . 51

5.2 Lista auxiliar . . . . . . . . . . . . . . . . 51

5.3 Lista de unigramas após processar a palavra aproximandamente 51

5.4 Exemplos de substituições . . . . . . . . . . . . . 5 53

5.5 Tabela de máscaras padrão . . . . . . . . . . . . . . . . . 62

5.6 Lista de termos gerados com máscaras $\mathrm{N}$ e $\mathrm{N} \mathrm{N} \ldots \ldots . . . .663$

5.7 Lista de termos gerados após realizar a primeira etapa . . . . . 67

5.8 Lista de termos gerados após realizar a segunda etapa . . . . . . 68

5.9 Lista de termos gerados após realizar a terceira etapa . . . . . 68

5.10 Lista de termos final . . . . . . . . . . . . . . . . 69

5.11 Lista de $n$-gramas. . . . . . . . . . . . . . 70

6.1 Configuração dos experimentos realizados . . . . . . . . . . 81

6.2 Configuração dos valores de Alpha e Theta . . . . . . . . . . . 82

6.3 Resultados dos CFUs da seção de esôfago . . . . . . . . . . . . 84

6.4 Correção ortográfica - seção de esôfago . . . . . . . . . . . . 85

6.5 Taxa de preenchimento do conjunto de teste para os experimentos Exp1, Exp2, Exp3 e Exp4 - seção de esôfago . . . . . . . . 990 
6.6 Possíveis padronizações indicadas pelo especialista . . . . . . . 96

6.7 Resultados dos CFUs da seção de estômago . . . . . . . . . . 97

6.8 Correção ortográfica - seção de estômago . . . . . . . . . . . . 97

6.9 Taxa de preenchimento do conjunto de teste para os experimentos Exp1, Exp2, Exp3 e Exp4 - seção de estômago . . . . . . . . 101

A.1 Número de termos raíz e número de atributos identificados usando 500 laudos de treinamento - seção de esôfago . . . . . . . . . 119

A.2 Tabela de precião e recall da lista de termos gerada usando 500 laudos de treinamento - seção de esôfago . . . . . . . . . 120

A.3 Taxa de preenchimento para o conjunto Tr de 500 laudos - seção de esôfago . . . . . . . . . . . . . . . . 120

A.4 Garbage gerado a partir do conjunto de 500 laudos de treinamento contendo 2002 frases, usando os limiares 0\%, 5\%, 10\% e $20 \%$ - seção de esôfago . . . . . . . . . . . . . . . . 121

A.5 Garbage gerado a partir do conjunto de 500 laudos de teste contendo 4009 frases, usando os limiares 0\%, 5\%, 10\% e 20\% - seção de esôfago . . . . . . . . . . . . . . . . . . . . . . 122

A.6 Número de termos raíz e número de atributos identificados usando 1000 laudos de treinamento - seção de esôfago . . . . . . . . 123

A.7 Tabela de precião e recall da lista de termos gerada usando 1000 laudos de treinamento - seção de esôfago . . . . . . . . . 123

A.8 Taxa de preenchimento para o conjunto $\operatorname{Tr}$ de 1000 laudos seção de esôfago . . . . . . . . . . . . . . . . . . . . . . . 123

A.9 Garbage gerado a partir do conjunto de 1000 laudos de treinamento contendo 3995 frases, usando os limiares 0\%, 5\%, 10\% e $20 \%$ - seção de esôfago . . . . . . . . . . . . . . . . . . . 124

A.10 Garbage gerado a partir do conjunto de 1000 laudos de teste contendo 4011 frases, usando os limiares 0\%, 5\%, 10\% e 20\% - seção de esôfago . . . . . . . . . . . . . . . . . . 125

A.11 Número de termos raíz e número de atributos identificados usando 2000 laudos de treinamento - seção de esôfago . . . . . . . . 126

A.12 Tabela de precisão e recall da lista de termos gerada usando 2000 laudos de treinamento - seção de esôfago . . . . . . . . . 126

A.13 Taxa de preenchimento para o conjunto $\operatorname{Tr}$ de 2000 laudos seção de esôfago . . . . . . . . . . . . . . . . 126

A.14 Garbage gerado a partir do conjunto de 2000 laudos de treinamento contendo 8005 frases, usando os limiares 0\%, 5\%, 10\% e $20 \%$ - seção de esôfago . . . . . . . . . . . . . . 127 
A.15 Garbage gerado a partir do conjunto de 2000 laudos de teste contendo 3998 frases, usando os limiares 0\%, 5\%, 10\% e 20\% - seção de esôfago . . . . . . . . . . . . . . . . . . . .

A. 16 Número de termos raíz e número de atributos identificados usando 4000 laudos de treinamento - seção de esôfago . . . . . . . . .

A.17 Tabela de precisão e recall da lista de termos gerada usando 4000 laudos de treinamento - seção de esôfago . . . . . . . . . .

A.18 Taxa de preenchimento para o conjunto $\operatorname{Tr}$ de 4000 laudos seção de esôfago . . . . . . . . . . . . . . . . . . . .

A. 19 Garbage gerado a partir do conjunto de 4000 laudos de treinamento contendo 15990 frases, usando os limiares 0\%, 5\%, 10\% e $20 \%$ - seção de esôfago

A.20 Garbage gerado a partir do conjunto de 4000 laudos de teste contendo 4013 frases, usando os limiares $0 \%, 5 \%, 10 \%$ e $20 \%$ - seção de esôfago

B.1 Número de termos raíz e número de atributos identificados usando 500 laudos de treinamento - seção de estômago . . . . . . . 133

B.2 Tabela de precisão e recall da lista de termos gerada usando 500 laudos de treinamento - seção de estômago . . . . . . . . . 134

B.3 Taxa de preenchimento para o conjunto Tr de 500 laudos - seção de estômago . . . . . . . . . . . . . . . . . . . . . . . 134

B.4 Garbage gerado a partir do conjunto de 500 laudos de treinamento contendo 4006 frases, usando os limiares 0\%, 5\%, 10\% e $20 \%$ - seção de estômago . . . . . . . . . . . . . . . . . . 135

B.5 Garbage gerado a partir do conjunto de 500 laudos de teste contendo 7966 frases, usando os limiares 0\%, 5\%, 10\% e 20\% - seção de estômago . . . . . . . . . . . . . . . . . . . 136

B.6 Número de termos raíz e número de atributos identificados usando 1000 laudos de treinamento - seção de estômago . . . . . . 137

B.7 Tabela de precisão e recall da lista de termos gerada usando 1000 laudos de treinamento - seção de estômago . . . . . . . . 137

B.8 Taxa de preenchimento para o conjunto Tr de 1000 laudos seção de estômago . . . . . . . . . . . . . . . .

B.9 Garbage gerado a partir do conjunto de 1000 laudos de treinamento contendo 7962 frases, usando os limiares 0\%, 5\%, 10\% e $20 \%$ - seção de estômago . . . . . . . . . . . . . . . 138 
B.10 Garbage gerado a partir do conjunto de 1000 laudos de teste contendo 7971 frases, usando os limiares 0\%, 5\%, 10\% e 20\% - seção de estômago . . . . . . . . . . . . . . . . . . . . . . 139

B.11 Número de termos raíz e número de atributos identificados usando 2000 laudos de treinamento - seção de estômago . . . . . . . 140

B.12 Tabela de precisão e recall da lista de termos gerada usando 2000 laudos de treinamento - seção de estômago . . . . . . . . 140

B.13 Taxa de preenchimento para o conjunto $\operatorname{Tr}$ de 2000 laudos seção de estômago . . . . . . . . . . . . . . . . . . . . 140

B.14 Garbage gerado a partir do conjunto de 2000 laudos de treinamento contendo 15911 frases, usando os limiares 0\%, 5\%, 10\% e $20 \%$ - seção de estômago . . . . . . . . . . . . . . . . . 141

B.15 Garbage gerado a partir do conjunto de 2000 laudos de teste contendo 8003 frases, usando os limiares 0\%, 5\%, 10\% e 20\% - seção de estômago . . . . . . . . . . . . . . . . . . . . . . . 142

B.16 Número de termos raíz e número de atributos identificados usando 4000 laudos de treinamento - seção de estômago . . . . . . . 143

B.17 Tabela de precisão e recall da lista de termos gerada usando 4000 laudos de treinamento - seção de estômago . . . . . . . . 143

B.18 Taxa de preenchimento para o conjunto $\operatorname{Tr}$ de 4000 laudos seção de estômago . . . . . . . . . . . . . . . . . . . . . . 143

B.19 Garbage gerado a partir do conjunto de 4000 laudos de treinamento contendo 31867 frases, usando os limiares 0\%, 5\%, 10\% e 20\% - seção de estômago . . . . . . . . . . . . . . . . . . . . 144

B.20 Garbage gerado a partir do conjunto de 4000 laudos de teste contendo 7961 frases, usando os limiares 0\%, 5\%, 10\% e 20\% - seção de estômago . . . . . . . . . . . . . . . . . . . . . . 145 


\section{Lista de Algoritmos}

1 Construção do Conjunto de Frases Únicas . . . . . . . . . . . . . 47

2 Aplicação de substituições . . . . . . . . . . . . . . 5 56

3 Lematização . . . . . . . . . . . . . . . . . 56 56

4 Extração de termos . . . . . . . . . . . . . . . . . 63

5 Aplicação de heurísticas - parte $1 \ldots \ldots$. . . . . . . . . . 65

6 Aplicação de heurísticas - parte $2 \ldots \ldots$. . . . . . . 66

7 Filtragem de termos candidatos . . . . . . . . . . . 67

8 Geração da tabela atributo-valor . . . . . . . . . . . . 75 


\section{Lista de Abreviaturas}

AT Árvore Trie

CFU Conjunto de Frases Únicas

EDA Endoscopia Digestiva Alta

ET Extração de Terminologia

GraphViz Graph Visualization Software

IM Informação Mútua

LA Lista Auxiliar

LABI Laboratório de Bioinformática

LABIC Laboratório de Inteligência Computacional

LTC Lista de Termos Candidatos

MT Mineração de Textos

NILC Núcleo Interinstitucional de Lingüística Computacional

NSP N-gram Statistics Package

PLN Processamento de Língua Natural

POS Part-of-speech

SEACAT Sistema de Extração Automática de Candidatos a Termos

TP-Discover Term Pattern Discover 


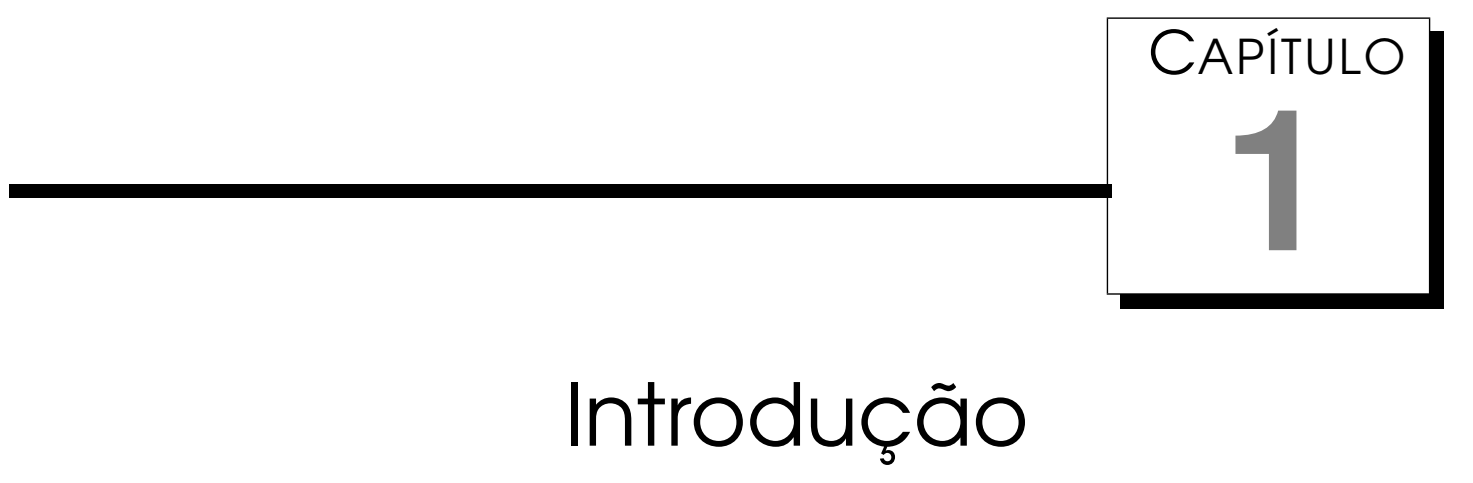

O desenvolvimento e utilização de tecnologias para a aquisição e armazenamento de dados, nas mais diversas áreas do conhecimento, têm permitido o acúmulo de dados em uma velocidade maior que a capacidade humana possui para processá-los. Esses dados podem estar representados em diferentes formatos, sendo que um dos formatos bastante utilizados é o formato textual não estruturado. Para que esses dados textuais brutos possam tornar-se úteis, é necessário que eles sejam representados de maneira apropriada para a extração de padrões, tal que um modelo que represente o conhecimento embutido nesses dados possa ser construído. Uma das maneiras de alcançar esse objetivo é por meio da realização do processo de Mineração de Textos - MT - (Feldman \& Sanger, 2006; Weiss et al., 2005). Esse processo consiste, basicamente, em três fases principais, que são: préprocessamento dos textos, extração de padrões e pós-processamento. Na fase de pré-processamento o conjunto de textos é transformado em uma representação adequada para ser utilizada pelos algoritmos de extração de padrões. Geralmente, os documentos são representados em uma tabela atributo-valor, a qual é utilizada na fase de extração de padrões. Depois de extraídos os padrões, eles são analisados na fase de pós-processamento.

Os textos, em geral, podem apresentar algum nível de estruturação na apresentação das informações, como também podem ser totalmente livres de estruturação. Para distinguir em qual nível de estruturação se encontra determinado texto, pode ser considerado como parâmetro a maneira como a informação é apresentada dentro do arquivo que contem o texto. 
Na Figura 1.1 é ilustrado um esquema que auxilia para um melhor entendimento dos níveis de estruturação de informações textuais (Chang et al., 2006). Conforme pode ser observado na figura, dados não estruturados são compostos por textos livres, por exemplo, artigos de notícias, os quais não possuem uma estrutura pré-definida. Os dados semi-estruturados possuem uma certa estrutura, por exemplo, registros médicos, anúncios e determinadas páginas Web. Finalmente, os dados estruturados possuem uma estrutura pré-definida, tal como as bases de dados ou arquivos textos altamente estruturados, nos quais as informações podem ser facilmente tratadas de acordo com a estrutura previamente definida.

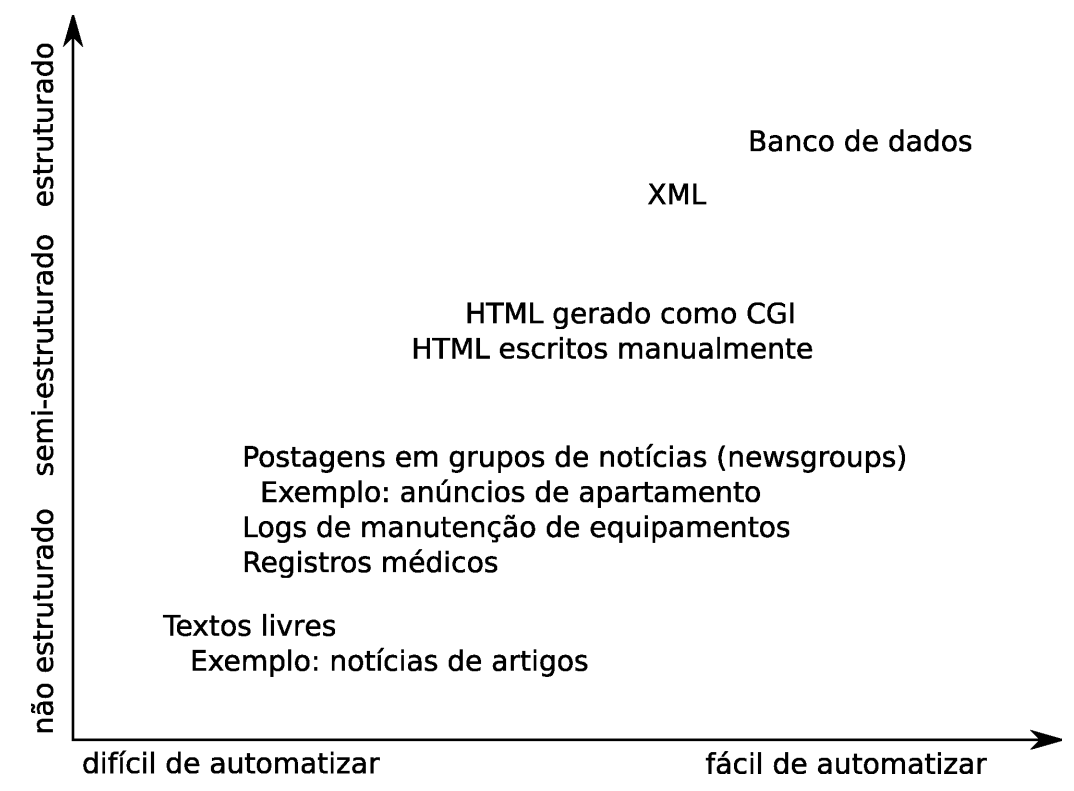

Figura 1.1: Tipos de estruturação de documentos (Chang et al., 2006)

Na Figura 1.1 também é possivel observar que as informações não estruturadas são as mais difíceis de serem tratadas utilizando um processo automatizável, enquanto que esse problema decresce quando a estruturação das informações é incrementada.

A linguagem natural é a maneira mais comum de comunicação humana. Na área biomédica ${ }^{1}$, conhecimento e dados são disseminados na forma escrita por meio de artigos na literatura científica, relatórios técnicos e administrativos bem como informações de pacientes (Cimino \& Shortliffe, 2006). Cada vez mais os computadores estão sendo utilizados para facilitar o processo de coleta, armazenamento e distribuição de informações biomédicas. Enquanto a capacidade para acessar as informações é altamente benéfica para pesquisadores, médicos e administradores, as informações, muitas vezes, não estão

\footnotetext{
${ }^{1}$ Segundo Cimino \& Shortliffe (2006), a informática biomédica engloba amplamente todas as áreas da saúde, de práticas clínicas e pesquisa biomédica.
} 
em uma forma adequada para que possam ser posteriormente processadas por um sistema computacional.

Um dos maiores impactos da computação na medicina é visto no processamento de dados estruturados, ou seja, informações representadas em um formato regular como uma tabela atributo-valor (Cimino \& Shortliffe, 2006). Desse modo, um sistema que realizasse transformação de informações médicas textuais em dados estruturados possibilitaria o desenvolvimento de novas aplicações na área médica que, de outra maneira, não seria possível. Em outras palavras, uma vez que as informações estejam estruturadas, seria possível desenvolver uma grande faixa de aplicações médicas, as quais seriam imprescindíveis para auxiliar médicos e pesquisadores.

Para exemplificar, suponha que uma clínica médica deseja obter determinadas informações a partir de um conjunto de laudos de pacientes, tais como quais pacientes foram atendidos em determinada data e quais medicamentos foram recomendados. A clínica também poderia estar interessada na identificação de padrões que pudessem auxiliar no processo de tomada de decisões, por exemplo, pacientes com sintomas X e Y são diagnosticados com a doença $Z$. Nesse caso, para que possa ser realizada uma análise mais completa dos laudos, tais como geração de estatísticas, gráficos, relatórios e extração de padrões, é necessário que os mesmos sejam transformados para um formato estruturado, tal como o formato atributo-valor, para que técnicas que auxiliem nessas tarefas sejam aplicadas. Depois de transformadas as informações para o formato atributo-valor, seria possível, portanto, a aplicação de algoritmos para a descoberta de padrões embutidos nos dados, os quais dificilmente o profissional da saúde iria descobrir por meio de uma análise manual. Alguns benefícios de se aplicar algoritmos para extração de padrões são:

- Identificação de padrões implícitos, ou seja, relacionamentos nas informações fornecidas nos exames e que possibilitariam chegar a um determinado diagnóstico. Desse maneira, o médico poderia chegar mais rapidamente a um diagnóstico correto, descartando informações que não auxiliam no diagnóstico;

- Identificação de agrupamentos nos dados, de modo que, com base nas informações do paciente, fosse possível dizer a qual grupo o paciente pertence.

Assim, a transformação de informações para o formato atributo-valor é de fundamental importância para a aplicação de algoritmos de extração de padrões. Vários desafios são encontrados no desenvolvimento de sistemas de 
transformação de informações médicas para o formato estruturado, conforme apresentados a seguir (Cimino \& Shortliffe, 2006).

Disponibilidade de laudos e confidencialidade: O desenvolvimento de um sistema de transformação de informações é baseado na análise de amostras de textos para serem processados. No domínio médico, isso significa que uma grande quantidade de registros de pacientes na forma digital deve estar disponivel para os desenvolvedores. Um problema é que nem todos os registros médicos estão no formato eletrônico. Em muitos hospitais, anotações clínicas, tais como notas escritas por enfermeiras ou mesmo a evolução do paciente, são escritas em papel e não são armazenadas no formato digital. Entretanto, sistemas de transformação de informação necessitam que os registros médicos estejam disponiveis eletronicamente na forma textual de modo que possam processá-los. Outra questão é que registros de pacientes são confidenciais, e a fim de torná-los acessíveis para propósitos de pesquisa, informações de identificação pessoal devem ser removidas, ou projetos serem submetidos anteriormente à aprovação da comissão de ética de modo que possam ser utilizados os laudos.

Expressividade: A linguagem natural é extremamente expressiva no sentido de que há, freqüentemente, diferentes maneiras para descrever um mesmo conceito médico, bem como há numerosas maneiras para expressar modificadores de um conceito. Por exemplo, laudos associados ao câncer podem ser expressos utilizando um grande número de termos, tais como neoplasma, tumor, lesão, massa e linfoma. Além disso, os modificadores desses termos tornam a tarefa de extração de informação mais complexa, uma vez que também devem ser levados em consideração.

Formatos heterogêneos: Não há um formato padrão para os laudos. Embora seções e subseções de laudos são importantes para muitas aplicaçãos porque elas provêm contexto, seus nomes não são padronizados. Por exemplo, diagnóstico, diagnóstico final e diagnóstico médico podem nomear as mesmas seções de um laudo. Outro problema ocorre porque o formato do texto nos laudos não é padronizado. Pontuações estão freqüentemente faltando ou estão inapropriadas. Por exemplo, uma nova linha pode ser utilizada para significar o final de uma sentença em vez de um ponto final. Outro problema é que alguns laudos contém tabelas com diferentes configurações.

Abreviação do texto: Geralmente, laudos médicos são bastante compactos, contém abreviações e freqüentemente omitem informações que podem 
ser facilmente inferidas por profissionais do domínio com base nos seus conhecimentos do contexto e do domínio. Um problema com as abreviações é que são altamente ambíguas. Por exemplo, a abreviação pe, do inglês, pode significar physical examination (exame físico), pleural effusion (efusão pleural) ou pulmonary embolism (embolismo pulmonar). Outro desafio está relacionado às informações omitidas ou implícitas, porque um sistema automático que utiliza a informação estruturada gerada por meio dos laudos, deverá automaticamente capturar as informações implícitas baseadas no conhecimento do domínio. Essa é uma tarefa muito complexa. Um exemplo simples é a localização de uma parte do corpo que está freqüentemente faltando no diagnóstico. Por exemplo, quando o termo massa ocorre em um laudo radiológico do tórax, significa massa no pulmão, mas se ocorresse em um laudo de mamografia, iria significar massa no seio.

Eventos raros: Sistemas que realizam a transformação de informações de linguagem natural geralmente precisam de um grande número de exemplos (laudos) de treinamento para treinar, refinar e testar o sistema. Uma vez que alguns eventos ocorrem raramente, pode ser difícil encontrar um grande número de laudos com esses eventos. Um recurso é utilizar bases de dados terminológicas, as quais podem ser úteis para fornecer conhecimento léxico para termos médicos pouco freqüentes.

Erros de ortografia: Registros médicos as vezes contém erros de ortografia, os quais podem fazer com que um sistema de transformação de informação não identifique determinada informação. A correção automática de erros de ortografia é difícil e poderia criar novos erros. Por exemplo, a palavra hiprtensão irá causar um erro de interpretação. Não é fácil corrigir essa palavra automaticamente sem um conhecimento adicional, uma vez que ela pode se referir a hipertensão ou hipotensão.

Falta de um conjunto de padronizações do dominio: O conhecimento do domínio que está sendo processado é importante para os sistemas de transformação de informação, uma vez que provêm informações do contexto que são freqüentemente necessárias. Por exemplo, o conhecimento do domínio facilitaria a recuperação de informações implícitas, i.e. a palavra massa em um mamograma denota massa no seio. Também facilita a resolução de uma palavra ambígua ou abreviada, por exemplo, pvc, do inglês, em um raio-x do tórax, denota pulmonar vascular congestion. Por outro lado, em um eletrocardiograma, denota premature ventricular complexes. 
Esses são alguns dos problemas que devem ser enfrentados quando está sendo construído um sistema para processar informações textuais relacionados a laudos médicos. Na realidade, vários desses problemas devem ser também enfrentados em outros domínios do conhecimento. O que varia é a intensidade com a qual eles aparecem em diferentes domínios.

Neste contexto, os laudos médicos podem ser do tipo estruturado, semiestruturado, não estruturado ou uma combinação desses formatos. Na Figura 1.2 é ilustrada a interação entre esses formatos de laudos.

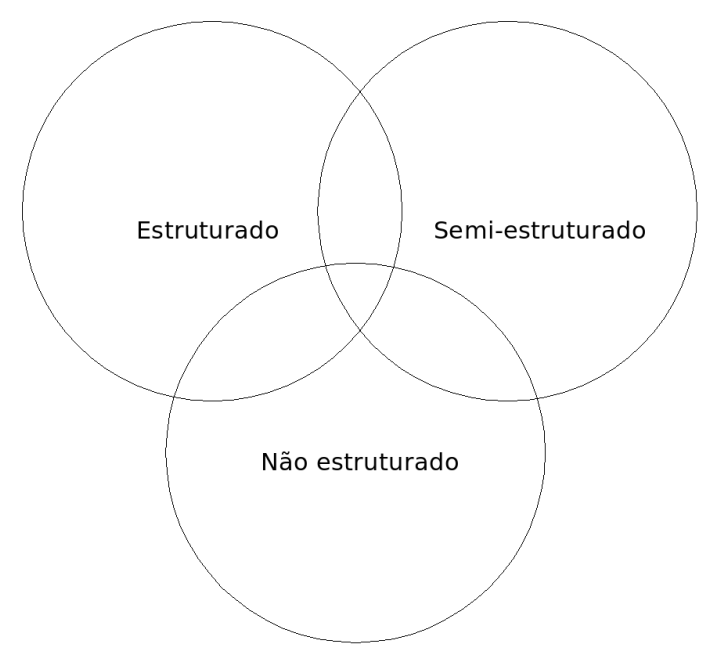

Figura 1.2: Tipos de laudos

Os laudos estruturados consistem de informações em um formato prédefinido. Isso facilita a extração e a transformação dessas informações para o formato atributo-valor. Geralmente, técnicas simples podem ser utilizadas para esse fim, uma vez que os laudos possuem uma estrutura rígida em relação às informações que eles contêm. Na Figura 1.3 é apresentado um fragmento de laudo estruturado da área de Andrologia. Nesse laudo, a extração de uma determinada informação pode ser realizada facilmente por meio da utilização de expressões regulares.

Os laudos não estruturados são aqueles que não exibem regularidade na apresentação das informações, ou seja, as mesmas estão descritas em língua natural. Neste caso, as informações a serem extraídas não são facilmente detectadas, a menos que se tenha algum conhecimento lingüístico sobre elas.

Por outro lado, os laudos semi-estruturados aparecem em um ponto intermediário entre laudos sem nenhuma estruturação (descritos em língua natural) e laudos completamente estruturados. Os laudos semi-estruturados são aqueles que apresentam alguma regularidade na disposição das informações, i.e., algumas informações no texto podem apresentar uma regularidade, enquanto outras informações aparecem de forma livre. 


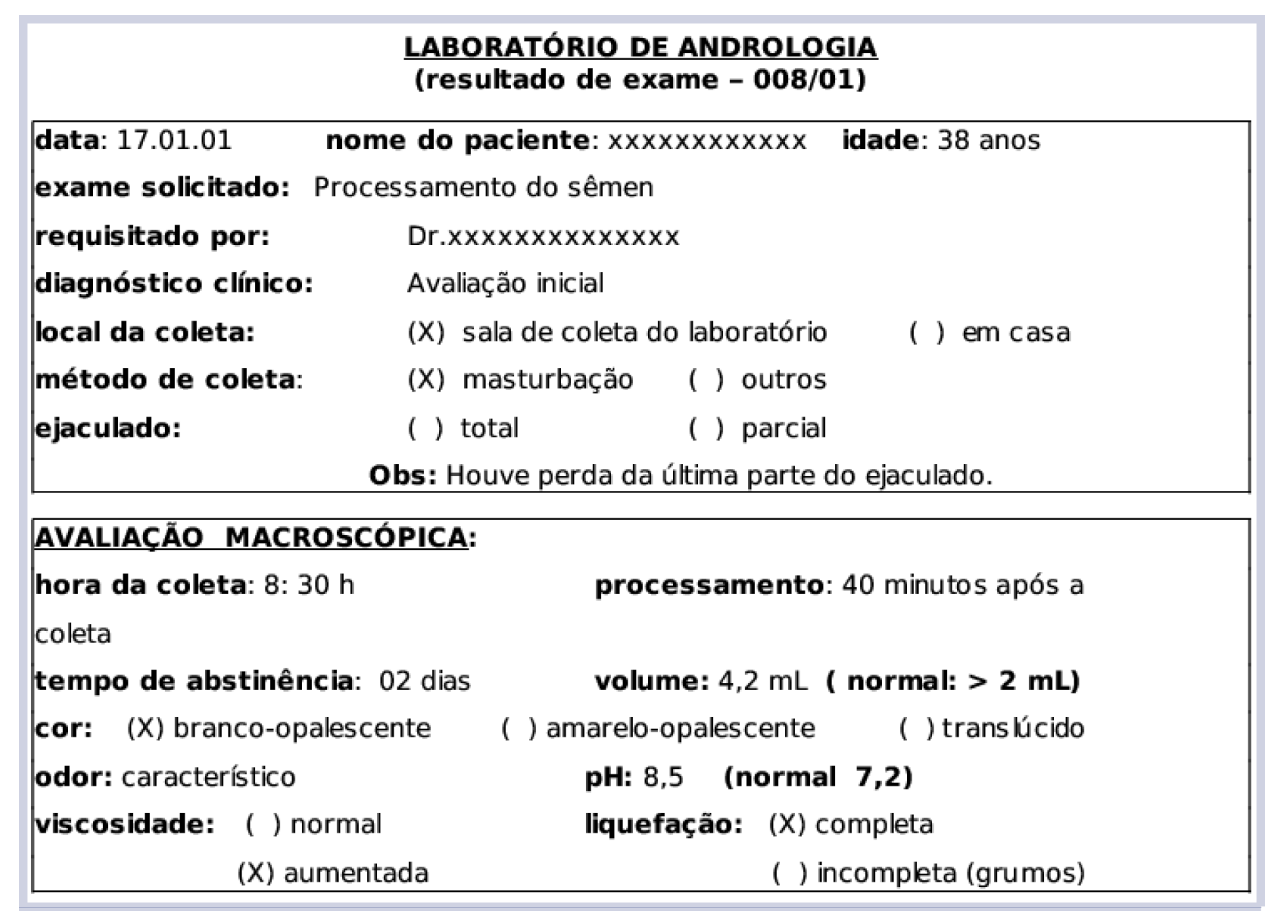

Figura 1.3: Laudo estruturado de Andrologia

Na Figura 1.4 é apresentado um exemplo de laudo semi-estruturado, conjuntamente com informações estruturadas e não estruturadas, da área de Endoscopia Digestiva Alta - EDA. Nesse laudo, é fácil observar uma divisão nas informações relacionadas ao esôfago, ao estômago, ao duodeno e a biópsia e conclusão do exame. Nas três primeiras seções ${ }^{2}$ as informações estão descritas em língua natural. Na última seção, a informação referente a biópsia está estruturada, enquanto que a informação referente à conclusão do exame está descrita em língua natural.

Um outro aspecto a ser ressaltado é que, muitas vezes, na linguagem médica são suprimidos alguns termos como artigos e verbos de modo a alcançar uma forma compacta na descrição das informações. Uma vez que a comunidade largamente usa e aceita essas formas alternativas, elas não são consideradas gramaticalmente incorretas, mas constituem uma sublinguagem (Cimino \& Shortliffe, 2006). Na linguagem médica existem várias sublinguagens, cada uma exibindo um conteúdo especializado e uma forma lingüística diferente. Essas sublinguagens médicas são mais fáceis de interpretar, uma vez que os padrões semânticos são mais restritos e, portanto, podem ser representados de uma maneira mais simples (Chen et al., 2005). Por exemplo, medicação, doença ou parte do corpo tem um pequeno número de padrões semânticos, por exemplo, medicação-trata-doença e parte-do-cor-

\footnotetext{
${ }^{2}$ Neste trabalho o termo seção de um laudo corresponde a uma porção contendo informações de um órgão do paciente que foi examinado.
} 


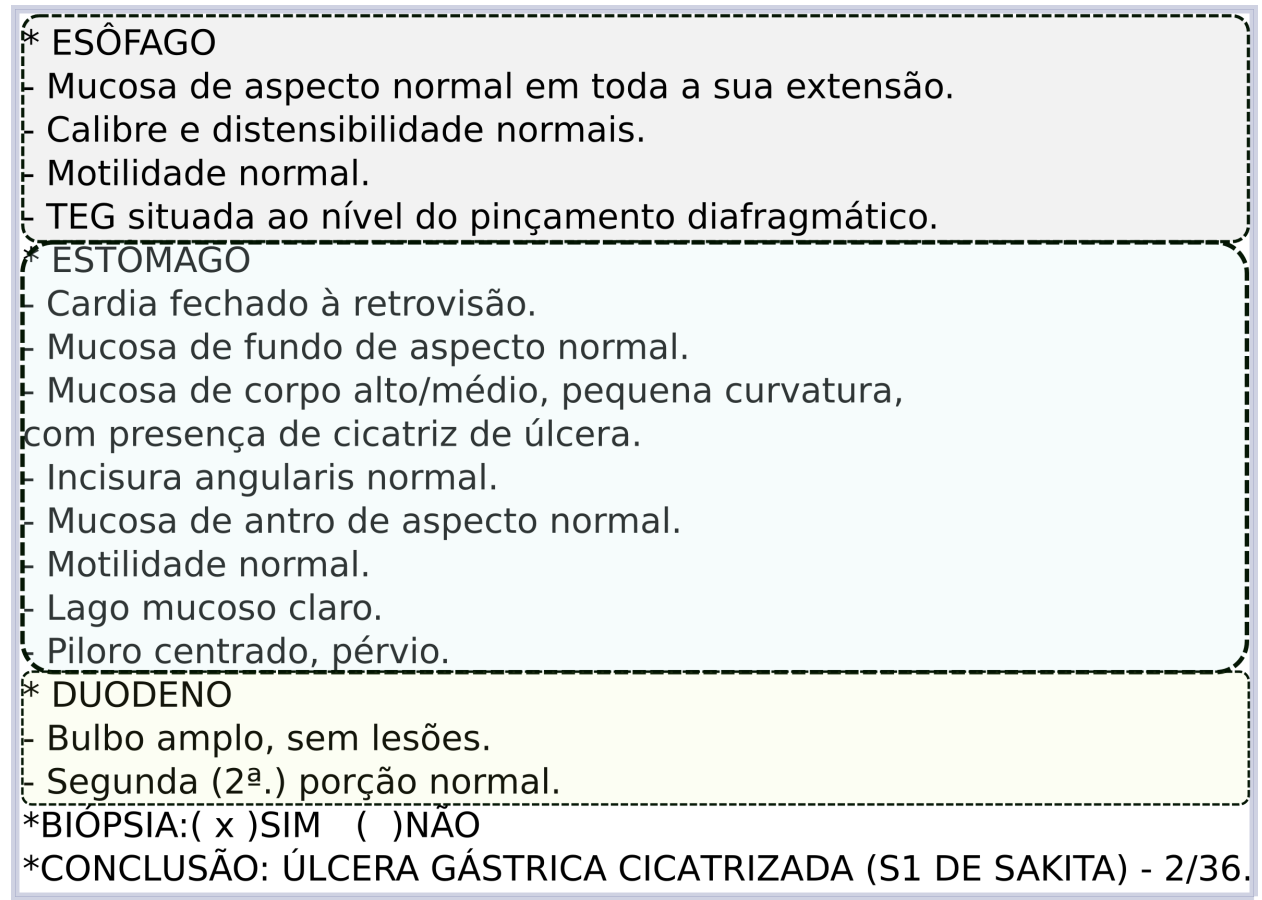

Figura 1.4: Laudo semi-estruturado de Endoscopia Digestiva Alta

po-tem-característica.

O objetivo deste trabalho consiste na proposta de uma metodologia para pré-processamento de laudos médicos não estruturados, que tem como resultado a representação atributo-valor das informações contidas nesses laudos.

Deve ser observado que este trabalho faz parte de um projeto de pesquisa mais amplo, desenvolvido conjuntamente por pesquisadores do Laboratório de Bioinformática - $\mathrm{LABI}^{3}$ - da Universidade Estadual do Oeste do Paraná e o Laboratório de Inteligência Computacional - $\mathrm{LABIC}^{4}-$ do ICMC/USP. É importante ressaltar que a idéia original de desenvolver uma metodologia para a transformação de laudos médicos em uma tabela atributo-valor, deve-se a Profa Huei Diana Lee, do LABI, a qual foi implementada e aplicada em diversos conjuntos de laudos médicos. A metodologia proposta pela Profa Huei Diana Lee encontra-se descrita em (Honorato et al., 2007, 2005) e já foi aplicada a diversos laudos médicos de domínios diferentes, alcançando bons resultados (Cherman et al., 2007; Spolaôr et al., 2007). Essa metodologia está baseada nas seguintes propriedades das informações não estruturadas encontradas em laudos médicos:

- As informações são descritas utilizando um vocabulário controlado;

- As informações consistem de frases assertivas simples.

\footnotetext{
${ }^{3}$ http://labi.pti.org.br:8090/labi/

${ }^{4}$ http://labic.icmc.usp.br/
} 
Entretando, a aplicação dessa metodologia exige uma intensa interação com o especialista do domínio, o que cria algumas dificuldades devido ao fato que, na maioria dos casos, os especialistas não dispõem de muito tempo para intervir nas diversas etapas da metodologia nas quais a sua participação é imprescindivel.

Assim, considerando que:

- Existe dificuldade na dependência do especialista;

- A existência de métodos de processamento de textos mais apurados;

Consideramos que é possível utilizar recursos computacionais de pré-processamento de textos para diminuir o tempo de atuação do especialista do domínio.

Essa hipótese motivou o desenvolvimento da metodologia proposta neste trabalho, a qual leva em conta a experiência adquirida na aplicação dessa primeira metodologia.

\subsection{Principais Objetivos do Trabalho}

O objetivo deste trabalho consiste da proposta, desenvolvimento e implementação de uma metodologia para o pré-processamento de laudos médicos não estruturados, ou seções desses laudos, que tem como resultado a representação em uma tabela atributo-valor das informações contidas nesses laudos. Um dos principais objetivos dessa metodologia é diminuir, sempre que possível, a intervenção do especialista, fornecendo, nas diversas fases da metodologia, informações que facilitam o trabalho a ser realizado pelo especialista. Para atingir esses objetivos, propomos uma abordagem de extração de terminologia para identificar termos de interesse, os quais são utilizados para gerar uma estrutura hierárquica (árvore) na qual está mapeado o contexto do termo identificado. A partir dessas árvores podem ser mais facilmente identificados os atributos que farão parte da tabela atributo-valor.

Outra característica da metodologia é que ela não necessita de conhecimentos externos do domínio, tais como dicionários de termos, regras semânticas ou ontologias do domínio para pré-processar os laudos. Para identificar os atributos, a metodologia trabalha no "mundo fechado" das informações contidas nos conjuntos de laudos.

Como produto deste trabalho foi desenvolvido o ambiente computacional Term Pattern Discover — TP-DISCOVER - o qual implementa todas as fases da metodologia. 


\subsection{Organização do Trabalho}

Está dissertação está organizada da seguinte maneira:

Capitulo 2 - Pré-processamento: Nesse capítulo são apresentadas as principais abordagens de pré-processamento de documentos que são utilizadas no processo de mineração de textos. São apresentados alguns tipos de representação de documentos e alguns métodos para identificação de atributos. Também são apresentadas algumas técnicas de redução de dimensionalidade e alguns trabalhos relacionados da área médica que aplicam algumas dessas técnicas;

Capítulo 3 - Extração de Terminologia: Nesse capítulo são apresentados conceitos da área de extração de terminologia e as principais abordagens que geralmente são utilizadas, assim como as vantagens e desvantagens de cada uma dessas abordagens;

Capitulo 4 - Visão Geral da Metodologia: Nesse capítulo é apresentada uma visão geral da metodologia proposta neste trabalho, a qual tem por objetivo a construção de uma representação atributo-valor a partir de informações não estruturadas encontradas em laudos médicos;

Capitulo 5 - Metodologia Desenvolvida: Nesse capítulo é descrita em maiores detalhes a metodologia proposta e descrita no Capítulo 4, juntamente com o método de extração de terminologia proposto;

Capitulo 6 - Avaliação Experimental: Nesse capítulo é apresentada a avaliação experimental da metodologia utilizando informações contidas em laudos médicos de Endoscopia Digestiva Alta. O comportamento da metodologia é analisado por meio de diversas avaliações que utilizam conjuntos de laudos de tamanhos diferentes, assim como variações dos parâmetros utilizados para executar o ambiente computacional TP-DISCOVER o qual implementa a metodologia;

Conclusões: Nesse capítulo são apresentadas as conclusões do trabalho e propostas para os trabalhos futuros. 


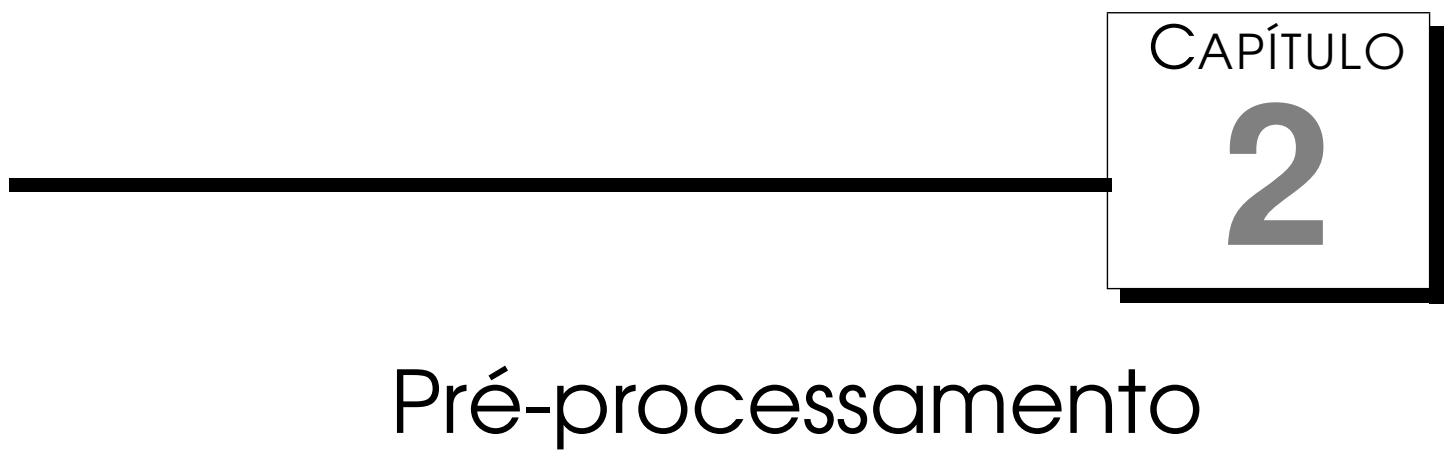

\subsection{Considerações Iniciais}

Neste capítulo são apresentados alguns conceitos relacionados ao processo de mineração de textos e é descrita em maiores detalhes a fase de pré-processamento de textos, que está mais diretamente relacionada com este trabalho.

\subsection{Mineração de Textos}

Mineração de Textos - MT - consiste no processo de extrair informações interessantes e conhecimento de um conjunto de documentos de textos. Conforme mencionado, o processo de MT consiste, basicamente, de quatro fases (Feldman \& Sanger, 2006; Rezende et al., 2003), conforme ilustra a Figura 2.1: coleta de documentos, pré-processamento, extração de padrões e pósprocessamento.

Na fase de coleta de documentos, o objetivo é reunir o conjunto de documentos a serem considerados no proceso de MT. Na fase de pré-processamento, foco de estudo deste trabalho, os documentos são transformados para uma representação adequada para ser utilizada na próxima fase. Depois de pré-processados, os documentos podem ser utilizados pelos algoritmos de extração de padrões. Na fase de extração de padrões, no caso do conjunto de documentos consistir de documentos rotulados, i.e., possuirem a informação adicional da classe a qual pertencem, é possível utilizar algoritmos de aprendizado supervisionado para induzir um classificador, o qual é responsável pela 


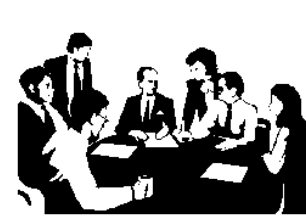

Coleta de

Documentos

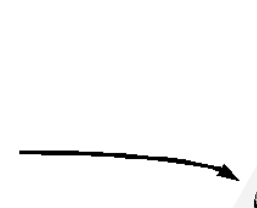

(2)

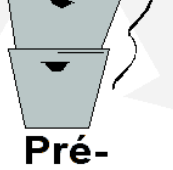

Préprocessamento
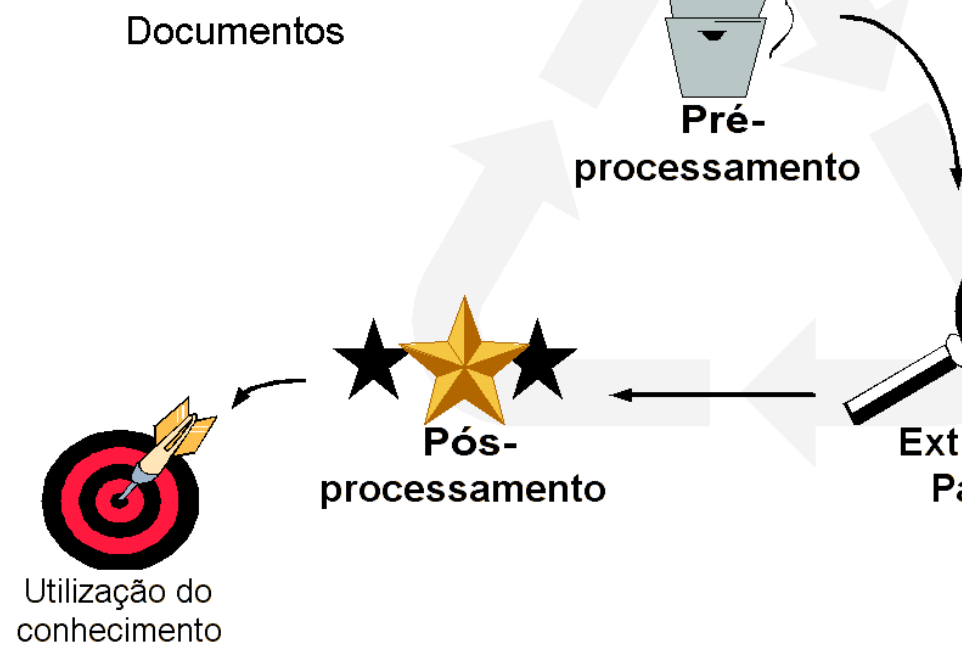

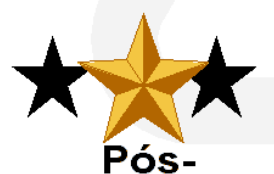

processamento

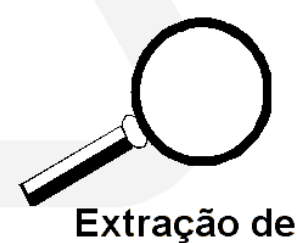

Padrões

Figura 2.1: Processo de mineração de textos

identificação da classe de novos documentos não rotulados. Caso o conjunto de documentos consistir de documentos não rotulados, é possível utilizar algoritmos de aprendizado não supervisionado (clustering) para encontrar clusters, tal que, documentos que pertencem a um mesmo cluster são similares entre si, de acordo com alguma medida de similaridade, e são não similares a documentos que pertencem a outros clusters (Hotho et al., 2005). Caso o conjunto de documentos possuir documentos rotulados e documentos não rotulados, é possivel utilizar algoritmos de aprendizado semi-supervisionado (Matsubara et al., 2007; Chapelle et al., 2006). Esses algoritmos representam uma junção dos algoritmos de aprendizado supervisionado e não supervisionado, e tem o potencial de reduzir a necessidade de documentos rotulados quando somente um pequeno conjunto de exemplos rotulados está disponível.

Finalmente, na fase de pós-processamento, os modelos obtidos na fase de extração de padrões devem ser avaliados e validados. Nessa avaliação, são geralmente utilizadas medidas objetivas, tais como medidas de precisão (Mitchell, 1997), ROC ${ }^{1}$ (Prati et al., 2008; Fawcett, 2006), similaridade (Halkidi et al., 2002a,b), e outras para avaliar o modelo construído pelo(s) algoritmo(s) de extração de padrões utilizado(s). Ainda, dependendo do domínio de conhecimento que está sendo tratado, além das medidas objetivas para avaliar os modelos obtidos, é de fundamental importância a avaliação subjetiva de um

\footnotetext{
${ }^{1}$ Receiver Operating Characteristic
} 
especialista do domínio para confirmar a validade do modelo.

\subsection{Pré-processamento}

Na fase de extração de padrões do processo de MT, são usualmente utilizados algoritmos de aprendizado supervisionado, não supervisionado ou semisupervisionado. Para realizar o aprendizado, é necessário representar os casos observados (exemplos) utilizando uma linguagem que permite descrever esses exemplos. Entre os diversos tipos de linguagem, uma delas, baseada na lógica de atributos, é amplamente utilizada pela maioria dos algoritmos de aprendizado. Nesse tipo de linguagem, cada caso (exemplo) do conjunto de exemplos observados, deve ser representado por um conjunto de atributos, que podem assumir diversos valores para descrever os exemplos. Nessa representação, comumente denominada de atributo-valor, cada exemplo é descrito pela dijunção ou conjunção dos valores dos atributos.

No caso de mineração de textos, é necessário encontrar os atributos mais apropriados que descrevem cada documento do conjunto de documentos e os valores a serem atribuídos a esses atributos. Usualmente, o número de atributos que descrevem cada documento, é grande. Assim, é importante reduzir esse número, escolhendo um subconjunto de atributos mais representativos, diminuindo assim a dimensão da tabela atributo-valor relacionada com a representação do conjunto de documentos.

A seguir são descritas algumas abordagens para realizar essas tarefas da fase de pré-processamento.

\subsection{Representação dos Documentos}

A maioria das abordagens propostas para encontrar o conjunto de atributos que descrevem um conjunto de documentos, utiliza as palavras nos documentos, i.e., os documentos são descritos utilizando as palavras que eles contêm. Uma maneira muito simples para encontrar esse conjunto de atributos é a abordagem bag-of-words, que somente considera a freqüência das palavras no conjunto de documentos, independente do contexto. Outras abordagens que levam em conta características adicionais nos textos para encontrar o conjunto de atributos, são descritas na Seção 2.3.4. Na Tabela 2.1 é mostrada a representação de um conjunto de $N$ documentos descritos por $M$ atributos. Nessa tabela, cada documento $d_{i}$ consiste de um exemplo na tabela atributovalor, e cada atributo $t_{i}$ corresponde a um termo (palavra) do conjunto de $M$ atributos. No caso dos documentos serem rotulados, cada um deles pode ser 
associado ao valor da classe $C_{i}$, do atributo classe $C$, ao qual pertence. No caso de documentos não rotulados, o atributo classe $C$ é inexistente.

Tabela 2.1: Representação atributo-valor de um conjunto de documentos

\begin{tabular}{|c|c|c|c|c||c|}
\hline & $t_{1}$ & $t_{2}$ & $\ldots$ & $t_{M}$ & $C$ \\
\hline \hline$d_{1}$ & $a_{11}$ & $a_{12}$ & $\ldots$ & $a_{1 M}$ & $c_{1}$ \\
\hline$d_{2}$ & $a_{21}$ & $a_{22}$ & $\ldots$ & $a_{2 M}$ & $c_{2}$ \\
\hline$\ldots$ & $\ldots$ & $\ldots$ & $\ldots$ & $\ldots$ & $\ldots$ \\
\hline$d_{N}$ & $a_{N 1}$ & $a_{N 2}$ & $\ldots$ & $a_{N M}$ & $c_{N}$ \\
\hline
\end{tabular}

Na tabela, cada documento $d_{i}$ é representado por um vetor $d_{i}=\left(a_{i 1}, a_{i 2}, \ldots . a_{i M}\right)$, no qual o valor $a_{i j}$ refere-se ao peso associado ao $j$-ésimo atributo do documento $i$. Os pesos das palavras (atributos) são considerados de modo a refletir a importância da palavra na discriminação dos documentos em que ela ocorre. Esses pesos são geralmente calculados automaticamente, como descrito a seguir.

\subsubsection{Valores dos Atributos}

A abordagem mais simples de definir os valores dos atributos é a booleana, a qual define o valor 1 caso a palavra (atributo) esteja presente no documento e define o valor 0 caso a palavra não esteja presente no documento - Equação 2.1 .

$$
\operatorname{bool}\left(t_{j}, d_{i}\right)= \begin{cases}1 & \text { se } t_{j} \in d_{i} \\ 0 & \text { caso contrário }\end{cases}
$$

De modo a alcançar melhores precisões pelos algoritmos, outros valores de atributos podem ser considerados. Uma abordagem é considerar a freqüência da palavra no documento, ou seja, se uma palavra ocorre dez vezes em um documento, este valor será armazenado no atributo correspondente. Essa medida, denominada $t f$ (term frequency), é definida pela Equação 2.2, na qual $\operatorname{freq}\left(t_{j}, d_{i}\right)$ é a freqüência do termo $t_{j}$ no documento $d_{i}$.

$$
t f\left(t_{j}, d_{i}\right)=\operatorname{freq}\left(t_{j}, d_{i}\right)
$$

Outra abordagem relacionada à freqüência da palavra em um documento é trocar a freqüência pela porcentagem de importância da palavra. A medida $t f$ idf (Salton \& Buckley, 1987) tem sido utilizada para calcular pesos ou escores para as palavras - Equações 2.3 e 2.4. A Equação 2.3 define que o peso associado à palavra $j$ é a freqüência do termo modificado por um fator escalar que indica a importância da palavra. O fator escalar idf, definido pela Equação 2.4 , é chamado inverse document frequency. Nessa equação, $N$ é o número de 
documentos da coleção e $d f\left(t_{j}\right)$ é o número de documentos nos quais o termo $t_{j}$ ocorre pelo menos uma vez. Assim, quando o termo aparece em todos os documentos o fator de ponderação é igual a 0 , e quando aparece em apenas 1 documento ele é $\log N$. Ou seja, quando uma palavra aparece em muitos documentos, é considerada pouco importante para discriminar documentos diferentes e sua escala é próxima a zero. Por outro lado, quando aparece em poucos documentos seu valor é maior.

$$
\begin{gathered}
t f-i d f(j)=t f(j) \times i d f(j) \\
i d f(j)=\log \left(\frac{N}{d f(j)}\right)
\end{gathered}
$$

Várias outras medidas foram propostas na literatura, mas a maioria delas podem ser consideradas variações das medidas aqui apresentadas (Soucy \& Mineau, 2005; Aas \& Eikvil, 1999).

\subsubsection{Redução de Dimensionalidade}

A abordagem bag-of-words tende a gerar tabelas com milhares de atributos. Se os algoritmos de extração de padrões podem lidar com alta dimensão de atributos, a abordagem bag-of-words pode ser bastante adequada. Entretanto, em muitas circunstâncias, pode ser que não seja eficiente trabalhar com um grande número de atributos, uma vez que a performance da maioria dos algoritmos de aprendizado tende a degradar rapidamente quando o número de atributos é alto (Sebastiani, 2006). Assim, é importante tentar reduzir o número de atributos que representa o conjunto de documentos. Deve ser observado que, dependendo do algoritmo de aprendizado utilizado, a redução de dimensionalidade pode aumentar a performance dos algoritmos. Algumas das abordagens que podem ser aplicadas para a redução da dimensionalidade da abordagem bag-of-words são brevemente descritas a seguir (Hotho et al., 2005; Sebastiani, 2002).

Remoção de stopwords: A idéia da remoção de stopwords é retirar palavras que não são importantes para discriminar documentos diferentes ou reconhecer documentos semelhantes, tais como artigos, preposições e conjunções. Se assume que tais palavras não representam informações do conteúdo que está armazenado nos documentos. Além dessas palavras, outras com essas características podem ser removidas.

Lematização: Métodos de lematização tentam mapear a forma dos verbos para o tempo infinitivo e substantivos para a forma singular. Entre- 
tanto, para que essa transformação seja realizada, a classe gramatical das palavras deve ser conhecida. Uma vez que o processo de etiquetação tem custo de tempo alto e está sujeito a erro, na prática, métodos de stemming freqüentemente são aplicados.

Stemming: Métodos de stemming consistem na identificação de diferentes inflexões referentes à mesma palavra e sua substituição por um radical comum, ou seja, tem o efeito de mapear diferentes formas morfológicas das palavras para um atributo comum. Por exemplo, as palavras considerar, considerado, consideração seriam transformadas para o radical consider, o qual substituiria as três palavras originais.

Seleção de Atributos: O número de palavras diferentes é grande mesmo em conjuntos pequenos de documentos. Assim, o número de atributos para uma coleção grande de documentos pode alcançar centenas de milhares. Em um processo de classificação, por exemplo, a maioria das palavras são irrelevantes para a tarefa de classificação e podem ser removidas sem prejudicar a performance do classificador. Na realidade, a seleção de atributos pode até melhorar a performance do classificador induzido pelo algoritmo de aprendizado (Sebastiani, 2002). A fase de pré-processamento que remove atributos considerados irrelevantes é chamada de seleção de atributos (ou feature selection). O procedimento de seleção de atributos consiste em associar um escore para cada atributo em potencial de acordo com uma métrica de seleção de atributos e, então, selecionar os melhores $k$ atributos. Vários métodos de seleção de atributos têm sido propostos (Feldman \& Sanger, 2006; Weiss et al., 2005; Lee, 2005). No trabalho de Forman (2003) é realizado um extenso estudo utilizando diversas métricas de seleção de atributos.

Construção de atributos: O processo de construção de atributos está relacionado à geração de um novo conjunto de atributos a partir do conjunto original. O número de atributos gerados é menor do que o número de atributos originais, uma vez que são gerados a partir dos anteriores, substituindo-os. Como exemplos dessas técnicas, pode-se citar o agrupamento de palavras (term clustering) (Slonim \& Tishby, 2000) e Latent Semantic Analysis (Landauer et al., 1998).

\subsubsection{Outras Abordagens para Identificação de Atributos}

As aplicações de pré-processamento que suportam a mineração de textos, tentam levar em conta diferentes elementos contidos nos documentos descri- 
tos em língua natural, de modo a transformá-los a partir de uma representação irregular e implicitamente estruturada em uma representação explicitamente estruturada. Entretanto, dada a potencialidade do grande número de palavras, frases e sentenças que um documento pode conter, uma tarefa essencial e importante no processo de mineração de textos é a identificação de um subconjunto simplificado de atributos que pode ser utilizado para representar um documento como um todo. O conjunto de atributos é denominado de modelo representacional de um documento e pode-se dizer que um documento é representado pelo conjunto de atributos que seu modelo representacional contém.

Conforme mencionado, uma das abordagens de representação mais utilizada é a bag-of-words. A maior vantagem dessa abordagem é a sua simplicidade, uma vez que geralmente, somente a freqüência das palavras (atributos) nos documentos é considerada, enquanto que toda a estrutura e a ordem das palavras é descartada. Entretanto, devido a essa característica, é frequentemente criticada por ignorar os relacionamentos entre as palavras, os quais são considerados essenciais para o entendimento humano. Assim, outras abordagens que levam em conta o relacionamento entre as palavras para identificar os atributos que discriminam um conjunto de documentos têm sido propostas (Feldman \& Sanger, 2006).

No trabalho de Caropreso et al. (2001) é realizada a identificação de atributos baseado em $n$-gramas. Depois são utilizadas várias técnicas de seleção de atributos para obter os melhores atributos. Scott \& Matwin (1999) examinaram algumas formas alternativas de representar documentos baseando-se nos relacionamentos sintáticos e semânticos das palavras. No trabalho de Koster \& Seutter (2002) são comparadas diferentes abordagens de representação de documentos para a classificação de textos. As formas de representação variam do uso de palavras (bag-of-words) até o uso de frases como atributos (bag-ofphrases). Diederich et al. (2003) usam uma representação bag-of-words e bagof-functional-words formada por unigramas e bigramas de palavras funcionais no texto. Os autores caracterizam como palavras funcionais todas as classes gramaticais excluindo substantivos, verbos e adjetivos. Na representação por palavra funcional supõe-se que o estilo do documento é preservado enquanto que o tópico é suprimido.

A área de extração de terminologia emprega várias abordagens para a geração e filtragem de lista dos termos candidatos mais significativos para representar um documento. Esse processo resulta em uma representação menor e mais rica semanticamente do que a abordagem bag-of-words. Neste trabalho foram utilizados alguns métodos da área de extração de terminologia para 
identificar termos de interesse em documentos médicos. No Capítulo 3 as abordagens de extração de terminologia são apresentadas com mais detalhes.

\subsection{Trabalhos Relacionados}

No contexto do processo de mineração de textos, este trabalho situa-se na fase de pré-processamento, especificamente na construção da representação atributo-valor que é utilizada pela maioria dos algoritmos de extração de padrões.

Na literatura são encontrados poucos trabalhos de aplicação de métodos da área de mineração de textos sobre laudos médicos. Isso pode ser devido ao fato de que é difícil obter as informações apropriadas dos registros médicos para construir um bom modelo de representação dessas informações utilizado as ferramentas atuais de pesquisa de informação. Alguns dos trabalhos encontrados na literatura são apresentados a seguir.

No trabalho de Zhou et al. (2006) foi desenvolvida a ferramente MEDIE, a qual realiza a extração e mineração de várias informações de registros clínicos referentes a complicações dos seios. Nesse sistema são propostas três abordagens. A primeira está relacionada à extração de termos médicos de interesse e, para auxiliar nessa tarefa, são utilizadas técnicas da área de extração de terminologia para a identificação dos termos utilizando uma ontologia do domínio para auxiliar nessa tarefa. Na segunda abordagem é realizada a extração de termos que estão relacionados sintática ou semanticamente. Nessa tarefa é aplicada uma abordagem baseada em grafos de relacionamentos. Na última abordagem é realizada a classificação dos registros de acordo com o uso do tabaco (pacientes fumantes, não fumantes ou ex-fumantes).

No trabalho de Lee et al. (2007) são aplicadas técnicas de mineração de textos sobre um conjunto de registros médicos contendo informações de diagnóstico de câncer com o objetivo de extrair padrões a partir desse conjunto de laudos. A abordagem proposta é dividida em três fases. Na primeira é aplicado um processo de extração de palavras-chave o qual faz uso de uma ontologia do domínio. Depois de extrair as palavras-chave, elas são utilizadas como atributos para representar os documentos. Após é aplicado um algoritmo de agrupamento sobre os documentos e são analisados os padrões e identificados os tópicos de modo a obter potenciais padrões associados com a doença do câncer.

No trabalho de McCowan et al. (2006) é construído um sistema para automaticamente classificar o estágio de um câncer de pulmão de paciente baseado na análise de texto do seu registro histológico. Primeiramente, os registros são 
pré-processados (correção ortográfica, expansão de abreviatura, stemming) e depois é construída uma representação do tipo bag-of-words a partir da qual é construído um classificador. Em outro trabalho Saad et al. (2006) realiza uma comparação entre duas abordagens de agrupamento aplicadas a registros médicos de colonoscopia e endoscopia. Nesse trabalho, primeiramente os documentos são pré-processados com a ajuda de um especialista do domínio, o qual auxilia na remoção de frases que considera inúteis. Também é realizada a remoção de stopwords e a aplicação de stemming. Depois de pré-processados, os documentos são transformados em uma representação bag-of-words de modo que possam ser aplicados algoritmos de agrupamento.

Alguns trabalhos encontrados na literatura buscam apenas estruturar as informações encontradas em registros médicos de modo que as informações estruturadas possam ser posteriormente consultadas. O trabalho de Bekhouche et al. (2004) tem por objetivo identificar eventos e informações descritas em registros médicos relacionados aos pacientes tais como sinais, diagnósticos, ações e resultados. Nesse trabalho são exploradas diversas formas de extrair essas entidades e eventos, as quais são representadas como listas de atributos, por exemplo De (data do exame), Dt (tipo do exame), S (sinais e sintomas), A (ação médica), D (diagnóstico) e R (resultados). Para realizar essa tarefa são usados léxicos do domínio e regras semânticas para identificação das informações de interesse.

Outra ferramenta, a AMBIT (Harkema et al., 2005) usa métodos da área de extração de informação com o objetivo de identificar entidades importantes nos registros e também relacionamentos importantes entre essas entidades. As entidades e relacionamentos identificados são armazenados em banco de dados para que possam ser acessados posteriormente, ou utilizados como base para a indexação de documentos para serem usados por métodos de recuperação de informação. O processo de extração de informação utilizado é composto por três estágios nos quais são realizadas análises léxicas, sintáticas e semânticas e de discurso. As informações consideradas relevantes são colocadas em uma representação estruturada para acesso posterior.

\subsection{Considerações Finais}

Neste capítulo foram apresentadas as principais abordagens de pré-processamento de documentos que são utilizadas no processo de mineração de textos. Foram apresentados alguns tipos de representação de documentos como bag-of-words e outros métodos que consideram aspectos sintáticos e semânticos dos textos para identificação de atributos. Também foram apresentadas 
algumas técnicas de redução de dimensionalidade e trabalhos da área médica relacionados. No próximo capítulo são apresentadas algumas abordagens de extração de terminologia. 


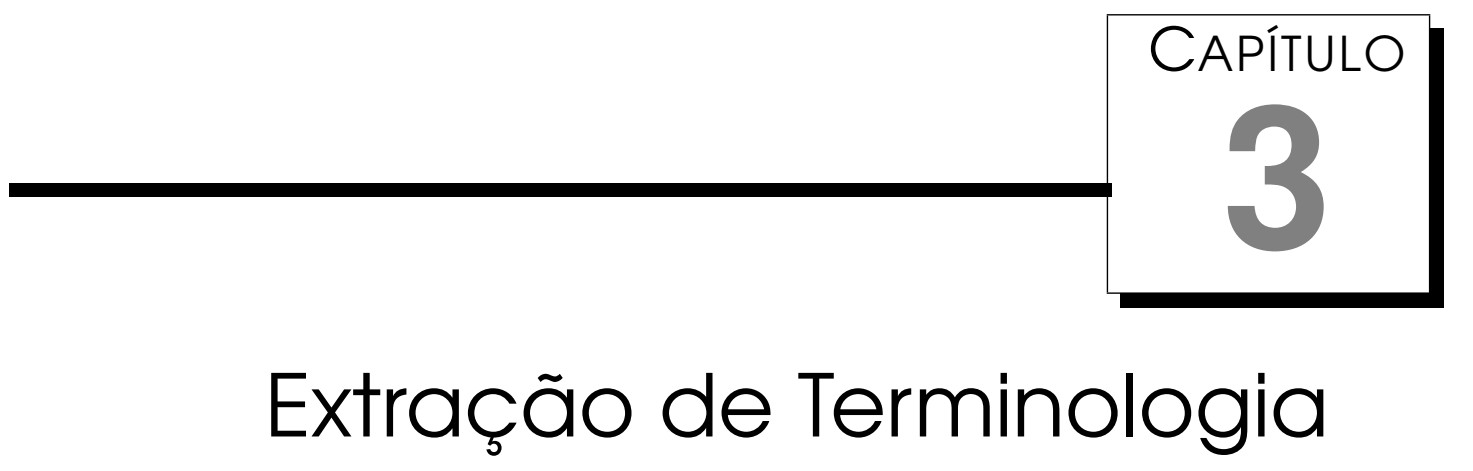

\section{1 Considerações Iniciais}

A terminologia é uma área de conhecimento e de práticas relacionados a termos técnico-científicos (da Graça Krieger, 2005) ${ }^{1}$. No aspecto teórico, a terminologia procura descrever a gênese e os modos de constituição e funcionamento das unidades lexicais especializadas, as quais são assim denominadas porque constituem-se e são utilizadas no âmbito de atividades profissionais e especializadas, com o objetivo de veicularem conceitos próprios de cada área do conhecimento. No aspecto prático, são desenvolvidos, basicamente, trabalhos de produção de glossários de diferentes áreas temáticas, dicionários especializados e banco de dados de terminologias. Conforme definido por Pavel \& Nolet (2002) a palavra terminologia significa:

"conjunto de palavras técnicas pertencentes a uma ciência, uma arte, um autor ou um grupo social"

Dois exemplos de terminologia seriam a terminologia da medicina e a terminologia usada pelos especialistas da computação. Tomando em um sentido mais restrito e especializado, as mesmas autoras designam terminologia como:

"disciplina linguística consagrada ao estudo científico dos conceitos e termos usados nas línguas de especialidade"

\footnotetext{
${ }^{1}$ Definição do dicionário Aurélio: 1. Terminologia. Conjunto de termos próprios de uma arte ou de uma ciência; nomenclatura. 2. Trato acerca desses termos. 3. Emprego de palavras peculiares a um escritor, a uma região, etc.
} 
Nesse contexto, língua especializada é a utilizada para proporcionar uma comunicação sem ambigüidades numa área determinada do conhecimento ou da prática, com base em um vocabulário e uso lingüístico específico, enquanto língua comum é aquela utilizada no cotidiano.

Os termos podem ser constituídos de uma palavra, neste caso denominados termos simples, ou compostos por mais de uma palavra, denominados termos multipalavras, termos compostos, termos complexos ou unidades terminológicas. Os termos compostos têm sido considerados como sendo as unidades preferidas para designação de conceitos terminológicos.

Com o desenvolvimento tecnológico, a possibilidade de utilizar ferramentas computacionais para lidar com grandes corpus ${ }^{2}$ possibilita observar e descrever fenômenos lingüísticos difíceis de perceber utilizando análises manuais (Almeida et al., 2006).

A área de extração de terminologia é importante em várias aplicações computacionais, tais como (Bagot et al., 1998):

- criação de glossários, vocabulários e dicionários terminológicos;

- criação de programas de tradução automática;

- indexação de textos;

- criação de bases de conhecimento;

- criação de sistemas de hipertextos;

- criação de sistemas especialistas; e

- análise de corpus.

Witschel (2005) apresenta outras aplicações da área de extração de terminologia. O autor argumenta que muitas aplicações de aprendizado de máquina e recuperação de informação necessitam de técnicas automáticas de indexação. Conforme mencionado, na fase de extração de padrões do processo de mineração de textos, as tarefas de agrupamento de dados e classificação de textos geralmente necessitam que as informações estejam descritas em uma tabela no formato atributo-valor, na qual os atributos consistem em um pequeno conjunto de termos e os valores dos atributos consistem de pesos que indicam a importância do atributo.

\footnotetext{
${ }^{2}$ Em lingüística, um corpus consiste em um conjunto de textos, os quais são utilizados em análises estatísticas, checagem de ocorrências e validação de regras lingüísticas em um universo específico.
} 
De acordo com Bagot (1999), um sistema de extração automática de candidatos a termos - SEACAT - é composto por um conjunto de programas para reconhecimento de unidades terminológicas de corpus e seu objetivo é automatizar a fase de seleção de todas unidades terminológicas de um texto especializado. Desse modo, o SEACAT promove a rapidez e sistematicidade ao trabalho de extração de terminologias. SEACATs são classificados de acordo com a metodologia que utilizam para reconhecer as unidades terminológicas. Tradicionalmente são distingüidos entre sistemas que utilizam (Paulo et al., 2002; Pantel \& Lin, 2001):

- conhecimento estatístico;

- conhecimento lingüístico; e

- conhecimento híbrido, ou seja, conhecimento estatístico juntamente com conhecimento lingüístico.

Em geral, os métodos estatísticos reconhecem as unidades terminológicas a partir de suas freqüências de ocorrência em um corpus. Os cálculos estatísticos podem oscilar desde freqüência simples de um termo no corpus até medidas mais complexas de identificação de termos candidatos, conforme apresentadas na Seção 3.3.

$\mathrm{Na}$ abordagem lingüística, tenta-se identificar termos por meio de sua estrutura lingüística, por exemplo, estrutura morfológica e sintática. Para esse propósito, textos são etiquetados com informações lingüísticas com ajuda de um analisador morfológico e um etiquetador part-of-speech que associa a classe gramatical a cada termo do texto. Depois de etiquetados, unidades terminológicas com determinadas classes gramaticais são filtradas a partir dos textos etiquetados por meio do uso de técnicas de casamento de padrões. Uma abordagem seria extrair os termos que casam com a máscara N N (substantivo substantivo). Outra técnica é filtrar os termos por meio do uso de estruturas de texto tais como definições ou contextos como "X é definido por" ou "X é composto por" (Zielinski \& Safar, 2005). Utilizando esse tipo de informações, os métodos baseados em conhecimento lingüístico poderão ser aplicados somente a uma língua. Para a utilização do sistema em uma língua diferente, é necessário um estudo lingüístico prévio e, provavelmente, de um novo projeto de alguns dos módulos do sistema.

Finalmente, têm-se os métodos que aplicam conhecimento estatístico e conhecimento lingüístico, denominados de métodos híbridos. Esses métodos podem ser de dois tipos: os que aplicam conhecimento estatístico primeiro e 
depois o lingüístico, e os que utilizam o conhecimento estatístico como complemento do lingüístico.

Nas próximas seções, essas abordagens são apresentadas com mais detalhes.

\subsection{Abordagem Lingüística}

Na abordagem lingüística, o reconhecimento de termos pode ser realizado, basicamente, por meio da captura de propriedades sintáticas (Pazienza et al., 2005). Na Tabela 3.1 são apresentados alguns padrões sintáticos, acompanhados de exemplos, extraídos do trabalho de Teline (2004), os quais foram utilizados para a extração de unidades terminológicas de um corpus de Revestimento Cerâmico em português.

Tabela 3.1: Padrões sintáticos (Teline, 2004)

\begin{tabular}{|r|l|}
\hline Padrão sintático & Exemplo \\
\hline substantivo preposição (+artigo) substantivo & absorção de água \\
\hline substantivo adjetivo adjetivo & grês porcelanato esmaltado \\
\hline substantivo preposição adjetivo & moagem a seco \\
\hline substantivo adjetivo & argila gorda \\
\hline substantivo substantivo & nefelina sienito \\
\hline adjetivo substantivo & ball clay \\
\hline substantivo & massa \\
\hline nome próprio & Rotocolor \\
\hline adjetivo & vitro-cerâmico \\
\hline verbo & deflocular \\
\hline
\end{tabular}

Assim, a extração de termos envolve uma pesquisa, no corpus, de todas as unidades que atendam a um padrão pré-especificado. Entre os pesquisadores que trabalham somente com análise lingüística, Bourigault (1992) considera que apenas essa análise gramatical superficial é suficiente para que possa ser realizado o reconhecimento de termos.

$\mathrm{Na}$ abordagem lingüística, ainda podem ser aplicadas outras técnicas com o intuito de refinar a terminologia. Por exemplo, pode ser utilizada uma lista de palavras irrelevantes (stop-list) para descartar todos os termos candidatos que contêm uma dessas palavras, i.e., remoção de stopwords.

Nesse contexto, segundo Pazienza et al. (2005), um reconhecedor de termos ideal que use a abordagem lingüística deve ser capaz de:

- analisar o corpus do domínio, identificando pelo menos a classe gramatical das palavras (part-of-speech);

- identificar e extrair termos candidatos por meio do uso de padrões (filtros lingüísticos);

- remover variações do termo original, mas preservando seu significado; e 
- implementar outros filtros lingüísticos que refinem a terminologia.

A ferramenta LEXTER, desenvolvida por Bourigault (1992), tem por objetivo produzir, a partir de um corpus de língua francesa de qualquer domínio, uma lista de unidades terminológicas candidatas, a qual é passada para um especialista do domínio para validação. Para detectar as unidades terminológicas, a LEXTER aplica uma abordagem lingüistica por meio de duas fases principais: uma de análise e outra de parsing. A fase de análise produz uma série de seqüências de textos, freqüentemente frases que contém substantivos que podem ser potenciais unidades terminológicas. Freqüentemente, as frases contêm subseqüências que também são potenciais unidades terminológicas. Assim, essas frases são denominadas "frases de substantivos de tamanho máximo" e sobre elas são aplicadas regras de parsing, as quais poderão extrair subseqüências de potenciais unidades terminológicas. Por exemplo, para uma frase que possui a estrutura gramatical substantivol adjetivo preposição determinante substantivo2 preposição substantivo3 poderão ser criadas regras do tipo substantivo1 adjetivo e substantivo2 preposição substantivo3 que são potenciais unidades terminológicas.

Outra ferramenta é a TERMINO (Savary \& Jacquemin, 2000), a qual realiza a extração de terminologia por meio da aplicação de três passos. No primeiro passo é aplicada a lematização e a análise morfológica do corpus. No próximo passo são extraídos os núcleos de frases substantivos. Por exemplo, na seqüência a very efficient word processor somente word processor é extraído. Um reconhecedor de termos filtra os núcleos de sintagmas nominais de modo a encontrar estruturas aninhadas. Por exemplo, na seqüência data management system são extraídos os termos data management. Finalmente pode ser utilizado um módulo que permite a visualização e classificação dos termos candidatos.

\subsection{Abordagem Estatística}

Medidas estatísticas aplicadas na extração de terminologia são de grande ajuda no que diz respeito a ordenação dos termos candidatos extraídos de um corpus. Essas medidas geralmente são aplicadas sobre $n$-gramas de palavras, os quais podem ser definidos como uma seqüência contígua ou não contígua de palavras que ocorrem próximas uma da outra no corpus. $N$-gramas contíguos, tipicamente referenciados apenas por $n$-grama, são aqueles nos quais as palavras ocorrem uma do lado da outra no corpus, enquanto $n$-gramas não contíguos, também referenciados como $n$-gramas posicionais, são aqueles nos 
quais as palavras estão localizadas dentro de uma janela específica em vez de uma palavra do lado da outra. Considere o exemplo extraído de McInnes (2004):

to be or not to be

As palavras desse texto seriam: to, be, or, not, to e be. Como palavras únicas, to, be, or e not são unigramas ${ }^{3}$. Um 2-grama é uma seqüência de duas palavras no corpus e um 3-grama é uma seqüência de três palavras, conforme ilustrado na Tabela 3.2.

Tabela 3.2: n-gramas
\begin{tabular}{|c|c|c|c|c|}
\hline 1-grama & to & be & or & not \\
\hline 2-grama & to be & be or & or not & not to \\
\hline 3-grama & to be or & be or not & or not to & not to be \\
\hline
\end{tabular}

A terminologia descrevendo $n$-gramas também pode ser aplicável para descrever $n$-gramas posicionais. Por exemplo, o 2-grama posicional para a sentença "to be or not to be", usando uma janela de tamanho 3, resulta nos 2gramas apresentados na Tabela 3.3.

Tabela 3.3: 2-gramas posicionais

\begin{tabular}{|l|l|l|l|l|l|l|l|}
\hline to be & to or & be or & be not & or not & or to & not to & not be \\
\hline
\end{tabular}

O uso de $n$-gramas posicionais pode aumentar o número de $n$-gramas observados no corpus, os quais não seriam identificados se fossem extraídos somente $n$-gramas contíguos. Entretando, como apresentado no trabalho de Dias \& Lopes (2005), n-gramas contíguos são mais prováveis de serem unidades terminológicas do que $n$-gramas não contíguos. Isso se deve ao fato de que as palavras em uma unidade terminológica tendem a ocorrer juntas mais freqüentemente do que seria de esperar por mera sorte. Medidas estatísticas de associação podem ser aplicadas para determinar a probabilidade das palavras em um n-grama ocorrerem juntas mais freqüentemente do que o normal.

Por exemplo, se a palavra "inteligência" é continuamente seguida pela palavra "artificial", pode-se dizer que as palavras "inteligência" e "artificial" são fortemente associadas uma com a outra, significando que elas ocorrem juntas não por acaso. Medidas estatísticas fornecem um meio de quantificar essa associação. Essas medidas são calculadas utilizando várias contagens de freqüências individuais e de co-ocorrência de um n-grama. A contagem

\footnotetext{
${ }^{3}$ Unigrama também pode ser referenciado como 1-grama, bigrama pode ser referenciado como 2-grama, e assim por diante.
} 
de freqüência de $n$-gramas pode ser convenientemente apresentada em uma tabela de contingência. Na Tabela 3.4 é apresentada uma tabela de contingência ${ }^{4}$ para 2-gramas $(x y)$.

Tabela 3.4: Tabela de contingência para 2-gramas

\begin{tabular}{|c|c|c|c|}
\hline & $y$ & $\tilde{y}$ & Total \\
\hline$x$ & $f(x, y)$ & $f(x, \tilde{y})$ & $f\left(x,{ }^{*}\right)$ \\
\hline$\tilde{x}$ & $f(\tilde{x}, y)$ & $f(\tilde{x}, \tilde{y})$ & $f\left(\tilde{x},{ }^{*}\right)$ \\
\hline Total & $f\left({ }^{*}, y\right)$ & $f\left(^{*}, \tilde{y}\right)$ & $N$ \\
\hline
\end{tabular}

A célula $f(x, y)$ representa a freqüência do 2-grama, ou seja, o número de vezes que as palavras $x$ e $y$ são encontradas juntas. A célula $f(x, \tilde{y})$ representa a freqüência que a palavra $x$ ocorre na primeira posição, mas a palavra $y$ não ocorre na segunda posição. A célula $f(\tilde{x}, y)$ representa a freqüência que a palavra $y$ ocorre na segunda posição do 2-grama, mas a palavra $x$ não ocorre na primeira posição e, a célula $f(\tilde{x}, \tilde{y})$, representa a freqüência que nem a palavra $x$ e nem a palavra $y$ ocorrem.

As freqüências $f\left(x,{ }^{*}\right)$ e $f\left(\tilde{x},{ }^{*}\right)$ representam as freqüências marginais. Essas freqüências correspondem, respectivamente, ao número de vezes que a palavra $x$ aparece, ou não aparece, na posição 1 do 2-grama. As freqüências marginais $f\left({ }^{*}, y\right)$ e $f(*, \tilde{y})$ correspondem, respectivamente, as freqüências nas quais a palavra y e $\tilde{y}$ aparece, ou não aparece, na posição 2 do 2-grama. Linhas marginais, colunas marginas e $N$ (tamanho do corpus) são necessárias para calcular o valor da freqüência esperada (E) para cada célula na tabela de contingência. A freqüência esperada de um unigrama indica o quão provável, ou seja, qual a chance de observar o unigrama em uma população (no corpus). Essa freqüência é dada pela Equação 3.1.

$$
E(x)=\frac{f(x)}{N}=P(x)
$$

A freqüência esperada de um 2-grama $(x, y)$ reflete o quão provável $x$ estará do lado de $y$, i.e., primeiro $x$ e depois $y$. A freqüência esperada para um 2grama, i.e., a probabilidade de ver os unigramas juntos, é dada pela Equação 3.2 .

$$
P(x, y)=P(x \mid y) P(y)
$$

onde $P(x \mid y)$ indica a probabilidade condicional de $x$ estar na frente de $y$ sempre que $y$ aparecer no texto. Caso as ocorrências de $x$ e $y$ sejam independentes então a probabilidade é dada pela Equação 3.3.

\footnotetext{
${ }^{4}$ Tabelas de contingência podem ser criadas para $n$-gramas de qualquer tamanho $n$, embora elas se tornem mais complicadas a medida que $n$ aumenta, porque o número de freqüências marginais aumenta na ordem de $2^{n}$.
} 


$$
P(x, y)=P(x) P(y)
$$

Os dados existentes na tabela de contingência podem também ser utilizados para avaliar um n-grama por meio do uso de medidas de associação. Três medidas que são comumente utilizadas para a estatística de $n$-gramas são (McInnes, 2004; Pazienza et al., 2005): log-likelihood, informação mútua e coeficiente dice. Essas medidas, juntamente com a medida de freqüência são apresentadas a seguir.

\subsubsection{Freqüência}

Freqüência não deriva de um princípio estatístico teórico, mas na simples suposição de que expressões freqüentes denotam um importante conceito para o domínio que está sendo examinado e, portanto, essas expressões devem assumir uma alta posição na lista de termos candidatos (Pazienza et al., 2005).

\subsubsection{Informação Mútua}

A informação mútua - IM - é uma medida de associação que pode ser definida como a quatidade de informação que uma variável contem sobre outra, ou seja, é a redução de incerteza de uma variável qualquer devido ao conhecimento de outra (Manning \& Schtze, 1999; Pantel \& Lin, 2001). Em outras palavras, se duas palavras, $x$ e $y$, têm probabilidades $\mathrm{P}(x)$ e $\mathrm{P}(y)$, então sua IM é definida pela Equação 3.4.

$$
\operatorname{IM}(x, y)=\log _{2} \frac{P(x, y)}{P(x) P(y)}
$$

A IM compara a probabilidade de observar $x$ e $y$ juntos (a probabilidade conjunta) com a probabilidade de observar $x$ e $y$ independentemente (Church $\&$ Hanks, 1989). Se há uma forte ligação entre $x$ e $y$, então a probabilidade conjunta $\mathrm{P}(x, y)$ será maior do que $\mathrm{P}(x) \mathrm{P}(y)$, e consequentemente $\operatorname{IM}(x, y) \gg 0$. Se não há nenhum relacionamento interessante entre $x$ e $y$, então $\mathrm{P}(x, y)=$ $\mathrm{P}(x) \mathrm{P}(y)$ e assim, $\operatorname{IM}(x, y)=0$. Se $x$ e $y$ estão em uma distribuição complementar, ou seja, não possuem nenhum relacionamento, então $\mathrm{P}(x, y)$ será muito menor do que $\mathrm{P}(x) \mathrm{P}(y)$ forçando então a $\operatorname{IM}(x, y) \ll 0$. Em outras palavras, a IM é maior quando todas as ocorrências de $x$ e $y$ são adjacentes e deteriora-se a medida que a ocorrência de $x$ e $y$ adjacentes diminui. Para aliviar o problema da IM ser menor para eventos de baixa freqüência, pode ser utilizada uma segunda medida, log-likelihood, a qual é robusta também para eventos que ocorrem raramente. 


\subsubsection{Log-likelihood}

Segundo Dunning (1993), o efeito prático de utilizar esse teste estatístico é que a análise textual pode ser realizada com um volume muito menor de texto do que geralmente é necessário em outros testes estatísticos, e permite que sejam realizadas comparações de significância com eventos que ocorrem raramente ou mesmo com eventos comuns. A taxa log-likelihood de $x$ e $y$ é definida pela Equação 3.5:

$$
\log L(x, y)=2\left(\log L\left(p_{1}, k_{1}, n_{1}\right)+\log L\left(p_{2}, k_{2}, n_{2}\right)-\log L\left(p, k_{1}, n_{1}\right)-\log L\left(p, k_{2}, n_{2}\right)\right)
$$

onde:

- $k_{1}$ é a freqüência de $x$ adjacente a $y$;

- $n_{1}$ é a freqüência de $y$;

- $k_{2}$ é a freqüência de $x$ seguido por palavras diferente de $y$;

- $n_{2}$ é a freqüência de palavras diferentes de $y$;

- $p_{1}=\frac{k_{1}}{n_{1}}$;

- $p_{2}=\frac{k_{2}}{n_{2}}$;

- $p=\frac{k_{1}+k_{2}}{n_{1}+n_{2}}$.

e $\log L(p, k, n)$ é dado pela Equação 3.6:

$$
\log L(p, k, n)=k \times \log (p)+(n-k) \times \log (1-p)
$$

A taxa log-likelihood de $x$ e $y$ atinge seu valor máximo quando todas as ocorrências de $x$ e $y$ são adjacentes. Entretando, a taxa também é alta para dois termos freqüentes que são raramente adjacentes (Pantel \& Lin, 2001).

\subsubsection{Dice}

A medida de associação entre duas variáveis quaisquer, denominada coeficiente Dice, definida na Equação 3.7, é semelhante à informação mútua.

$$
\operatorname{Dice}(x, y)=\frac{2 \times f(x, y)}{f(x)+f(y)}
$$

O coeficiente Dice depende apenas da freqüência do 2-grama, e produz escores normalizados entre 0 e 1 , sendo que valores próximos de 1 indicam uma forte associação entre as duas palavras $x$ e $y$ (Smadja et al., 1996). 


\subsection{Abordagem Híbrida}

Sistemas de extração de terminologia tradicionalmente combinam técnicas lingüísticas e estatísticas em abordagens denominadas híbridas (Patry \& Langlais, 2005). Geralmente, a análise lingüística é realizada antes da aplicação das medidas estatísticas, para que sejam selecionados todos os candidatos que apresentam algum padrão lingüístico sobre os quais serão aplicados testes estatísticos. Em outras palavras, os testes estatísticos trabalham sobre uma lista de termos candidatos selecionados por meio da aplicação de filtros lingüísticos.

Várias ferramentas utilizam a abordagem híbrida. Entre elas, a ferramenta ACABIT (Daille, 1996) aplica uma abordagem híbrida que combina uma filtragem lingüística com um ranqueamento estatístico e a aquisição de termos a partir do corpus é realizada em dois passos: um passo de filtragem, no qual são extraídos termos candidatos do corpus e um passo de ranqueamento, o qual ordena os termos candidatos em ordem decrescente de qualidade. No primeiro passo são extraídos termos candidatos por meio da aplicação de máscaras ${ }^{5}$ (N ADJ, N N, N PREP N) sobre o corpus etiquetado. Depois, os termos candidadatos extraídos são ordenados de acordo com algumas medidas estatísticas como freqüência e log-likelihood. Outra ferramenta, TERMS (Justeson \& Katz, 1995), permite a extração de terminologias que casam com a expressão regu$\operatorname{lar}((\mathrm{A} \mid \mathrm{N})+\mathrm{I}(\mathrm{A} \mid \mathrm{N}) *(\mathrm{~N}$ P)(A | N)*)N. Depois são aplicadas medidas de associações estatísticas sobre a lista de termos extraídos. Todos os termos que aparecem somente uma vez são rejeitados.

\subsection{Avaliação}

Independente da técnica que é utilizada para a extração de terminologia a partir de um corpus, é necessário avaliar os termos extraídos pelo sistema de extração de terminologia utilizado. O objetivo da extração automática de terminologia, de recuperar todos os termos de interesse, nunca é alcançado completamente na prática. Isso resulta em um certo nível de ruído (noise) (termos recuperados incorretamente), e um certo nível de silêncio (silence) (termos corretos mas não recuperados). As duas medidas principais para avaliar a qualidade dos sistemas de extração de terminologia são a precisão e o recall.

A precisão, $\mathrm{P}$, é definida como a proporção de ocorrências relevantes dentro de todas ocorrências recuperadas. O recall, $\mathrm{R}$, é definida como a proporção de

\footnotetext{
${ }^{5} \mathrm{~N}=$ substantivo; $\mathrm{ADJ}=$ adjetivo; $\mathrm{VERB}=$ verbo; $\mathrm{PREP}=$ preposição; $\mathrm{ART}=$ artigo
} 
ocorrências recuperadas dentro de todas ocorrências relevantes. Precisão e recall são definidas respectivamente pelas Equações 3.8, 3.9, onde $I_{e}$ corresponde as ocorrências recuperadas e $I_{r}$ corresponde as ocorrências relevantes.

$$
\begin{aligned}
& P=\frac{I_{e} \cap I_{r}}{I_{e}} \\
& R=\frac{I_{e} \cap I_{r}}{I_{r}}
\end{aligned}
$$

A dificuldade da avaliação de extração de terminologia está relacionada à determinação do conjunto de ocorrências relevantes $\left(I_{r}\right)$ de termos de um dado corpus. Na abordagem clássica, supõe-se que exista uma lista de referência que foi elaborada a priori por um especialista do domínio depois de uma exaustiva análise manual do corpus. Infelizmente, a definição de termos relevantes está longe de ser clara porque ela depende da aplicação particular em que está sendo realizada a extração de terminologia (Savary \& Jacquemin, 2000). Por exemplo, o termo doença genética pode ser importante no contexto de indexação automática porque pode ser um bom descritor do conteúdo do documento, mas pode não ser interessante para a construção de um vocabulário. Em outras palavras, uma avaliação objetiva de um sistema de extração de terminologia é possivel, mas com relação a aplicação particular que está sendo realizada.

Outro método que pode ser aplicado para a avaliação quando não existe a lista de referência é a validação. Nesse caso, a performance é avaliada por um especialista que valida os termos extraídos pelo sistema. O valor da precisão é, neste caso, a porcentagem de termos candidatos extraídos que foram considerados termos pelo especialista. Deve ser observado que essa tarefa tem alto custo de tempo. Segundo Pazienza et al. (2005), na validação manual devem ser observados dois aspectos. Primeiro, a validação deve ser realizada por mais de um especialista, para que a avaliação seja mais confiável. Segundo, deve ser informado ao especialista qual a noção de termo, com o intuito de evitar diferentes validações, baseado na intuição de cada especialista do que considera termo.

\subsection{Considerações Finais}

Segundo Bagot (1999), a maioria dos sistemas, independente da abordagem que utilizam, não são totalmente satisfatórios no que se refere à extração automática de terminologia. Já os métodos baseados exclusivamente em conhecimento estatístico são condicionados ao tamanho do corpus que está sendo 
utilizado para a extração de termos candidatos. Se o corpus é pequeno, podese gerar alto nível de silêncio, i.e., termos corretos terão baixa freqüência e não serão recuperados, mesmo que sejam importantes. Por outro lado, mesmo se o corpus for constituído por milhares de ocorrências, sempre existirá uma porcentagem de palavras que não serão recuperadas devido a baixa freqüência de ocorrência de uso no corpus. Outro problema dos métodos estatísticos é que eles podem gerar muito ruído, i.e., são gerados muitos termos candidatos que não apresentam valor terminológico. Esses termos geralmente são palavras que não apresentam significado em textos especializados, sendo pertencentes à língua geral. Esse problema pode ser aliviado removendo stopwords. Embora possam ocorrer os problemas citados anteriormente, os métodos estatísticos possuem a vantagem de serem independentes da língua.

Quanto a abordagem lingüística, segundo Bagot (1999), uma desvantagem dos sistemas que trabalham com esse tipo de informação é a grande quantidade de ruído gerada, uma vez que nem todas as palavras que são consideradas pelo sistema como unidades terminológicas o são. Esse problema existe pelo fato de que a maioria dos padrões encontrados correspondem a unidades léxicas e fraseológicas que não apresentam uso especializado.

Em relação aos sistemas híbridos, no caso em que é aplicado primeiro o método estatístico e depois o lingüístico, acontecem os mesmos problemas de silêncio encontrados nos métodos puramente estatísticos. Por outro lado, no caso em que primeiro é aplicado conhecimento lingüístico e depois estatístico, os resultados finais podem ser melhores, uma vez que a estatística pode auxiliar no pocesso de detecção, confirmando ou recusando a condição de termo de uma unidade lingüística. 


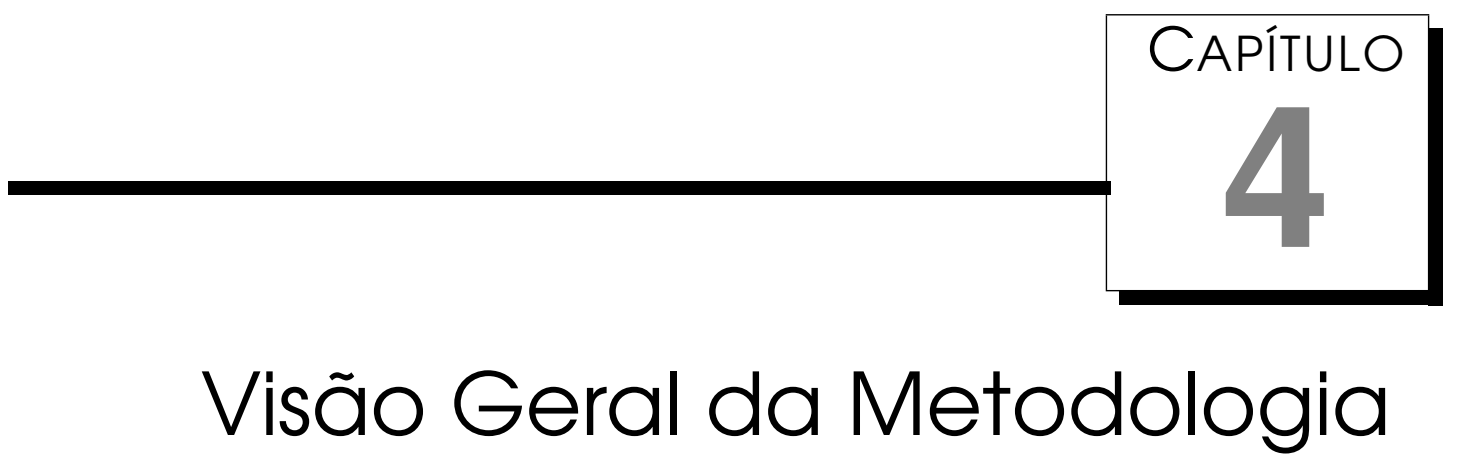

\section{1 Considerações Iniciais}

Neste capítulo é apresentada a idéia geral da metodologia proposta para o pré-processamento de informações não estruturadas, a qual está descrita em detalhes no Capítulo 5. É importante lembrar que a metodologia está baseada nas duas seguintes propriedades presentes nas informações não estruturadas de laudos médicos:

- As informações são descritas utilizando um vocabulário controlado; e

- As informações consistem de frases assertivas simples.

Além disso, a metodologia deve diminuir, tanto quanto possível, o trabalho do especialista do domínio.

Um outro aspecto importante da metodologia proposta tem a ver com o uso de conhecimento externo do domínio. Conforme mencionado na Seção 2.3.4, do Capítulo 2, muitos trabalhos relacionados fazem uso de algum tipo de conhecimento prévio do domínio para realizar o pré-processamento de textos. Geralmente, esses recursos consistem de dicionários de termos, regras semânticas e ontologias do domínio, entre outros, já definidas para diferentes domínios de conhecimento. Entretando, consideramos que o uso desse tipo de conhecimento externo pode apresentar mais desvantagens que vantagens quando o conhecimento se refere a um domínio de conhecimento bem restrito, como é o caso de laudos médicos. 
Assim, neste trabalho foi decidido não utilizar nenhum tipo de recurso externo, somente são considerados o conjunto de documentos a serem préprocessados e o conhecimento do especialista. Deve ser ressaltado ainda que a metodologia proposta permite ao especialista do domínio a atuação em cada uma das fases que a constituem com o objetivo de considerar incluir o aspecto semâtico dos atributos utilizados para representar os documentos, ela também pode ser utilizada sem a participação do especialista.

\subsection{Metodologia Proposta}

A metodologia consiste de cinco fases, ilustradas na Figura 4.1.

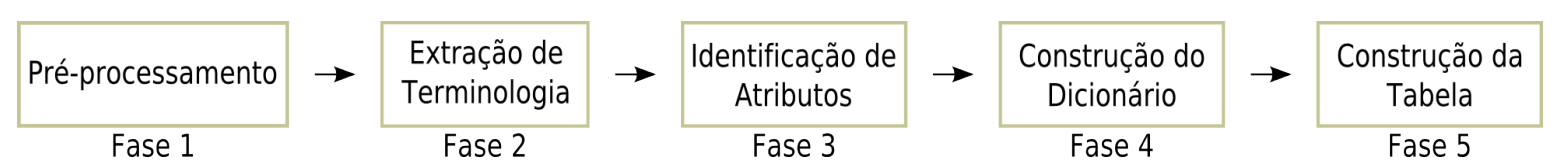

Figura 4.1: Fases da metodologia

Conforme mencionado na seção 2.3.1, na fase de pré-processamento, na maioria das vezes as informações textuais são transformadas para uma reprensentação bag-of-words. Porém, um dos problemas dessa representação é que ela não leva em consideração o relacionamento entre as palavras enquanto que métodos de representação que levem em consideração esses relacionamentos podem alcançar melhores resultados na representação de textos. Assim, neste trabalho propomos utilizar uma abordagem da área de extração de terminologia. A seguir é descrita a idéia geral utilizada no desenvolvimento de cada uma das fases da metodologia proposta.

\subsubsection{Fase 1 - Pré-processamento}

Mais especificamente, na fase de pré-processamento os documentos são preparados para a fase de extração de terminologia por meio de tarefas como remoção de stopwords, transformação para letras minúsculas, correção ortográfica e aplicação de substituições. A aplicação de substituições consiste na tarefa de substituir uma seqüência de uma ou mais palavras por outra seqüência de uma ou mais palavras. Por exemplo, nesta tarefa podem ocorrer interações com o especialista para que sejam mapeados sinônimos de palavras. Deve ser observado que essa tarefa do especialista é facilitada no caso de laudos médicos. Como poderá ser observado nos próximos capítulos, o número de frases diferentes utilizadas nos laudos é somente $5 \%$ ou menos que o 
total de frases utilizadas em todo o conjunto de laudos. Esse conjunto de frases únicas, denominado CFU, tem um papel muito importante na metodologia proposta.

\subsubsection{Fase 2 - Extração de Terminologia}

Após realizar o pré-processamento é realizada a extração de unidades terminológicas de interesse, as quais são utilizadas para a identificação de partes consideradas importantes das frases dos documentos, conforme ilustrado na Figura 4.2.

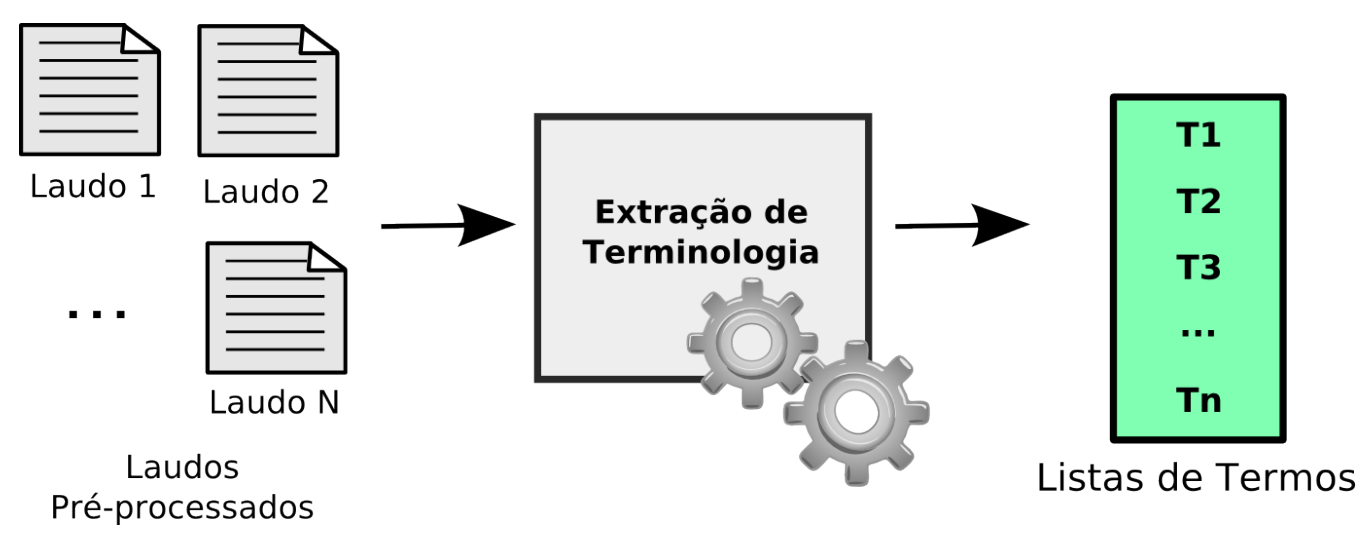

Figura 4.2: Extração de terminologia

Nesse caso, estamos interessados na extração de unidades terminológicas que indicam informações que freqüentemente são mapeadas pelo médico nos laudos. Por exemplo, considere as seguintes frases extraídas de diferentes laudos, as quais descrevem um determinado segmento do estômago.

mucosa antro com enantema.

mucosa antro com presença erosões.

mucosa antro aspecto normal.

Nosso interesse é, por meio da aplicação de métodos da área de extração de terminologia, extrair automaticamente termos de interesse. No caso das frases apresentadas, o objetivo é descobrir os termos mucosa antro, os quais representam o nome de um segmento do estômago que foi observado pelo médico e que está sendo mapeado no laudo.

Como descrito no Capítulo 3, vários métodos são propostos na área de extração de terminologia para a identificação de unidades terminológicas de interesse, como o estatístico, o lingüístico e o híbrido. Neste trabalho é proposto o uso de um método híbrido, o qual utiliza conhecimento lingüístico associado às freqüências dos termos. Para isso, na fase de extração de terminologia, os 
documentos são etiquetados utilizando um etiquetador part-of-speech, o qual associa a cada palavra do documento sua classe gramatical (substantivo (N), adjetivo (ADJ), verbo (VERB), entre outros). Após etiquetados os documentos é realizada a extração de termos que casam com determinadas máscaras. Neste trabalho são utilizadas as máscaras $\mathrm{N}$ e N N, uma vez que os termos que pertencem a essa classe gramatical geralmente são utilizados pelos médicos para a descrição de um local ou segmento que está sendo avaliado. Após gerada a lista de termos utilizando as máscaras citadas, são aplicadas algumas heurísticas sobre essa lista, descritas em maiores detalhes na Seção 5.3.4 do próximo capítulo, com o intuito de reduzir o número de termos, uma vez que usando somente máscaras podem ser recuperados termos que possuem baixa freqüência e não são de interesse. Nesse ponto pode ocorrer uma nova interação com o especialista de modo que ele identifique manualmente os termos que realmente devem ser utilizados para o mapeamento de informações nos laudos e remova termos que considere não interessantes.

\subsubsection{Fase 3 - Identificação de Atributos}

A identificação de atributos não é realizada apenas com a lista final de termos identificada na fase de extração de terminologia. Neste trabalho estamos também interessados nos termos que aparecem no contexto (lado direito) desses termos, ou seja, em partes das frases em que esses termos estão presentes. Portanto, na fase de identificação de atributos, para cada termo da lista de termos identificada na fase de extração de terminologia, é gerada uma árvore, cuja raíz é o termo extraído da lista gerada na fase de extração de terminologia, conforme ilustrado na Figura 4.3.

Para uma determinada árvore, os ramos correspondem ao contexto do termo raiz no conjunto de laudos, ou seja, correspondem as palavras que aparecem do lado do termo identificado na fase de extração de terminologia. Nos ramos também são armazenadas as freqüências dos termos.

Para exemplificar, considere que os termos terço distal foram identificados na fase de extração de terminologia como sendo um termo raiz, i.e., eles constituem uma unidade terminológica. Agora considere as seguintes frases presentes no conjunto de laudos nos quais os termos terço distal estão presente, como ilustrado na Tabela 4.1.

A partir dessas frases, é gerada uma estrutura semelhante à apresentada na Tabela 4.2, na qual $p_{i}$ corresponde à palavra na posição $i$ da frase e $f_{p_{i}}$ corresponde à freqüência da palavra na posição $i$. É importante ressaltar que $f_{p_{1} p_{2}, \ldots, p_{k}}$, corresponde à freqüência com que as palavras $p_{1}, p_{2}, \ldots, p_{k}$ aparecem 


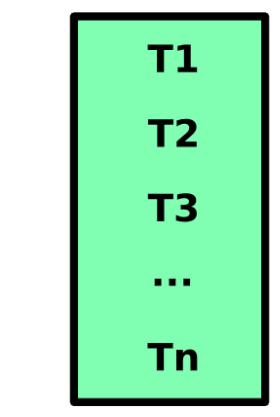

Listas de Termos
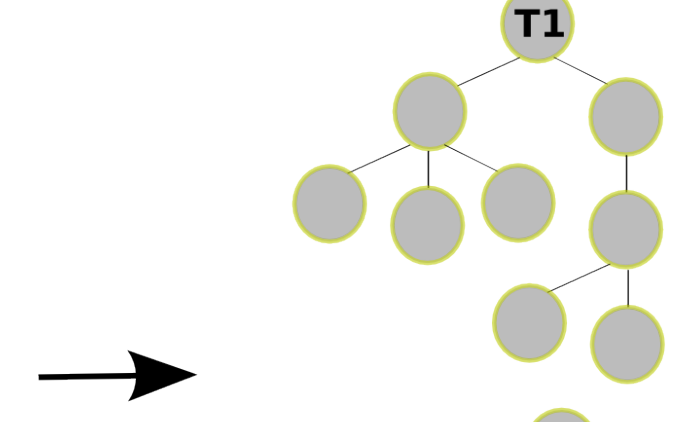

T3

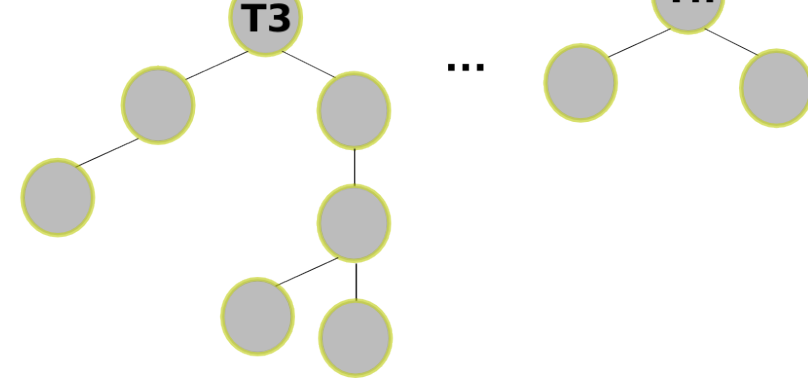

Figura 4.3: Geração de árvores a partir dos termos identificados

Tabela 4.1: Exemplos de frases e freqüências de ocorrência

\begin{tabular}{|c|c|}
\hline Frases & Freqüência \\
\hline \hline terço distal com erosões lineares & 10 \\
\hline terço distal com erosões confluentes & 40 \\
\hline terço distal com erosões & 80 \\
\hline terço distal com lesões & 20 \\
\hline terço distal com enantema & 10 \\
\hline terço distal coloração esbranquiçada & 70 \\
\hline
\end{tabular}

juntas no conjunto de documentos. A partir dessa estrutura é gerada a árvore

Tabela 4.2: Estrutura das frases

\begin{tabular}{|c|c|c|c|c|c|c|c|}
\hline$p_{1}$ & $f_{p_{1}}$ & $p_{2}$ & $f_{p_{1} p_{2}}$ & $p_{3}$ & $f_{p_{1} p_{2} p_{3}}$ & $p_{4}$ & $f_{p_{1} p_{2} p_{3} p_{4}}$ \\
\hline \multirow[t]{5}{*}{ terço distal } & \multirow[t]{5}{*}{230} & \multirow[t]{4}{*}{ com } & \multirow[t]{4}{*}{160} & \multirow[t]{2}{*}{ erosões } & \multirow[t]{2}{*}{80} & lineares & 10 \\
\hline & & & & & & confluentes & 40 \\
\hline & & & & lesões & 20 & & \\
\hline & & & & enantema & 10 & & \\
\hline & & coloração & 70 & esbranquiçada & 70 & & \\
\hline
\end{tabular}

ilustrada na Figura 4.4.

Utilizando essa informação, a árvore é gerada automaticamente com base na análise de cada palavra $p_{i}$ e da freqüência da palavra $p_{i}$ no conjunto de documentos. Durante o processo de geração da árvore, se $f_{p_{i}}=f_{p_{i+1}}$ então as palavras $p_{i}$ e $p_{i+1}$ são concatenadas e é verificada a freqüência $f_{p_{i+2}}$ da próxima palavra $p_{i+2}$ na frase. Se a freqüência $f_{p_{i+2}}$ é a mesma que as palavras anteriores, então $p_{i+2}$ é concatenada a $p_{i}$ e $p_{i+1}$. Esse processo continua enquanto as freqüências de palavras sucessivas são iguais. Quando a freqüência de uma palavra for diferente das anteriores, é efetivamente criado o nó com a concatenação das palavras cujas freqüências são iguais. Caso $f_{p_{i}}$ for diferente de $f_{p_{i+1}}$ 


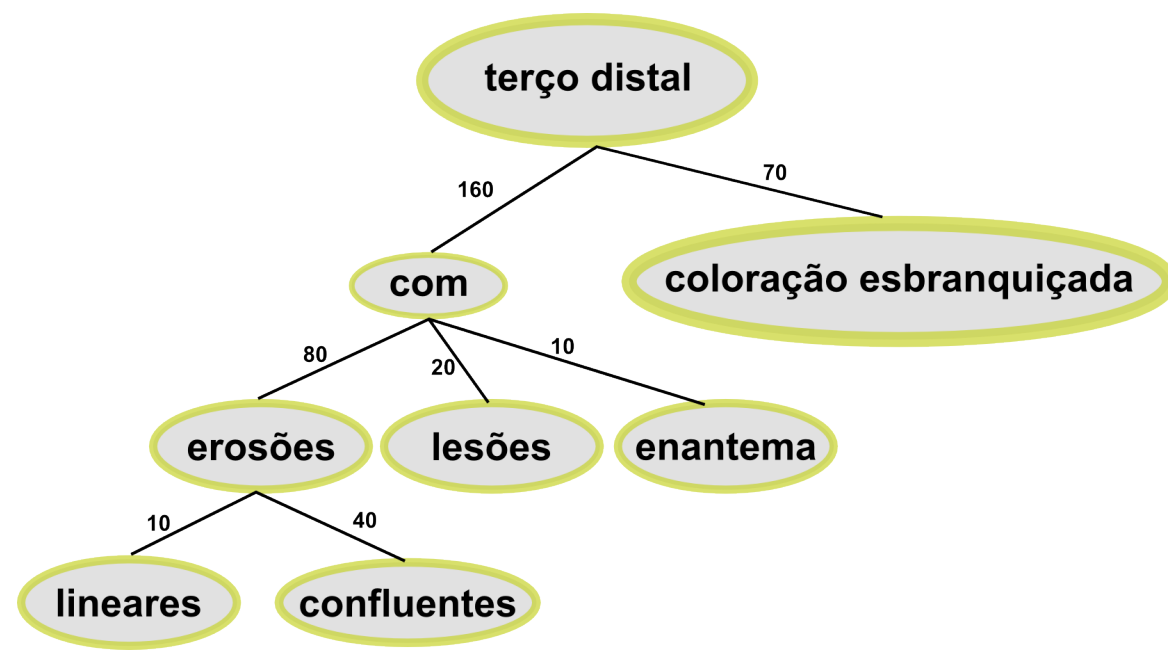

Figura 4.4: Exemplo de árvore gerada a partir do termo raiz terço distal

cria-se um nó apenas com $p_{i}$ e o processo de construção da árvore continua.

No exemplo considerado, primeiramente é criado o nó raiz terço distal, identificado pelo método de extração de terminologia. Depois é verificado o termo com. Como não existe nenhuma palavra subseqüente que tem a mesma freqüência, então o termo com é colocado como filho do termo raiz e é criada a aresta que liga os dois nós com a freqüência com que os termos aparecem juntos. Depois é identificado o termo erosões como filho do termo com. Os termos lineares e confluentes são colocados como filhos do termo erosões, uma vez que são termos finais das frases. Após, são colocados como filhos do termo com os termos finais lesões e enantema. Os termos coloração e esbranquiçada são colocados no mesmo nó pois possuem a mesma freqüência. A geração das árvores é realizada para todos os termos raiz identificados na fase de extração de terminologia.

As árvores geradas possuem uma estrutura semelhante à árvore ilustrada na Figura 4.5. Nessa árvore o termo $\alpha$, onde o tamanho de $\alpha$ é dado por

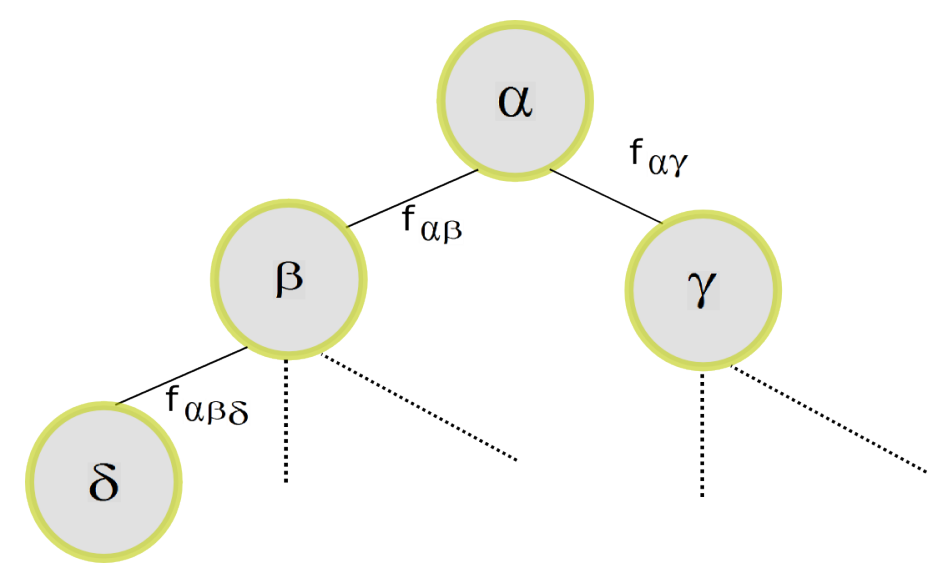

Figura 4.5: Árvore gerada 
$1 \leq|\alpha| \leq 2$, corresponde ao nó raiz identificado pelo método de extração de terminologia, os termos $\beta$ e $\gamma$ são filhos ${ }^{1}$ de $\alpha$ e $\delta$ é filho de $\beta$. Conforme mencionado, na árvore também são armazenadas as freqüências em que dois termos aparecem juntos. Por exemplo, a freqüência com que $\alpha$ e $\beta$ aparecem juntos é $f_{\alpha \beta}$, já a freqüência com que $\alpha \beta \delta$ aparecem juntos é $f_{\alpha \beta \delta}$ e $f_{\alpha \beta \delta}<f_{\alpha \beta}$. Essa relação entre as freqüências se verifica em todos os ramos da árvore.

Após a construção do conjunto de árvores, é realizada a identificação dos atributos que irão compor a tabela atributo-valor. A identificação de atributos pode ser realizada de duas maneiras: manual, i.e, com o auxílio do especialista, ou automática. Na primeira, um especialista do domínio deve analisar as árvores geradas e identificar os ramos que correspondem a um atributo. Na identificação automática, a identificação de atributos é realizada por meio de pesquisas em cada uma das árvores e, todos os ramos que possuirem freqüência maior ou igual a um determinado limiar, o qual é definido pelo usuário, são considerados atributos; caso contrário são descartados.

Por exemplo, considere o limiar $l$ e a árvore da Figura 4.5. Na identificação automática de atributos, primeiro é verificado se $f_{\alpha \beta} \geq l$ e, se for, é gerado o atributo $\alpha \beta$. Depois é verificado se $f_{\alpha \beta \delta} \geq l$ e, se for, é definido $\alpha \beta \delta$ como atributo. Por último é verificado se $f_{\alpha \gamma} \geq l$ e, se for, é definido $\alpha \gamma$ como atributo. Por outro lado, na identificação manual, o especialista pode analisar cada uma das árvores geradas automaticamente pela metodologia e decidir quais atributos irão compor a tabela atributo-valor.

\subsubsection{Fase 4 - Construção do Dícionário}

Depois de identificados os atributos, eles são inseridos em um dicionário, denominado de dicionário de conhecimento. Suponha que a partir da árvore da Figura 4.5 tenham sido identificados os atributos $\alpha \beta, \alpha \beta \delta$ e $\alpha \gamma$. Esses atributos são inseridos no dicionário e a construção da tabela é realizada com base no dicionário e no conjunto de documentos. Cada laudo corresponde a uma linha da tabela atributo-valor.

\subsubsection{Fase 5 - Construção da Tabela Atributo-valor}

O processo de preenchimento da tabela é realizado por meio de ciclos de pesquisa entre as informações dos documentos e os atributos inseridos no dicionário na fase anterior. Se a seqüência de termos definida por um determinado atributo do dicionário for identificada em um laudo, o valor desse

\footnotetext{
${ }^{1}$ Todos os filhos possuem um número de palavras maior ou igual a 1.
} 
atributo é preenchido com 1 (presente). Se a seqüência não for identificada no laudo, o atributo é preenchido com 0 (ausente).

Por exemplo, considerando somente os atributos cujos nomes começam com a unidade terminológica correspondente ao termo $\alpha$, e considerando que esses atributos são $\alpha \beta \alpha \beta \delta$ e $\alpha \gamma$ seria construída uma tabela atributo-valor na qual esses atributos poderiam ter os valores mostrados na Tabela 4.3.

Tabela 4.3: Tabela atributo-valor gerada

\begin{tabular}{|c|c|c|c|c|}
\hline Documento & $\alpha \beta$ & $\alpha \beta \delta$ & $\alpha \gamma$ & $\cdots$ \\
\hline \hline doc1.txt & 1 & 1 & 1 & $\cdots$ \\
\hline doc2.txt & 0 & 0 & 1 & $\cdots$ \\
\hline doc3.txt & 1 & 0 & 1 & $\cdots$ \\
\hline$\vdots$ & $\vdots$ & $\vdots$ & $\vdots$ & $\cdots$ \\
\hline docN.txt & 1 & 1 & 0 & $\cdots$ \\
\hline
\end{tabular}

Como pode ser observado nesse exemplo, sempre que o valor do atributo $\alpha \beta \delta$ for 1 para um determinado documento, o valor do atributo $\alpha \beta$ também será 1. Em outras palavras, se os termos $\alpha \beta \delta$ são contíguos em um documento, também são contíguos os termos $\alpha \beta$. Essa maneira de construir os atributos tem a vantagem que, após construída a tabela atributo-valor, além de poder ser utilizada por algoritmos de extração de padrões utilizando esses valores booleanos, a informação nessa tabela também permite ao especialista generalizar os atributos que representam o conjunto de documentos.

Uma maneira muito simples de realizar essa generalização de atributos, processo denominado de construção de atributos ou aprendizado construtivo, no qual subconjuntos de atributos são substituídos por um atributo que representa uma combinação desse subconjunto de atributos, é calcular inicialmente a freqüência absoluta do valor dos atributos na tabela atributo-valor.

Após, investigando essas freqüências absolutas e considerando o valor semântico desses atributos, o especialista poderia decidir quais subconjuntos de atributos poderiam ser considerados para construir novos atributos. Por exemplo, considerando os atributos $\alpha \beta$ e $\alpha \gamma$, o especialista poderia decidir substituir esses dois atributos por um único atributo $\alpha(\beta \text { ou } \gamma)^{2}$, cujo valor seria $f_{\alpha \beta}+f_{\alpha \gamma}$ para cada documento. Analogamente, o especialista poderia decidir construir o atributo $\alpha(\beta e \gamma)$ cujo valor seria dado pelo $\min \left(f_{\alpha \beta}, f_{\alpha \gamma}\right)$ para cada documento.

Além de construir novos atributos, desconsiderando os atributos utilizados na construção desses atributos, o especialista também poderia decidir não considerar alguns dos atributos da tabela. Um caso típico refere-se aos atributos $\alpha \beta$ e $\alpha \beta \delta$. Nesse caso, o atributo $\alpha \beta \delta$ consiste de uma especialização do

\footnotetext{
${ }^{2} \mathrm{Ou}$ seja, um único atributo no qual será mapeado se $\alpha \beta$ ou $\alpha \gamma$ aparece no documento.
} 
atributo $\alpha \beta$. Dependendo do significado dos atributos, o especialista poderia decidir desconsiderar o atributo $\alpha \beta \delta$.

\subsection{Considerações Finais}

Neste capítulo foi apresentada uma visão geral da metodologia proposta para realizar o pré-processamento de um conjunto de laudos médicos com o objetivo de transformar as informações nesses laudos em uma tabela atributovalor. Deve ser ressaltado que a metodologia pode ser aplicada a conjuntos de documentos de outros domínios, caso esse conjunto possua as duas propriedades presentes nas informações de laudos médicos citadas no início deste capítulo. 


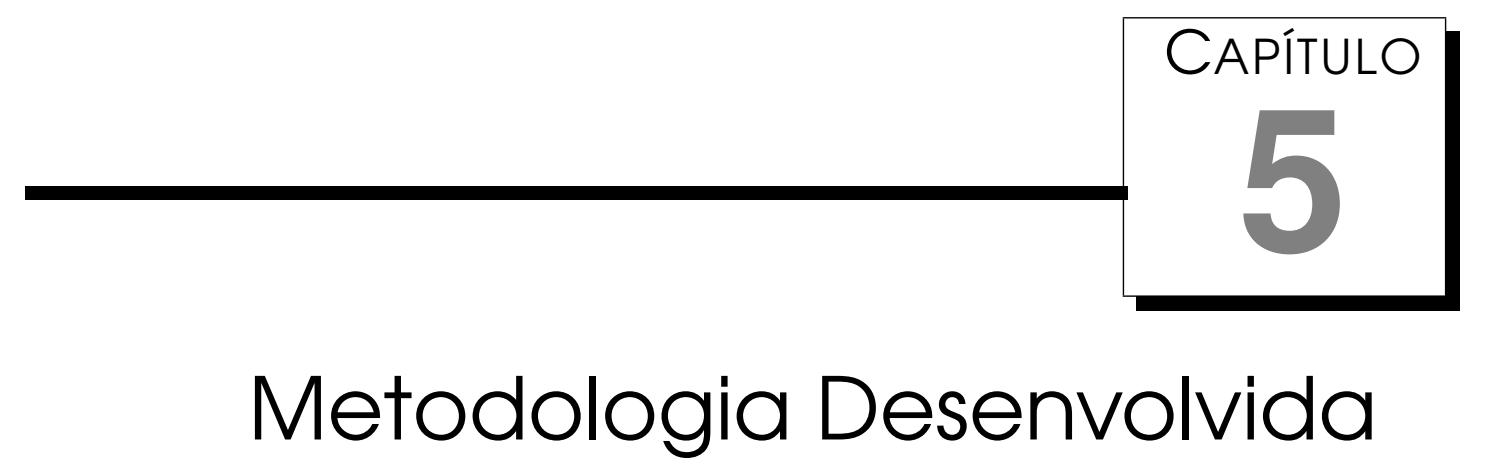

\subsection{Considerações Iniciais}

No capítulo anterior foi apresentada uma visão geral da metodologia desenvolvida. Neste capítulo essa metodologia é descrita em maiores detalhes. Conforme mencionado, a metodologia é composta pelas seguintes cinco fases, conforme apresentadas na Figura 5.1:

1. Pré-processamento;

2. Extração de terminologia;

3. Identificação de atributos;

4. Construção do dicionário; e

5. Construção da tabela atributo-valor.

Na fase de pré-processamento, o conjunto de documentos é preparado para a próxima fase, a de extração de terminologia, por meio de tarefas tais como toquenização, segmentação, construção de frases únicas, remoção de stopwords e lematização. Na fase de extração de terminologia são geradas, a partir da coleção de documentos, listas de termos do domínio que possuem determinadas propriedades sintáticas. Os termos identificados são utilizados na terceira fase, na identificação de atributos, na qual, a partir de cada termo da lista de termos identificados, são geradas árvores a partir das quais são identificados os atributos que irão compor a tabela atributo-valor. Depois de identificados 


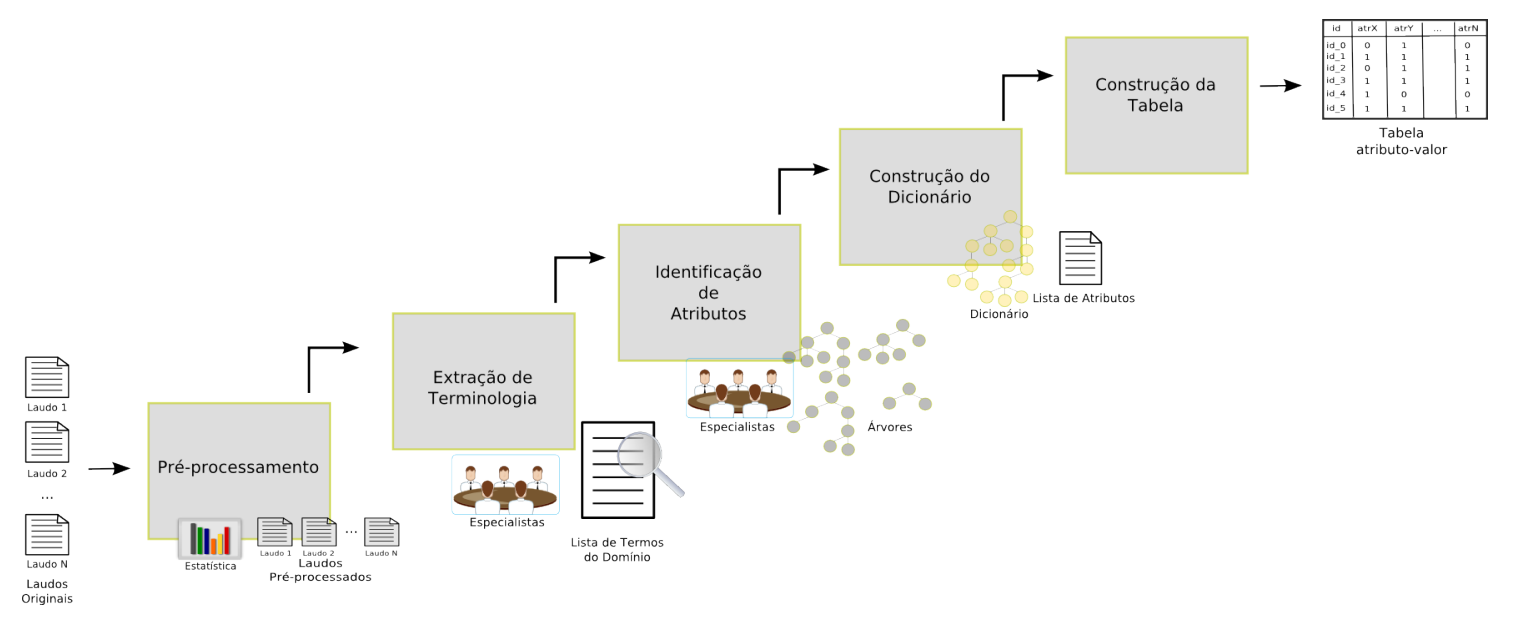

Figura 5.1: Metodologia desenvolvida

os atributos, os mesmos são mapeados em um dicionário, o qual é utilizado na última fase da metodologia, a de construção da tabela atributo-valor. $\mathrm{Na}$ construção dessa tabela são utilizados o conjunto de documentos, o dicionário e a lista de atributos identificados. A tabela é constituída por atributos binários, ou seja, o valor dos atributos é zero ou um; ou ausente ou presente. Portanto, durante o processamento do texto, se a seqüência de texto extraída de um documento (laudo) "casar" com uma seqüência inserida no dicionário, é mapeado no atributo correspondente da tabela o valor presente; caso contrário, é mapeado o valor ausente. Foi desenvolvido um ambiente computacional, denominado Term Pattern Discover - TP-Discover (Honorato \& Monard, 2008b), o qual implementa todas as fases da metodologia proposta neste trabalho. Todas as ferramentas auxiliares utilizadas no desenvolvimento do TP-Discover estão descritas em (Honorato \& Monard, 2008a). Algumas dessas ferramentas foram desenvolvidas e/ou treinadas no Núcleo Interinstitucional de Lingüística Computacional $-\mathrm{NILC}^{1}-$ do ICMC/USP. A seguir é descrita cada uma das fases da metodologia.

\subsection{Pré-processamento}

A fase de pré-processamento consiste de sete etapas, as quais são aplicadas sobre o conjunto de laudos do domínio que está sendo trabalhado. Essas etapas correspondem à preparação do corpus por meio de tarefas como:

1. Segmentação do laudo;

2. Construção do Conjunto de Frases Únicas - CFU;

\footnotetext{
${ }^{1}$ http://www.nilc.icmc.usp.br/nilc/index.html
} 
3. Remoção de stopwords;

4. Transformação para letras minúsculas;

5. Correção ortográfica;

6. Aplicação de substituições; e

7. Aplicação do lematizador.

\subsection{Preparação do Corpus}

Conforme mencionado no Capítulo 1, em muitos laudos do domínio médico acontece de as informações estarem divididas, i.e., segmentadas, dentro dos laudos. Por exemplo, o laudo da Figura 1.3 na página 7 , de Andrologia, possui duas seções, uma na qual são mapeadas informações gerais do paciente e outra na qual é colocada a avaliação macroscópica do paciente. No laudo da Figura 1.4 na página 8, de Endoscopia Digestiva Alta, o qual foi utilizado no estudo de caso deste trabalho, existem quatro divisões, uma na qual estão inseridas informações do esôfago, outra do estômago, outra do duodeno e outra de conclusões do exame.

Conforme pode ser observado, o formato do laudo pode variar, mas, geralmente, existe uma certa divisão nas informações, as quais podem ser observadas por meio dos termos indicativos (cabeçalhos) utilizados pelo médico durante o exame. Por exemplo, no laudo de EDA, ilustrado na Figura 1.4, podem ser observados cinco seções, conforme ilustrados na Figura 5.2.

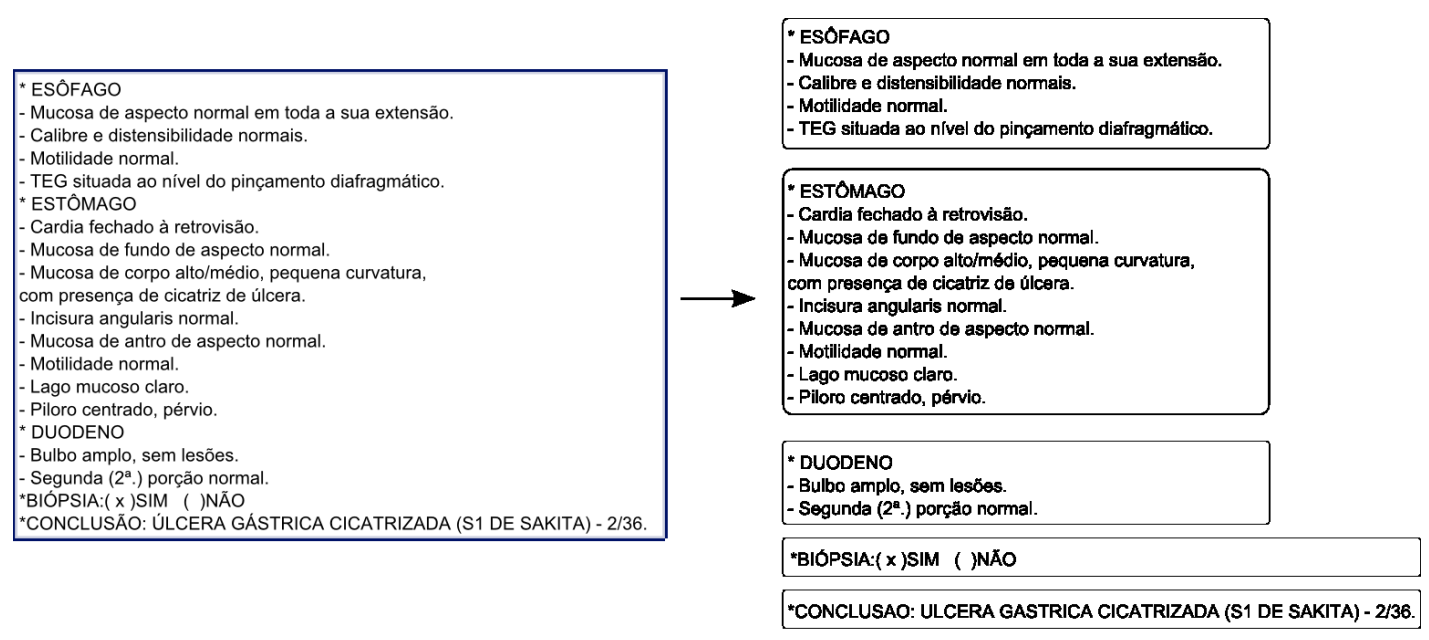

Figura 5.2: Divisão das seções do laudo de Endoscopia Digestiva Alta

Neste trabalho adotamos a estratégia de processar cada seção separadamente. Deve ser observado que a tarefa de divisão dos laudos em seções é 
específica para cada domínio do conjunto de laudos. Porém, após análise pelo especialista do domínio, essa tarefa pode ser realizada automaticamente. Após o processamento das seções individuais, as tabelas geradas para cada seção podem ser facilmente unidas, formando uma única tabela atributo-valor. Nas próximas seções, é considerado que os algoritmos estão sendo aplicados sobre um determinada seção do laudo, caso o laudo possua várias seções.

\subsubsection{Construção do Conjunto de Frases Únicas}

A segunda etapa do pré-processamento tem por objetivo reunir em um único arquivo, denominado Conjunto de Frases Únicas, todas as frases diferentes de todos os documentos. Deve ser observado que as características do CFU são importantes para os bons resultados da metodologia proposta. Ele deve ser um conjunto com um número reduzido de frases. Isso se verifica no caso de laudos médicos, tratados este trabalho, mas também se verifica em documentos de outros domínios nos quais, também, tanto o vocabulário quanto a forma de expressar fatos são bastante controlados.

A Figura 5.3 ilustra o processo realizado para a geração do CFU. Nesse processo, a primeira tarefa a ser realizada é a toquenização ${ }^{2}$, na qual é aplicado sobre o conjunto de documentos o algoritmo de toquenização.

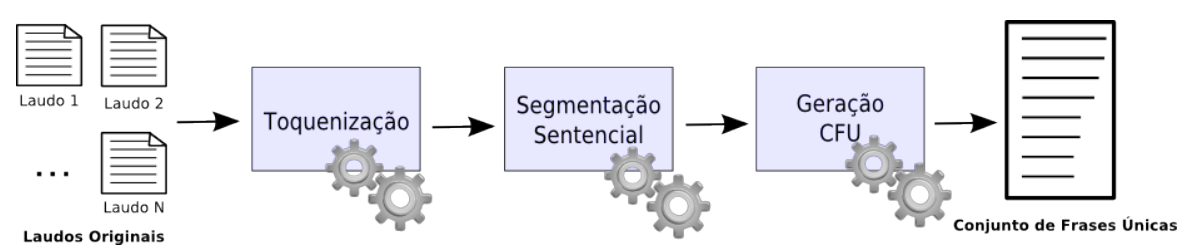

Figura 5.3: Exemplo de geração do CFU

Após a aplicação do algoritmo de toquenização ${ }^{3}$, é aplicado o segmentador sentencial automático sobre o conjunto de documentos. A segmentação sentencial é o processo de segmentar um texto em unidades menores, que podem ser sentenças, parágrafos e até mesmo tópicos. A granularidade da segmentação depende exclusivamente da aplicação a que se destina a segmentação sentencial. Neste trabalho foi utilizado o segmentador SENTER ${ }^{4}$ (Pardo, 2006) e a segmentação sentencial realizada sobre o conjunto de documentos resulta em setenças (frases) as quais são utilizadas na construção do CFU.

O Algoritmo 1 é responsável pelo processo de geração do CFU. Primeira-

\footnotetext{
${ }^{2}$ Toquenização consiste no processo de separar palavras e pontuações por espaço em branco.

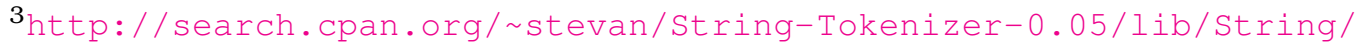
Tokenizer.pm

${ }^{4}$ SENtence splitTER
} 


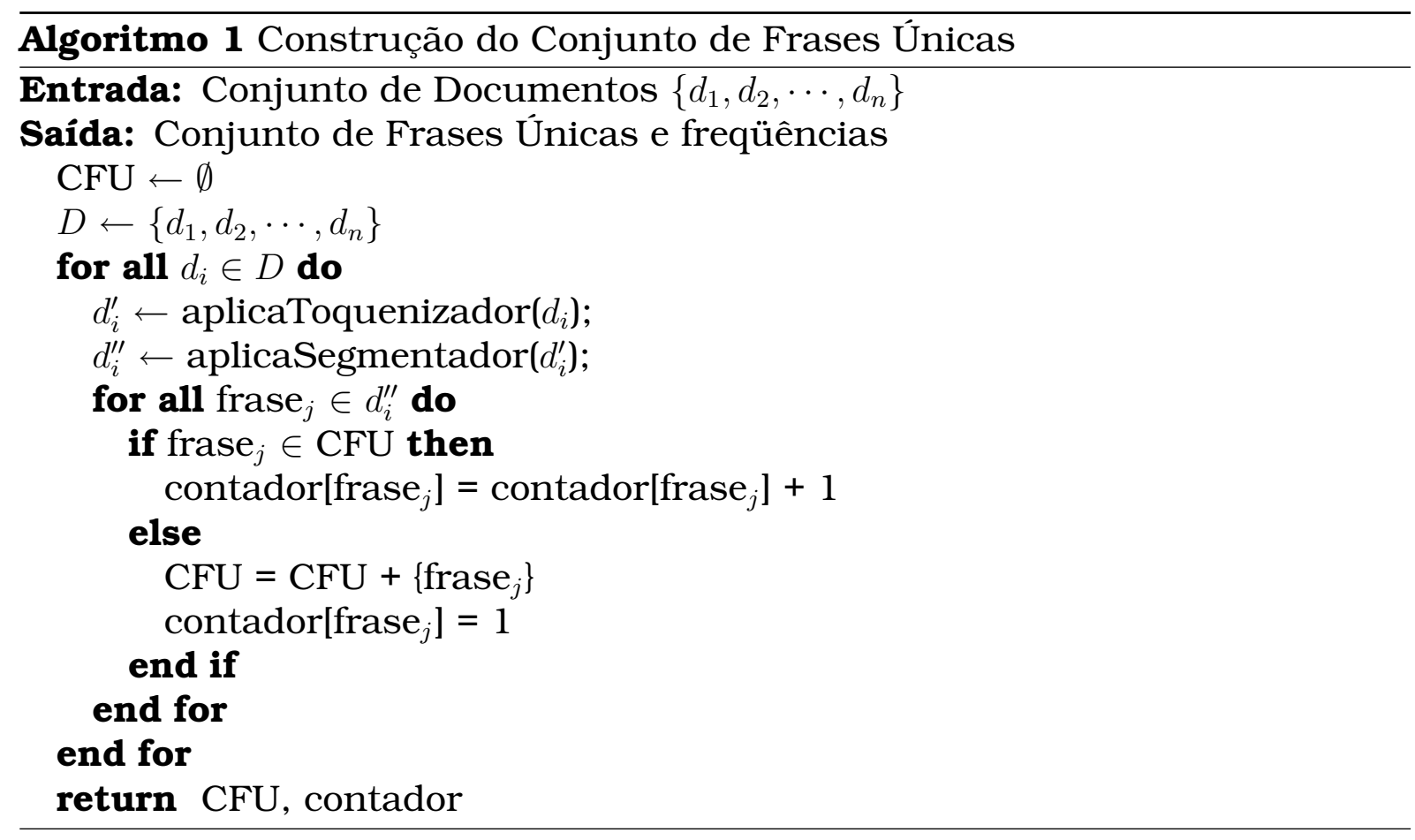

mente é realizada a toquenização e depois a segmentação sentencial do documento. No próximo passo é criado o conjunto de frases únicas CFU e é computada a freqüência dessas frases. Após a execução do algorítmo, essa informação é armazenada em um arquivo de frases únicas no formato XML.

Na Figura 5.4 é ilustrado o fragmento de um arquivo de frases únicas, onde a tag fraseUnica armazena uma frase única, sua respectiva freqüência e se a frase foi processada ou não, caso esteja sendo realizada uma análise manual juntamente com o especialista.

São também extraídas e armazenadas em um arquivo XML várias informações estatísticas das frases que fazem parte do $\mathrm{CFU}$, tais como número de frases, número de palavras, média de palavras por frase, tamanho da maior frase, maiores frases, tamanho da menor frase e menores frases. Na Figura 5.5 é ilustrado um arquivo XML com essas informações. Ambos arquivos XML, i.e., o arquivo contendo o CFU e o arquivo contendo as estatísticas, são utilizados em etapas posteriores da aplicação da metodologia. É importante observar que a cada processamento que é realizado sobre o conjunto de documentos, tais como a aplicação de padronização, a correção ortográfica e a lematização, é gerado um novo CFU e as respectivas estatísticas. Os CFU anteriores são armazenados, uma vez que podem ser consultados posteriormente. 


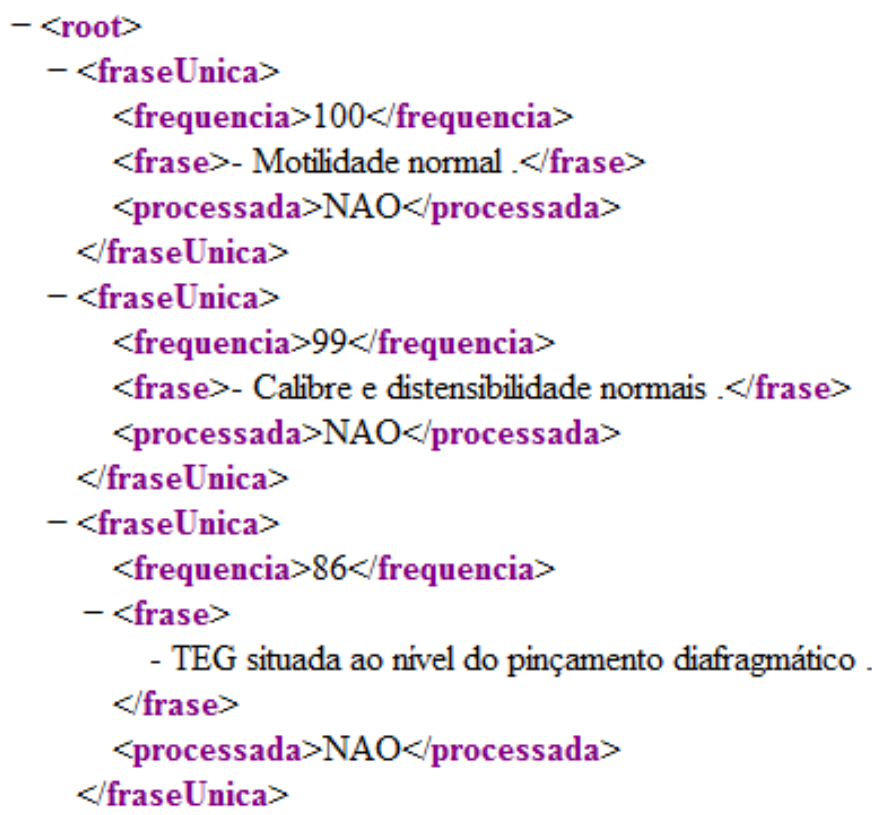

Figura 5.4: Exemplo do arquivo do CFU

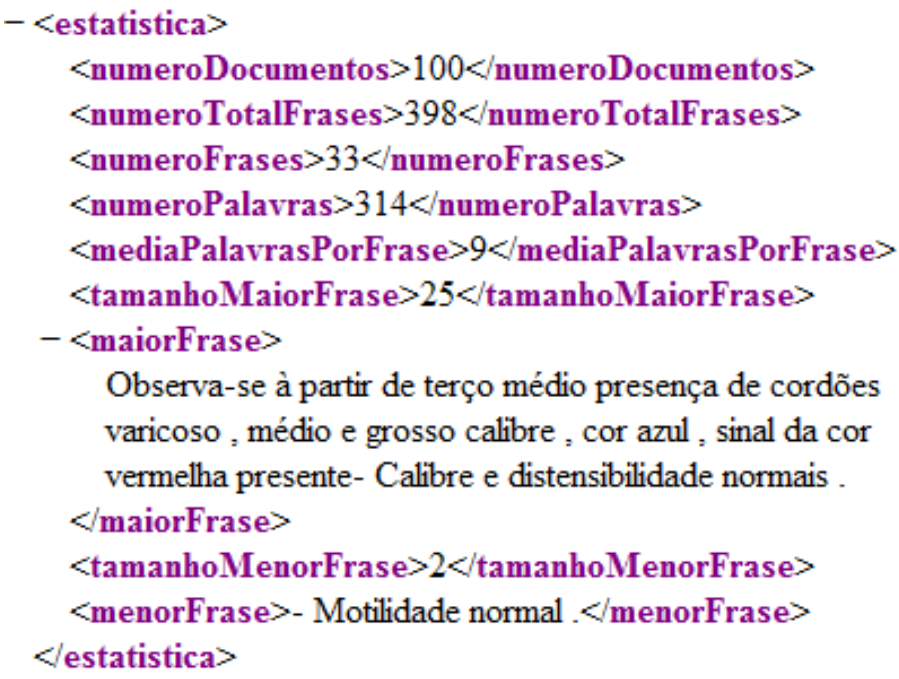

Figura 5.5: Exemplo do arquivo de estatística do CFU

\subsubsection{Remoção de Stopwords}

Essa tarefa tem por objetivo remover do conjunto de documentos palavras que não são de interesse para a análise do texto, ou seja, são palavras consideradas não relevantes tais como conjunções, artigos e preposições. A seguir é apresentado um conjunto de frases, com as stopwords sublinhadas, e o respectivo conjunto no qual as stopwords foram removidas.

Frases com stopwords 
Mucosa em toda a sua extensão com presença de pontos e placas esbranquiçadas.

Mucosa de terço distal com presença de uma erosão linear.

Calibre e distensibilidade normais

Frases sem stopwords

Mucosa toda extensão com presença pontos placas esbranquiçadas.

Mucosa terço distal com presença erosão linear.

Calibre distensibilidade normais.

A lista de stopwords (stoplist) pode ser incrementada por meio de interações com especialistas do domínio, nas quais, além das stopwords usuais, outras stopwords do domínio podem ser acrescentadas pelo especialista. As stopwords são armazenadas em um arquivo XML. Na Figura 5.6 é apresentado o fragmento de um arquivo de stopwords.

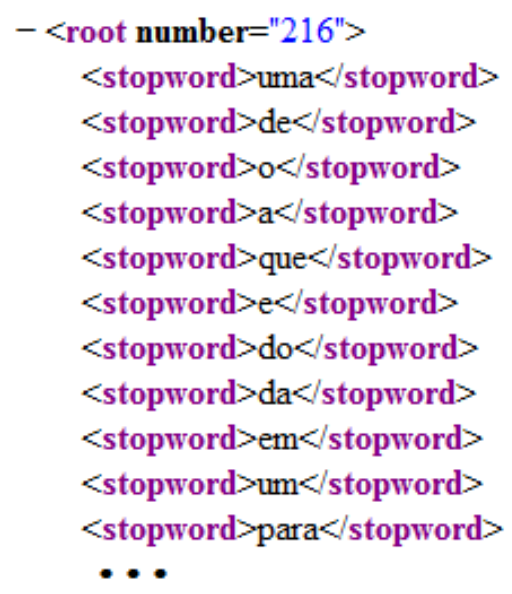

Figura 5.6: Exemplo do arquivo de stopwords

\subsubsection{Transformação para Minúsculo}

Nessa etapa, as informações presentes no conjunto de laudos são tranformadas para minúsculo.

\subsubsection{Correção Ortográfica}

Conforme mencionado, muitas vezes durante a digitação das informações que o médico coletou do paciente para os laudos, são inseridas palavras com erros de ortografia. Sendo assim, foi desenvolvido um módulo que auxilia na correção dos termos que apresentam possíveis erros de ortografia. Duas 
maneiras de aplicar esse módulo de correção são possíveis, uma manual e outra semi-automática. Neste último caso são identificados automaticamente possíveis termos mapeados de maneira incorreta e é necessário uma interação do usuário para validar os termos que estão realmente com erros de ortografia.

No modo manual, deve ser analisado manualmente o CFU com o intuito de identificar termos ortograficamente errados. Os termos identificados devem ser inseridos no módulo de correção juntamente com o termo correto. Por exemplo, se forem identificados os termos aproximandamente e aproxmadmente como termos errados, os mesmos devem ser inseridos no sistema junto com o termo correto aproximadamente, de modo que posteriormente sejam alterados os termos incorretos pelo termo correto.

Com o objetivo de auxiliar o usuário no processo de correção ortográfica do conjunto de documentos, neste trabalho foi implementado um algoritmo que auxilia nessa tarefa. Esse algoritmo utiliza uma idéia simples baseada no cálculo de distância entre palavras, e tem por objetivo identificar os possiveis termos que deverão ser corrigidos no conjunto de documentos. É importante ressaltar que o algoritmo não faz a correção automática, mas sim gera uma lista de possiveis correções.

A idéia de usar o cálculo de distância entre palavras foi introduzida em um algoritmo proposto por Damerau (1964), que difundiu a idéia de distância mínima de edição (minimum edit). Basicamente, o conceito de distância mínima de edição quantifica a idéia de uma seqüência de caracteres estar próxima a outra, pela contagem do número de operações de caracteres (como inserção, deleção e substituição) que são realizadas para transformar uma string em outra. Usando essa métrica, os melhores candidatos para a palavra correta são aqueles que apresentam a distância mínima de edição. No algoritmo implementado neste trabalho, no cálculo da distância entre palavras foi utilizada a medida de Levenshtein (Kruskal, 1983) ${ }^{5}$, a qual é uma medida de similaridade entre duas strings $S$ e $T$. A distância é o número de remoções, inserções e substituições necessária para transformar $S$ em $T$.

O algoritmo implementado não faz uso de nenhum conhecimento adicional, mas apenas das informações presentes no conjunto de documentos. Para exemplificar, a seguir é apresentado um exemplo de sua aplicação. O algoritmo primeiramente gera, a partir do conjunto de documentos, uma lista de unigramas com suas respectivas freqüências. Nessa lista, cada unigrama também possui um marcador, o qual indica se o unigrama já foi processado durante a aplicação do algoritmo. Para exemplificar, considere a lista de unigramas e as respectivas freqüências de um conjunto de documentos apresen-

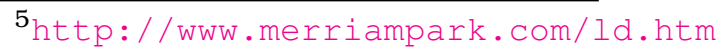


tada na Tabela 5.1.

Tabela 5.1: Lista de unigramas

\begin{tabular}{|c|c|c|}
\hline Palavra & Freqüência & Processada \\
\hline \hline aproximandamente & 2 & não \\
\hline aproximadamente & 172 & não \\
\hline aproximadmaente & 1 & não \\
\hline terço & 274 & não \\
\hline terso & 2 & não \\
\hline deterço & 1 & não \\
\hline
\end{tabular}

Primeiramente é considerado o primeiro termo da lista de unigramas, nesse caso aproximandamente, e ele é marcado como processado. Depois é criada uma lista auxiliar - LA - e inserido o unigrama aproximandamente nessa lista. A partir desse ponto o algoritmo realiza o cálculo da distância da palavra aproximandamente com todas as palavras restantes da lista de unigramas. As palavras que possuem distância $\leq 2$ são marcadas como processadas na lista de unigramas e inseridas na LA. Em seguida, depois de completamente processada a lista de unigramas, o algoritmo identifica a palavra que possui maior freqüência na LA e coloca como sugestão de palavra correta, conforme ilustrado na Tabela 5.2.

Tabela 5.2: Lista auxiliar

\begin{tabular}{|c|c|c|}
\hline Palavra & Freqüência & Sugestão Correta \\
\hline \hline aproximandamente & 2 & \\
\hline aproximadamente & 172 & $\mathrm{X}$ \\
\hline aproximadmaente & 1 & \\
\hline
\end{tabular}

As palavras restantes da LA são colocadas como possíveis palavras incorretas. Após gerar a primeira lista a partir da palavra aproximandamente, a lista de unigramas vai estar com a configuração ilustrada na Tabela 5.3. Nesse ponto, o algoritmo continua a execução para a próxima palavra da lista de unigramas ainda não processada, neste caso terço, e realiza o mesmo procedimento novamente.

Tabela 5.3: Lista de unigramas após processar a palavra aproximandamente

\begin{tabular}{|c|c|c|}
\hline Palavra & Freqüência & Processado \\
\hline \hline aproximandamente & 2 & sim \\
\hline aproximadamente & 172 & sim \\
\hline aproximadmaente & 1 & sim \\
\hline terço & 274 & não \\
\hline terso & 2 & não \\
\hline deterço & 1 & não \\
\hline
\end{tabular}

No final do processamento tem-se a lista de sugestões de correção na qual cada sugestão possui uma ou mais possiveis palavras incorretas que deverão ser analisadas. Assim, a complexidade do algoritmo implementado é $O\left(n^{2}\right)$. 
Finalmente, a lista de sugestões com as possiveis palavras incorretas correpondentes é armazenada em um arquivo do tipo XML. Na Figura 5.7 é ilustrado um trecho desse arquivo, no qual a tag termoSugerido armazena a sugestão de palavra correta e a tag listaTermos armazena a lista de possiveis palavras erradas que deverão ser substituídas pela palavra correta.

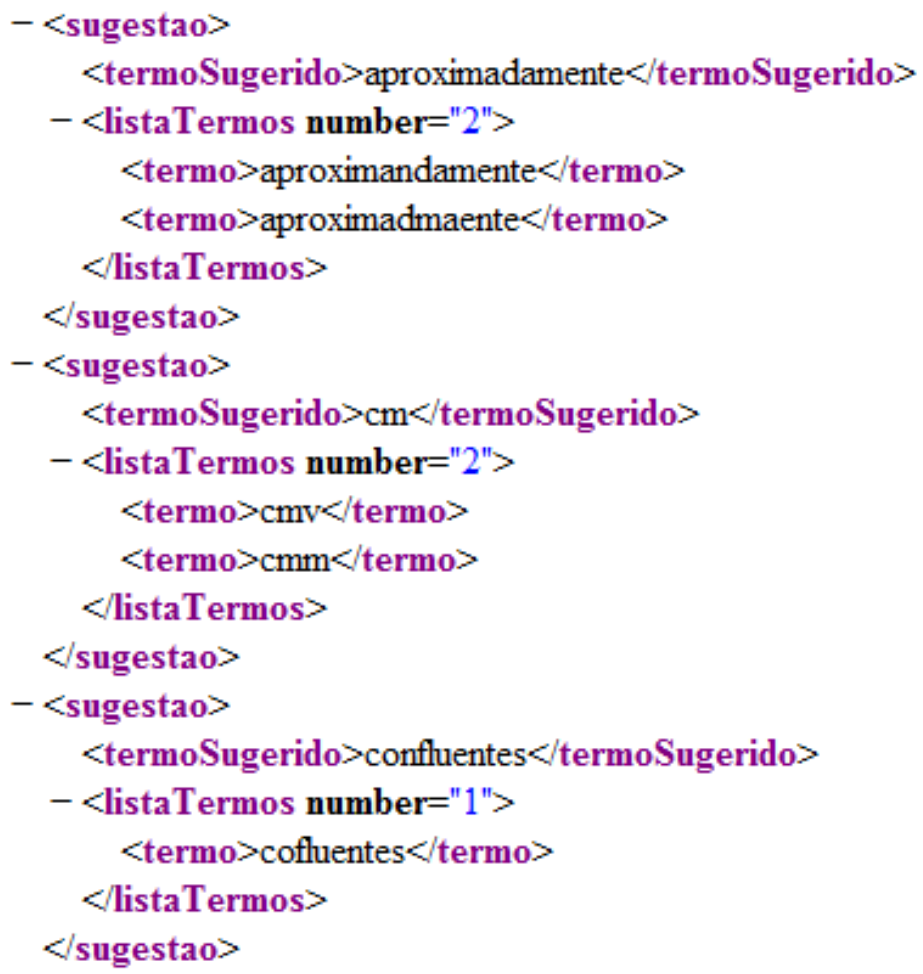

Figura 5.7: Exemplo do arquivo de correção de termos incorretos

Após construída essa lista, o usuário deve analisar, por meio de uma interface do sistema que implementa a metodologia proposta (Honorato \& Monard, 2008b), e selecionar quais sugestões geradas pelo algoritmo estão corretas. Depois dessa seleção, o algoritmo de correção é executado, o qual processa todos os documentos do conjunto de documentos e aplica as correções sugeridas.

\subsubsection{Normalização}

A normalização parte do fato de que um conceito pode ter várias representações. A idéia é evitar que muitas formas de uma palavra sejam associadas com o mesmo conceito. Por exemplo, o conceito de "livro" pode ser "objeto físico constituído de um número de páginas colocadas juntas" e pode ser representado por "livro" e "livros". O processo de normalização propõe que essas duas formas devem ser agrupadas em apenas uma que tem o mesmo significado. Alguns tipos de normalização são o tratamento de sinônimos e a 
lematização. A seguir são descritas sucintamente essas abordagens e como elas são aplicadas neste trabalho.

\subsubsection{Aplicação de Substituições}

No domínio médico, é freqüente a utilização de sinônimos na descrição de informações semelhantes presentes nos laudos médicos, ou a presença de frases que expressam dois eventos em uma mesma frase. Isso faz com que a normalização das informações contidas nos laudos seja necessária. Neste trabalho, o tratamento de sinônimos e de frases que expressam mais de um evento, tarefa que denominamos de aplicação de substituições, deve ser realizada manualmente pelo especialista. Após a obtenção do conjunto de frases únicas CFU é possível para o especialista identificar, manualmente, parte das informações que poderão ser substituídas. Na Tabela 5.4 são apresentados dois exemplos de substituições, definidas pelo especialista, que podem ser realizadas.

Tabela 5.4: Exemplos de substituições
\begin{tabular}{|c|c|}
\hline Antes da substituição & Depois da substituição \\
\hline coloração esbranquiçada & anormal \\
\hline $\begin{array}{c}\text { calibre distensibilidade } \\
\text { normais }\end{array}$ & $\begin{array}{c}\text { calibre normal } \\
\text { distensibilidade normal }\end{array}$ \\
\hline
\end{tabular}

O termo coloração esbranquiçada, utilizado para descrever a característica de um tecido biológico, é sinônimo de que o tecido está anormal. A frase calibre distensibilidade normais, representa dois eventos diferentes, ou seja, essa frase indica que calibre está normal (calibre normal) e distensibilidade está normal (distensibilidade normal). Portanto, no arquivo de substituições deve ser mapeada a transformação dessa frase de modo a aparecer, depois da substituição, apenas um evento em cada frase. A construção do arquivo de substituição é realizada a medida que informações que podem ser substituídas são identificadas, o que pode acontecer em qualquer fase da metodologia. Desse modo, o arquivo de substituições permite que se trabalhe com um vocabulário controlado e também auxilia na padronização de frases com mais de um evento.

No mapeamento das substituições, sugeridas pelo especialista, é gerado um arquivo no formato XML no qual são armazenadas as substituições que devem ser realizadas. Diversos tipos de substituições podem ser mapeadas. As principais substituições identificadas são:

- Substituição de palavras;

- Substituição de frases; e 
- Substituição por expressão regular.

Na Figura 5.8 é ilustrado o trecho de um arquivo XML no qual estão mapeadas algumas substituições realizadas pelo especialista. Nesse arquivo, a tag sequenciaOriginal indica a seqüência que deverá ser substituída e na lista de substituições é armazenada a lista de substituições, definida pela tag sequenciaNova.

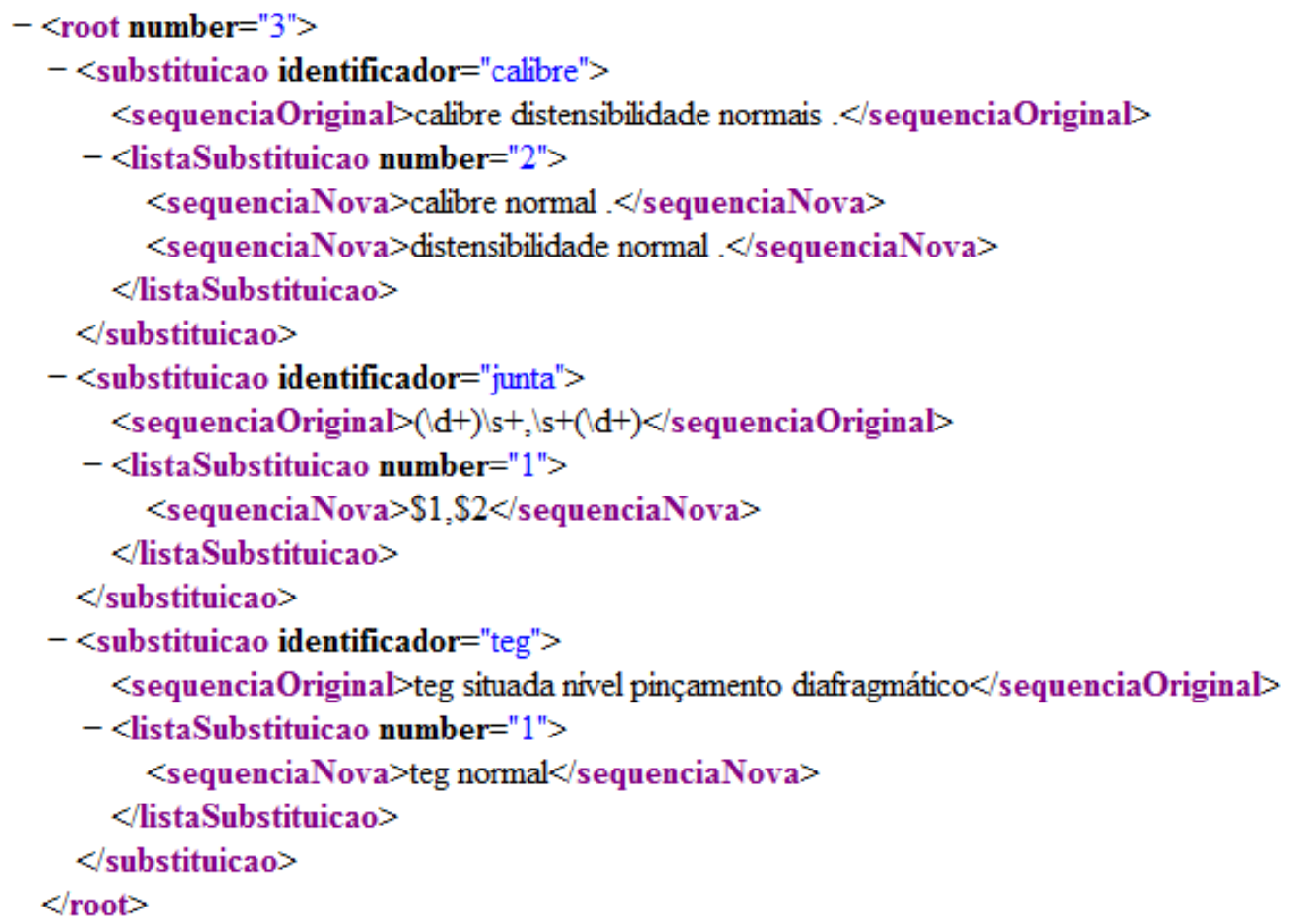

Figura 5.8: Exemplo do arquivo de substituição

Neste trabalho, é utilizado o módulo Text::RewriteRules ${ }^{6}$. Assim, para aplicar as substituições, primeiramente foi desenvolvido um algoritmo para converter o arquivo XML gerado para o arquivo do Perl no formato utilizado pelo módulo Text::RewriteRules. A seguir é ilustrado o arquivo gerado automaticamente a partir do XML apresentado na Figura 5.8.

use Text: :RewriteRules;

RULES calibre

calibre distensibilidade normais.==>calibre normal.

distensibilidade normal.

\section{ENDRULES}

RULES junta

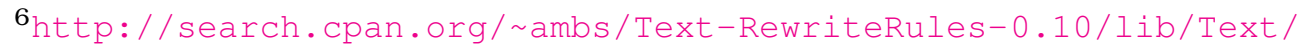
RewriteRules.pm
} 
$(\backslash d+) \backslash s+, \backslash s+(\backslash d+)==>\$ 1, \$ 2$

ENDRULES

RULES teg

teg situada nível pinçamento diafragmático==>teg normal

ENDRULES

1 ;

Depois de gerado automaticamente o arquivo de regras a ser utilizado pelo módulo Text::RewriteRules, o mesmo é utilizado no processamento do conjunto de documentos, conforme é ilustrado na Figura 5.9.

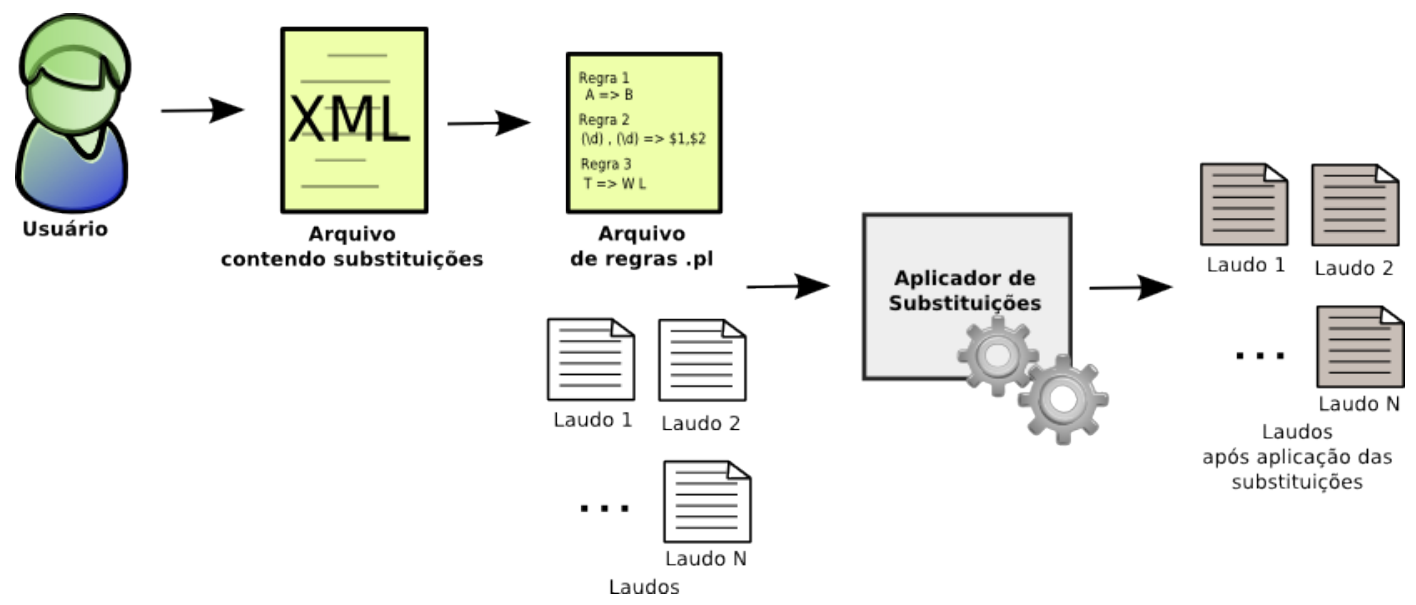

Figura 5.9: Processo de aplicação das substituições

O Algoritmo 2 apresenta o processo realizado para aplicar as substituições no conjunto de documentos. A variável $C D S A$ corresponde a Conjunto de Documentos com Substituições Aplicadas.

Nesse algoritmo, para cada linha do documento é chamada a função definida pelo identificador. Conforme mencionado, caso alguma regra tenha o antecedente atendido, é retornada a seqüência de substituição, ou seja, o conseqüente da regra, a qual é substituída na linha do documento.

\subsubsection{Aplicação de Lematização}

Esta tarefa tem por objetivo aplicar a lematização sobre o conjunto de documentos que está sendo processado. Uma das muitas formas de representar uma palavra é substituí-la pela sua forma primitiva. A lematização é o processo de transformar verbos para sua forma no infinitivo e substantivos e adjetivos para o masculino singular. Neste trabalho é utilizado o TREETAG$\mathrm{GER}^{7}$ (Schmid, 1994). No Algoritmo 3 é apresentado o processo utilizado para

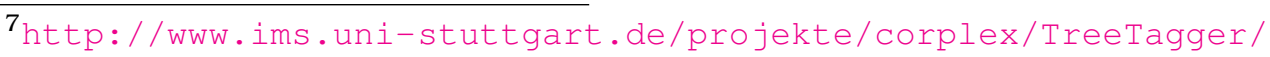




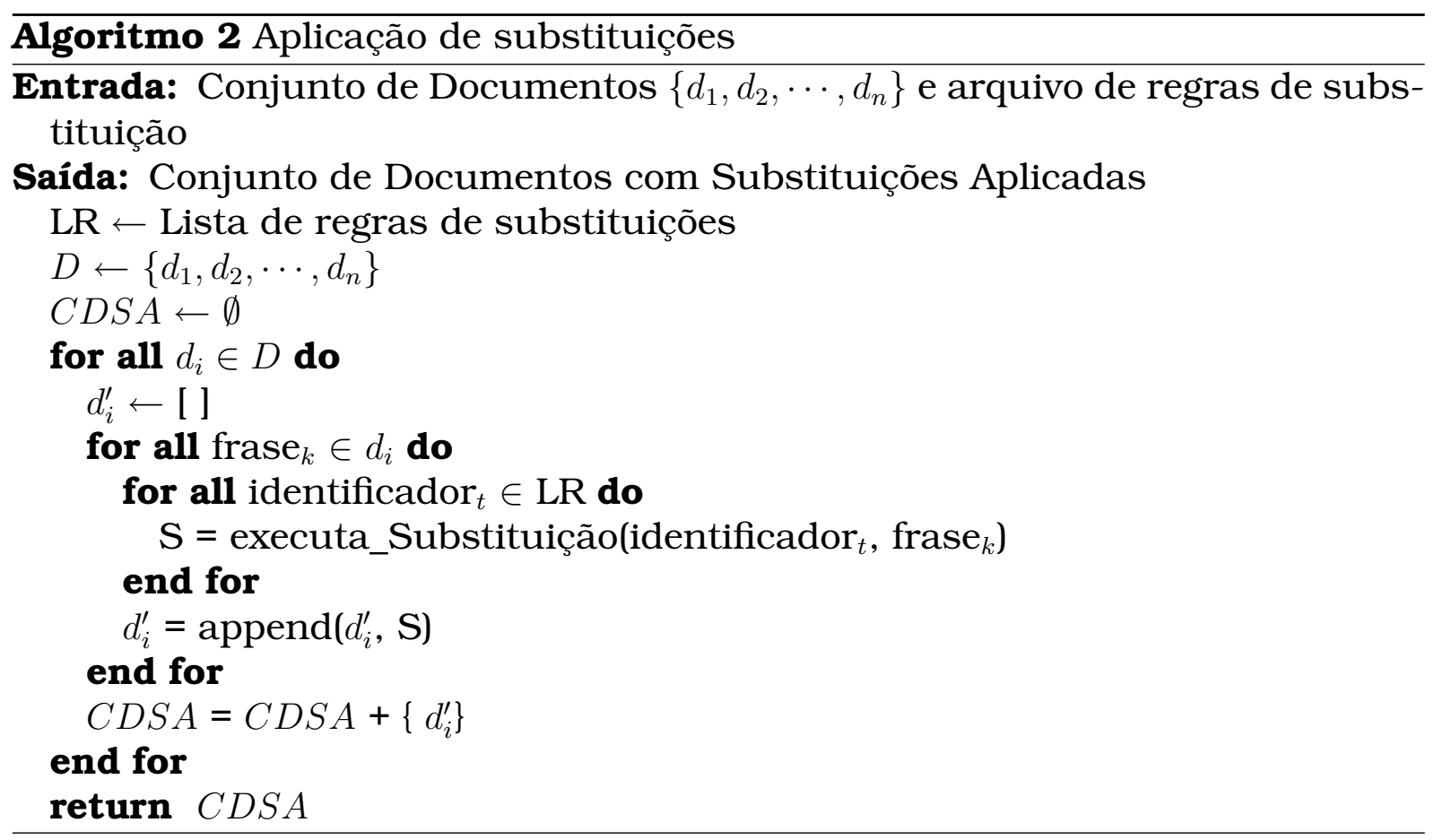

realizar a lematização do conjunto de documentos. A variável $C D L$ corresponde a Conjunto de Documentos Lematizados.

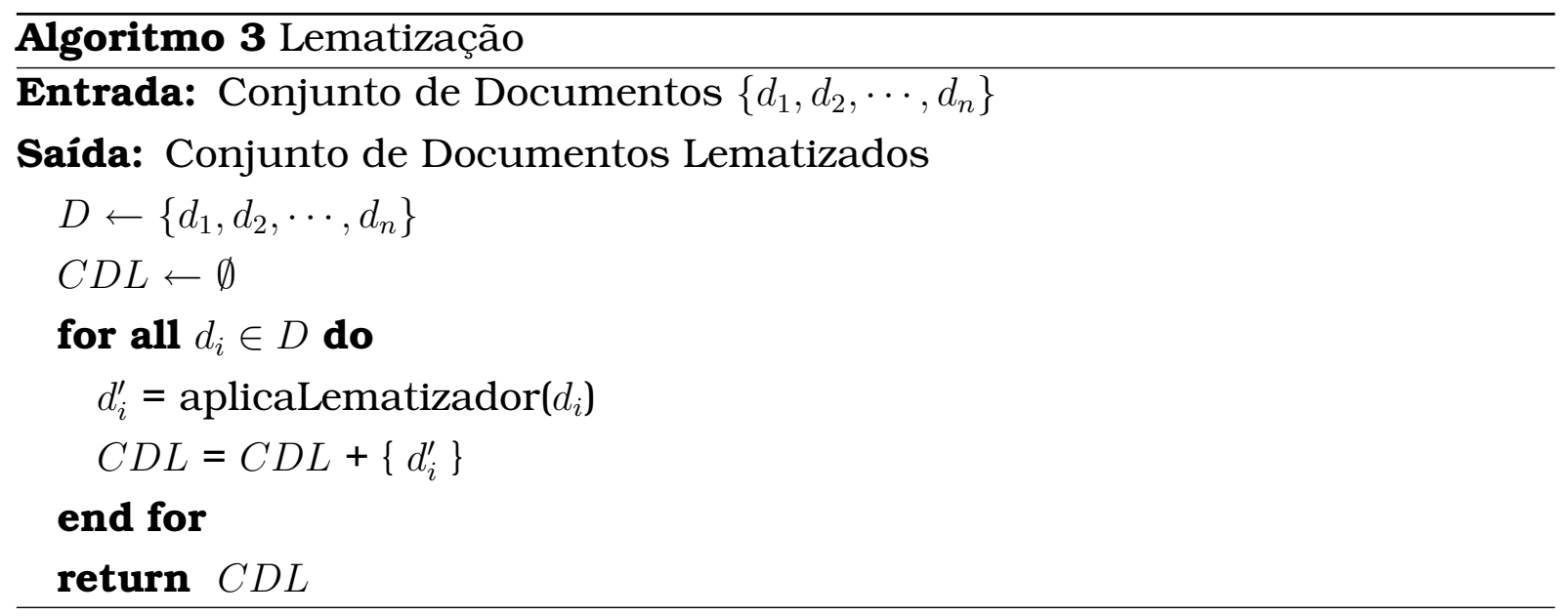

\subsection{Extração de Terminologia}

Depois de realizar o pré-processamento no conjunto de documentos, ele está pronto para ser processado na segunda fase, a de extração de terminologia - Figura 5.1 na página 44. Nesse trabalho, conforme mencionado, a segunda fase tem por objetivo extrair termos do domínio que são freqüentemente utilizados pelo profissional da saúde, geralmente um médico, no mapeamento de informações nos laudos. Neste caso, não estamos interessados em extrair todas as unidades terminológicas do domínio que está sendo abordado, mas 
nosso interesse é extrair as unidades terminológicas que indicam informações que estão sendo coletadas do paciente durante o exame e que encontram-se no laudo.

Para exemplificar o tipo de terminologia que estamos interessados, considere os seguintes termos extraídos de um laudo de Endoscopia Digestiva Alta, especificamente da seção de esôfago: calibre, motilidade, terço distal, teg e mucosa. Agora considere esses termos de acordo como aparecem freqüentemente nos laudos de esôfago:

calibre normal.

motilidade normal.

terço distal com erosões lineares.

teg situada nível pinçamento diafragmático.

mucosa de aspecto normal em toda extensão.

Os termos sublinhados podem constituir nome de órgãos, localizações e características dessas localizações que são mapeadas pelo médico durante a realização do exame. Conforme mencionado, a idéia de capturar apenas os termos acima citados está no fato de que posteriormente, na nossa proposta, esses termos são utilizados para a geração de uma estrutura hierárquica (árvore) a partir da qual é possivel identificar os possiveis relacionamentos (contexto) que esses termos possam ter.

Para a identificação das unidades terminológicas que são utilizadas para gerar a estrutura hierárquica, neste trabalho é adotada uma abordagem híbrida seguida da aplicação de algumas heurísticas sobre o conjunto de termos identificados.

Conforme mencionado, na abordagem lingüística e híbrida, informações como classe gramatical, como nomes (N), adjetivos (ADJ) e verbos (VERB), são adicionadas no corpus. Um fator primordial para a escolha do método híbrido está no fato de que os termos de nosso interesse neste trabalho são, na maioria dos casos, pertencentes à uma determinada classe gramatical e, sobre esses termos, é calculada a freqüência de cada um. Conforme mencionado, depois de realizar a extração de termos usando a abordagem híbrida, são aplicadas algumas heurísticas que auxiliam na redução do número de termos que é utilizado na terceira fase da metodologia.

Com base nas considerações apresentadas, neste trabalho é proposta a seguinte metodologia para a extração da terminologia de interesse, ilustrada na Figura 5.10.

Essa metodologia é composta de três etapas. Na primeira etapa é realizada a etiquetação do conjunto de documentos. Na segunda é realizada a extração 


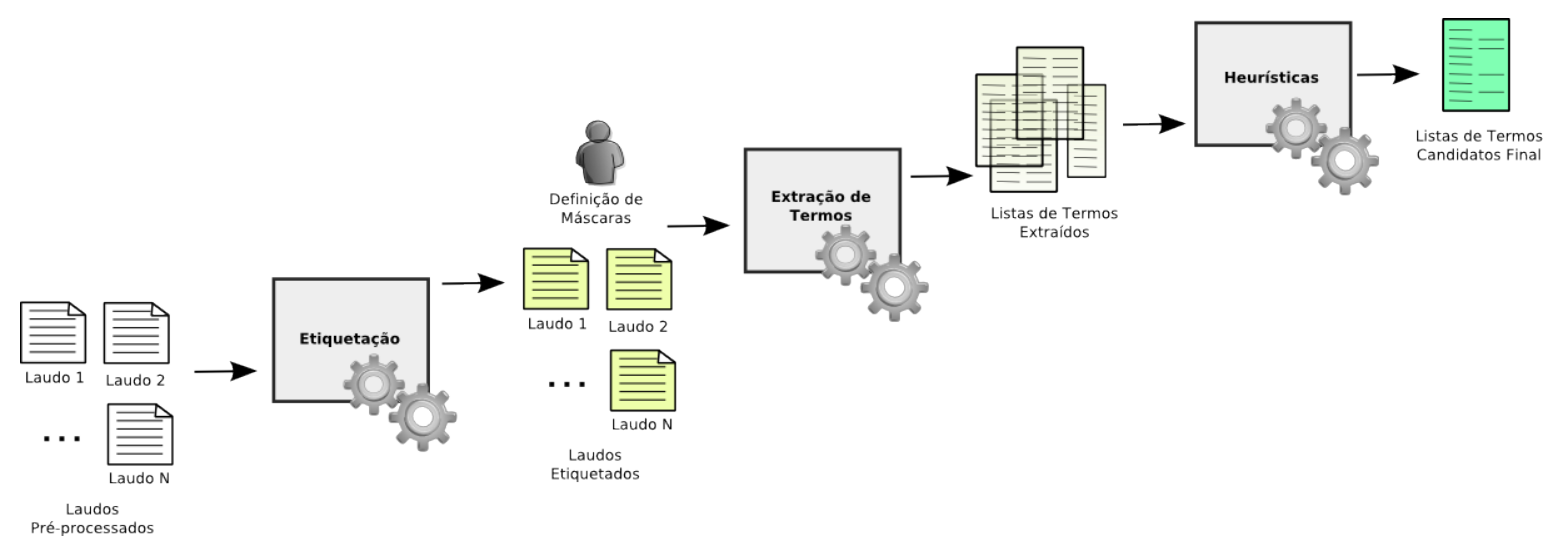

Figura 5.10: Metodologia para extração de termos

de termos sobre o conjunto de documentos etiquetados, utilizando a abordagem híbrida. Na terceira etapa, são aplicadas algumas heurísticas sobre a lista de termos extraídos na segunda etapa com o objetivo de selecionar o subconjunto de unidades terminológicas a serem utilizadas posteriormente. A seguir é apresentado detalhadamente o processo de extração de unidades terminológicas proposto neste trabalho.

\subsection{Etiquetação dos Documentos}

A primeira tarefa que deve ser realizada no processo de extração de terminologia usando a abordagem híbrida é a etiquetação dos documentos a partir dos quais serão extraídos os termos. Neste trabalho utilizamos o etiquetador MXPost (Ratnaparkhi, 1996). Um problema identificado utilizando esse etiquetador, é que ele foi treinado com textos livres da língua portuguesa do Brasil. Assim, para o domínio específico da medicina, ele não é totalmente adequado pois identifica algumas etiquetas de maneira incorreta. Vale observar que o treinamento de um etiquetador é uma tarefa extremamente demorada que requer muito trabalho manual, e envolve uma grande força tarefa de pessoas envolvidas nas diferentes etapas do treinamento do etiquetador. Assim, para usar um etiquetador em domínios mais específicos, o mais aconselhável é realizar um tunning do etiquetador já treinado para conseguir atender o domínio específico.

Com esse fim, neste trabalho foi adotado o seguinte procedimento. Primeiramente é aplicado o etiquetador MXPOsT sobre o CFU gerado na primeira fase, indicado pelo usuário, o qual pode ser o CFU padronizado e corrigido ou o CFU padronizado, corrigido e lematizado. Como resultado é gerado o $\mathrm{CFU}$ etiquetado. Após gerar o CFU etiquetado é realizada uma análise manual do CFU etiquetado, com o intuito de identificar as etiquetas incorretas, conforme 


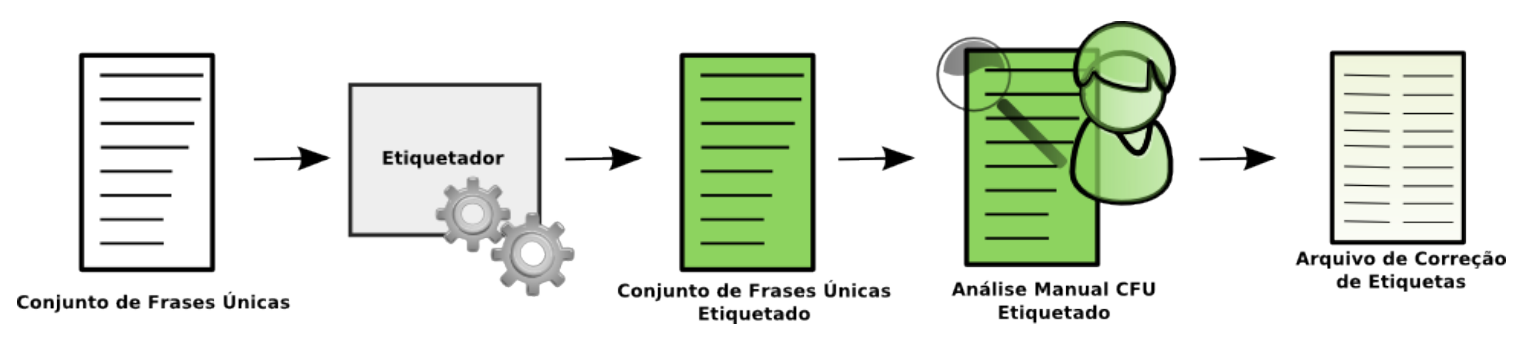

Figura 5.11: Geração e análise do CFU etiquetado

mostra a Figura 5.11. Na análise manual do CFU podem ser necessárias interações com o especialista do domínio, uma vez que podem existir palavras que são consagradas pelo uso na área e que não estão presentes no dicionário $^{8}$. Quando um termo com uma etiqueta incorreta é identificado, o termo é adicionado a um arquivo, no formato XML, de correção de etiquetas, junto com a etiqueta correta. Depois que o CFU etiquetado for analisado por completo, o algoritmo de correção de etiquetas deve ser aplicado, conforme mostra a Figura 5.12, o qual irá retornar um novo CFU com as etiquetas corrigidas.

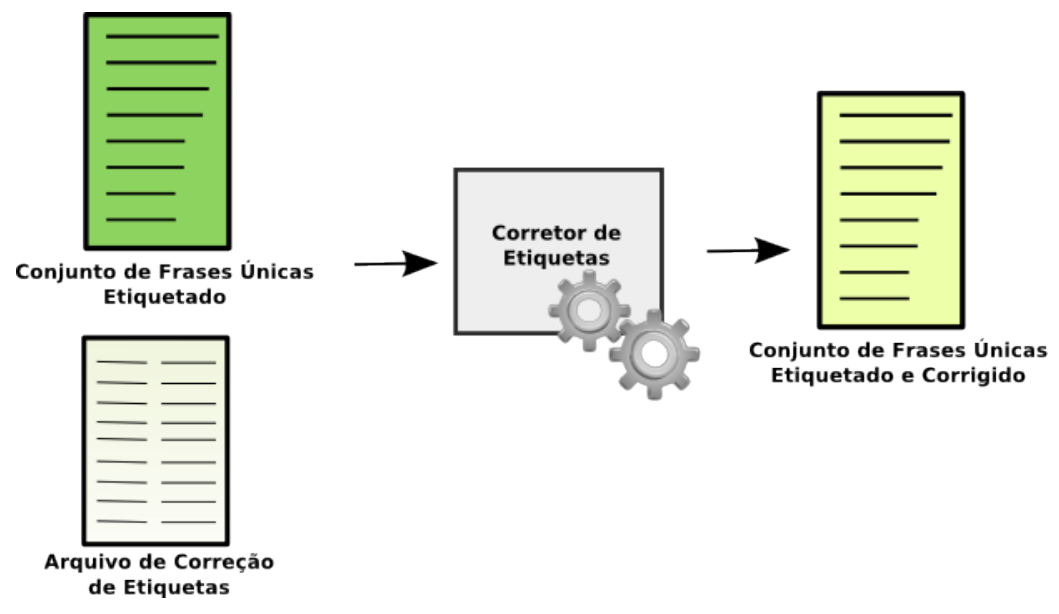

Figura 5.12: Aplicação do algoritmo de correção de etiquetas

Na Figura 5.13 é ilustrado o trecho de um arquivo de correção de etiquetas. Por exemplo, a tag termos refere-se ao termo analisado e a tag etiqueta corresponde a etiqueta correta a ser associada a esse termo.

$\mathrm{O}$ arquivo de correção de etiquetas contendo os termos incorretamente etiquetados pelo Mxpost é utilizado quando for etiquetado o conjunto de documentos, conforme ilustrado na Figura 5.14. Nesse processo, primeiro é realizada a etiquetação do conjunto de laudos utilizando o etiquetador MxPosT e, depois de etiquetar os laudos, é aplicado o corretor de etiquetas sobre o

\footnotetext{
${ }^{8} \mathrm{Na}$ Web existem alguns dicionários online que podem auxiliar nessa tarefa, tais como o da Academia Brasileira de Letras, no endereço http://www. academia.org.br/ e o Priberam, no endereço http://www.priberam.pt/. Outro excelente dicionário para português disponível na internet é o Aulete Digital, disponível no endereço www.auletedigital.com.br.
} 


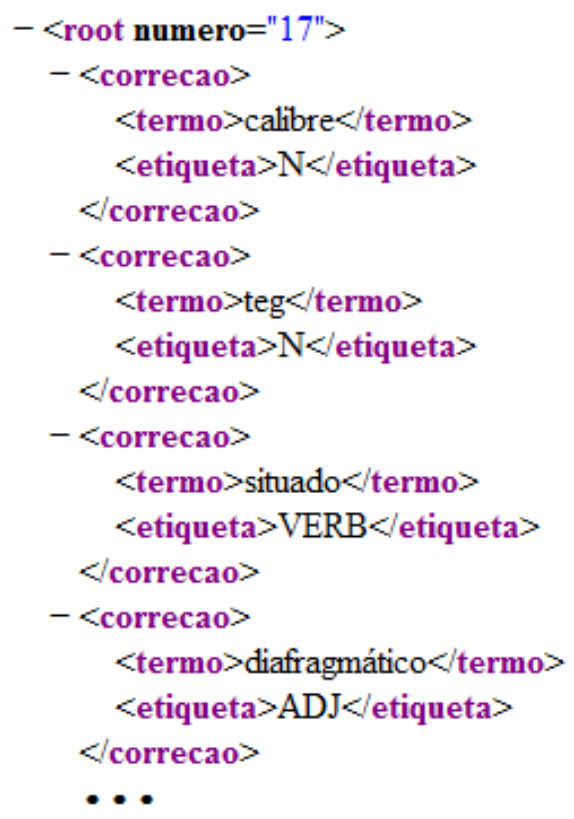

Figura 5.13: Exemplo do arquivo de correção de etiquetas

conjunto de laudos usando o arquivo de correção de etiquetas. O corretor implementado realiza o processamento no conjunto de documentos e os termos que tiveram uma nova etiqueta definida no arquivo de correção de etiquetas têm a etiqueta alterada. Como resultado desse processo, tem-se o conjunto de laudos etiquetados com as etiquetas corretas, a partir dos quais pode ser realizada a extração de termos utilizando a abordagem hibrída proposta.

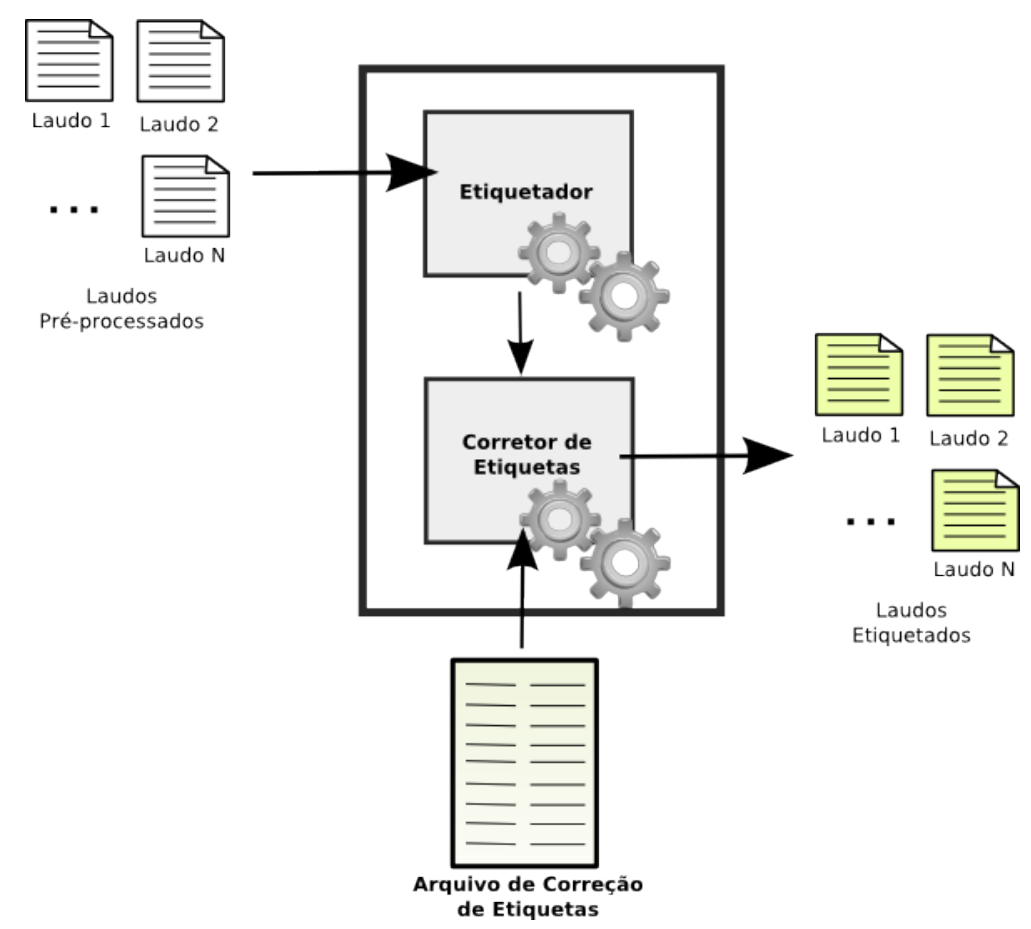

Figura 5.14: Processo de etiquetação do conjunto de documentos 


\subsubsection{Definição de Máscaras}

A definição das máscaras que serão utilizadas para a extração de termos não é única para todos os domínios, ou seja, algumas máscaras são mais representativas em alguns domínios do que em outros. Uma análise do corpus pode ser realizada com o intuito de identificar os termos mais freqüentes (Teline et al., 2003). Conforme mencionado, neste trabalho, a metodologia segue o princípio de que as informações são mapeadas como local ou característica de uma parte do corpo e informações associadas à esse local ou característica, conforme exemplo na Figura 5.15, no qual constam frases extraídas de um laudo de EDA, especificamente da seção de esôfago. Nessa figura, os termos sublinhados correspondem a locais e determinadas características da seção de esôfago que são mapeadas pelo médico no momento do exame do paciente.

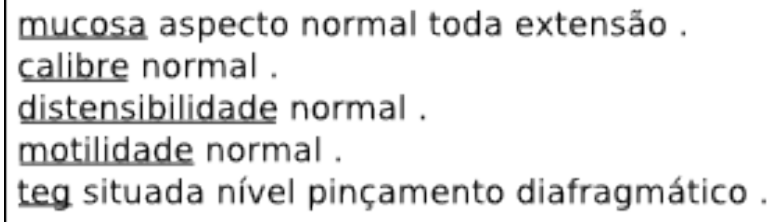

Figura 5.15: Exemplos de frases extraídas de um laudo

Na Figura 5.16 é ilustrado o arquivo da Figura 5.15 etiquetado. Observe

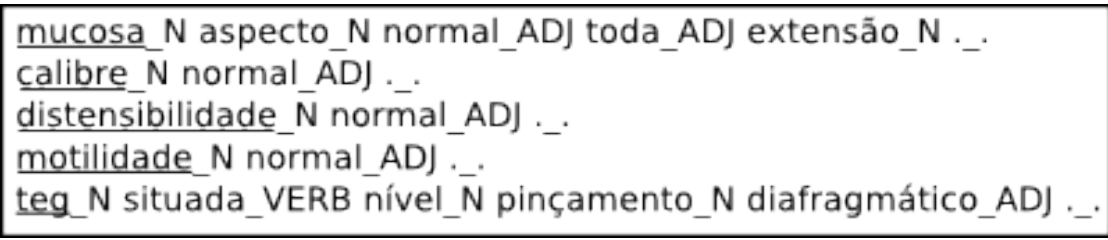

Figura 5.16: Exemplos de frases etiquetadas extraídas de um laudo

que os termos nos quais estamos interessados (sublinhados) aparecem com a etiqueta $\mathrm{N}$.

Na metodologia proposta, embora possam ser definidos diversos tipos de máscaras, notou-se que duas máscaras são freqüentemente utilizadas no mapeamento das informações. Essas duas máscaras, ilustradas na Tabela 5.5, foram definidas como padrão na implementação realizada. Caso o usuário queira utilizar outras máscaras, elas podem ser facilmente incluídas no sistema. 
Tabela 5.5: Tabela de máscaras padrão

\begin{tabular}{|c|}
\hline nome (N) \\
\hline \hline nome (N) nome (N) \\
\hline
\end{tabular}

\subsubsection{Extração de Termos dos Documentos}

Depois de definidas as máscaras mais apropriadas para o conjunto de documentos utilizados, é realizada a extração de termos, conforme ilustrado na Figura 5.17. Para realizar a extração de termos, o algoritmo recebe o conjunto de documentos etiquetados e o conjunto de máscaras definido pelo usuário. $\mathrm{O}$ resultado consiste de listas de termos, cada uma correspondente a uma determinada máscara que foi definida - duas listas no caso de utilizar as máscaras padrão. No Algoritmo 4 é apresentado o processo de extração de termos.

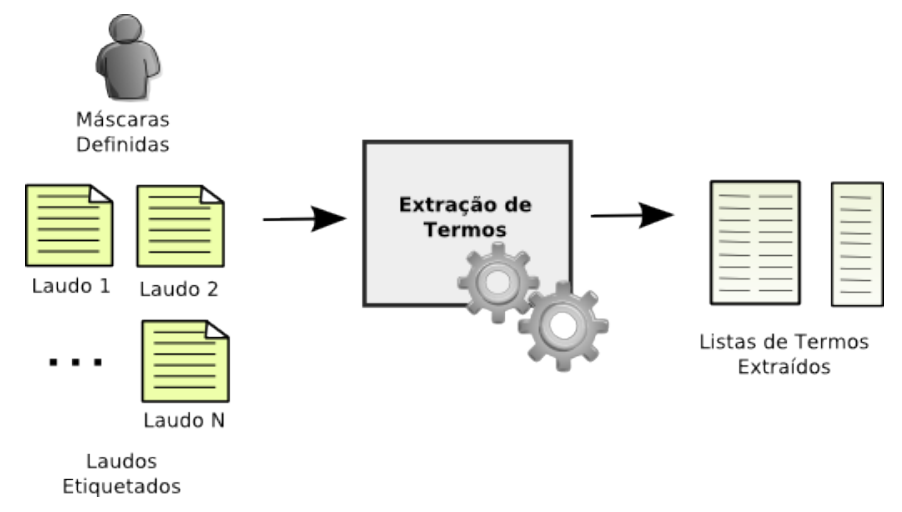

Figura 5.17: Processo de extração de termos

Após a construção da lista de termos e as respectivas freqüências pelo Algoritmo 4, ela é dividida em diversas listas de termos, cada lista correspondente a uma determinada máscara que foi definida.

Por exemplo, se foram definidas as máscaras $\mathrm{N}, \mathrm{N}$ N e N ADJ, serão criadas três listas de termos com as freqüências correspondentes, ou seja, uma lista com os termos que casaram com a máscara $\mathrm{N}$, outra lista com termos que casaram com a máscara $\mathrm{N} N$ e uma lista de termos que casaram com a máscara N ADJ.

Para ilustrar, na Tabela 5.6 são apresentadas as listas de termos geradas a partir das máscaras $\mathrm{N}$ (unigramas) e $\mathrm{N} \mathrm{N}$ (bigramas), juntamente com as respectivas freqüências extraídas. Essas duas listas foram geradas a partir de um conjunto de 100 laudos de Endoscopia Digestiva Alta, especificamente do esôfago.

Nessa tabela é possivel observar que muitos termos possuem baixa freqüência. Além disso, é possível observar que alguns termos que aparecem na lista de unigramas também fazem parte da lista de bigramas. Nesse contexto, é 


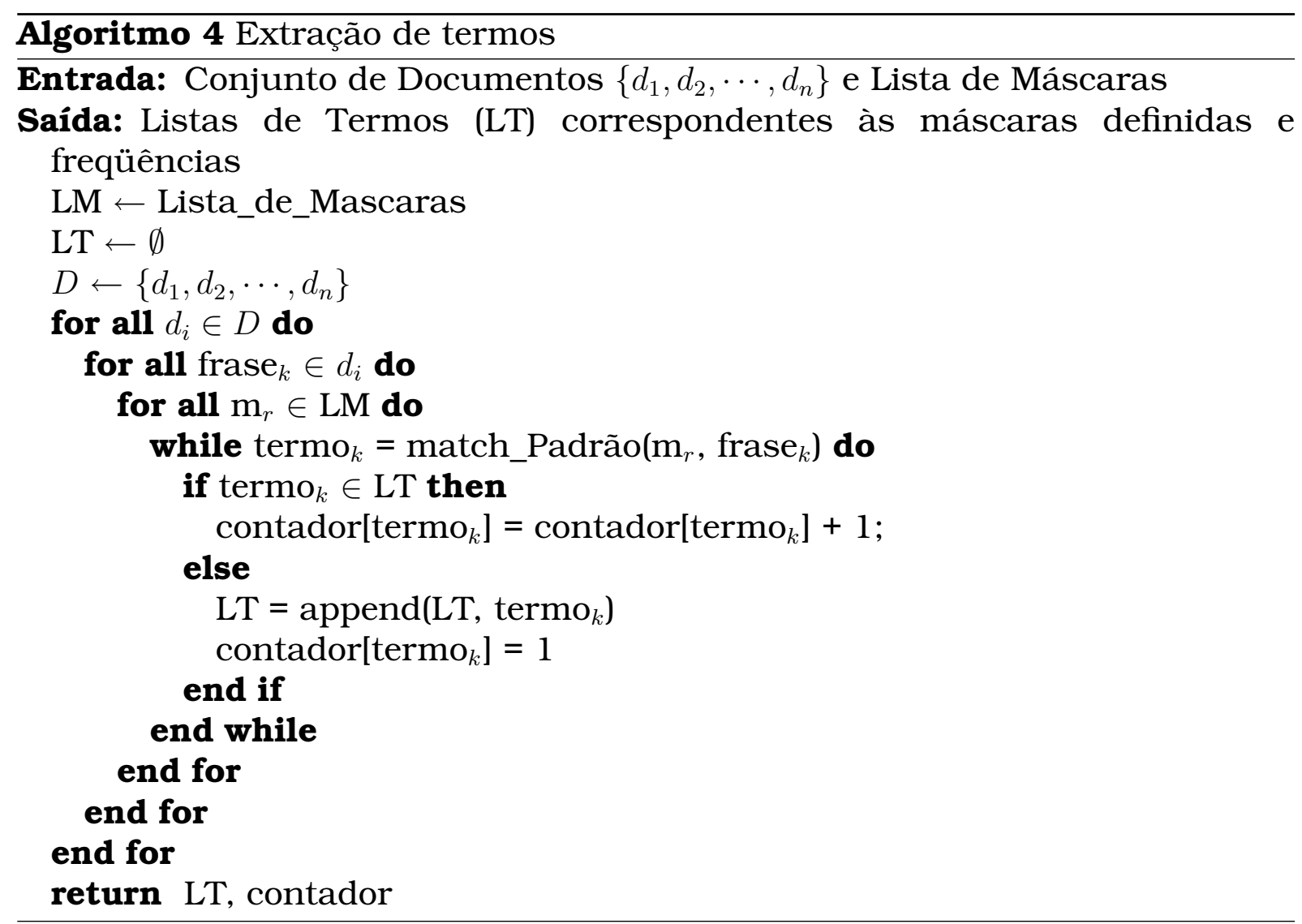

Tabela 5.6: Lista de termos gerados com máscaras $\mathrm{N}$ e $\mathrm{N} \mathrm{N}$

\begin{tabular}{|c|c|c|c|c|}
\hline N & Freqüência & & N N & Freqüência \\
\hline calibre & 100 & & calibre distensibilidade & 100 \\
\hline pinçamento & 100 & & nível pinçamento & 86 \\
\hline motilidade & 100 & & mucosa aspecto & 81 \\
\hline distensibilidade & 100 & mucosa terço & 14 \\
\hline teg & 99 & presença erosões & 10 \\
\hline mucosa & 97 & & cm ads & 4 \\
\hline nível & 86 & presença pontos & 2 \\
\hline extensão & 82 & mucosa tipo & 2 \\
\hline aspecto & 81 & presença cordões & 1 \\
\hline terço & 19 & erosões terço & 1 \\
\hline presença & 13 & área estenose & 1 \\
\hline erosões & 11 & & sinal cor & 1 \\
\hline ads & 4 & & & \\
\hline coloração & 4 & & \\
\hline cm & 4 & & & \\
\hline cor & 3 & & & \\
\hline tipo & 2 & & \\
\hline pontos & 2 & & \\
\hline biópsia & 2 & & & \\
\hline barrett & 2 & & \\
\hline cordões & 2 & & \\
\hline monilíase & 2 & & & \\
\hline área & 1 & & & \\
\hline estenose & 1 & & \\
\hline circunferência & 1 & & & \\
\hline lesão & 1 & & & \\
\hline placas & 1 & & \\
\hline resíduos & 1 & & & \\
\hline sinal & 1 & & & \\
\hline & & & \\
\hline
\end{tabular}


bom lembrar que os termos utilizados pelos médicos para apresentar um determinado conceito são quase sempre os mesmos, e são aqueles que tem uma freqüência maior.

\subsubsection{Aplicação de Heurísticas}

Com o objetivo de encontrar as unidades terminológicas mais apropriadas do domínio, neste trabalho são propostas algumas heurísticas com o intuito de realizar uma filtragem sobre as listas de termos que foram geradas. Essas heurísticas trabalham sobre uma lista qualquer de unigrama e uma lista qualquer de bigramas e levam em consideração a freqüência dos termos presentes nas duas listas. Caso fossem utilizadas listas maiores que bigramas, por exemplo, trigramas, essas heurísticas deveriam ser re-definidas para levar em conta esse fato. Como mencionado, no domínio considerado, o uso de bigramas para encontrar as unidades terminológicas mostrou-se adequado e é o método padrão atualmente implementado.

As heurísticas implementadas são aplicadas em duas etapas. Na primeira etapa são analisados os termos da lista de unigramas que fazem parte de termos bigramas na lista de bigramas. Nessa etapa é gerada uma lista inicial de termos candidatos. Na segunda etapa é analisada a lista de candidatos com o intuito de remover termos unigramas que fazem parte de termos bigramas. Por exemplo, na lista de candidatos pode existir o unigrama distensibilidade e o bigrama calibre distensibilidade. Dependendo das freqüências desses termos, o termo distensibilidade pode ser removido, pois o bigrama calibre distensibilidade é mais adequado. Após aplicadas essas heurísticas é analisada a lista de candidatos e removidos todos os termos que possuem uma freqüência menor do que um limiar definido.

Para exemplificar a aplicação das heurísticas propostas, considere as listas de unigramas e bigramas de termos apresentadas na Tabela 5.6. Na aplicação das heurísticas são utilizados dois parâmetros definidos pelo usuário: Alpha e Theta, os quais são utilizados na identificação das unidades terminológicas. No exemplo vamos utilizar o valor de Alpha=95\%, o valor de Theta=10\% e será apresentado em detalhes o processamento dos seguintes unigramas: calibre, pinçamento, motilidade, distensibilidade, teg e mucosa.

Inicialmente é criada uma Lista de Termos Candidatos — LTC vazia. Depois é inicializado o processameto das listas de unigramas e bigramas. Primeiramente é analisado o termo calibre. A partir desse termo, é verificado o número de vezes que ele aparece como primeiro termo na lista de bigramas. Nesse caso, podemos ter três situações: o termo calibre pode não aparecer, 
pode aparecer uma vez ou pode aparecer mais de uma vez. O parâmetro Alpha é utilizado nos dois últimos casos.

No caso do termo calibre podemos observar que ele aparece uma vez na lista de bigramas. Portanto, é realizada a seguinte verificação, conforme apresentado no Algoritmo 5, no qual a variável Unigrama corresponde a calibre e a variável Bigrama corresponde a calibre distensibilidade.

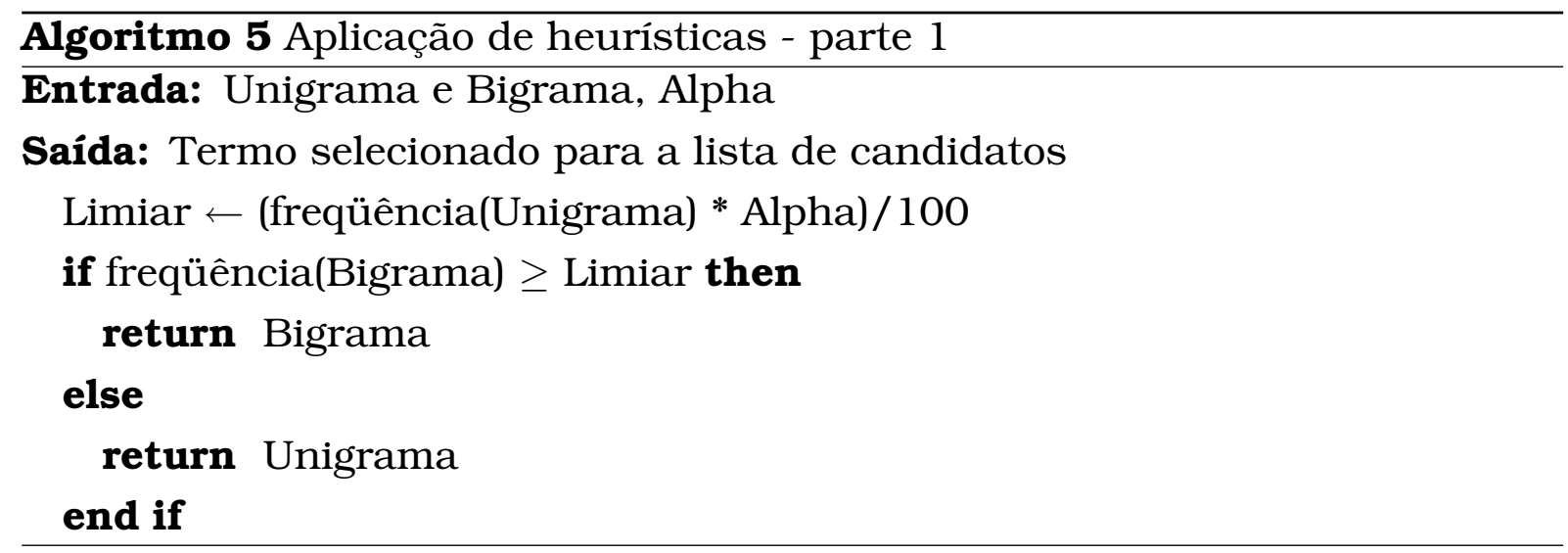

Se a freqüência do bigrama, nesse caso, calibre distensibilidade for maior ou igual ao limiar calculado, então é escolhido o bigrama para ser inserido na LTC, senão é escolhido o unigrama calibre. Em outras palavras, dependendo do valor de Alpha especificado, a heurística proposta dá preferência a possíveis unidades terminológicas unigramas ou bigramas. Neste caso é inserido o termo calibre distensibilidade na LTC, já que o limiar é igual a $95 \%$.

O próximo termo a ser processado é o termo pinçamento. A partir desse termo é verificado se existe algum bigrama cujo primeiro termo é pinçamento. Nesse caso não existe, portanto o termo pinçamento é inserido na LTC. O termo motilidade também é inserido na LTC, uma vez que não existe nenhum bigrama cujo primeiro termo é motilidade. Da mesma maneira acontece com os termos distensibilidade e teg.

No processamento do termo mucosa é identificado que na lista de bigramas existem três bigramas cujos primeiros termos são mucosa. Nesse caso, é utilizado novamente o parâmetro Alpha e é utilizado o seguinte procedimento, conforme apresentado no Algoritmo 6. 


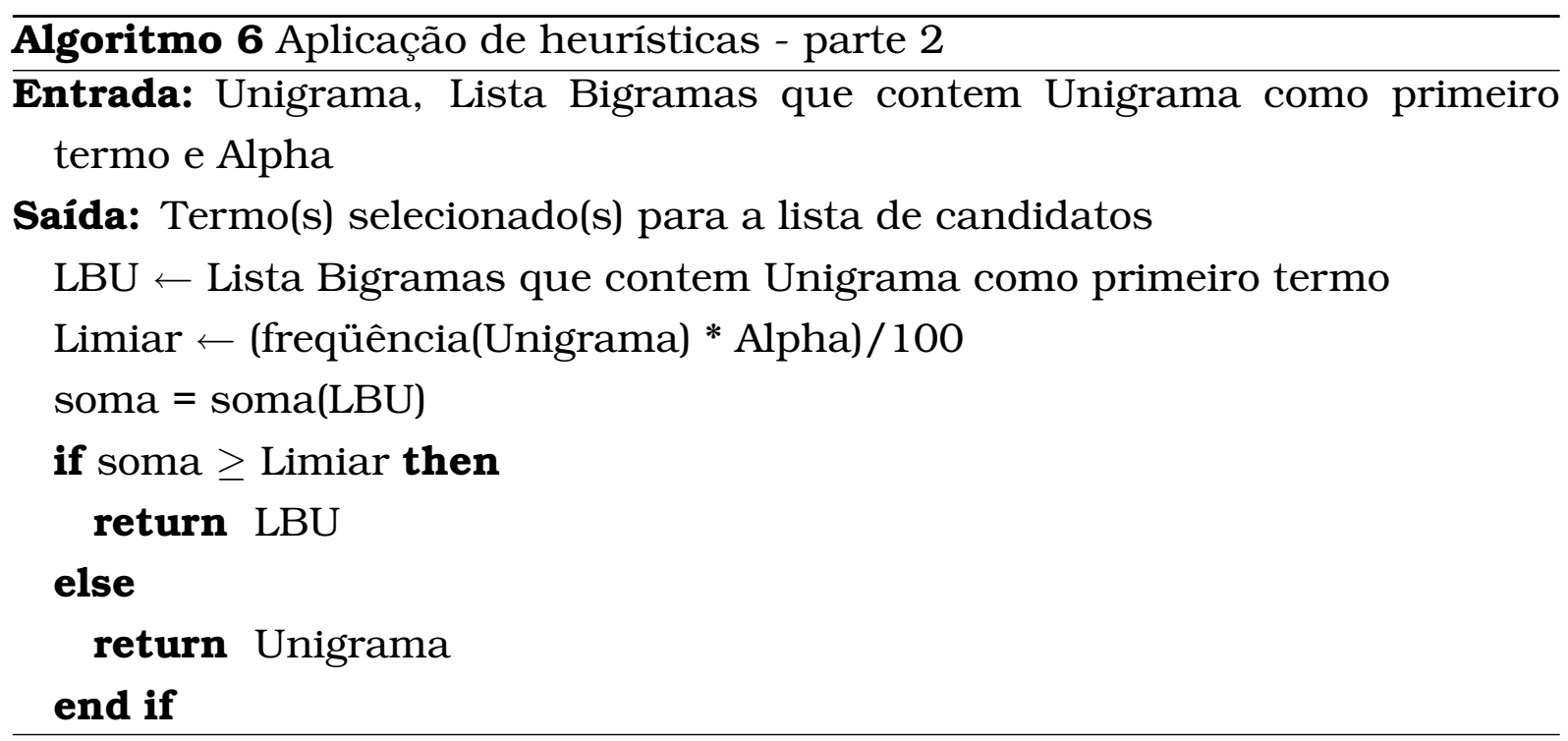

Nesse algoritmo são somadas as freqüências dos três bigramas que contém o unigrama mucosa e, se a soma for maior do que o limiar definido, são retornados os três bigramas e inseridos na LTC, senão é adicionado apenas o unigrama mucosa. No exemplo considerado são adicionados os três bigramas na $\mathrm{LTC}^{9}$.

O procedimento realizado para o processamento dos termos exemplificados acima é realizado para todos os termos restantes da lista de unigramas. Na Tabela 5.7 é apresentado o resultado da primeira etapa da aplicação das heurísticas.

Na segunda etapa é realizado o processamento da LTC com o objetivo de identificar e remover unigramas que fazem parte de algum bigrama. Os unigramas removidos são os que apresentam a mesma freqüência dos bigramas. No exemplo considerado, após essa etapa, não participam da LTC da Tabela 5.7, os termos distensibilidade, ads, aspecto, tipo, pontos e estenose. A nova LTC é apresentada na Tabela 5.8.

Na terceira etapa é realizada a remoção de todos os termos da LTC da Tabela 5.8 que possuem freqüência abaixo do limiar Theta, conforme apresentado no Algoritmo 7.

Nessa etapa é utilizado o parâmetro Theta e o número de laudos, portanto, todos os termos que possuem freqüência abaixo do limiar definido pelo Theta são removidos da LTC. A lista final, após a aplicação das heurísticas, é ilustrada na Tabela 5.9.

Após a execução desse algoritmo, tem-se a lista final de termos a serem utilizados como unidades terminológicas. É possível observar que houve uma

\footnotetext{
${ }^{9}$ Observe que se o parâmetro Alpha for definido como $100 \%$, então apenas se o brigrama ou a soma dos brigramas for igual à freqüência do unigrama, o bigrama ou os bigramas são inseridos na LTC, caso contrário é inserido o unigrama.
} 
Tabela 5.7: Lista de termos gerados após realizar a primeira etapa

\begin{tabular}{|c|c|}
\hline Termos & Freqüência \\
\hline calibre distensibilidade & 100 \\
\hline pinçamento & 100 \\
\hline motilidade & 100 \\
\hline distensibilidade & 100 \\
\hline teg & 99 \\
\hline mucosa aspecto & 81 \\
\hline mucosa terço & 14 \\
\hline mucosa tipo & 2 \\
\hline nivel pinçamento & 86 \\
\hline extensão & 82 \\
\hline aspecto & 81 \\
\hline terço & 19 \\
\hline presença erosões & 10 \\
\hline presença pontos & 2 \\
\hline presença cordões & 1 \\
\hline erosões & 11 \\
\hline ads & 4 \\
\hline coloração & 4 \\
\hline $\mathrm{cm}$ ads & 4 \\
\hline cor & 3 \\
\hline tipo & 2 \\
\hline pontos & 2 \\
\hline gástrica & 2 \\
\hline biópsia & 2 \\
\hline barrett & 2 \\
\hline cordões & 2 \\
\hline monilíase & 2 \\
\hline área estenose & 1 \\
\hline estenose & 1 \\
\hline circunferência & 1 \\
\hline lesão & 1 \\
\hline placas & 1 \\
\hline resíduos & 1 \\
\hline sinal cor & 1 \\
\hline
\end{tabular}

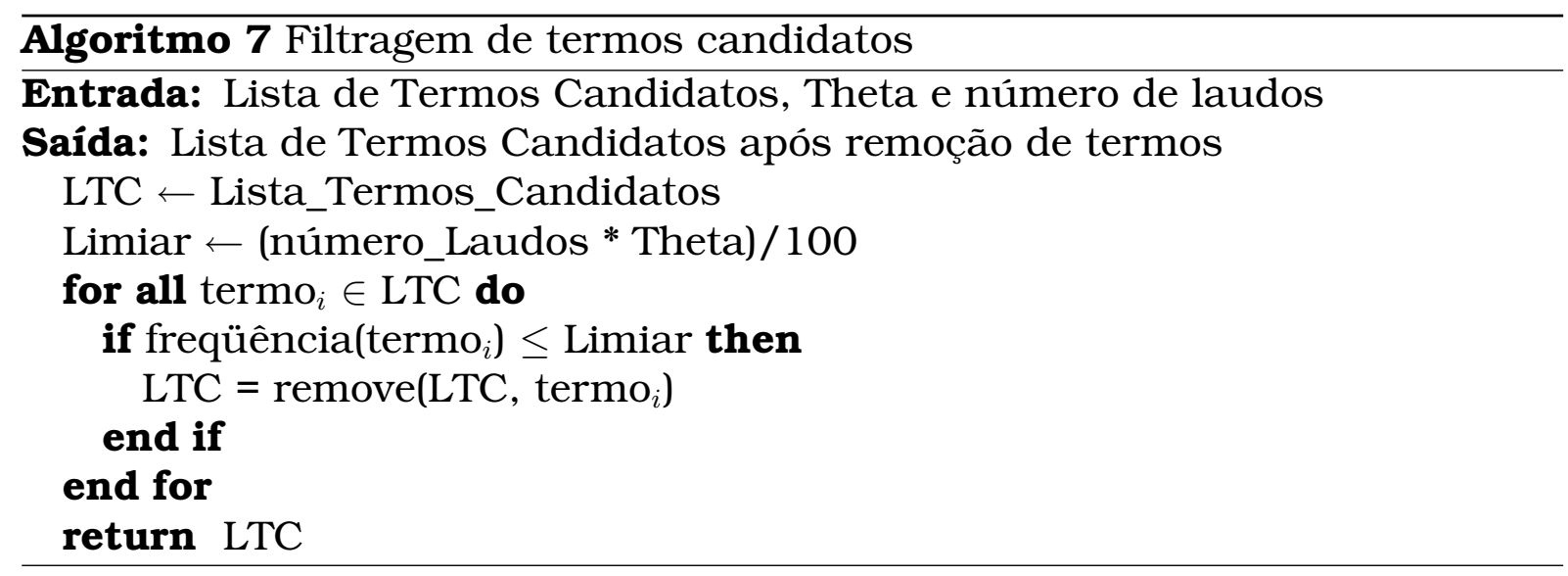

redução significativa do número de termos na lista final em relação ao número de termos das listas originais. Os termos da lista final são utilizados na próxima fase, a de identificação de atributos que serão mapeados na tabela atributo-valor. 
Tabela 5.8: Lista de termos gerados após realizar a segunda etapa

\begin{tabular}{|c|c|}
\hline Termos & Freqüência \\
\hline calibre distensibilidade & 100 \\
\hline pinçamento & 100 \\
\hline motilidade & 100 \\
\hline teg & 99 \\
\hline mucosa aspecto & 81 \\
\hline mucosa terço & 14 \\
\hline mucosa tipo & 2 \\
\hline nível pinçamento & 86 \\
\hline extensão & 82 \\
\hline terço & 19 \\
\hline presença erosões & 10 \\
\hline presença pontos & 2 \\
\hline presença cordões & 1 \\
\hline erosões & 11 \\
\hline coloração & 4 \\
\hline $\mathrm{cm}$ ads & 4 \\
\hline cor & 3 \\
\hline gástrica & 2 \\
\hline biópsia & 2 \\
\hline barrett & 2 \\
\hline cordões & 2 \\
\hline monilíase & 2 \\
\hline área estenose & 1 \\
\hline circunferência & 1 \\
\hline lesão & 1 \\
\hline placas & 1 \\
\hline residuos & 1 \\
\hline sinal cor & 1 \\
\hline
\end{tabular}

Tabela 5.9: Lista de termos gerados após realizar a terceira etapa

\begin{tabular}{|c|c|}
\hline Termos & Freqüência \\
\hline \hline calibre distensibilidade & 100 \\
\hline pinçamento & 100 \\
\hline motilidade & 100 \\
\hline teg & 99 \\
\hline mucosa aspecto & 81 \\
\hline mucosa terço & 14 \\
\hline nível pinçamento & 86 \\
\hline extensão & 82 \\
\hline terço & 19 \\
\hline erosões & 11 \\
\hline
\end{tabular}

\subsection{Identificação de Atributos}

Conforme mencionado, nesta fase, a partir de cada termo identificado na fase de extração de terminologia, é construída uma estrutura hierárquica, representada por uma árvore, cuja raiz é representada por uma unidade terminológica, a partir da qual são identificados os atributos para compor a tabela atributo-valor que será gerada na próxima fase. A partir de cada árvore podem ser identificados zero ou mais atributos para compor a tabela. A identificação dos atributos é realizada em três etapas:

1. Definição de termos que serão utilizados como raiz da árvore;

2. Geração das árvores; e 
3. Identificação dos atributos a partir da árvore gerada.

A seguir é apresentada uma descrição detalhada do processo de identificação de atributos.

\subsubsection{Definição de Termos raiz}

Depois de gerada a lista de termos na fase anterior de extração de terminologia, a identificação dos termos que serão utilizados para gerar as árvores pode ser realizada de duas maneiras, as quais podem ser automática ou manual. No modo automático, todos os termos são considerados como termos raiz, ou seja, a partir de cada termo é gerada uma árvore. No modo manual, uma análise, junto com o especialista, pode ser realizada sobre a lista de termos com o intuito de identificar os termos que realmente serão utilizados no mapeamento de informações. Nessa análise podem ser identificados termos da língua geral e, desse modo, o especialista pode auxiliar nessa tarefa indicando quais termos poderão ser utilizados para raiz das árvores. É importante ressaltar que nessa abordagem manual é realizada pelo especialista uma análise do significado dos termos, ou seja, é utilizada semântica na análise das informações.

Para exemplificar, considere a Tabela 5.9 com a lista de termos identificados na fase anterior. No modo automático, todos esses termos serão considerados como termos raiz. Por outro lado, no modo manual, a partir dessa lista os termos pinçamento, nível pinçamento, extensão e erosões podem ser removidos, uma vez que fazem parte da língua geral, não caracterizam localizações ou o nome de um componente de um órgão que está sendo analisado ou não são termos de interesse. A Tabela 5.10 apresenta a lista final que seria utilizada, após a remoção pelo especialista desses termos, na construção das árvores na próxima etapa.

Tabela 5.10: Lista de termos final

\begin{tabular}{|c|c|}
\hline Termos & Freqüência \\
\hline \hline calibre distensibilidade & 100 \\
\hline motilidade & 100 \\
\hline teg & 99 \\
\hline mucosa aspecto & 81 \\
\hline mucosa terço & 14 \\
\hline terço & 19 \\
\hline
\end{tabular}

É importante ressaltar que dependendo do termo, se for da língua geral, por exemplo, a remoção do termo pode ser realizada por um leigo. 


\subsubsection{Geração de Árvores}

Depois de definidos os termos raiz das árvores é executado o algoritmo de geração de árvores, lembrando que para cada termo considerado como unidade terminológica é gerada uma árvore cuja raiz é definida pelo termo. Neste trabalho, conforme foi mencionado, as árvores são geradas a partir de listas de $n$-gramas, as quais são geradas a partir do conjunto de documentos, pela ferramenta $\mathrm{NsP}^{10}$ (Banerjee \& Pedersen, 2003).

Para exemplificar a construção das árvores considere que o termo lago pertence ao conjunto de unidades terminológicas identificadas. Considere também que foram encontrados os seguintes $n$-gramas ${ }^{11}$ no conjunto de documentos - Tabela 5.11.

Tabela 5.11: Lista de $n$-gramas.

\begin{tabular}{|c|c|c|c|c|}
\hline 1-grama & 2-grama & 3-grama & 4-grama & 5-grama \\
\hline lago & lago mucoso & lago mucoso claro & lago mucoso tinto bile & - \\
\hline & & lago mucoso tinto & & \\
\hline
\end{tabular}

O número de $n$-gramas a ser considerado na construção da árvore é determinado pelo valor da variável $N M A X$ definida pelo usuário. $N M A X$ indica até qual lista de $n$-gramas deve ser realizada a pesquisa no momento de gerar as árvores. Por exemplo, se $N M A X$ é 3 , então para gerar a árvore será pesquisada até na lista de trigramas. O valor de $N M A X$ padrão no TP-Discover é definido pelo número médio de palavras por frase do conjunto de documentos. No exemplo é considerado $N M A X=5$.

Inicialmente é definida a árvore cuja raiz é o termo lago, conforme a Figura 5.18.

lago

Figura 5.18: Termo raiz da árvore

No próximo passo é realizada uma busca nas listas de $n$-gramas $(n>1$ no exemplo abordado), nas quais o termo lago é o primeiro elemento, com o objetivo de definir as sub-árvores do termo definido como raiz. Primeiramente é processada a lista de 2-gramas. Como há somente um elemento nessa lista, que tem como primeiro termo lago, então o "último grama" desse 2-grama (mucoso no exemplo considerado) é inserido na árvore como único filho da raiz lago, conforme ilustra a Figura 5.19

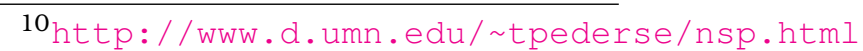

${ }^{11}$ Observe que se a unidade terminológica identificada é $j$-grama, então são pesquisadas as listas de $n$-gramas para $n>j$
} 


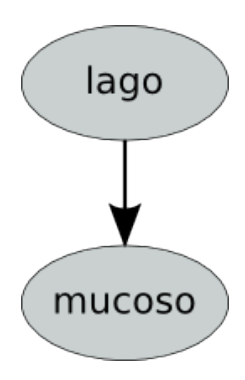

Figura 5.19: Filho do termo raiz

Após é analisada a lista de 3-grama correspondente ao 2-grama lago mucoso. Nesse caso tem-se dois 3-grama lago mucoso claro e lago mucoso tinto. Primeiramente é processado o 3-grama lago mucoso claro. Como $N M A X>3$, a lista 4-gramas é processada. Como não há nenhum 4-gramas que contem lago mucoso claro, o nó com o termo claro é um nó terminal da árvore. No caso do termo 3-grama lago mucoso tinto, considerando que existe somente um 4-grama lago mucoso tinto bile e não existe nenhum 5-grama que contém esse 4-grama, é inserido o termo composto tinto bile como nó terminal da árvore, conforme ilustrado na Figura 5.20.

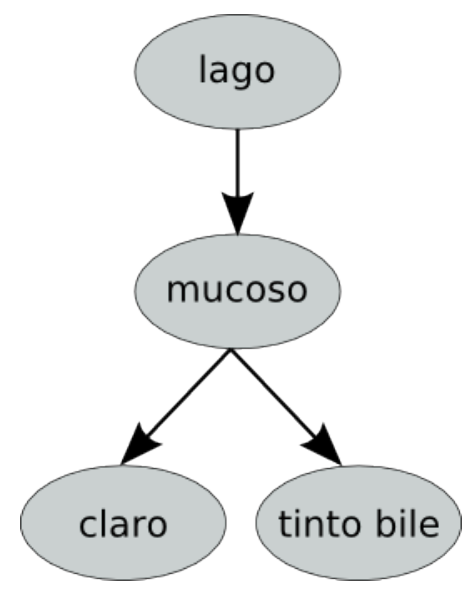

Figura 5.20: Filho do termo mucoso

Após terem sido geradas todas as árvores que tem como raiz as unidades terminológicas, elas são armazenadas em um arquivo no formato XML. Na Figura 5.21 é ilustrado o arquivo XML no qual está armazenada a estrutura de árvores correspondentes às unidades terminológicas lago e cardia. Nessa árvore, a tag nivel1 indica o primeiro nível da árvore, a tag nivel2 indica o segundo nivel e assim sucessivamente. Também são armazenadas as freqüências desses termos compostos de um nível para outro, de modo que possam ser utilizados no momento de identificação de atributos que irão compor a tabela atributo-valor.

A partir desse arquivo XML é possível gerar as figuras que representam 


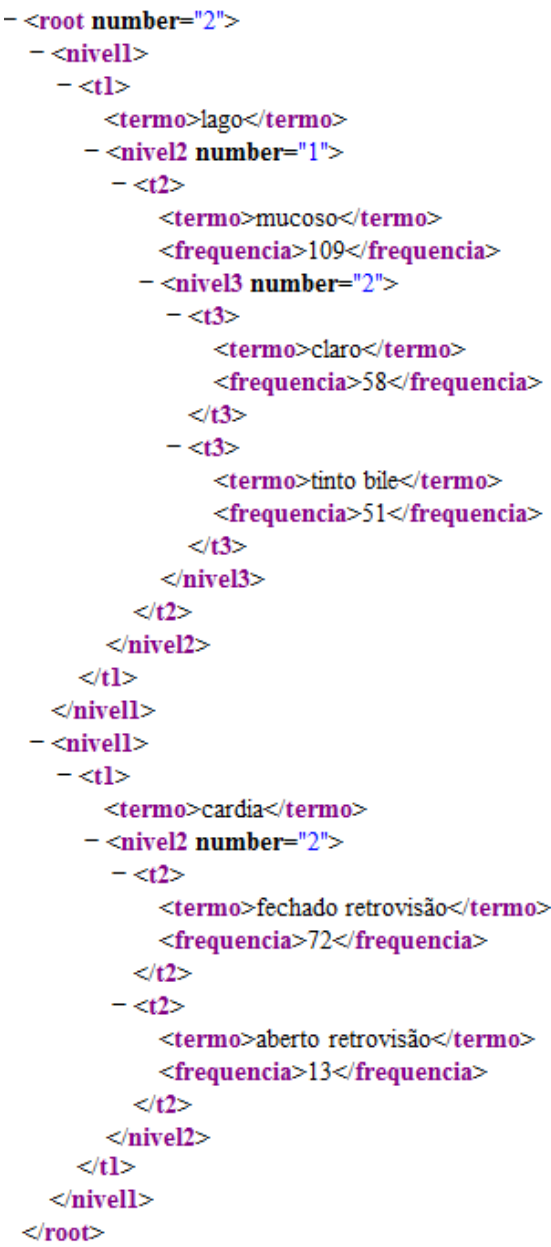

Figura 5.21: Arquivo correspondente a árvore gerada a partir dos termos lago e cardia

as árvores que estão mapeadas nele. A geração das figuras das árvores é realizada utilizando a ferramenta GRAPHVIZ ${ }^{12}$ (Gansner \& North, 2000). As figuras das árvores são criadas individualmente; portanto, a partir das árvores apresentadas na Figura 5.21, serão geradas duas figuras, sendo que uma terá como raiz o termo lago e a outra terá como raiz o termo cardia. Nas Figuras 5.22 e 5.23 estão ilustradas, respectivamente, as árvores geradas a partir do termo lago e do termo cardia, correspondentes ao arquivo XML da Figura 5.21.

A visualização dessas árvores é muito útil para o especialista. Assim, foi implementado um procedimento que tem como entrada a descrição XML da árvore a ser desenhada e que gera o arquivo com os comandos correspondentes para a ferramenta GRAPHVIZ desenhar essa árvore. Na Figura 5.24 é ilustrado o arquivo de descrição da figura gerado a partir do termo lago, utilizado pelo GRAPHVIZ para desenhar a árvore final da Figura 5.22.

12 http://www.GraphViz.org/ 


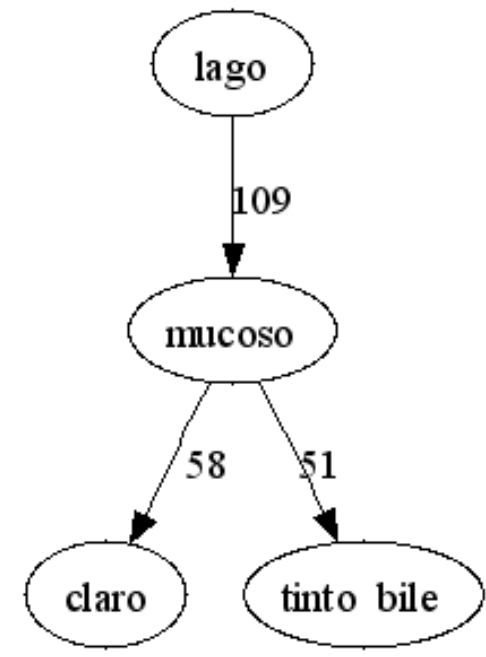

Figura 5.22: Árvore gerada a partir do termo lago

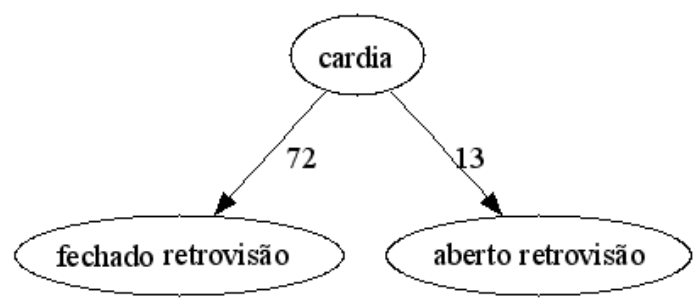

Figura 5.23: Árvore gerada a partir do termo cardia

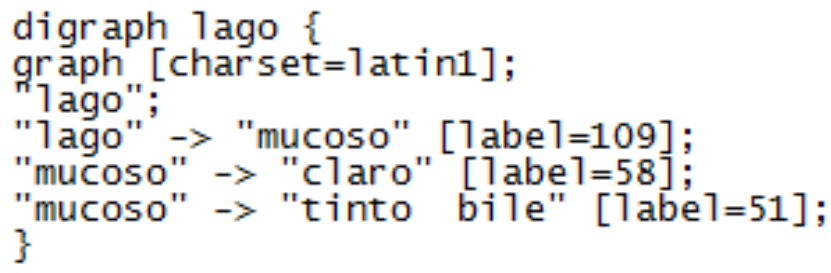

Figura 5.24: Arquivo com os comandos do GRAPHVIZ gerado a partir da descrição XML do termo lago

\subsubsection{Definição de Atributos}

Neste trabalho, a identificação dos atributos que participarão da tabela atributo-valor é realizada de maneira automática. Depois que foi gerada a árvore para cada termo raiz (unidade terminológica), é realizada uma busca nas árvores geradas, de modo a identificar o conjunto de atributos que fará parte da tabela atributo-valor. Como mencionado, foi decidido que os atributos são binários, ou seja, o valor do atributo poderá receber apenas dois valores, os quais são, presente (1), ou ausente (0), tal que valor do atributo $=\{0,1\}$.

A identificação dos atributos é realizada por meio de uma pesquisa automática em cada árvore, partindo do termo raiz. Nesse caso, o caminho a partir da raiz da árvore até um nó intermediário, ou mesmo, o nó folha que possuir 
freqüência acima de um determinado limiar em relação ao número de laudos que foi utilizado para gerar a árvore, é mapeado como atributo. Esse limiar é definido pelo usuário e seu valor padrão é $5 \%$. Considere a árvore ilustrada na Figura 5.25, gerada a partir do termo raiz mucosa fundo, a qual foi gerada pelo GraphViz utilizando 100 laudos do conjunto de laudos de Endoscopia Digestiva Alta.

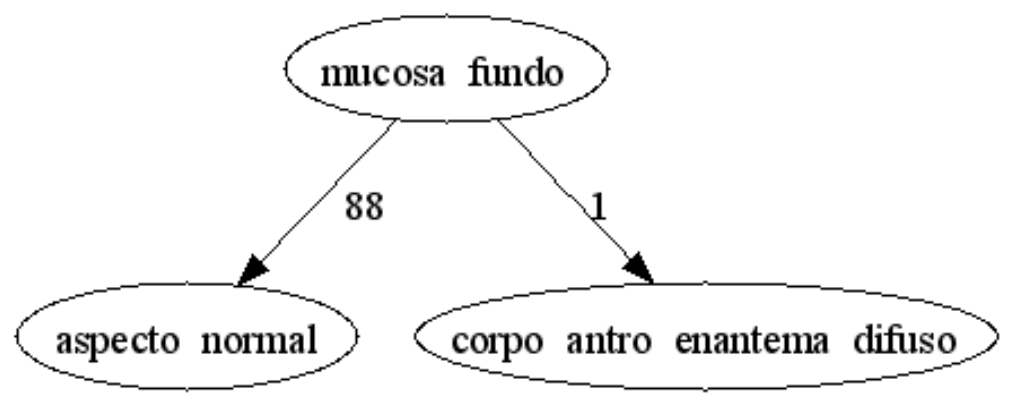

Figura 5.25: Árvore gerada a partir do termo mucosa fundo

Essa árvore informa que a seqüência mucosa fundo aspecto normal aparece 88 vezes no conjunto de 100 laudos, enquanto que a seqüência mucosa corpo antro enantema difuso aparece somente uma vez. Se for utilizado o limiar de $5 \%$, i.e. $5 \%$ do número de laudos processados, isso indica que somente seqüências que aparecem no mínimo 5 vezes devem ser consideradas. Portanto, somente será identificado um atributo, o atributo mucosa fundo aspecto normal. Por outro lado, se a árvore for a ilustrada na Figura 5.22 , gerada com os mesmos 100 documentos, então com o limiar de 5\%, serão identificados dois atributos: lago mucoso claro e lago mucoso tinto bile. Em outras palavras, nem todos os ramos das árvores, i.e., seqüências de termos que aparecem nos laudos, são transformados em atributos. No final dessa pesquisa, todos os ramos das árvores que possuem uma freqüência maior que o limiar padrão ou o limiar definido pelo usuário, são mapeadas como atributos para compor a tabela atributo-valor ${ }^{13}$.

Uma outra abordagem para a definição dos atributos é realizar uma análise manual das árvores geradas juntamente com o especialista do domínio. Nesse caso seria usado conhecimento semântico.

\subsection{Construção do Dícionário}

Depois que foram identificados os atributos, é necessário inseri-los em uma estrutura adequada que possibilite posteriormente a busca, no conjunto de

\footnotetext{
${ }^{13}$ Observe que um limiar de $0 \%$ faz com que sejam considerados todos os atributos na árvore, independente da sua freqüência no conjunto de documentos.
} 
documentos, por seqüências que "casem" com esses nomes de atributos. A essa estrutura denominamos dicionário de conhecimento. Neste trabalho foi adotada a árvore trie (Ziviani, 2007) como a estrutura de dados que implementa o dicionário de conhecimento. Depois de identificados os atributos, com base na análise das árvores geradas, os mesmos são inseridos na árvore trie, i.e., na árvore trie são inseridas as seqüências identificadas nas árvores. Por exemplo, se for identificado que a seqüência lago mucoso claro é um atributo, essa seqüência será inserida na árvore trie. Essa árvore é utilizada na última fase da metodologia, a de construção da tabela atributo-valor.

\subsection{Construção da Tabela Atributo-valor}

A tabela atributo-valor é definida no Capítulo 2, Tabela 2.1, página 14, para exemplos não rotulados. Neste trabalho, cada exemplo $d_{i}$ na Tabela 2.1, refere-se a uma laudo ${ }_{i}$ do conjunto de laudos. O Algoritmo 8 descreve em alto nível a construção dessa tabela.

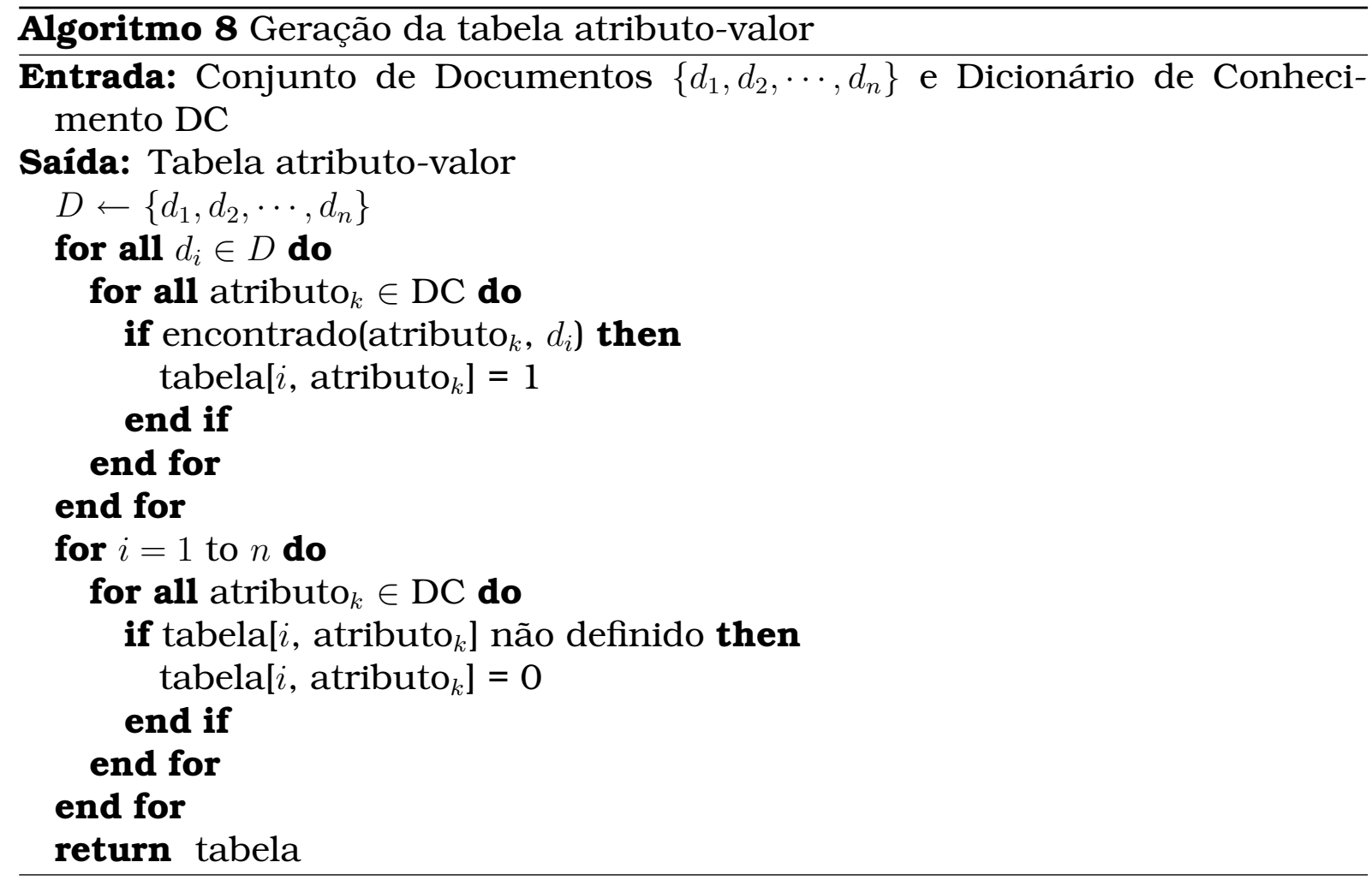

O preenchimento da tabela é realizado por meio de um ciclo de pesquisas entre o conjunto de documentos e o dicionário de conhecimento. Se uma determinada seqüência do laudo está presente no dicionário de conhecimento, o valor presente é colocado no atributo correspondente da tabela.

Na Figura 5.26 é ilustrado um trecho da tabela atributo-valor na qual foram 
mapeados os três atributos identificados na Seção 5.4.3. Nessa tabela são ma-

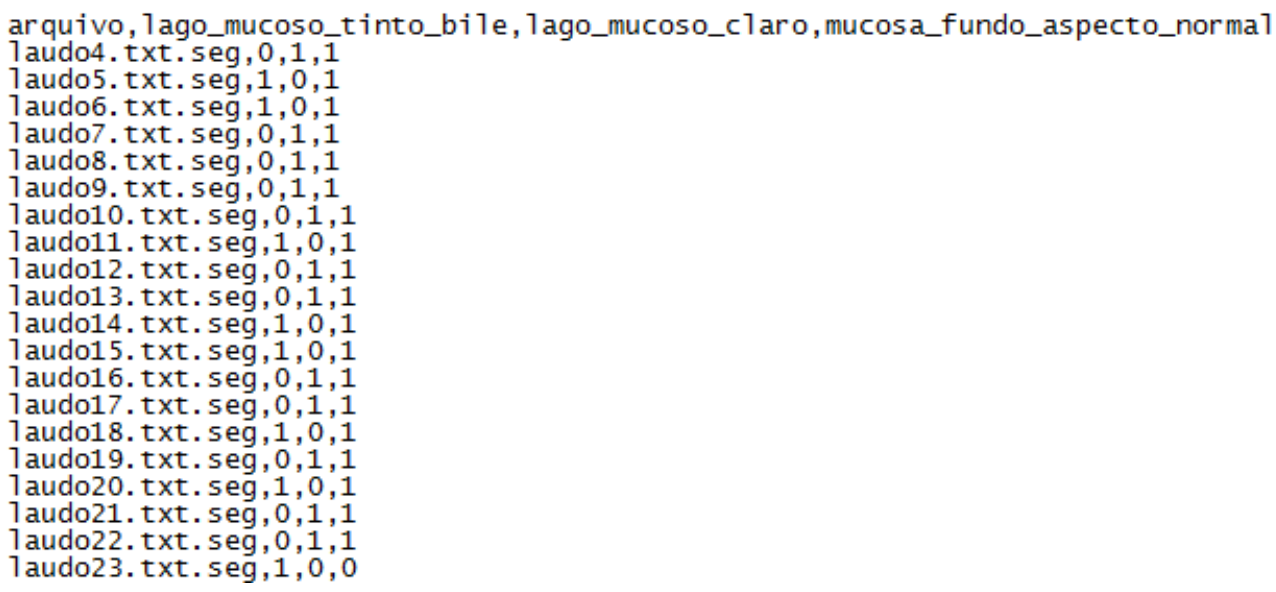

Figura 5.26: Exemplo da tabela atributo-valor

peados, além do nome dos atributos, o nome do arquivo texto correspondente ao laudo que foi processado. Essa informação é importante, uma vez que laudos de determinado domínio podem ser divididos, conforme foi apresentado na Seção 5.2.1 . Assim, com o nome do arquivo mapeado, posteriormente é possível, se for necessário, juntar as tabelas criadas para cada seção do laudo em uma única tabela atributo-valor.

Durante o processamento das frases para o preenchimento da tabela atributo-valor, cada frase pode ser processada totalmente, parcialmente ou não sofrer nenhum processamento.

De modo a registrar o número de frases que foram processadas parcialmente ou não foram processadas, é gerado um arquivo, o qual denominamos de garbage, no qual são armazenadas as frases dos documentos que não sofreram nenhum processamento e as frases que foram processadas parcialmente $^{14}$. É bom ressaltar que essa é uma informação importante para avaliar um dos aspectos da metodologia proposta, uma vez que indica a porcentagem de frases que estão sendo processadas completamente, parcialmente ou não estão sofrendo nenhum processamento, em relação ao número total de frases do conjunto de documentos.

\subsection{Considerações Finais}

Neste capítulo foi descrita a metodologia de transformação de informações não estruturadas em informações estruturadas representadas em uma tabela

\footnotetext{
${ }^{14}$ Frases não processadas são aquelas nas quais não foi reconhecido nenhum dos atributos da tabela atributo-valor. Frases processadas parcialmente são aquelas nas quais foi reconhecido pelo menos um atributo em qualquer parte da frase, mas outras partes da frase não foram processadas.
} 
atributo-valor. Nessa metodologia não é realizada automaticamente uma análise aprofundada do texto, como a realizada por métodos da área de processamento de língua natural, nos quais também é realizada a análise semântica. Neste trabalho é realizada uma análise sintática parcial, usando técnicas da área de extração de terminologia. A partir dessa análise, são identificados termos de interesse que são utilizados para a geração de estruturas hierárquicas (árvores) a partir das quais são identificados os atributos que irão compor a tabela atributo-valor. Depois de identificados os atributos é construído um dicionário de conhecimento, o qual é utilizado no momento do mapeamento das informações na tabela atributo-valor. No final da aplicação da metodologia tem-se a tabela atributo-valor preenchida a qual pode ser utilizada para a aplicação de algoritmos de extração de padrões.

Quanto ao aspecto semântico, a metodologia proposta permite incorporar semântica, mas ela deve ser incorporada manualmente com a participação do especialista. Assim, caso o especialista não participe do processo, tem-se um processo automático, que não considera o aspecto semântico, para escolher os atributos da tabela atributo-valor. No outro extremo, com a participação do especialista, tem-se um processo no qual o aspecto semântico também é considerado na metodologia proposta.

No próximo capítulo é avaliada experimentalmente a metodologia implementada utilizando um conjunto de laudos de Endoscopia Digestiva Alta. 


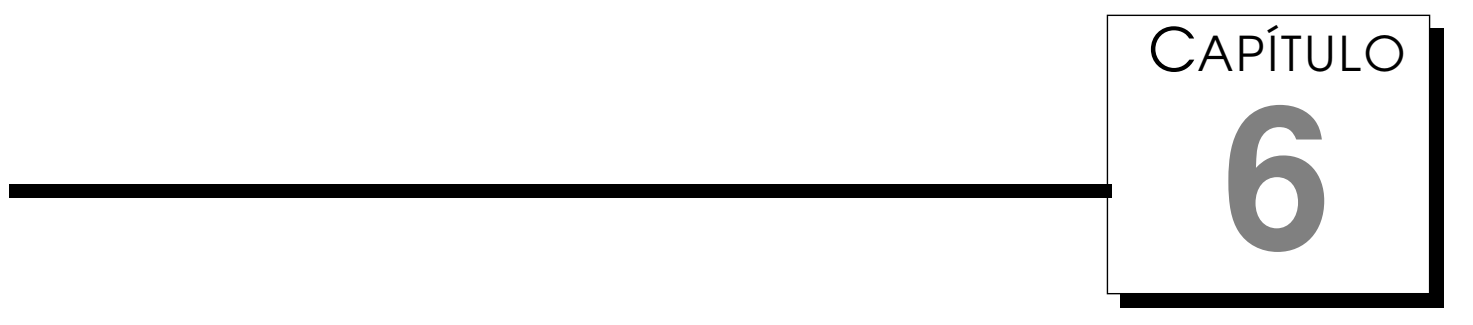

\section{Avaliação Experimental}

Neste capítulo é apresentada a avaliação experimental da metodologia desenvolvida, a qual foi realizada utilizando o ambiente computacional TP-DISCOVER. Foram realizados vários experimentos considerando o aspecto quantitativo, nos quais a metodologia foi avaliada sobre vários conjuntos de documentos variando os diferentes parâmetros que ela utiliza. Também foi realizada a avaliação de qualidade da lista de termos identificada pelo método de extração de terminologia. Nos experimentos foi utilizado um conjunto de 6000 laudos médicos da área de Endoscopia Digestiva Alta - EDA.

\section{1 Descrição do Conjunto de Laudos}

Os laudos utilizados neste trabalho foram obtidos por meio de parcerias do LABI com o Hospital Municipal de Paulínia - SP. Todos os laudos estão em lingua portuguesa, em formato digital armazenados em arquivos do tipo TXT e não possuem informações de referência, como nome do paciente ou médico que realizou o exame. Os laudos utilizados possuem o formato ilustrado na Figura 6.1.

Conforme pode ser observado, o laudo é dividido em cinco seções: esôfago, estômago, duodeno, biópsia e conclusões do exame. Nas três primeiras porções e no última as informações estão descritas em língua natural. As informações sobre biópsia estão estrututras. 


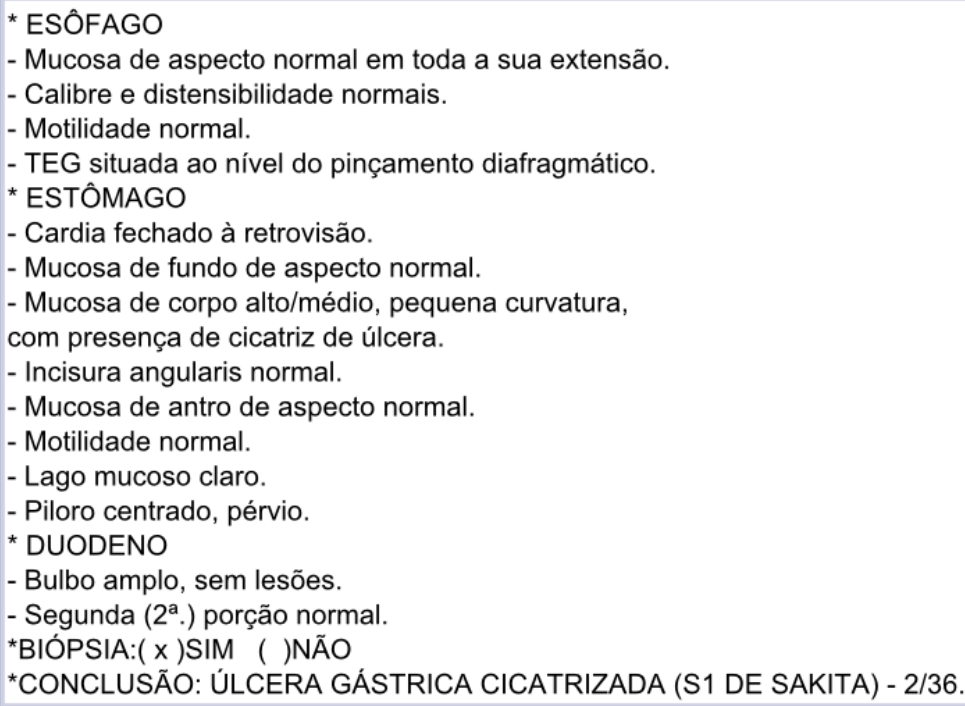

Figura 6.1: Laudo de EDA

\subsection{Configurações dos Experimentos}

Para realizar os experimentos, foram analisados duas seções dos laudos de EDA, especificamente as informações do esôfago e estômago, conforme o processo ilustrado na Figura 6.2.

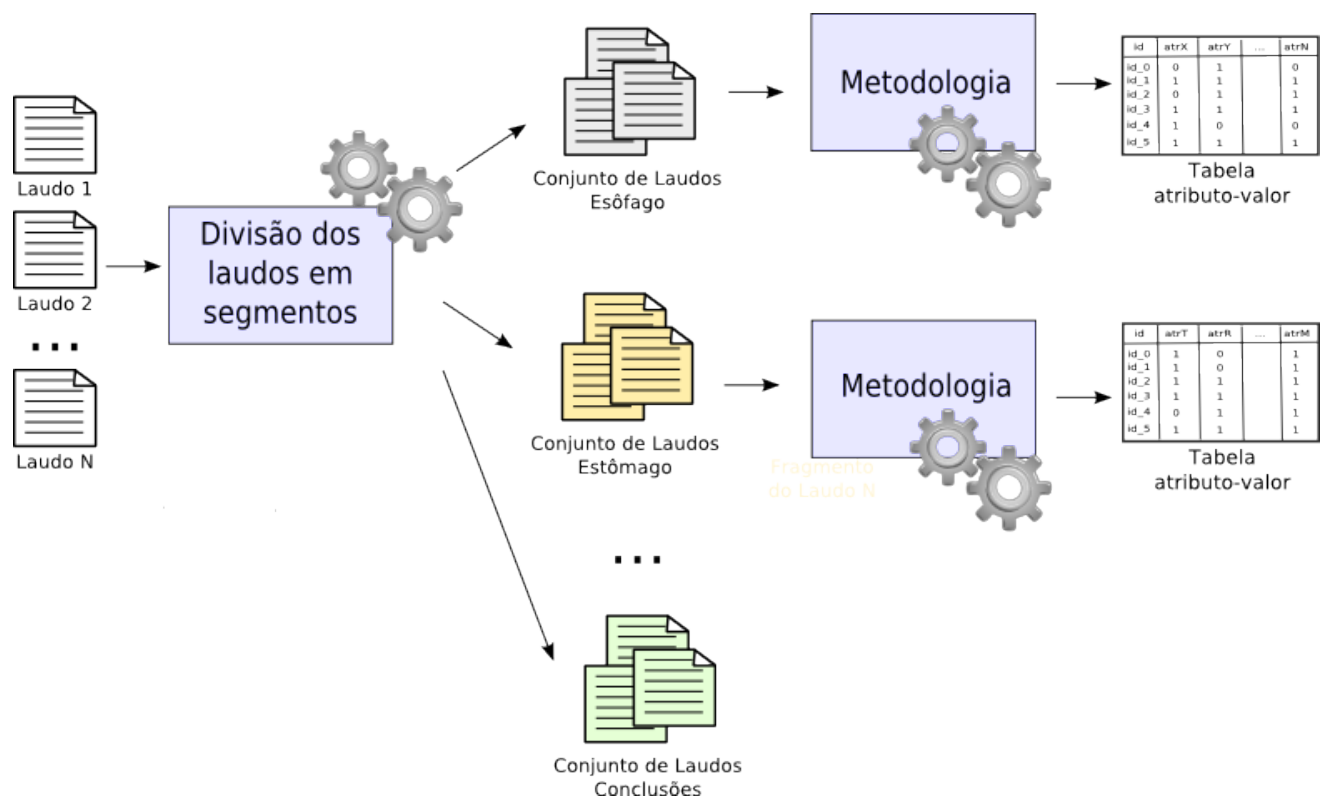

Figura 6.2: Divisão dos laudos

Nesse processo, primeiramente os 6000 laudos foram divididos de acordo com as seções que contêm, ou seja, um conjunto de documentos de esôfago, outro de estômago, outro de duodeno, outro de biópsia e outro de conclusões do exame. Depois foi aplicada a metodologia, separadamente, aos conjuntos de esôfago e estômago. 
Como mencionado, a metodologia proposta pode ser utilizada sem nenhuma intervenção do especialista, i.e., usando somente conhecimento sintático e procedimentos heurísticos para identificar as unidades terminológicas, ou com a intervenção do especialista. Neste último caso, obviamente, os resultados obtidos serão melhores, pois o especialista poderá analisar resultados parciais, assim como corrigir interativamente nomes semanticamente inapropriados de atributos utilizando, em cada um dos passos da metodologia, conhecimento semântico do domínio.

Neste trabalho, foi decidido avaliar os resultados da aplicação da metodologia sem a intervenção do especialista. Assim, sem dúvida alguma, os resultados experimentais apresentados referem-se a resultados obtidos no pior caso. Como os resultados necessitam ser avaliados não somente quantitativamente mas também qualitativamente, o conhecimento do especialista somente foi utilizado para calcular os valores de precisão e recall na fase de extração de terminologia, para os quais é necessário conhecer os termos de interesse do domínio.

Para avaliar a metodologia proposta no pior caso, foram realizados vários experimentos utilizando 4 (quatro) diferentes conjuntos de documentos relacionados ao esôfago e ao estômago, os quais foram amostrados com reposição do conjunto total de 6000 documentos disponíveis. Na Tabela 6.1 é mostrado o número de documentos no conjunto de treinamento $(\mathrm{Tr})$ e teste (Te) de cada um desses quatro experimentos.

Tabela 6.1: Configuração dos experimentos realizados

\begin{tabular}{|c|c|c|}
\hline Id. Experimento & Tr & Te \\
\hline Exp1 & 500 & 1000 \\
\hline Exp2 & 1000 & 1000 \\
\hline Exp3 & 2000 & 1000 \\
\hline Exp4 & 4000 & 1000 \\
\hline
\end{tabular}

Em outras palavras, no Exp1 foram amostrados 1500 documentos do conjunto total de documentos, os quais foram divididos em 500 para treinamento e 1000 para teste. No Exp2 foram amostrados 2000 documentos do conjunto total de documentos e foram divididos em 1000 para treinamento e 1000 para teste. Analogamente para o Exp3 e Exp4. Ou seja, conjuntos diferentes de documentos foram utilizado em cada experimento.

$\mathrm{Na}$ aplicação da metodologia, na fase de extração de terminologia foram utilizados diferentes valores para os parâmetros Alpha e Theta, de modo que fosse possivel observar a influência deles na identificação dos termos de interesse do conjunto de laudos. Portanto, para cada experimento identificado na Tabela 6.1, foram utilizadas nove variações dos valores de Alpha e Theta, as 
quais são apresentadas na Tabela 6.2.

Tabela 6.2: Configuração dos valores de Alpha e Theta

\begin{tabular}{|c|c|c|}
\hline Id & Alpha & Theta \\
\hline \multirow{3}{*}{$\mathrm{a}$} & 100 & 5 \\
\cline { 2 - 3 } & 100 & 10 \\
\cline { 2 - 3 } & 100 & 20 \\
\hline \multirow{3}{*}{$\mathrm{b}$} & 95 & 5 \\
\cline { 2 - 3 } & 95 & 10 \\
\cline { 2 - 3 } & 95 & 20 \\
\hline \multirow{3}{*}{$\mathrm{c}$} & 90 & 5 \\
\cline { 2 - 3 } & 90 & 10 \\
\cline { 2 - 3 } & 90 & 20 \\
\hline
\end{tabular}

Para cada experimento (Exp1, Exp2, Exp3 e Exp4), foram aplicadas as 5 fases da metodologia, conforme o esquema ilustrado na Figura 6.3 e descrito a seguir.

Fase 1: É realizado o pré-processamento dos laudos do conjunto de treinamento e teste, por meio de tarefas como segmentação do laudo (Figura 6.2), construção dos CFUs, remoção de stopwords, transformação para minúsculo ${ }^{1}$ e correção ortográfica. Neste trabalho não foi aplicada a lematização sobre o conjunto de documentos, uma vez que não foram alcançados bons resultados com o lematizador TREETAGGER. Isso se deve ao fato de que o lematizador utiliza a classe gramatical da palavra que vai lematizar e, como foi treinado com textos da língua geral, para o domínio médico os resultados não foram bons;

Fase 2: É aplicado o processo de extração de terminologia e aplicadas as heurísticas utilizando os valores diferentes de Alpha e Theta;

Fase 3: A partir de cada termo da lista de termos gerada na fase anterior é construída uma árvore, a qual tem como ramos os termos que aparecem no contexto do termo raiz (lado direito). A partir de cada árvore gerada, é realizada a identificação dos atributos, de acordo com quatro limiares de freqüência com que os termos aparecem no contexto do termo raiz;

Fase 4: Os atributos identificados são inseridos no dicionário de conhecimento, o qual é utilizado na construção da tabela atributo-valor;

Fase 5: Nessa fase são realizadas duas tarefas. A primeira consiste na geração da tabela atributo-valor com base no dicionário construído utilizando o conjunto de treinamento o qual é avaliado sobre o mesmo conjunto de treinamento. Nessa tarefa também é gerado o arquivo de garbage, o qual

\footnotetext{
${ }^{1}$ Não são removidas as acentuações das palavras.
} 


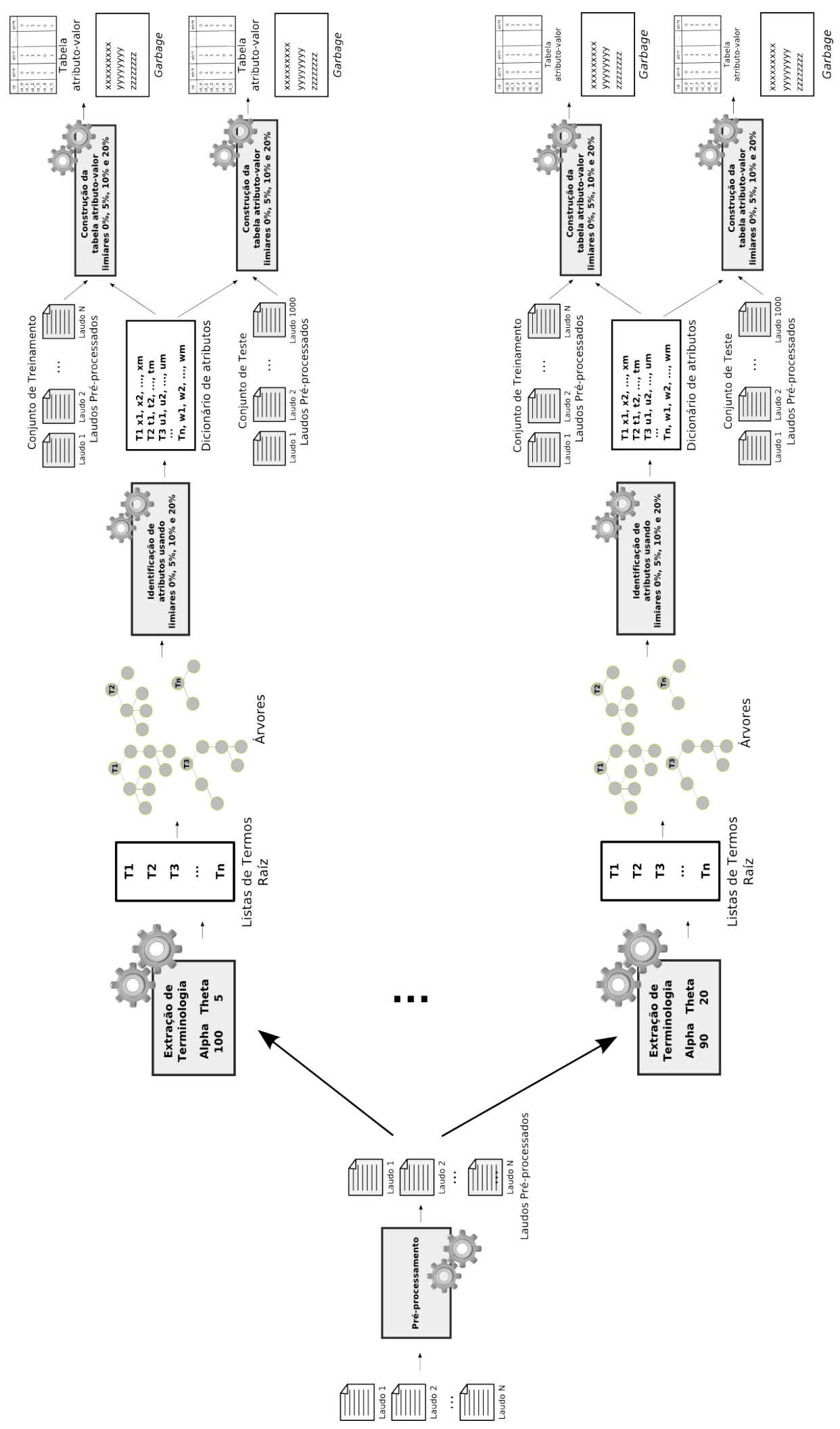

Figura 6.3: Configuração dos experimentos

mapeia as frases que foram processadas parcialmente e as frases que não foram processadas. Na segunda tarefa é realizado o mesmo procedimento, usando o mesmo dicionário mas agora avaliando o conjunto de 
teste.

\subsection{Resultados - Seção de Esôfago}

Nessa seção são apresentados e discutidos os resultados obtidos na aplicação da metodologia sobre os conjuntos de laudos de esôfago, divididos conforme experimentos citados na seção anterior.

\subsubsection{Aspecto Quantitativo}

Conforme mencionado, uma das hipóteses deste trabalho é que as informações presentes no conjunto de laudos são compostas por frases assertivas e utilizam um vocabulário controlado. Na Tabela 6.3 é apresentado o número de frases dos CFUs após cada etapa da fase de pré-processamento.

Tabela 6.3: Resultados dos CFUs da seção de esôfago

\begin{tabular}{|c|c|c|c|c|c|c|}
\hline $\begin{array}{c}\text { Doc. } \\
\operatorname{Tr}\end{array}$ & $\begin{array}{c}\text { Frases } \\
a_{1}\end{array}$ & $\begin{array}{c}\text { Num. CFU } \\
a_{2}\left(\% a_{1}-a_{2}\right)\end{array}$ & $\begin{array}{c}\text { Num. CFU } \\
\text { Padronizado } \\
a_{3}\left(\% a_{2}-a_{3}\right)\end{array}$ & $\begin{array}{c}\text { Num. CFU Pad. } \\
\text { Corrigido } \\
a_{4}\left(\% a_{3}-a_{4}\right)\end{array}$ & $\begin{array}{c}\text { Redução no } \\
\text { pré-proc. } \\
\left(\% a_{2}-a_{4}\right)\end{array}$ & $\begin{array}{c}\text { Redução } \\
\text { total } \\
\left(\% a_{1}-a_{4}\right)\end{array}$ \\
\hline 500 & 2002 & $110(94,5 \%)$ & $102(7,3 \%)$ & $97(4,9 \%)$ & $11,80 \%$ & $95,20 \%$ \\
\hline 1000 & 3995 & $189(95,3 \%)$ & $184(2,6 \%)$ & $168(8,7 \%)$ & $11,10 \%$ & $95,80 \%$ \\
\hline 2000 & 8005 & $339(95,8 \%)$ & $322(5,0 \%)$ & $296(8,1 \%)$ & $12,70 \%$ & $96,30 \%$ \\
\hline 4000 & 15990 & $610(96,2 \%)$ & $572(6,2 \%)$ & $518(9,4 \%)$ & $15,10 \%$ & $96,80 \%$ \\
\hline
\end{tabular}

A primeira coluna, Doc. Tr, mostra o número de documentos de treinamento considerado. A coluna Frases $\left(a_{1}\right)$ mostra o total de frases enquanto que a coluna Num. CFU $\left(a_{2}\right)$ mostra o total de frases únicas e a porcentagem de redução nos respectivos conjuntos de documentos. As colunas Num. CFU Padronizado $\left(a_{3}\right)$ e Num. CFU Padronizado Corrigido $\left(a_{4}\right)$ mostram, respectivamente, o número de frases únicas após a remoção de stopwords e transformação para minúsculo no primeiro caso, e após a correção ortográfica no segundo caso. As porcentagens entre parênteses indicam a redução em cada um desses passos. A coluna Redução no pré-processamento mostra a porcentagem total de redução de frases únicas, superior a 10\% em todos os casos, e a última coluna a porcentagem de redução entre o número original de frases e o número final de frases únicas após pré-processamento. Como pode ser observado, o número final de frases diferentes constitui menos de $5 \%$ do total de frases nos diferentes conjuntos de documentos utilizados.

Esse resultado é importante uma vez que comprova a hipótese de que está sendo utilizado um vocabulário controlado e são utilizadas frases assertivas simples no mapeamento das informações do esôfago. 
O pré-processamento foi realizado por meio da aplicação de tarefas de remoção de stopwords, transformação para minúsculo e correção ortográfica. Conforme mencionado, neste trabalho foi implementado um algoritmo para auxiliar a correção ortográfica. Esse algoritmo gera uma lista de possiveis correções que devem ser validadas pelo usuário. Na Tabela 6.4 são apresentados os resultados da aplicação do algoritmo de correção ortográfica sobre cada conjunto de documentos de treinamento utilizado nos experimentos.

Tabela 6.4: Correção ortográfica

\begin{tabular}{|c|c|c|}
\hline $\begin{array}{c}\text { Doc. } \\
\text { Tr }\end{array}$ & $\begin{array}{c}\text { Num. sugestões } \\
\text { identificadas }\end{array}$ & $\begin{array}{c}\text { Num. sugestões } \\
\text { corretas }\end{array}$ \\
\hline 500 & 35 & $10(28,6 \%)$ \\
\hline 1000 & 48 & $18(37,5 \%)$ \\
\hline 2000 & 66 & $27(40,9 \%)$ \\
\hline 4000 & 101 & $43(42,6 \%)$ \\
\hline
\end{tabular}

A segunda coluna da tabela, Num. sugestões identificadas, mostra o número de palavras, sugeridas pelo algoritmo, para realizar a correção de listas consideradas incorretas pelo algoritmo e que deveriam ser substituídas, respectivamente, pela palavra correta sugerida pelo algoritmo. Por exemplo, considere que o algoritmo sugere as palavras aproximadamente e terço como palavras corretas para substituir as seguintes listas de palavras:

aproximadamente $\leftarrow$ aproximandamente, aproximadmente terço $\leftarrow$ terso, deterço

A última coluna, Num. sugestões corretas, mostra o número dessas palavras, confirmadas como corretas pelo usuário e, entre parênteses, a porcentagem de acerto do algoritmo proposto. Como pode ser observado, a mínima taxa de acerto, $28 \%$, foi obtida utilizando o conjunto de 500 documentos. Com um número maior de documentos a taxa de sugestões corretas aumentou, uma vez que está sendo considerada uma quantidade maior de informações para identificar sugestões de correções. Consideramos esse resultado bom, uma vez que o corretor não faz uso de nenhum conhecimento externo para construir a lista de sugestões. Posteriormente pretendemos melhorar esse corretor, por meio da incorporação de algumas heurísticas no algoritmo.

Conforme mencionado, para cada um dos quatro experimentos (Exp1, Exp2, Exp3 e Exp4) foram utilizados diferentes valores para os parâmetros de Alpha e Theta, conforme foi apresentado na Tabela 6.2. Para cada valor de Alpha e Theta foram realizados os experimentos de modo a extrair as seguintes informações: 
- Número de termos raiz;

- Número de atributos gerados utilizando limiares de poda da árvore iguais a $0 \%, 5 \%, 10 \%$ e $20 \%$;

- Taxas de preenchimento ${ }^{2}$ da tabela atributo-valor gerada a partir do conjunto de treinamento e taxa de preenchimento da tabela gerada a partir do conjunto de teste;

- Garbage contendo o número de frases que foram processadas parcialmente e número de frases que não foram processadas, para o conjunto de treinamento e teste ${ }^{3}$.

Deve ser lembrado que as informações da taxa de preenchimento e do garbage apresentadas neste capítulo referem-se aos resultados dos experimentos sobre o conjunto de teste.

A primeira tarefa antes de gerar as árvores a partir das quais são gerados os atributos consiste na identificação dos termos que serão utilizados como raiz das árvores. Conforme mencionado, neste trabalho, utilizamos uma abordagem híbrida de extração de terminologia para identificar esses termos. Para isso, o conjunto de documentos foi etiquetado e depois foram extraídos os termos pertencentes à classe gramatical N e N N. Sobre a lista de termos extraídos foram aplicadas as heurísticas que usam os valores de Alpha e Theta correspondentes.

Após realizar a identificação desses termos (unidades terminológicas), os mesmos foram utilizados como termos raiz para gerar as árvores a partir das quais são identificados os atributos. Depois de geradas as árvores, foi realizada a identificação de atributos que compõem a tabela atributo-valor. Nos experimentos, utilizamos os limiares de poda das árvores 0\%, 5\%, 10\% e 20\%. Deve ser lembrado que, utilizar o limiar 0\% corresponde a transformar todos os ramos das árvores geradas em nomes de atributos. Na Figura $6.4^{4}$ é ilustrado o gráfico que mostra a relação entre o número de termos raiz identificados e o número de atributos gerados utilizando o limiar de poda $0 \%$, para os experimentos realizados.

Nesse gráfico, no eixo $x$ estão representadas as variações de Theta (5\%, $10 \%, 20 \%)$. Os gráficos identificados com $a, b$ e $c$ representam, respectivamente, os resultados obtidos com os valores de Alpha 100\%, 95\% e 90\%,

\footnotetext{
${ }^{2}$ Ver Tabelas A.3, A.8, A.13 e A.18 no Apêndice.

${ }^{3}$ Ver Tabelas A.4, A.9, A.14 e A.19 para garbage do conjunto de treinamento e Tabelas A.5, A.10, A.15 e A.20 para garbage do conjunto de teste, no Apêndice.

${ }^{4}$ Ver Tabelas A.1, A.6, A.11 e A.16 no Apêndice.
} 


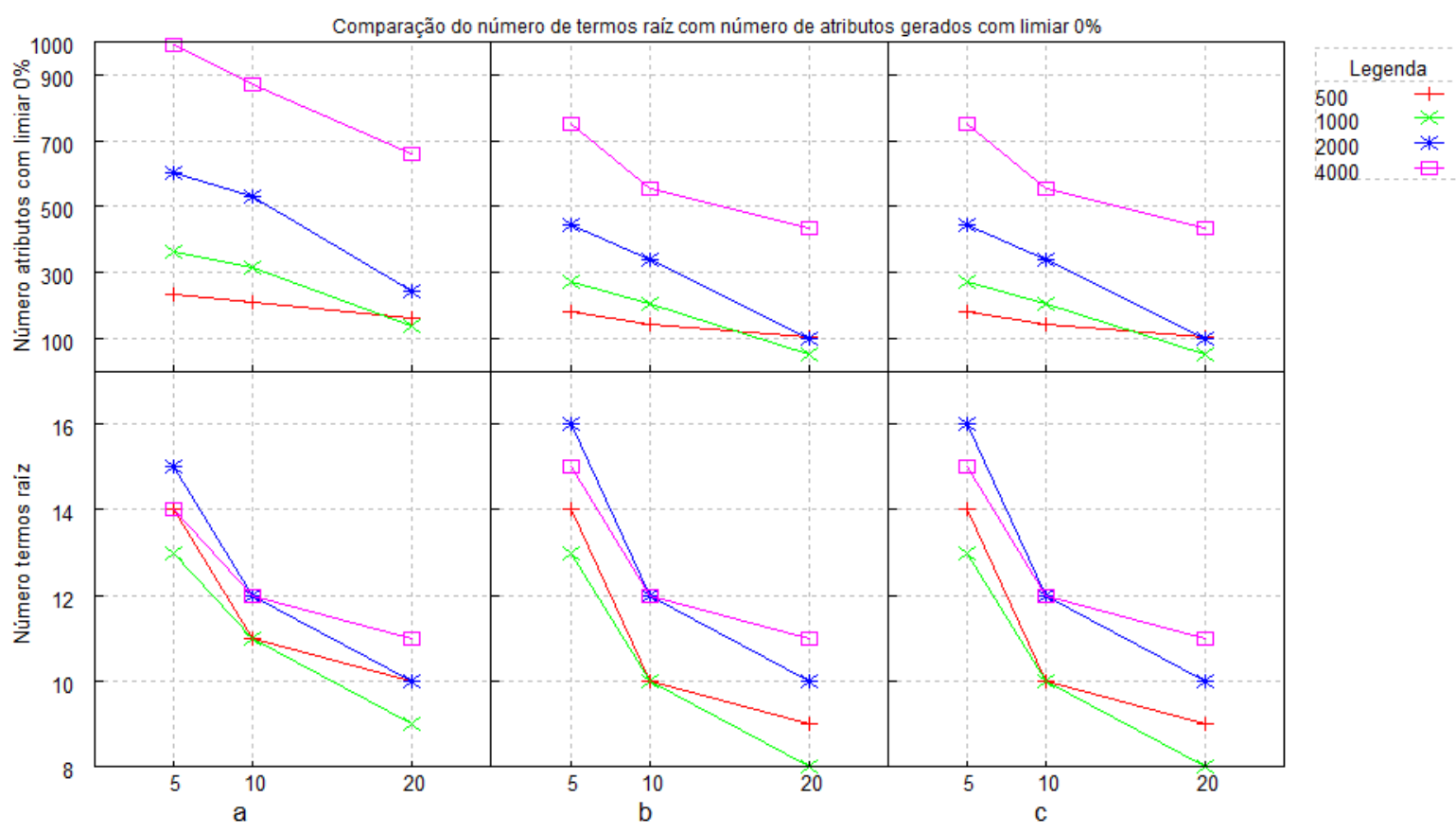

Figura 6.4: Relação entre número de termos raiz e número de atributos gerados utilizando limiar igual a $0 \%$

conforme apresentados na Tabela 6.2. É possivel observar que usando as variações $b$ e $c$, os resultados foram iguais, ou seja, usando Alpha = 95\% e Alpha $=90 \%$, os termos identificados foram iguais. Isso significa que no restante dos experimentos da seção de esôfago, os resultados correspondentes aos $b$ e $c$ dos experimentos são todos iguais.

É possível observar no gráfico que quanto maior o número de documentos do conjunto de treinamento, maior o número de atributos identificados. Essa característica deve-se ao fato de que quanto mais documentos, existirão mais variações no contexto de um determinado termo raiz e, conseqüentemente, mais ramos serão criados a partir desse termo. Por outro lado, o número de termos raiz não variou muito ${ }^{5}$. É importante ressaltar que neste trabalho estamos considerando todos os termos extraídos como termos raiz e, no caso de usar o limiar 0\%, todos os possíveis atributos em cada ramo das árvores são utilizados. Em um processo com interação com o especialista, tanto o número de termos raiz quanto o número de atributos certamente seria menor, uma vez que seriam utilizados somente termos de interesse, validados pelo especialista.

Para avaliar o número de atributos que são considerados em relação ao número total identificado com o limiar de poda igual a $0 \%$, foram utilizados

\footnotetext{
${ }^{5}$ Observe que a escala do eixo $y$ para representar os números de termos raiz é diferente da escala para representar o número de atributos.
} 
os limiares de 5\%, 10\% e 20\%. Nas Figuras 6.5, 6.6 e $6.7^{6}$ são ilustrados, respectivamente, os gráficos que mostram a proporção com relação ao limiar 0\%, de atributos considerados usando esses limiares, para os valores de Alpha $100 \%(a), 95 \%(b)$ e $90 \%(c)^{7}$.

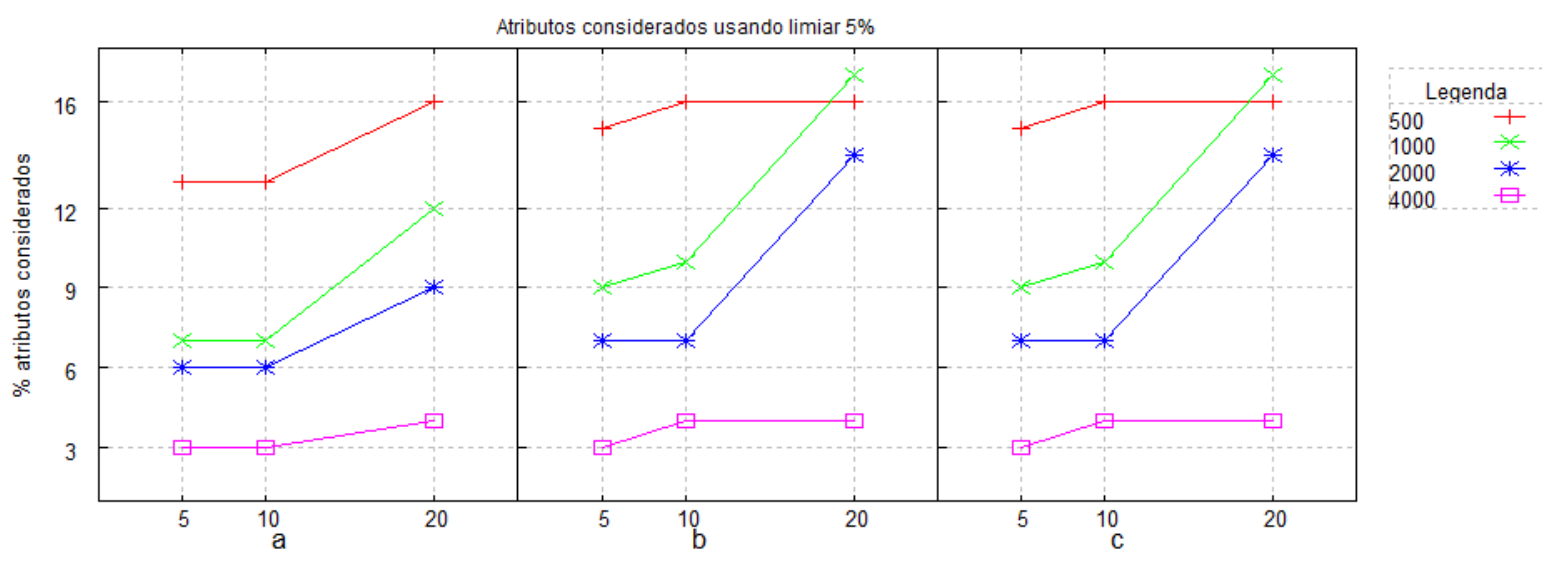

Figura 6.5: Taxa de atributos considerados utilizando limiar igual a 5\%

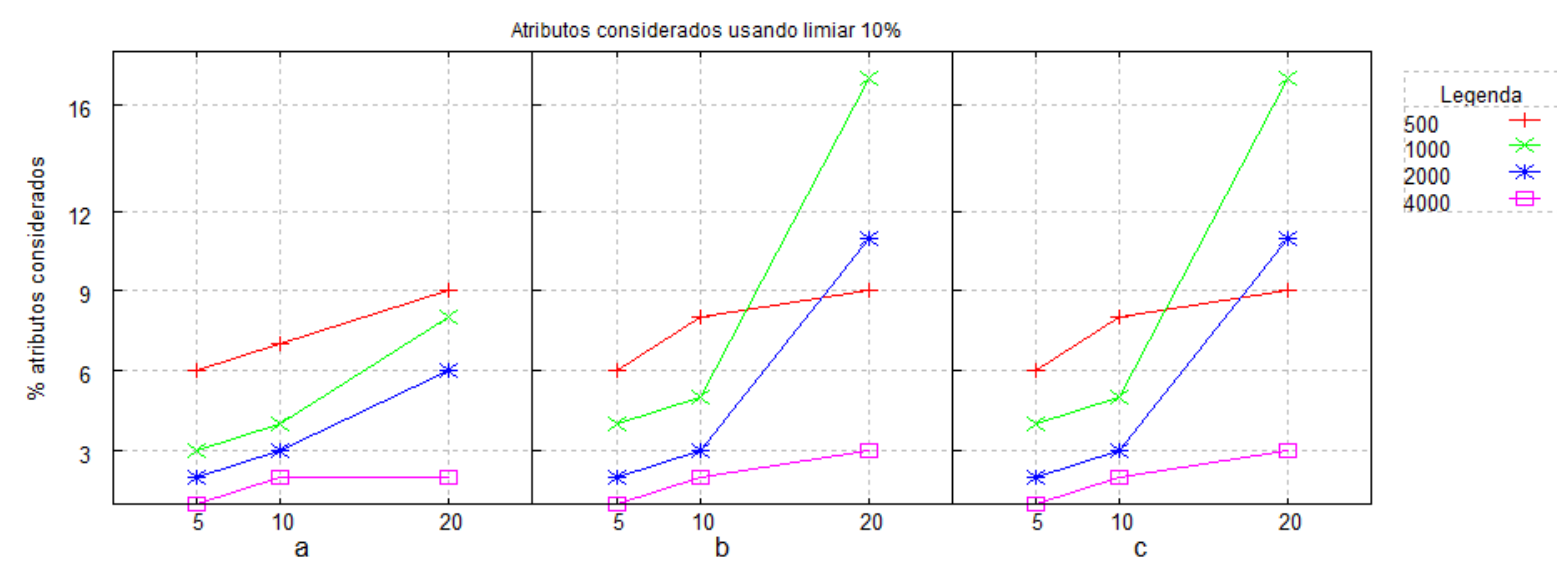

Figura 6.6: Taxa de atributos considerados utilizando limiar igual a 10\%

No gráfico no qual foi utilizado o limiar de 5\%, o número de atributos considerados em relação ao número total gerado é maior do que usando limiares de $10 \%$ e $20 \%$, uma vez que grande parte dos ramos das árvores possuem freqüência maior ou igual que 5\%. É importante observar que para o conjunto de treinamento de 4000 laudos, a taxa de atributos considerados é menor pois, conforme observado na Figura 6.4, para esse experimento foi gerado um número muito maior de atributos, o que indica que foram geradas árvores com muitos ramos de freqüência menor que 5\%. Por outro lado, a taxa de atributos considerados para o conjunto de treinamento de 500 laudos é maior, uma

\footnotetext{
${ }^{6}$ Ver Tabelas A.1, A.6, A.11 e A.16 no Apêndice.

${ }^{7}$ Observe que esses gráficos referem-se a proporção de atributos e não ao número de atributos, o qual é dado pelo produto do número total de atributos gerados utilizando o limiar $0 \%$ — Figura 6.4 - multiplicado pela taxa correspondente - Figura 6.5.
} 


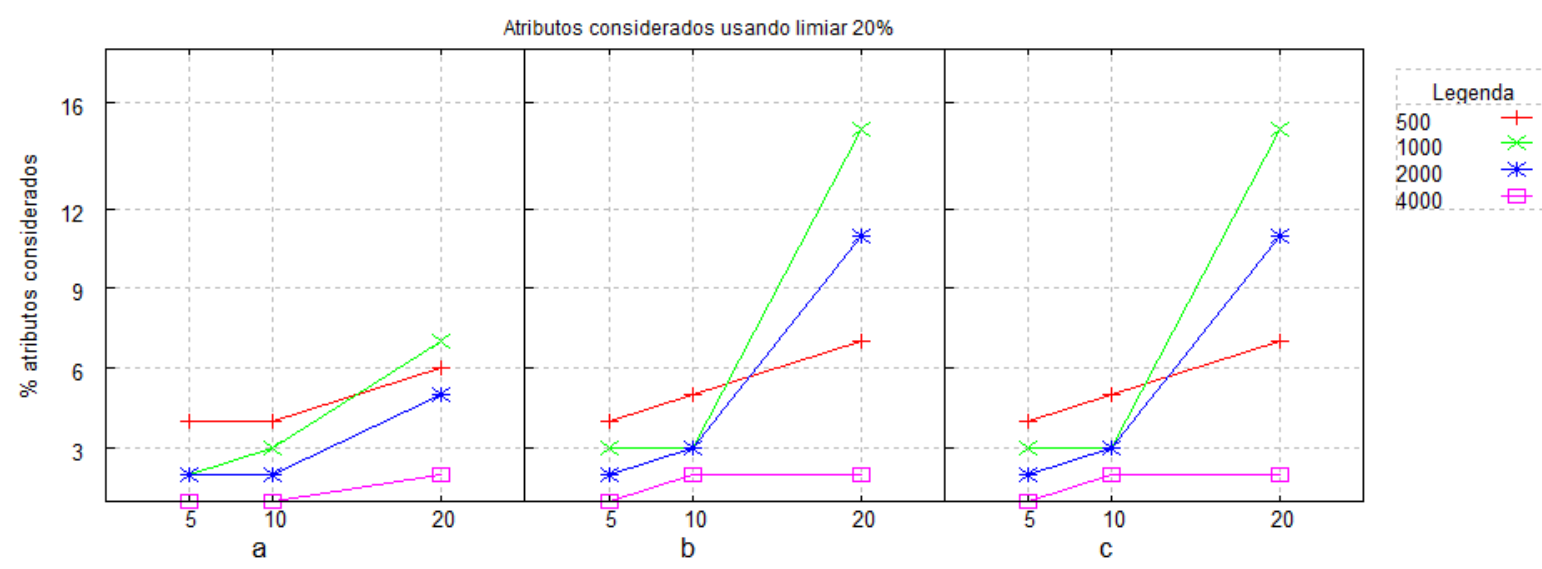

Figura 6.7: Taxa de atributos considerados utilizando limiar igual a 20\%

vez que o número de atributos gerado usando o limiar 0\% é menor. Embora a taxa de atributos considerados de um experimento para outro seja grande, a variação do número de atributos não é grande, conforme pode ser observado nas Tabelas A.1, A.6, A.11 e A.16, no Apêndice. Conforme foi mencionado, isso se deve ao fato de que, com um conjunto maior de documentos para treinamento, são geradas árvores com muitos ramos com freqüência baixa, enquanto os ramos com freqüência maiores estão próximos a raiz da árvore. Guando se aumenta o limiar de poda, somente serão considerados atributos próximos da raiz. Assim, o número total de atributos considerados utilizando um limiar de $20 \%$ é menor que o limiar $10 \%$ que é ainda menor que com um limiar de $5 \%$.

Após identificados os atributos utilizando os diferentes limiares $(0 \%, 5 \%$, $10 \%$ e $20 \%$ ) foi realizada a construção do dicionário e o preenchimento da tabela atributo-valor. Na Tabela 6.5 são apresentadas as taxas de preenchimento das tabelas geradas nos experimentos Exp1, Exp2, Exp3 e Exp4, respectivamente, usando os 1000 documentos do conjunto de teste correspondente a cada experimento.

Como esperado, usando limiar 0\%, a taxa de preenchimento é bastante baixa, ou seja, tem-se uma tabela bastante esparsa. Por outro lado, conforme o valor do limiar aumenta (5\%, 10\% e $20 \%)$, a taxa de preenchimento é incrementada, uma vez que o número de atributos é menor para limiares maiores, ou seja, estão sendo considerados como atributos apenas seqüências de palavras que têm freqüência maior. Para todos os casos, para o limiar 20\%, a taxa de preenchimento se estabiliza em aproximadamente $90 \%$.

Durante a construção das tabelas também é gerado o arquivo garbage no qual é armazenado o número de frases do conjunto de documentos que foram processadas parcialmente e o número de frases que não sofreram nenhum 
Tabela 6.5: Taxa de preenchimento do conjunto de teste para os experimentos Exp1, Exp2, Exp3 e Exp4

\begin{tabular}{|c|c|c|c|c|c|}
\hline \multirow{4}{*}{$\begin{array}{c}\text { Alpha/ } \\
\text { Theta }\end{array}$} & \multicolumn{4}{|c|}{ Taxa Preenchimento } \\
\cline { 3 - 6 } & \multirow{3}{*}{ Exp1 } & $4 \%$ & $5 \%$ & $10 \%$ & $20 \%$ \\
\hline \multirow{4}{*}{} & \multirow{3}{*}{$\mathrm{b}$} & 5,2 & 34,2 & 64,1 & 90,1 \\
\cline { 3 - 6 } & & 6,7 & 39,7 & 64,1 & 90,1 \\
\cline { 3 - 6 } & & 5,0 & 31,8 & 64,1 & 90,3 \\
\cline { 3 - 6 } & & 6,2 & 36,5 & 64,1 & 90,3 \\
\cline { 3 - 6 } & \multirow{3}{*}{$\mathrm{c}$} & 7,7 & 46,6 & 74,7 & 90,3 \\
\cline { 3 - 6 } & & 5,0 & 31,8 & 64,1 & 90,3 \\
\cline { 3 - 6 } & & 6,2 & 36,5 & 64,1 & 90,3 \\
\cline { 3 - 6 } & & 7,7 & 46,6 & 74,7 & 90,3 \\
\hline
\end{tabular}

\begin{tabular}{|c|c|c|c|c|c|}
\hline & \multirow{2}{*}{$\begin{array}{c}\text { Alpha/ } \\
\text { Theta }\end{array}$} & \multicolumn{4}{|c|}{ Taxa Preenchimento } \\
\hline & & $0 \%$ & $5 \%$ & $10 \%$ & $20 \%$ \\
\hline \multirow{9}{*}{ Exp2 } & \multirow{3}{*}{ a } & 3,2 & 37,5 & 72,4 & 89,7 \\
\hline & & 3,5 & 41,2 & 72,4 & 89,7 \\
\hline & & 7,3 & 56,5 & 77,1 & 89,7 \\
\hline & \multirow{3}{*}{ b } & 3,5 & 35,4 & 71,2 & 92,3 \\
\hline & & 4,5 & 40,7 & 71,2 & 92,3 \\
\hline & & 14,7 & 83,4 & 83,4 & 92,3 \\
\hline & \multirow{3}{*}{ c } & 3,5 & 35,4 & 71,2 & 92,3 \\
\hline & & 4,5 & 40,7 & 71,2 & 92,3 \\
\hline & & 14,7 & 83,4 & 83,4 & 92,3 \\
\hline & \multirow{2}{*}{$\begin{array}{c}\text { Alpha/ } \\
\text { Theta }\end{array}$} & \multicolumn{4}{|c|}{ Taxa Preenchimento } \\
\hline & & $0 \%$ & $5 \%$ & $10 \%$ & $20 \%$ \\
\hline \multirow{9}{*}{ Exp3 } & \multirow{3}{*}{ a } & 2,5 & 39,6 & 76,2 & 89,2 \\
\hline & & 2,8 & 43,8 & 76,2 & 89,2 \\
\hline & & 5,6 & 55,7 & 79,9 & 89,2 \\
\hline & \multirow{3}{*}{$\mathrm{b}$} & 2,7 & 36,8 & 78,4 & 89,7 \\
\hline & & 3,4 & 42,8 & 78,4 & 89,7 \\
\hline & & 10,1 & 72,0 & 89,7 & 89,7 \\
\hline & \multirow{3}{*}{ c } & 2,7 & 36,8 & 78,4 & 89,7 \\
\hline & & 3,4 & 42,8 & 78,4 & 89,7 \\
\hline & & 10,1 & 72,0 & 89,7 & 89,7 \\
\hline
\end{tabular}

\begin{tabular}{|c|c|c|c|c|c|}
\hline \hline \multirow{8}{*}{$\begin{array}{c}\text { Alpha/ } \\
\text { Theta }\end{array}$} & \multicolumn{4}{|c|}{ Taxa Preenchimento } \\
\cline { 3 - 6 } & \multirow{3}{*}{ a } & $0 \%$ & $5 \%$ & $10 \%$ & $20 \%$ \\
\hline \multirow{4}{*}{ Exp4 } & 1,5 & 42,6 & 72,2 & 88,7 \\
\cline { 3 - 6 } & \multirow{3}{*}{$\mathrm{b}$} & 1,7 & 46,3 & 72,2 & 88,7 \\
\cline { 3 - 6 } & & 2,2 & 49,1 & 72,2 & 88,7 \\
\cline { 3 - 6 } & & 1,6 & 40,1 & 73,2 & 89,2 \\
\cline { 3 - 6 } & \multirow{3}{*}{$\mathrm{c}$} & 2,1 & 45,7 & 73,2 & 89,2 \\
\cline { 3 - 6 } & & 2,5 & 58,1 & 77,6 & 89,2 \\
\cline { 3 - 6 } & & 2,6 & 40,1 & 73,2 & 89,2 \\
\cline { 3 - 6 } & & 2,5 & 58,1 & 73,6 & 89,2 \\
\hline
\end{tabular}


processamento.

Nos gráficos ilustrados nas Figuras 6.8, 6.9, 6.10 e $6.11^{8}$ é apresentada a porcentagem de frases que tiveram algum problema de processamento durante a construção das tabelas geradas nos experimentos Exp1, Exp2, Exp3 e Exp4, no conjunto de teste. Nesses gráficos é apresentada a taxa de frases não processadas ou processadas parcialmente, a partir dos atributos identificados utilizando limiares 0\%, 5\%, 10\% e 20\%.

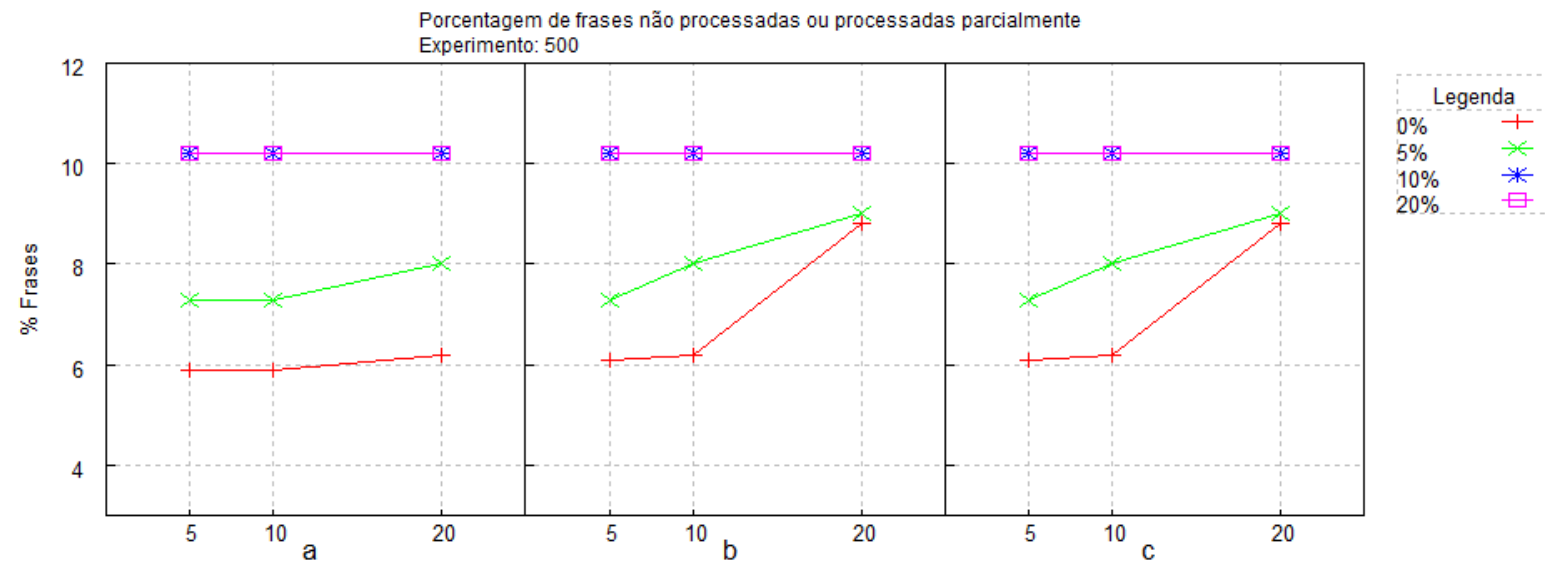

Figura 6.8: Garbage correspondente ao experimento Exp1, usando 4009 frases do conjunto Te

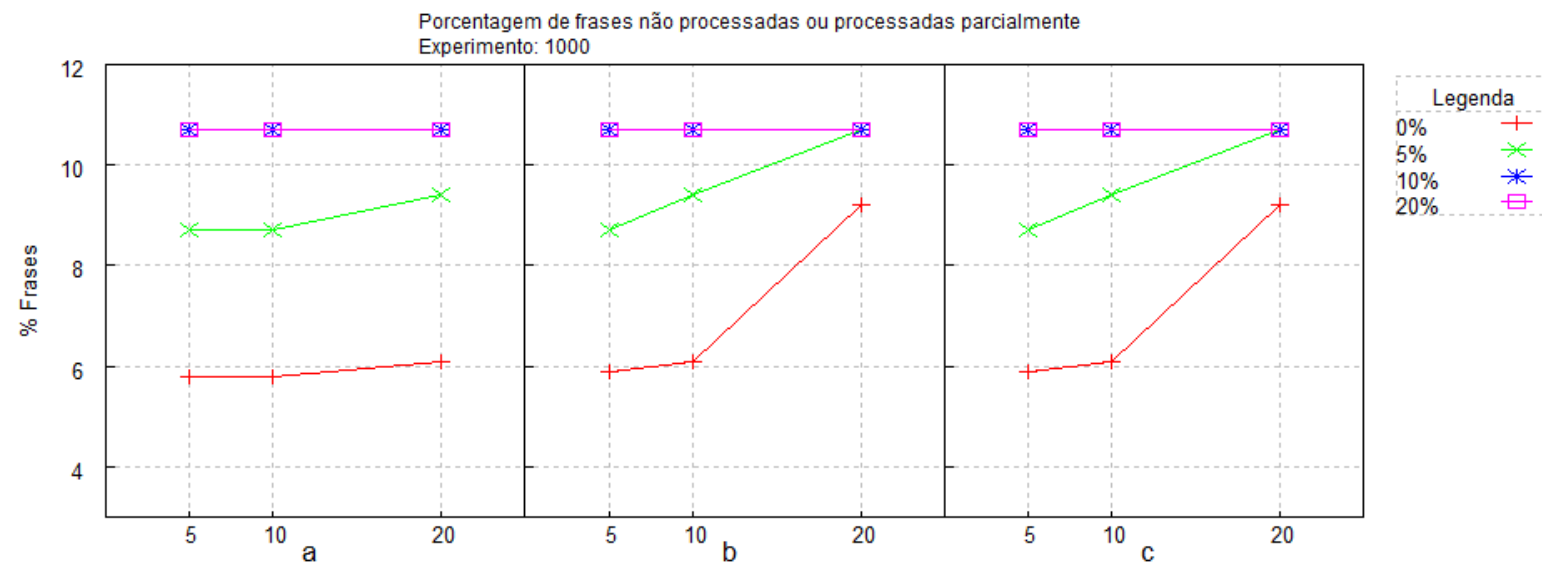

Figura 6.9: Garbage correspondente ao experimento Exp2, usando 4011 frases do conjunto Te

É possivel notar que, usando limiar 0\%, uma porcentagem baixa de frases foram processadas parcialmente ou não foram processadas, ou seja, a maioria das frases foi processada completamente. Isso se deve ao fato de que os atributos identificados mapeiam quase todas informações dos conjuntos de

\footnotetext{
${ }^{8}$ Ver Tabelas A.5, A.10, A.15 e A.20 no Apêndice.
} 


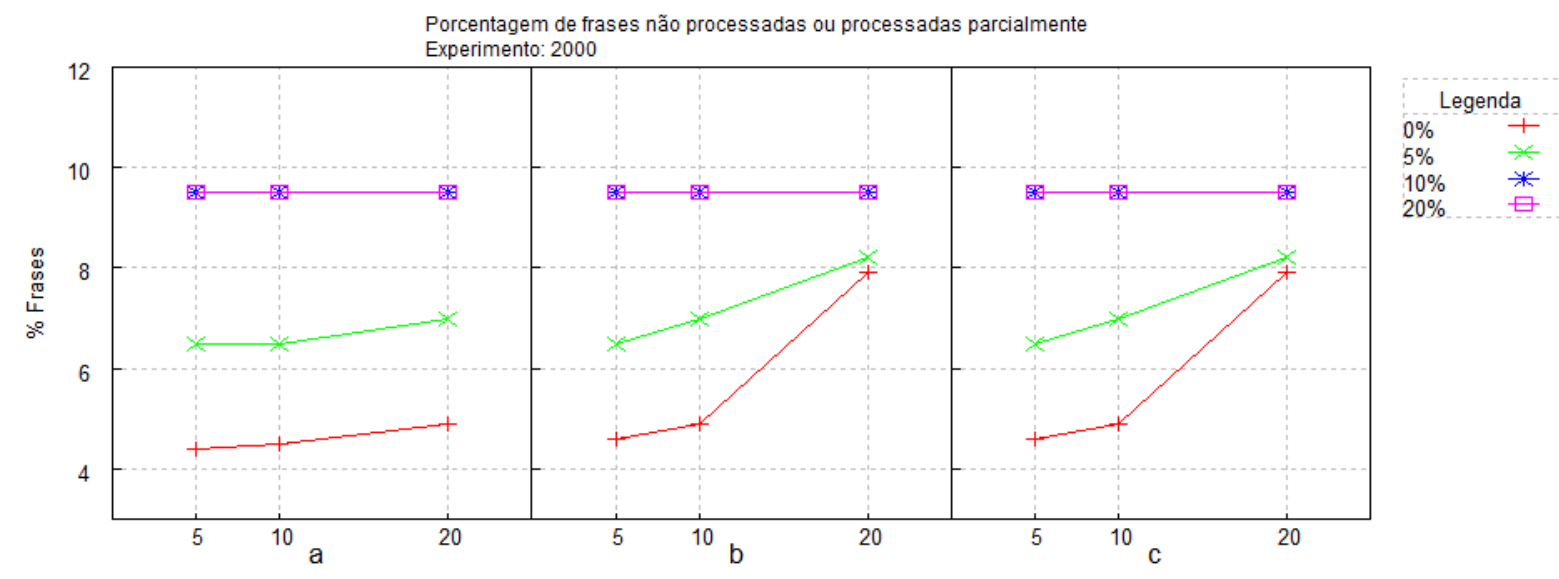

Figura 6.10: Garbage correspondente ao experimento Exp3, usando 3998 frases do conjunto Te

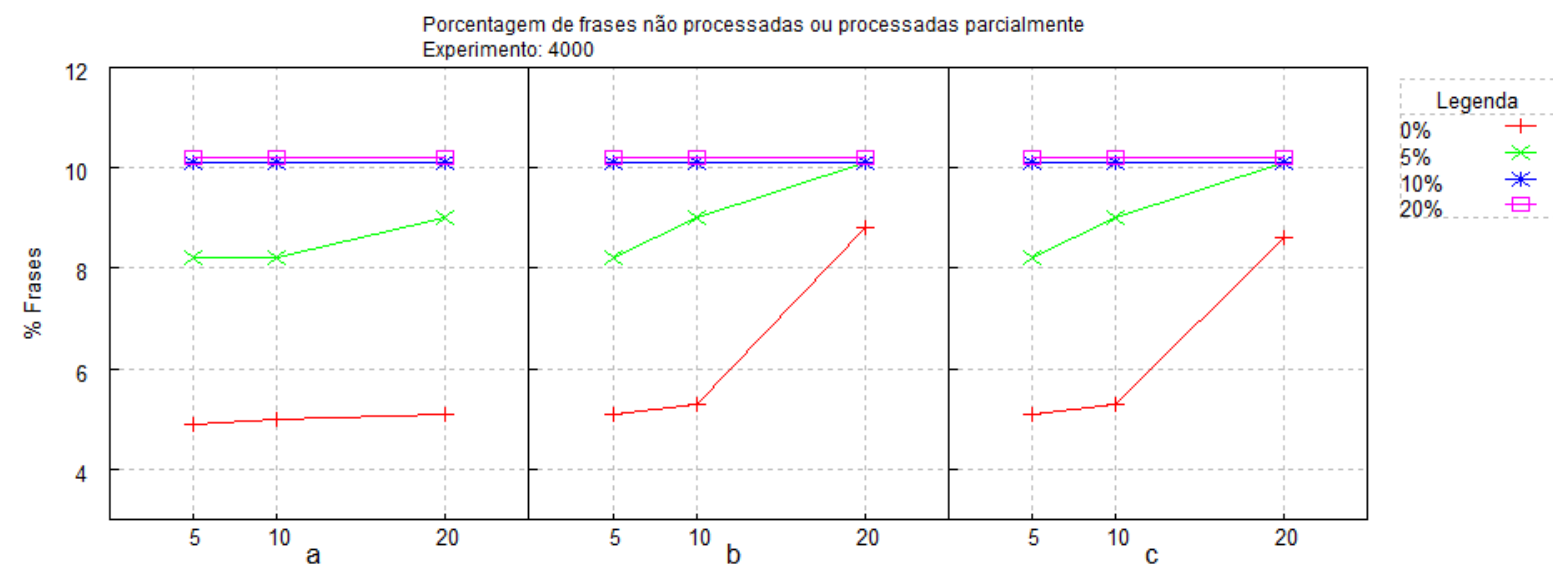

Figura 6.11: Garbage correspondente ao experimento Exp4, usando 4013 frases do conjunto Te

documentos. Usando o limiar de 5\% a taxa de frases processadas parcialmente ou não processadas já é maior, pois, conforme a poda da árvore fica maior, o número de atributos considerados diminui. Assim, aquelas frases que contêm atributos pouco freqüentes não serão completamente processadas. Em outras palavras, os resultados obtidos são esperados. Entretando, é interessante observar que essa porcentagem de frases não processadas ou processadas parcialmente se estabiliza em aproximadamente 10\% em todos os experimentos para limiares de poda de 10\% e 20\% das árvores responsáveis pela identificação dos atributos.

Os gráficos apresentados referem-se ao garbage gerado utilizando o conjunto de documentos de teste, que possuem aproximadamente 4000 frases. Assim, pode ser observado que em todos os experimentos aproximadamente 400 frases ficam sem processar ou são processadas parcialmente para limiares de poda de $10 \%$ ou superior. 
Também foi medido o número de frases processadas parcialmente ou não processadas utilizando o próprio conjunto de treinamento, i.e., o conjunto de 500 (2002 frases), 1000 (3995 frases), 2000 (8005 frases) e 4000 (15990 frases) documentos. Exceto para o conjunto de treinamento de 500 documentos, os resultados são semelhantes aos obtidos utilizando os conjuntos de testes com os 1000 documentos correspondentes a cada experimento.

\subsubsection{Aspecto Qualitativo}

Como mencionado, os experimentos foram realizados sem nenhuma intervenção do especialista. Em outras palavras, o ambiente computacional TP-Discover que implementa a metodologia (Honorato \& Monard, 2008b) foi executado utilizando somente conhecimento sintático e procedimentos heurísticos para identificar as unidades terminológicas. Assim, o aspecto qualitativo considerado refere-se a qualidade dessas unidades terminológicas.

De modo a avaliar a qualidade dos termos extraídos pelo método de extração de terminologia que foram utilizados como termos raiz das árvores usadas para a identificação dos atributos, foram realizados os cálculos de precisão e recall das listas de termos geradas. Para que pudessem ser realizados esses cálculos, foi utilizada uma lista de referência considerando somente as informações contidas nos documentos da seção de esôfago, na qual constam os termos que estávamos interessados em identificar na nossa abordagem de extração de terminologia.

Nos gráficos 6.12, 6.13, 6.14 e 6.159 são apresentados os resultados para identificação de termos utilizando os respectivos conjuntos de documentos a partir dos experimentos Exp1, Exp2, Exp3 e Exp4, respectivamente. É importante lembrar que esses valores de precisão e recall correspondem ao pior caso da aplicação da metodologia, uma vez que não houve nenhuma interação com o especialista para validar os termos que foram extraídos usando a abordagem híbrida de extração de terminologia juntamente com a aplicação de heurísticas. Com uma interação com os especialistas poderiam ser removidos termos que não são de interesse ou termos da língua geral.

Esses gráficos representam a precisão (eixo $y$ ) e recall (eixo $x$ ) que foram alcançados utilizando as variações de Alpha e Theta, descritas na Tabela 6.2 na página 82. Para distinguir os resultados, os valores de Theta são mostrados entre parênteses.

Conforme pode ser observado, não ocorrem variações muito grandes nas medidas de precisão e recall entre os diferentes, e correspondentes experi-

\footnotetext{
${ }^{9}$ Ver Tabelas A.2, A.7, A.12 e A.17 no Apêndice.
} 


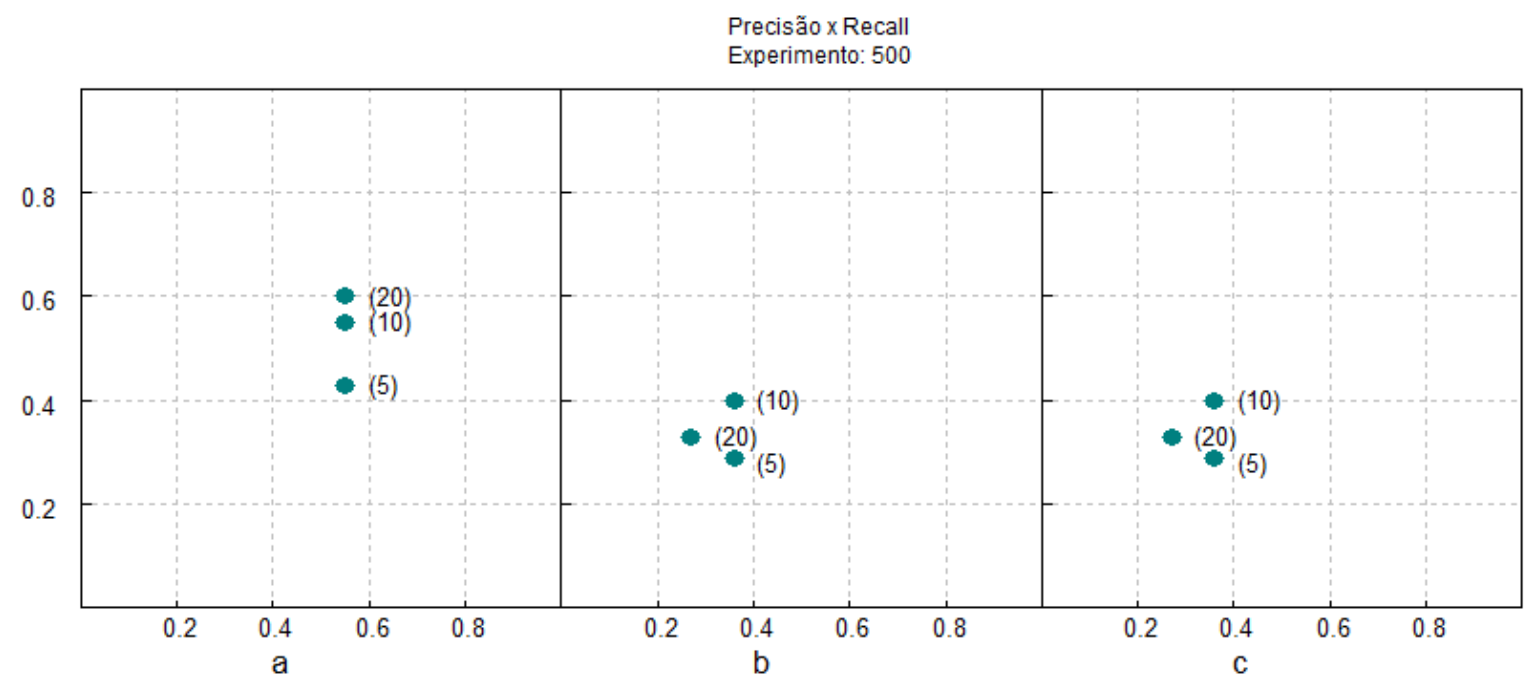

Figura 6.12: Precisão e recall para o experimento Exp1

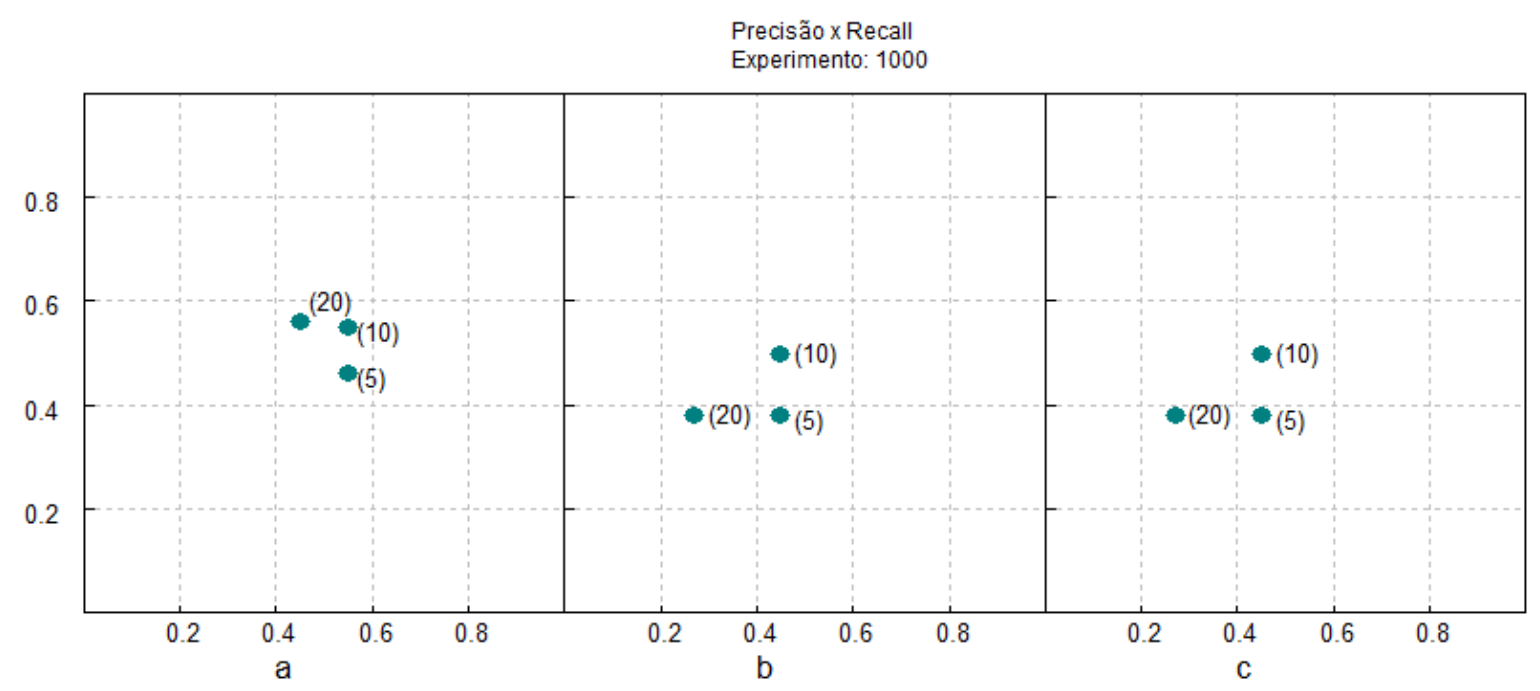

Figura 6.13: Precisão e recall para o experimento Exp2

mentos. Porém, nota-se que o melhor recall foi alcançado utilizando o valor de Alpha igual a 100\% nos experimentos Exp1 e Exp4, usando Theta igual a $5 \%$ e $10 \%$. Deve ser levado em conta que devido ao uso de um vocabulário controlado, o uso de conjunto de laudo de tamanhos diferentes para a extração de terminologia de interesse não influenciou muito e, em alguns casos até degradou a precisão, porque termos não interessantes foram colocados na lista devido sua alta freqüência no conjunto de documentos. Esse tipo de problema seria facilmente solucionado se o TP-DISCOVER fosse executado com a participação do especialista.

Analisando a lista de referência do conjunto de documentos correspondentes a seção de esôfago, foi possivel observar que a maioria dos termos fornecidos são unigramas e, usando Alpha igual a 100\%, a identificação desses 


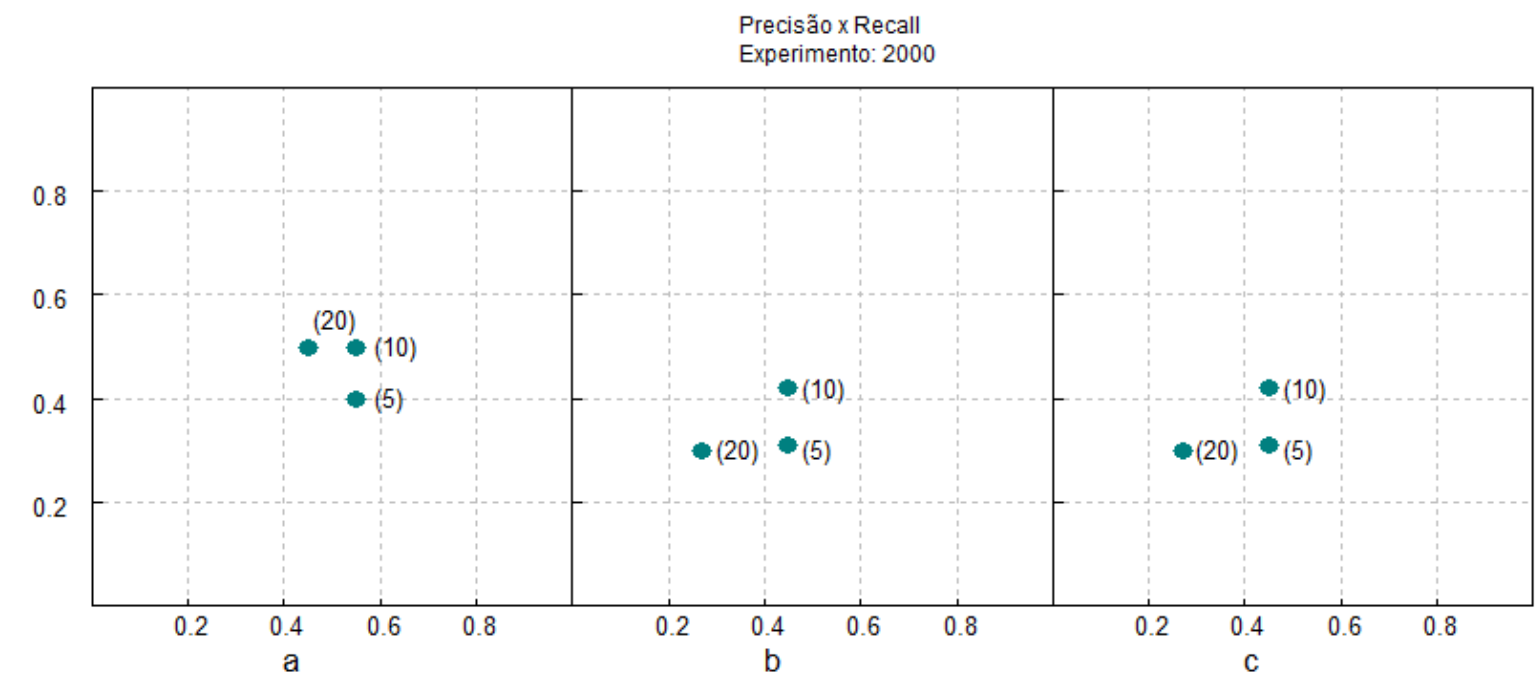

Figura 6.14: Precisão e recall para o experimento Exp3

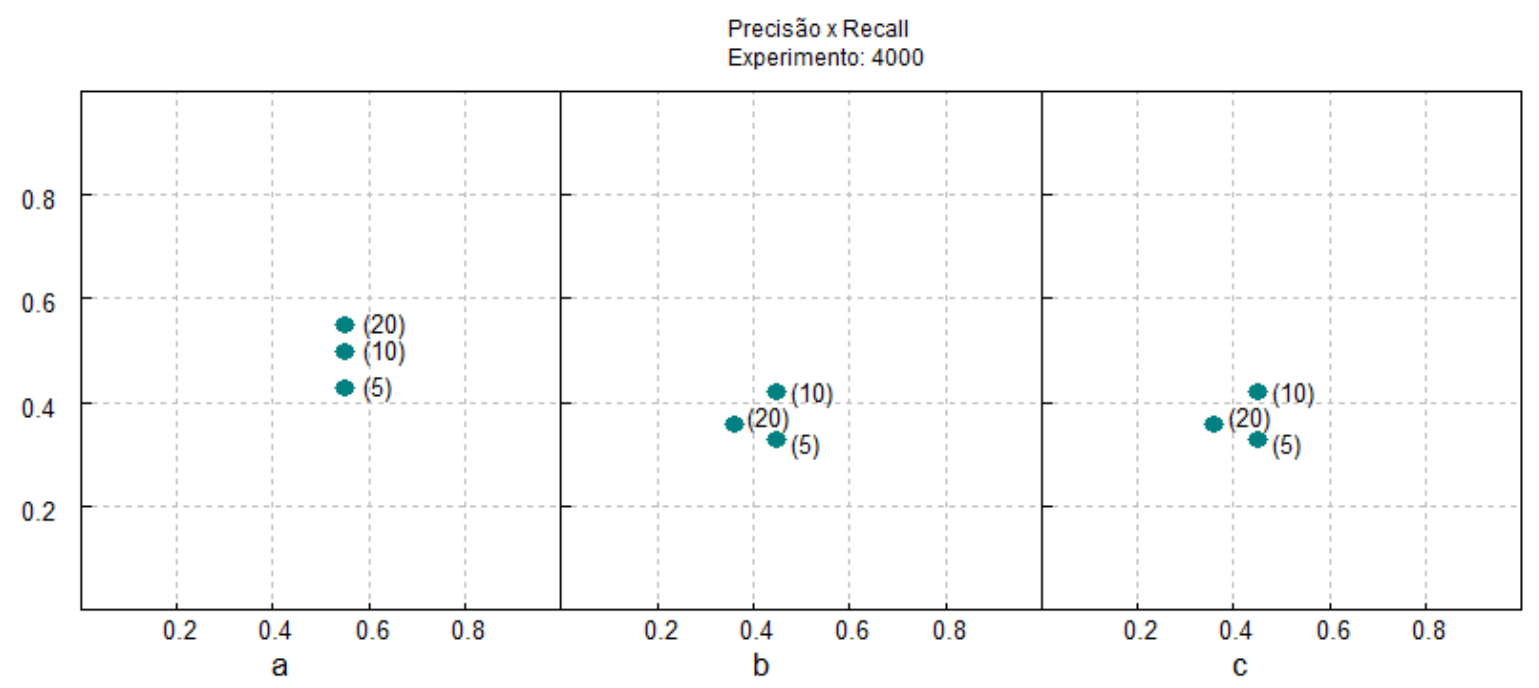

Figura 6.15: Precisão e recall para o experimento Exp4

termos foi favorecida. Por outro lado, usando Alpha igual a 95\% e 90\%, a identificação de bigramas é favorecida. Isso faz com que alguns termos que são identificados usando Alpha igual a 100\%, não o são quando é usado Alpha igual a 95\% e 90\%, pois pode ocorrer que esses termos sejam extraídos juntamente com outro termo.

Por exemplo, o termo calibre, que faz parte da lista de referência, é identificado com Alpha igual a 100\%, mas não é identificado quando Alpha é igual a 95\% e 90\%, pois o método para identificar unidades terminológicas considerao conjuntamente com o termo distensibilidade, uma vez que os dois ocorrem freqüentemente juntos.

Como mencionado, os resultados de precisão e recall poderiam ser melhorados consideravelmente caso houvesse interação com o especialista, porque, 
conforme foi observado, o número de termos identificados pelo método proposto para a extração de terminologia geralmente é baixo e, desse modo, a análise da lista de termos poderia ser realizada e corrigida rapidamente pelo especialista.

Analisando os atributos gerados, pode ser observado que poderiam ser aplicadas algumas padronizações no conjunto de documentos com o auxílio do especialista, considerando o significado dos atributos. Na Tabela 6.6 são ilustradas algumas padronizações, que denominados de substituições, que poderiam ser aplicadas pelo especialista de modo a melhorar a qualidade dos atributos ou reduzir o número de atributos que seriam identificados.

Tabela 6.6: Possíveis padronizações indicadas pelo especialista

\begin{tabular}{|c|c|c|}
\hline Id & Frases sem padronização & Frases padronizadas \\
\hline \hline 1 & $\begin{array}{c}\text { Teg nível de pinçamento diafragmático } \\
\text { Teg próxima pinçamento diafragmático } \\
\text { Teg pormal }\end{array}$ & $\begin{array}{c}\text { Calibre normal } \\
\text { Distensibilidade normal }\end{array}$ \\
\hline 2 & Calibre distensibilidade normais & $\begin{array}{c}\text { Mucosa terço superior normal } \\
\text { Mucosa terço médio normal } \\
\text { Mucosa terço inferior normal }\end{array}$ \\
\hline 3 & Mucosa aspecto normal toda extensão \\
\hline
\end{tabular}

Conforme pode ser observado nessa tabela, muitas frases que ocorrem freqüentemente poderiam ser padronizadas para uma única frase (caso 1). Por outro lado, frases que mapeiam mais de um evento na mesma frase (caso 2 e 3) poderiam ser padronizadas de modo que os eventos fossem mapeados separadamente.

As padronizações ilustradas nessa tabela poderiam ser facilmente identificadas pelo especialista por meio da análise das árvores que são geradas e são mostradas graficamente pelo TP-DISCOVER. Dessa maneira, a qualidade dos atributos poderia ser melhorada consideravelmente, em relação à abordagem na qual não é utilizado o auxílio do especialista.

\subsection{Resultados - Seção de Estômago}

Nessa seção são apresentados e discutidos os resultados obtidos na aplicação da metodologia sobre os conjuntos de laudos de estômago, divididos conforme experimentos citados na Seção 6.2.

\subsubsection{Aspecto Quantitativo}

Analogamente ao experimento realizado com a seção de esôfago - Tabela 6.3 da página 84 , de modo a comprovar a hipótese de que o conjunto de do- 
cumentos é formado por frases assertivas e utiliza um vocabulário controlado, foram gerados os CFUs na fase de pré-processamento usando os quatro conjuntos de treinamento. Na Tabela 6.7 são apresentados o número de frases do CFUs após cada etapa da fase de pré-processamento.

Tabela 6.7: Resultados dos CFUs da seção de estômago

\begin{tabular}{|c|c|c|c|c|c|c|}
\hline $\begin{array}{c}\text { Doc. } \\
\mathrm{Tr}\end{array}$ & $\begin{array}{c}\text { Frases } \\
a_{1}\end{array}$ & $\begin{array}{c}\text { Num. CFU } \\
a_{2}\left(\% a_{1}-a_{2}\right)\end{array}$ & $\begin{array}{c}\text { Num. CFU } \\
\text { Padronizado } \\
a_{3}\left(\% a_{2}-a_{3}\right)\end{array}$ & $\begin{array}{c}\text { Num. CFU Pad. } \\
\text { Corrigido } \\
a_{4}\left(\% a_{3}-a_{4}\right)\end{array}$ & $\begin{array}{c}\text { Redução no } \\
\text { pré-proc. } \\
\left(\% a_{2}-a_{4}\right)\end{array}$ & $\begin{array}{c}\text { Redução } \\
\text { total } \\
\left(\% a_{1}-a_{4}\right)\end{array}$ \\
\hline 500 & 4006 & $256(93,61 \%)$ & $251(2,0 \%)$ & $232(7,6 \%)$ & $9,40 \%$ & $94,20 \%$ \\
\hline 1000 & 7962 & $403(94,94 \%)$ & $394(2,2 \%)$ & $355(9,9 \%)$ & $11,90 \%$ & $95,50 \%$ \\
\hline 2000 & 15911 & $711(95,53 \%)$ & $693(2,5 \%)$ & $629(9,2 \%)$ & $11,50 \%$ & $96,00 \%$ \\
\hline 4000 & 31867 & $1217(96,18 \%)$ & $1169(3,9 \%)$ & $1045(10,6 \%)$ & $14,10 \%$ & $96,70 \%$ \\
\hline
\end{tabular}

Como pode ser observado, o número de frases em cada um dos quatro conjuntos de documentos de treinamento considerados é aproximadamente o dobro que o número de frases da seção de esôfago. Entretando, após o préprocessamento, o número final de frases diferentes também constitui menos de $5 \%$ do total de frases nos diferentes conjuntos de documentos utilizados, como no caso da seção de esôfago. Esse resultado comprova a hipótese de que está sendo utilizado um vocabulário controlado e são utilizadas frases assertivas no mapeamento das informações do estômago, assim como foi constatado na seção de esôfago.

Quanto aos resultados da aplicação do algoritmo de correção ortográfica desenvolvido neste trabalho, os resultados são apresentados na Tabela 6.8.

Tabela 6.8: Correção ortográfica

\begin{tabular}{|c|c|c|}
\hline $\begin{array}{c}\text { Doc. } \\
\text { Tr }\end{array}$ & $\begin{array}{c}\text { Num. sugestões } \\
\text { identificadas }\end{array}$ & $\begin{array}{c}\text { Num. sugestões } \\
\text { corretas }\end{array}$ \\
\hline 500 & 51 & $20(39,2 \%)$ \\
\hline 1000 & 74 & $35(47,3 \%)$ \\
\hline 2000 & 99 & $54(54,5 \%)$ \\
\hline 4000 & 131 & $79(60,3 \%)$ \\
\hline
\end{tabular}

Comparando esses resultados com os obtidos para a seção de esôfago Tabela 6.4 na página 85, é possível observar que a porcentagem de acertos é sempre maior para a seção de esôfago, incrementando também com o número de documentos considerados, atingindo uma taxa de acerto de $60,3 \%$ quando o maior número de documentos é utilizado nos experimentos, para o conjunto de treinamento.

Todos os experimentos tiveram a mesma configuração dos experimentos realizados com a seção de esôfago. Assim, após realizar o pré-processamento no conjunto de documentos, primeiramente foram identificados os termos raiz, depois foram geradas as árvores utilizando esses termos e em seguida foram identificados os atributos utilizando os limiares de poda. 
Na Figura 6.16 é ilustrado o gráfico que mostra a relação entre o número de termos raiz identificados e o número de atributos gerados utilizando o limiar de poda $0 \%$, para os experimentos realizados. Nessa figura é possível observar

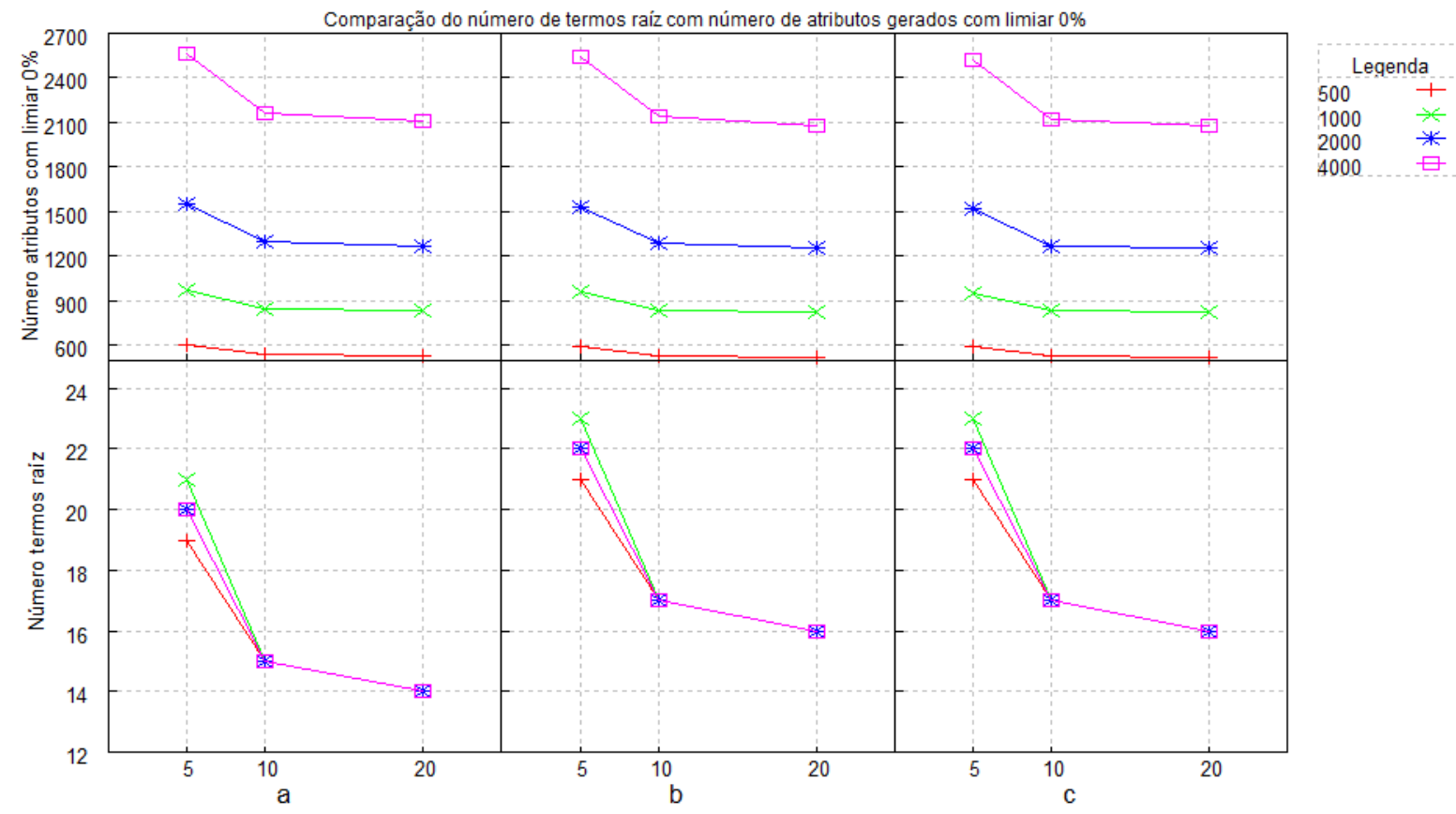

Figura 6.16: Relação entre número de termos raiz e número de atributos gerados utilizando limiar igual a $0 \%$

que o número de atributos é maior do que o número identificado na seção de esôfago. É possível observar que usando as variações $a, b$ e $c$ de Alpha e Theta — Tabela 6.2 na página 82 - os resultados não variaram muito. Isso indica que as listas de termos raiz identificadas não foram muito diferentes.

Analogamente aos experimentos da seção de esôfago, é possivel observar no gráfico que quanto maior o número de documentos do conjunto de treinamento, maior o número de atributos identificados. Isso se deve a mesma razão descrita nos experimentos do esôfago, ou seja, quanto mais documentos forem utilizados para gerar as árvores, existirão mais variações no contexto de um determinado termo raiz e, conseqüentemente, mais ramos serão criados a partir desse termo. Por outro lado, o número de termos raiz não variou muito nos experimentos. Apenas o número de atributos para as configurações $b$ e $c$ de Alpha e Theta foi um pouco maior.

Para avaliar o número de atributos que são considerados em relação ao número total identificado com o limiar de poda igual a $0 \%$, foram utilizados os limiares de 5\%, 10\% e 20\%. Nas Figuras $6.17,6.18$ e $6.19^{10}$ são ilustrados os gráficos que mostram o número de atributos considerados usando esses

\footnotetext{
${ }^{10}$ Ver Tabelas B.1, B.6, B.11 e B.16 no Apêndice.
} 
limiares.

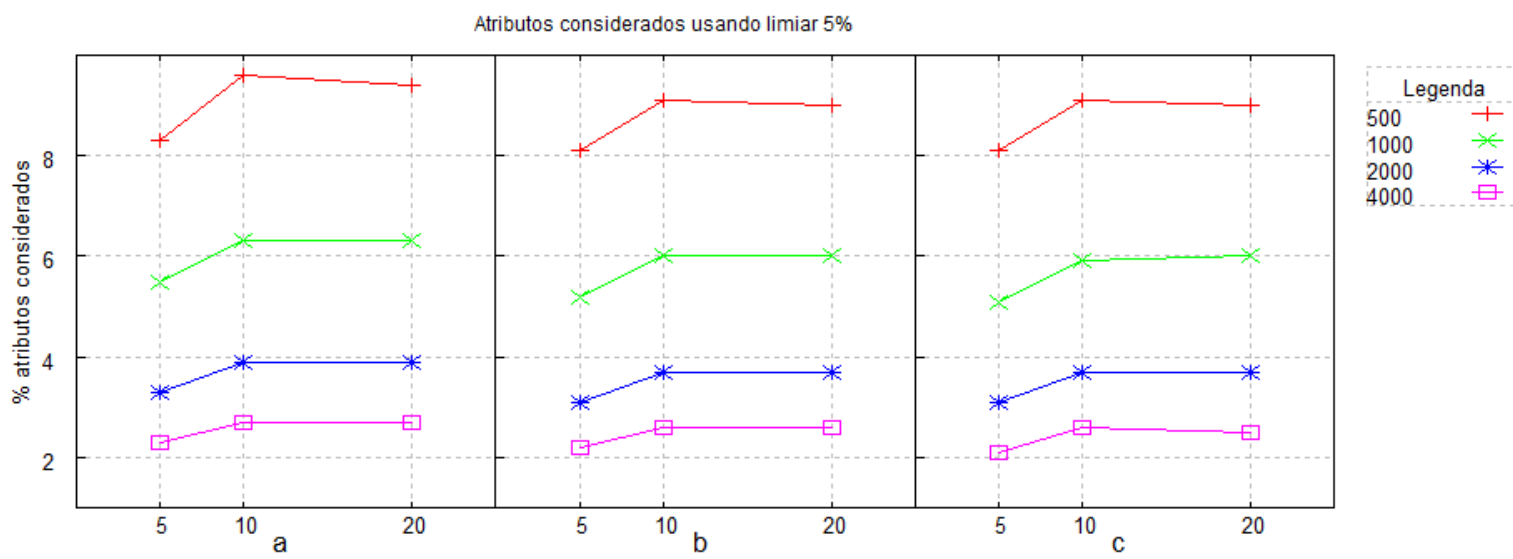

Figura 6.17: Taxa de atributos considerados utilizando limiar igual a 5\%

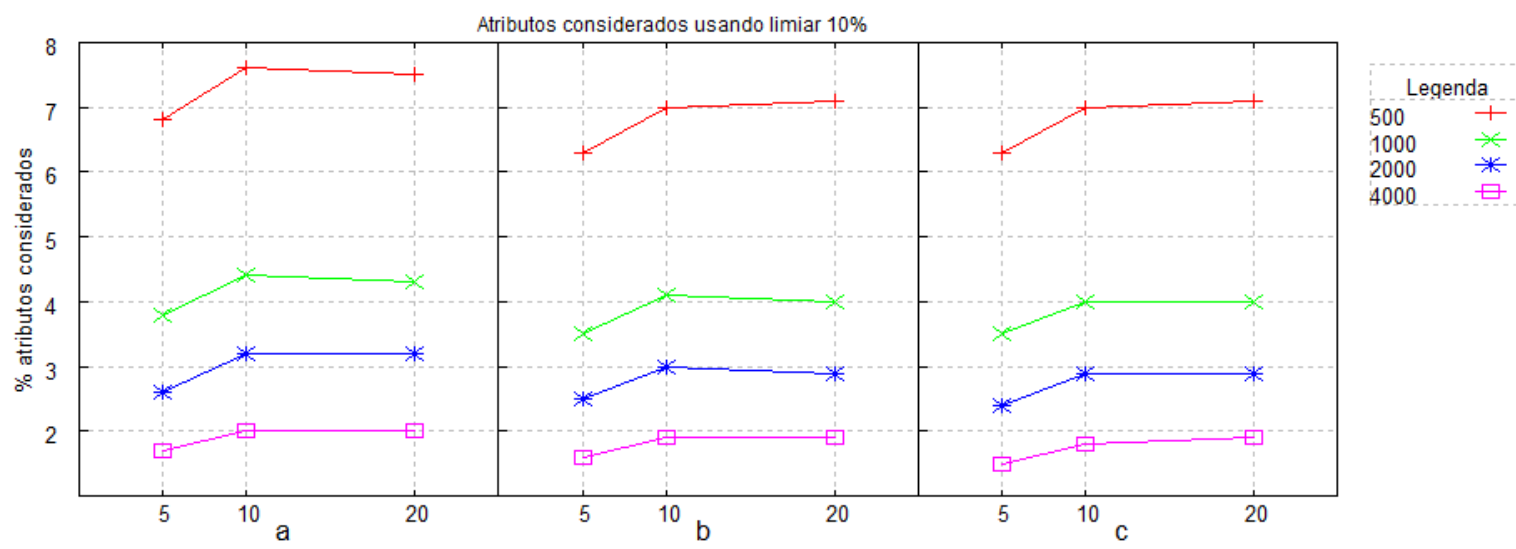

Figura 6.18: Taxa de atributos considerados utilizando limiar igual a 10\%

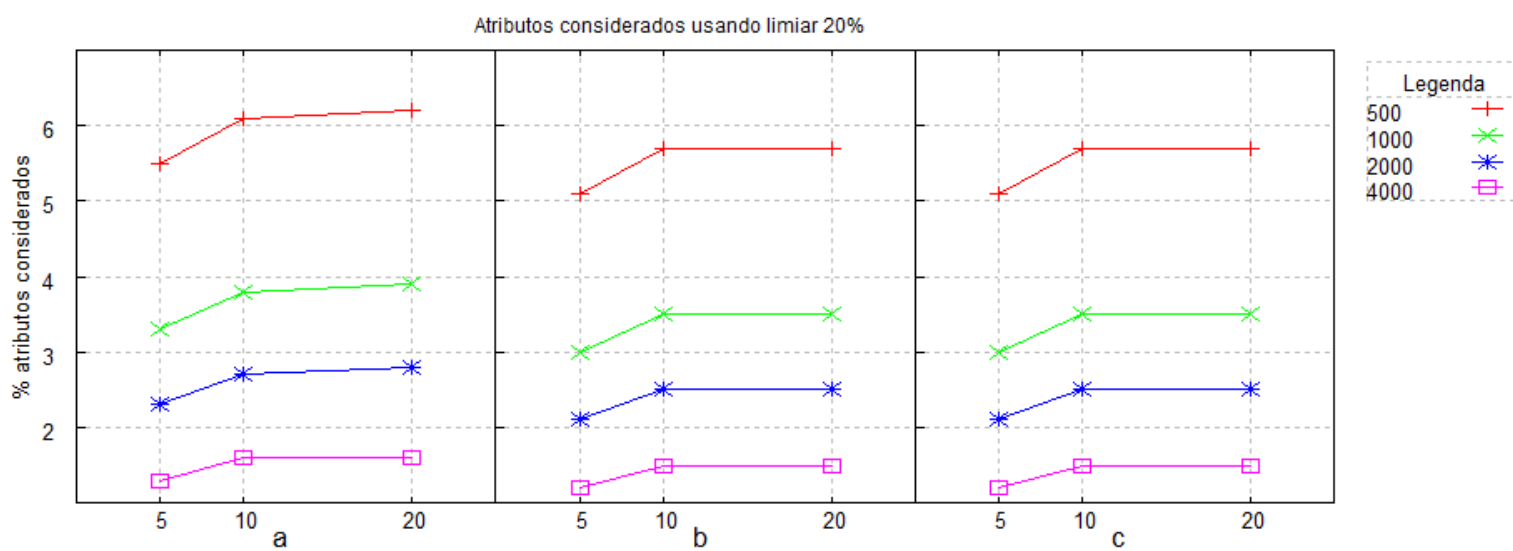

Figura 6.19: Taxa de atributos considerados utilizando limiar igual a 20\%

Utilizado o limiar de 5\%, a taxa de atributos considerados em relação ao número total gerado é maior, uma vez que grande parte dos ramos das árvores 
possuem freqüência maior ou igual que 5\%. Da mesma maneira que aconteceu nos experimentos do esôfago, a taxa de atributos considerados para o conjunto de treinamento do experimento Exp4 é menor, uma vez que usando esse conjunto de treinamento é gerado um número consideravelmente maior de ramos do que o experimento Exp1.

Embora a taxa de atributos considerados pareça maior para o experimento Exp1 do que para o Exp4, é possível observar que o número de atributos não varia muito entre esses experimentos ${ }^{11}$. Essa característica deve-se às mesmas razões apresentadas nos experimentos da seção de esôfago.

Por outro lado, no caso em que são considerados somente ramos que possuem freqüência maior ou igual a 10\%, o número de atributos considerados é menor, uma vez que estão sendo considerados os ramos que com freqüência maior ou igual a $10 \%$ do número de laudos. Isso se confirma no gráfico da Figura 6.19 (limiar de poda de 20\%), no qual o número de atributos considerados é menor que para os limiares de $5 \%$ e $10 \%$.

Após identificados os atributos utilizando os diferentes limiares $(0 \%, 5 \%$, $10 \%$ e $20 \%$ ) foi realizada a construção do dicionário e o preenchimento da tabela atributo-valor. Na Tabela 6.9 são apresentadas as taxas de preenchimento das tabelas geradas nos experimentos Exp1, Exp2, Exp3 e Exp4, respectivamente, usando o conjunto de teste.

Analogamente aos resultados da seção de esôfago, usando limiar 0\%, a taxa de preenchimento foi bastante baixa, ou seja, tem-se uma tabela bastante esparsa. Por outro lado, conforme o valor do limiar de poda aumenta (5\%, $10 \%$ e $20 \%$ ), a taxa de preenchimento é incrementada, uma vez que o número de atributos é menor quando se usa limiares maiores.

Nos gráficos ilustrados nas Figuras 6.20, 6.21, 6.22 e 6.23 ${ }^{12}$ são apresentadas a porcentagem de frases que tiveram algum problema de processamento durante a construção das tabelas geradas nos experimentos Exp1, Exp2, Exp3 e Exp4, no conjunto de teste. Analogamente aos experimentos com a seção de esôfago, nesses gráficos são apresentadas a taxa de frases não processadas ou processadas parcialmente, a partir dos atributos identificados utilizando limiares $0 \%, 5 \%, 10 \%$ e $20 \%$.

É possivel notar que, usando limiar 0\%, uma porcentagem baixa de frases não são processadas, ou são processadas parcialmente. Conforme aumenta o limiar de poda da árvore, um número cada vez maior de frases são processadas parcialmente ou não são processadas, de modo semelhante ao que foi constatado na seção de esôfago. Porém, pode ser observado, que em todos

\footnotetext{
${ }^{11}$ Ver Tabelas B.1, B.6, B.11 e B. 16 no Apêndice

${ }^{12}$ Ver Tabelas B.5, B.10, B. 15 e B.20 no Apêndice.
} 
Tabela 6.9: Taxa de preenchimento do conjunto de teste para os experimentos Exp1, Exp2, Exp3 e Exp4

\begin{tabular}{|c|c|c|c|c|c|}
\hline & \multirow{2}{*}{$\begin{array}{c}\text { Alpha/ } \\
\text { Theta }\end{array}$} & \multicolumn{4}{|c|}{ Taxa Preenchimento } \\
\hline & & $0 \%$ & $5 \%$ & $10 \%$ & $20 \%$ \\
\hline \multirow{9}{*}{ Exp1 } & \multirow{3}{*}{ a } & 4,0 & 42,7 & 52,7 & 62,1 \\
\hline & & 4,4 & 42,7 & 52,7 & 62,1 \\
\hline & & 4,4 & 44,1 & 53,7 & 62,1 \\
\hline & \multirow{3}{*}{ b } & 3,5 & 40,1 & 50,4 & 58,9 \\
\hline & & 3,9 & 40,1 & 50,4 & 58,9 \\
\hline & & 4,0 & 40,9 & 50,4 & 58,9 \\
\hline & \multirow{3}{*}{ c } & 3,5 & 40,1 & 50,4 & 58,9 \\
\hline & & 3,9 & 40,1 & 50,4 & 58,9 \\
\hline & & 4,0 & 40,9 & 50,4 & 58,9 \\
\hline & \multirow{2}{*}{$\begin{array}{c}\text { Alpha/ } \\
\text { Theta }\end{array}$} & \multicolumn{4}{|c|}{ Taxa Preenchimento } \\
\hline & & $0 \%$ & $5 \%$ & $10 \%$ & $20 \%$ \\
\hline \multirow{9}{*}{ Exp2 } & \multirow{3}{*}{ a } & 2,4 & 40,5 & 54,7 & 60,8 \\
\hline & & 2,8 & 40,5 & 54,7 & 60,8 \\
\hline & & 2,8 & 41,1 & 55,9 & 60,8 \\
\hline & \multirow{3}{*}{ b } & 2,2 & 37,3 & 51,2 & 57,3 \\
\hline & & 2,5 & 37,3 & 51,2 & 57,3 \\
\hline & & 2,5 & 37,8 & 52,4 & 57,3 \\
\hline & \multirow{3}{*}{ c } & 2,2 & 37,8 & 52,4 & 57,3 \\
\hline & & 2,5 & 37,8 & 52,4 & 57,3 \\
\hline & & 2,5 & 37,8 & 52,4 & 57,3 \\
\hline & Alpha/ & & xa Pre & hchim & ato \\
\hline & Theta & $0 \%$ & $5 \%$ & $10 \%$ & $20 \%$ \\
\hline \multirow{9}{*}{ Exp3 } & \multirow{3}{*}{ a } & 1,7 & 45,8 & 55,1 & 61,8 \\
\hline & & 2,0 & 45,8 & 55,1 & 61,8 \\
\hline & & 2,0 & 47,3 & 56,2 & 61,8 \\
\hline & \multirow{3}{*}{ b } & 1,5 & 42,7 & 52,0 & 58,8 \\
\hline & & 1,8 & 42,7 & 52,0 & 58,8 \\
\hline & & 1,8 & 44,2 & 53,1 & 58,8 \\
\hline & \multirow{3}{*}{ c } & 1,5 & 43,4 & 53,1 & 58,8 \\
\hline & & 1,8 & 43,4 & 53,1 & 58,8 \\
\hline & & 1,8 & 44,2 & 53,1 & 58,8 \\
\hline & Alpha/ & & xa Pre & tchim & ato \\
\hline & Theta & $0 \%$ & $5 \%$ & $10 \%$ & $20 \%$ \\
\hline \multirow{9}{*}{ Exp4 } & \multirow{3}{*}{ a } & 1,0 & 41,1 & 53,3 & 63,0 \\
\hline & & 1,2 & 41,1 & 53,3 & 63,0 \\
\hline & & 1,2 & 42,2 & 54,3 & 63,0 \\
\hline & \multirow{3}{*}{ b } & 0,9 & 38,2 & 50,3 & 59,9 \\
\hline & & 1,1 & 38,2 & 50,3 & 59,9 \\
\hline & & 1,1 & 39,3 & 51,3 & 59,9 \\
\hline & \multirow{3}{*}{ C } & 0,9 & 38,7 & 51,3 & 59,9 \\
\hline & & 1,1 & 38,7 & 51,3 & 59,9 \\
\hline & & 1,1 & 39,3 & 51,3 & 59,9 \\
\hline
\end{tabular}




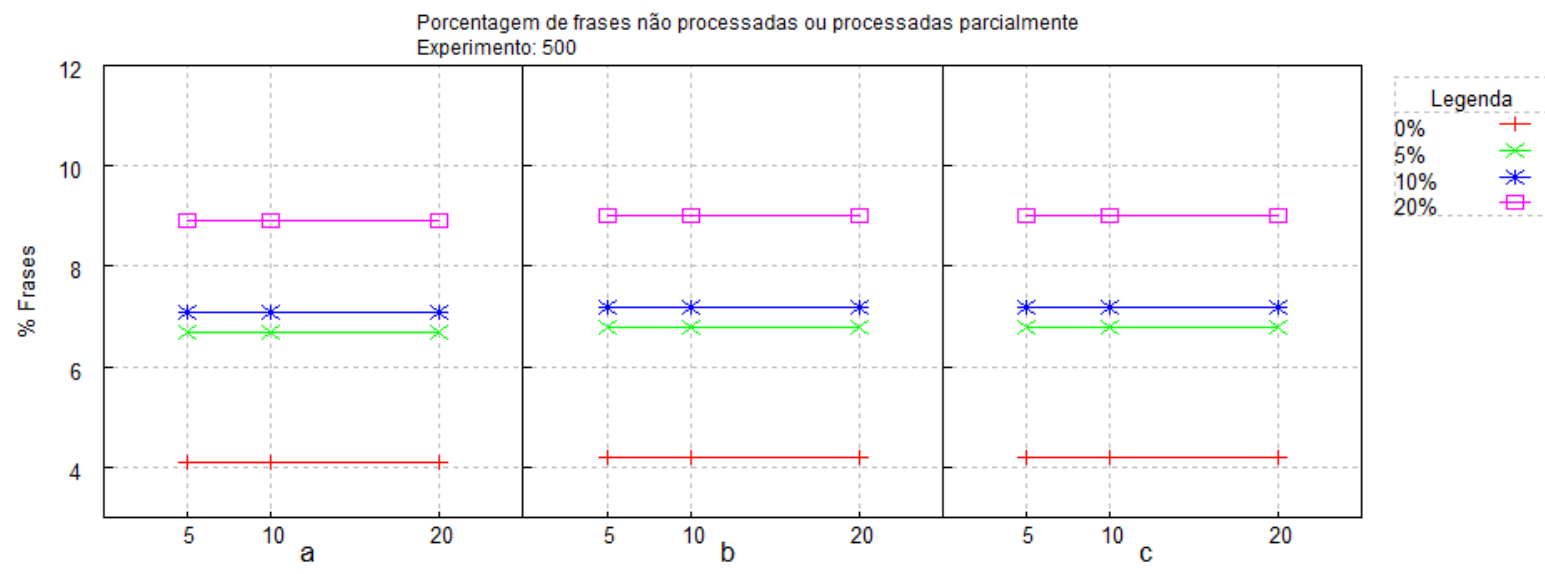

Figura 6.20: Garbage correspondente ao experimento Exp1, usando 7966 frases do conjunto Te

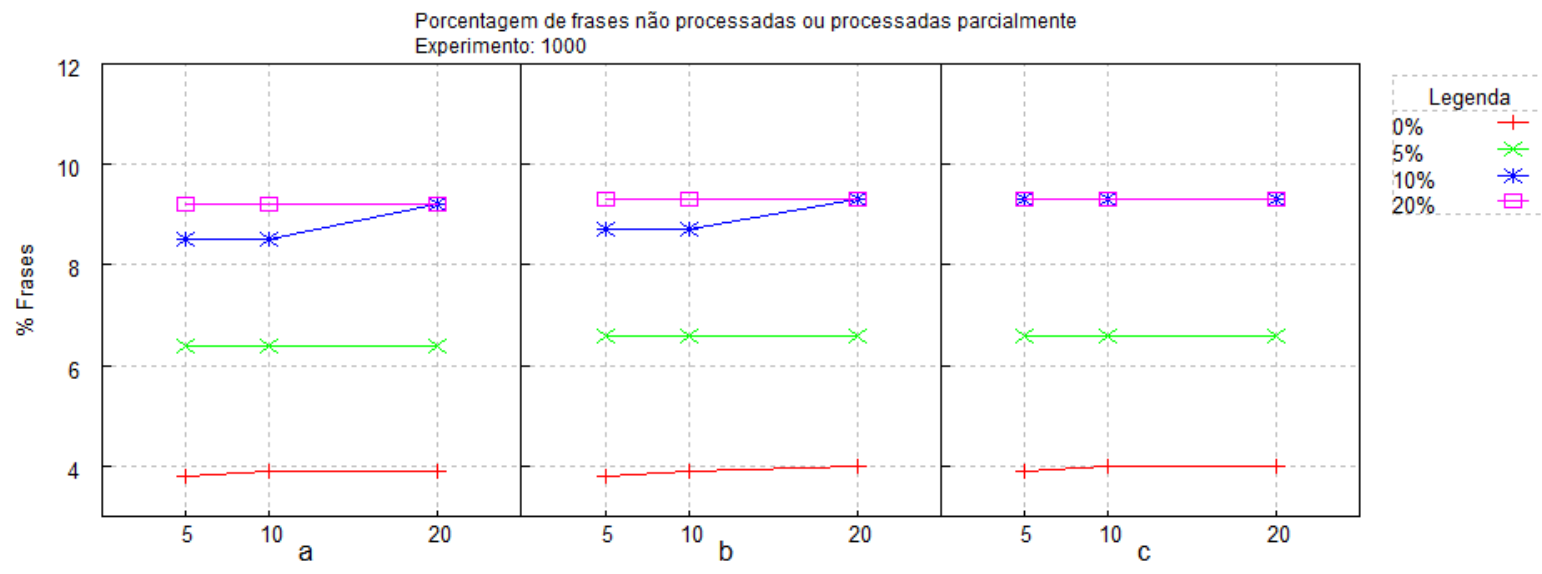

Figura 6.21: Garbage correspondente ao experimento Exp2, usando 7971 frases do conjunto Te

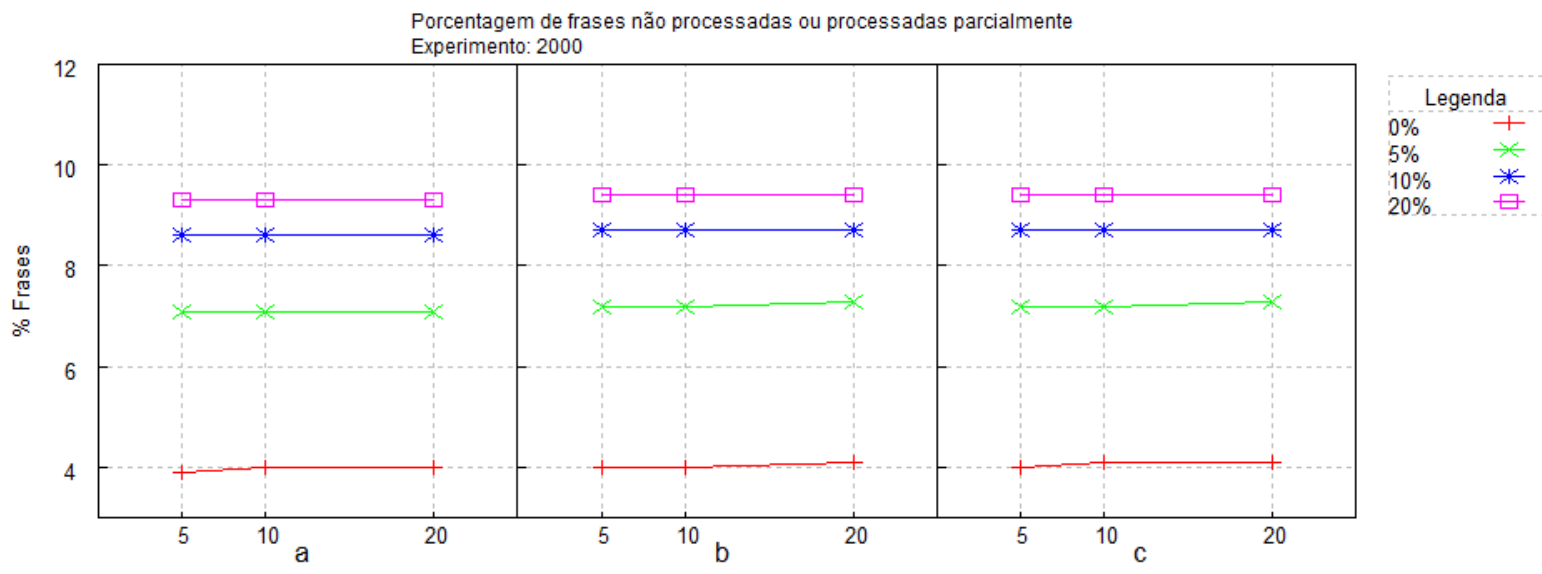

Figura 6.22: Garbage correspondente ao experimento Exp3, usando 8003 frases do conjunto Te

os casos, o valor de Theta influiu menos que na seção de esôfago na variação dessas porcentagens. 


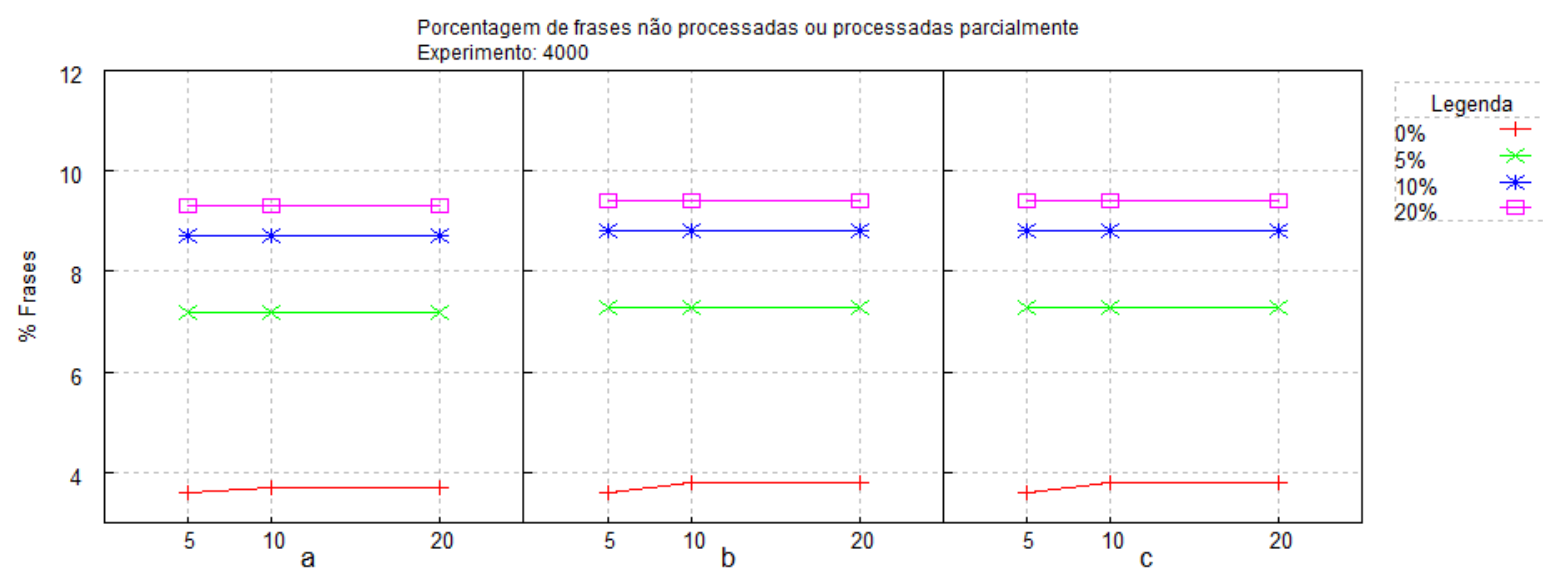

Figura 6.23: Garbage correspondente ao experimento Exp4, usando 7961 frases do conjunto Te

\subsubsection{Aspecto Qualitativo}

Quanto ao aspecto qualitativo, de maneira semelhante a seção de esôfago, foram realizados os cálculos de precisão e recall das listas de termos geradas com base em uma lista de referência considerando apenas as informações contidas nos documentos da seção de estômago. Nos gráficos 6.24, 6.25, 6.26 e $6.27^{13}$ são apresentados os resultados para identificação de termos a partir dos experimentos Exp1, Exp2, Exp3 e Exp4, respectivamente, usando o conjunto de treinamento. Vale lembrar mais uma vez que esses valores de precisão e recall correspondem ao pior caso da aplicação da metodologia.

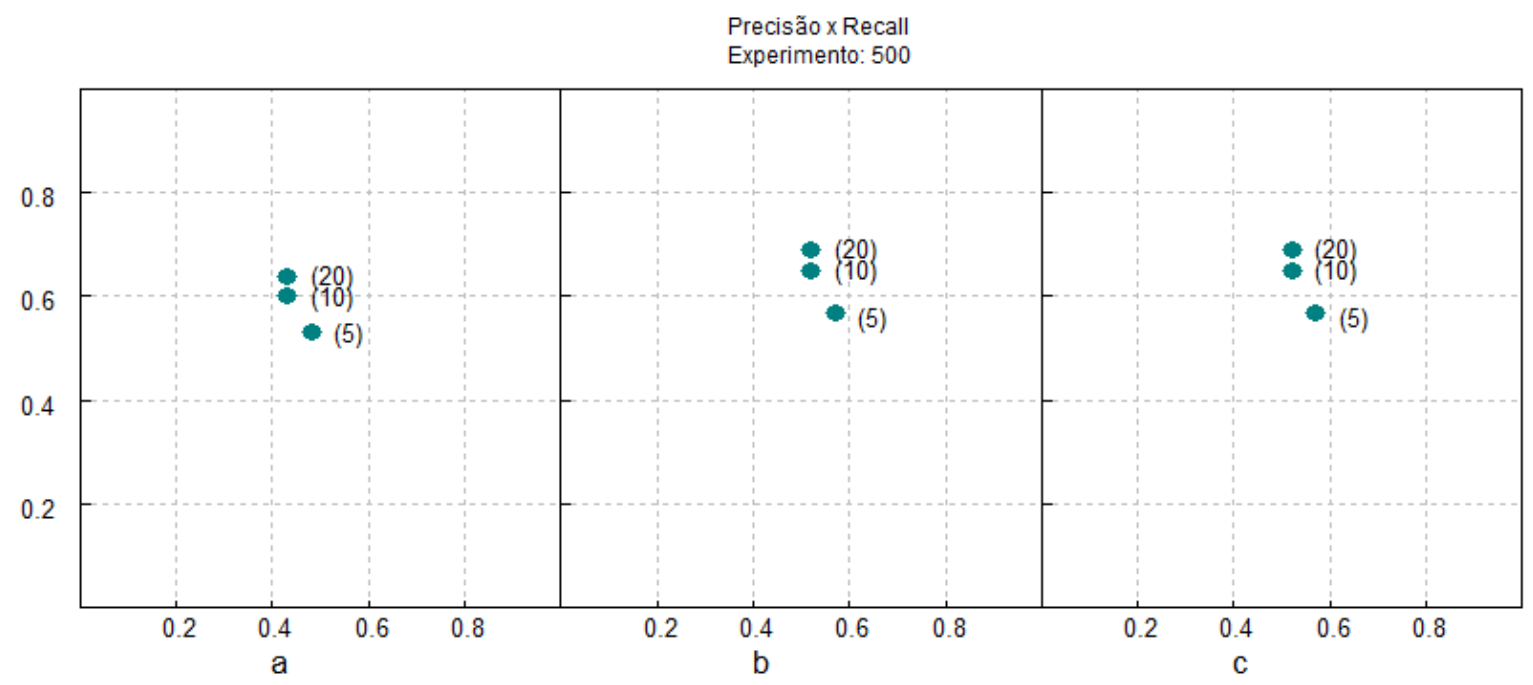

Figura 6.24: Precisão e recall para o experimento Exp1

Os gráficos representam a precisão e recall que foram alcançadas utilizando as variações de Alpha e Theta.

\footnotetext{
${ }^{13}$ Ver Tabelas B.2, B.7, B.12 e B.17 no Apêndice.
} 


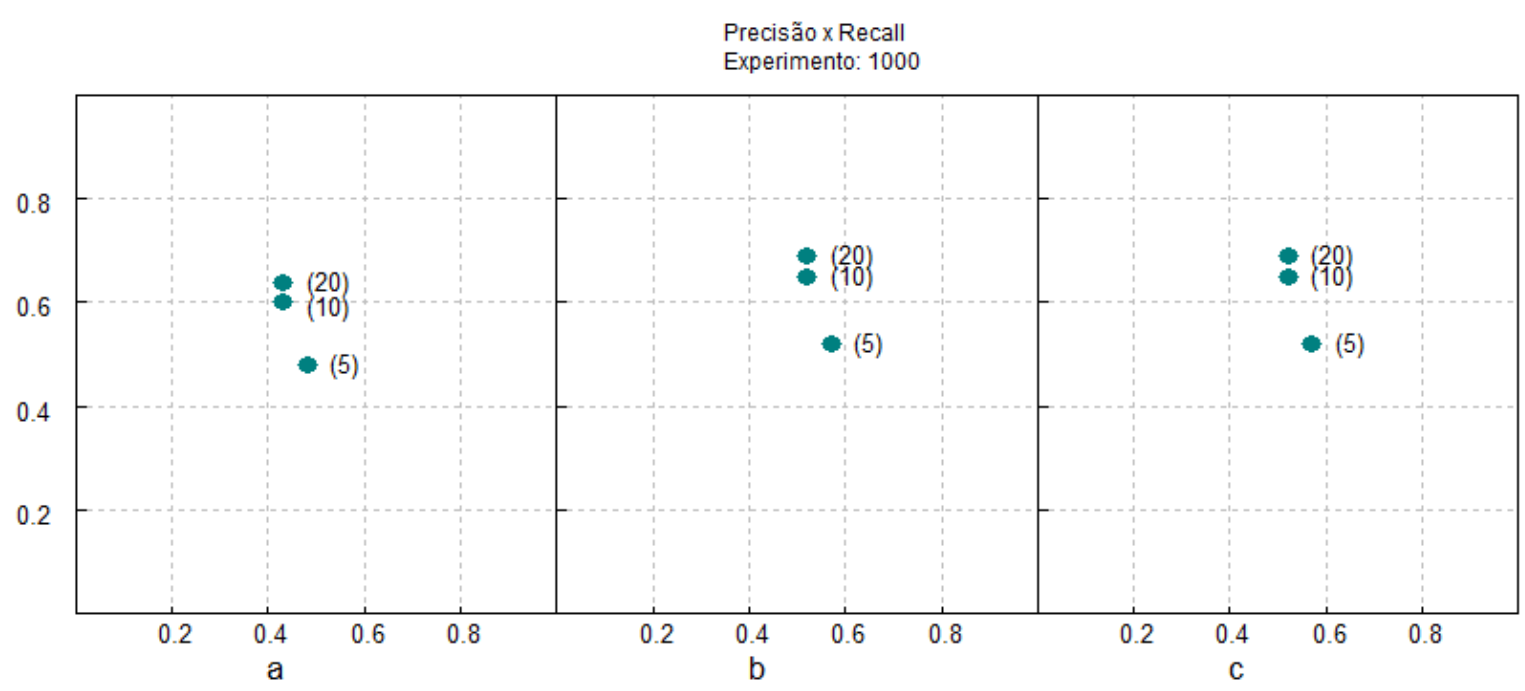

Figura 6.25: Precisão e recall para o experimento Exp2

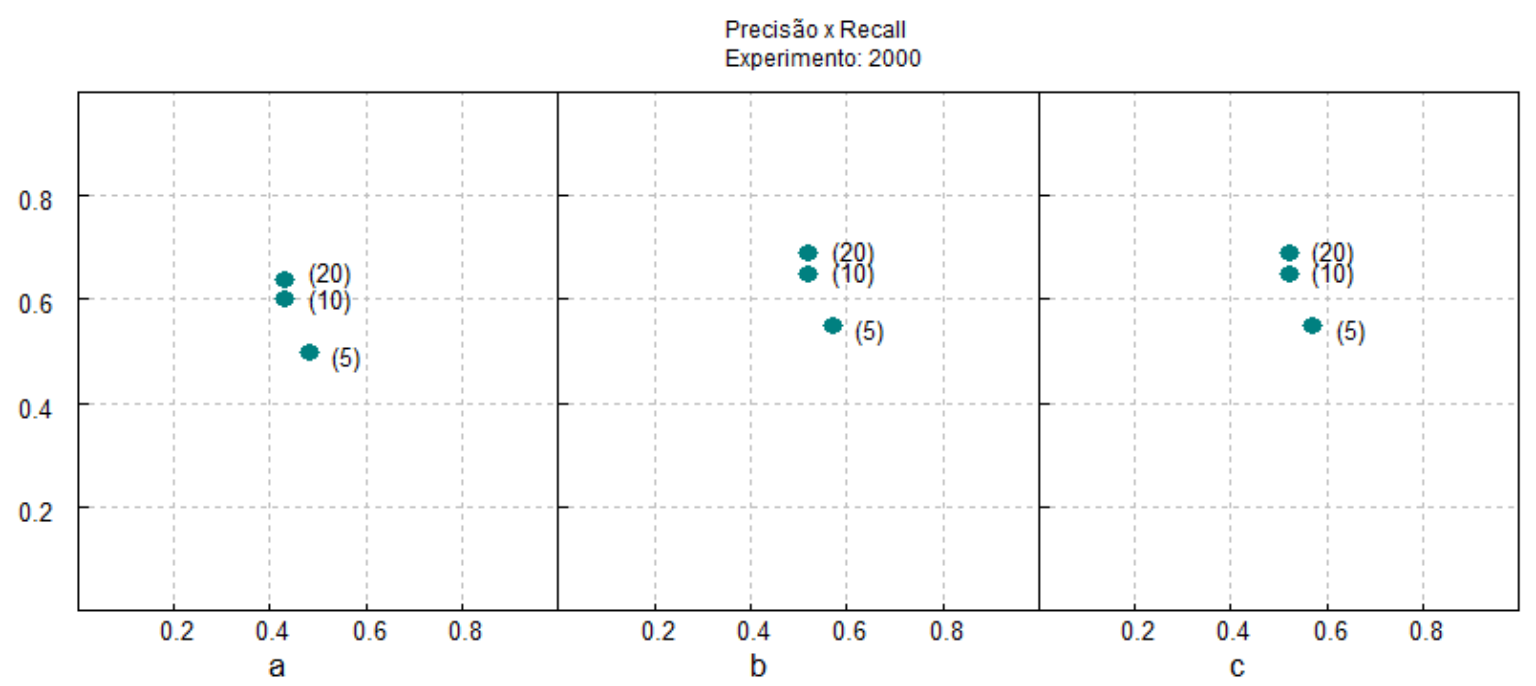

Figura 6.26: Precisão e recall para o experimento Exp3

Novamente pode ser observado que não ocorrem variações muito grandes nos valores de precisão e recall entre os diferentes experimentos. No entanto, foram alcançadas melhores precisão e recall usando Alpha $=95 \%$ e Alpha $=$ 90\%. Analisando a lista de referência, notou-se que muitos termos de interesse utilizados nessa seção de estômago são bigramas e, conforme mencionado, Alpha $=95 \%$ e Alpha $=90 \%$ favorecem a identificação desse tipo de termo. Deve ser levado em conta que devido ao uso de um vocabulário controlado, o uso de conjunto de laudo de tamanhos diferentes para a extração de terminologia de interesse não influenciou muito em relação a melhores resultados de precisão e recall. Analogamente ao que foi apresentado na descrição dos resultados da seção de esôfago, na seção de estômago foram encontrados os mesmos problemas de padronização, os quais, com a interação do espe- 


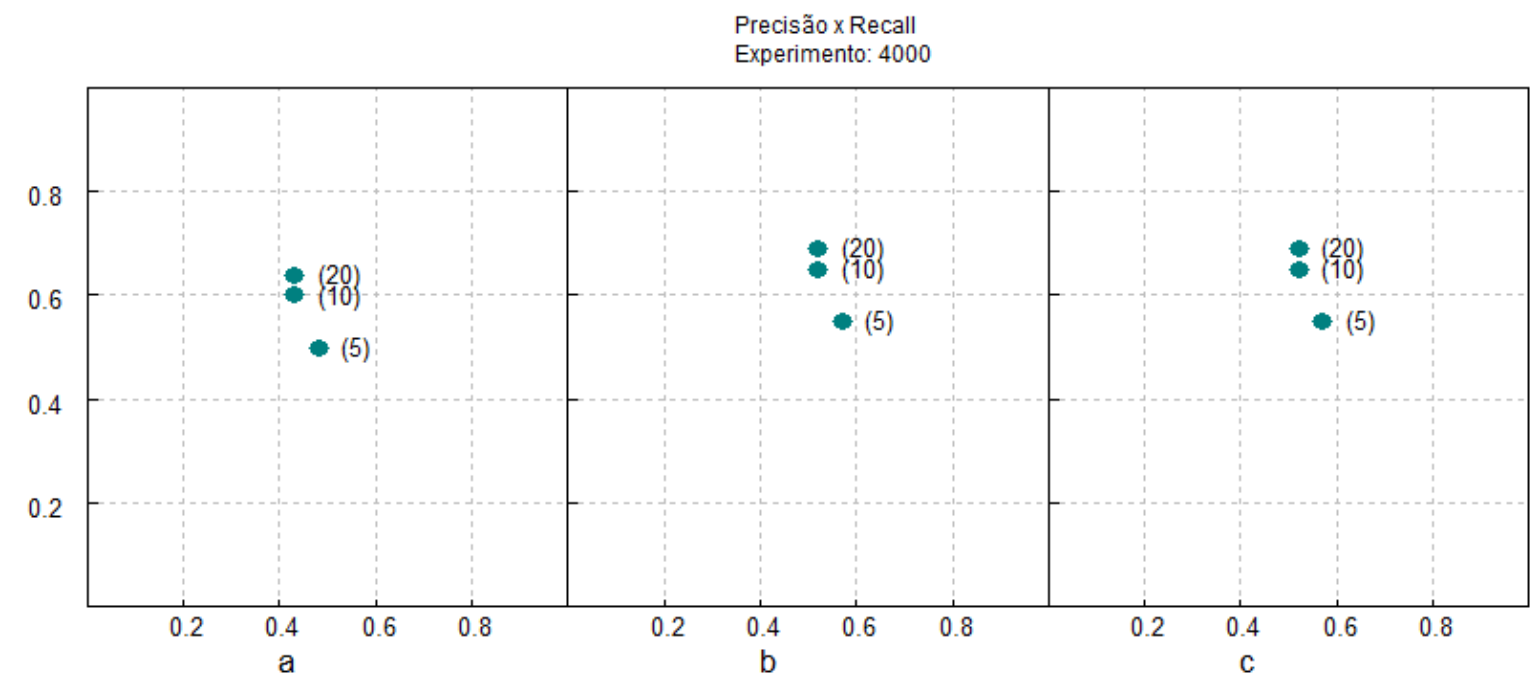

Figura 6.27: Precisão e recall para o experimento Exp4

cialista poderiam ser aliviados, aumentando a performance da metodologia proposta.

\subsection{Considerações Finais}

Neste capítulo foi descrita uma avaliação experimental da metodologia proposta neste trabalho utilizando laudos de Endoscopia Digestiva Alta, mais especificamente, utilizando informações das seções de esôfago e de estômago. A metodologia foi avaliada por meio de vários experimentos nos quais foram considerados diversas variações dos parâmetros utilizados pelo ambiente computacional TP-Discover que implementa a metodologia. Desse modo, foi possível observar os resultados obtidos sob a influência desses parâmetros.

A partir das análises realizadas, podemos constatar alguns aspectos gerais:

- O limiar de poda da árvore influencia fortemente o número de atributos a serem utilizados para descrever os conjuntos de documentos e, conseqüentemente, a taxa de preenchimento da tabela atributo-valor;

- Os valores de precisão e recall poderiam ser melhorados consideravelmente caso houvesse a análise do especialista sobre a lista de termos identificada na fase de extração de terminologia. Com a confirmação e/ou a correção desses termos pelo especialista, seriam construídos atributos mais representativos para mapear as informações nos laudos;

- Os valores de Alpha e Theta são importantes na identificação das unidades terminológicas, pois eles influenciam na preferência de identificar unidades terminológicas unigramas ou bigramas; 
- É possível aplicar a metodologia utilizando apenas conhecimento sintático. Porém, é bom lembrar que a interação com especialista(s), o qual colocaria conhecimento semântico, possibilitaria melhores resultados. 


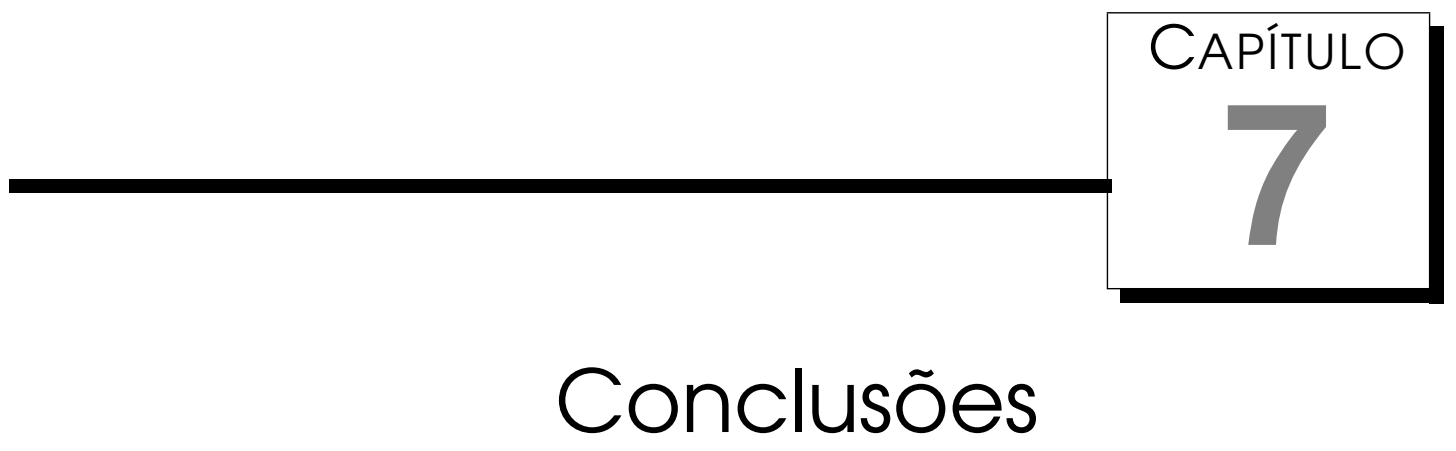

Cada vez mais informações são coletadas e armazenadas digitalmente, nas diversas áreas do conhecimento. Grande parte dessas informações são armazenadas em língua natural, no formato textual não estruturado. Uma área de pesquisa bastante ativa está relacionada a aplicação de técnicas de aprendizado de máquina para extração de conhecimento (padrões) a partir dessas informações. Para realizar a extração de padrões a partir do conjunto de documentos textuais, é necessário que esses documentos sejam transformados para uma representação adequada, geralmente uma representação atributovalor, para ser utilizada por algoritmos de extração de padrões. Diversas soluções têm sido propostas para realizar essa transformação, mas a maioria delas consiste de soluções gerais no sentido de não considerar as características intrínsicas do conjunto de documentos.

Entretando, devido a complexidade do problema, bem como a grande variedade e características diferentes dos textos armazenados eletronicamente, melhores resultados podem ser almejados se essas características são levadas em conta. Essa é a idéia na qual se apóia este trabalho, i.e., mapear as informações de conjuntos de documentos com características específicas em uma representação atributo-valor, explorando ao máximo essas propriedades particulares do conjunto de documentos.

Especificamente, neste trabalho propomos e implementamos uma metodologia que pode ser aplicada em conjuntos de documentos não estruturados que verificam as duas seguintes propriedades:

1. As informações são descritas utilizando um vocabulário controlado; e 
2. As informações consistem de frases assertivas simples.

Essas propriedades são encontradas em muitos conjuntos de documentos, entre eles, laudos médicos não estruturados, como os que foram utilizados para avaliar a metodologia proposta, a qual foi implementada em um ambiente computacional, o TP-Discover.

Um aspecto importante no desenvolvimento do trabalho foi a decisão de somente utilizar as informações contidas no conjunto de documentos, sem depender de informações externas (exceto do(s) especialista(s) do domínio caso participe(m) do processo), tais como dicionários terminológicos, ontologias do domínio, regras semânticas e outros, disponiveis na internet. Ou seja, o ambiente TP-DISCOVER que implementa a metodologia pode ser executado off-line. Também, deve ser ressaltado que a metodologia pode ser aplicada "automaticamente" considerando somente o aspecto morfo-sintático das informações. Caso o especialista participar do processo, ele pode considerar e incluir o aspecto semântico das informações, interagindo, com maior ou menor grau, nas diversas fases da metodologia.

A avaliação de uma metodologia, que também permite a intervenção de um especialista para incluir conhecimento semântico, o qual, sem dúvida alguma, permite a obtenção de melhores resultados, foi a maior motivação para avaliar a metodologia no pior caso. Ou seja, a metodologia foi avaliada sem a intervenção do especialista, i.e., utilizando somente conhecimento morfo-sintático e procedimentos heurísticos para identificar as unidades terminológicas que definem a raiz das árvores responsáveis pela posterior definição dos termos que participam na tabela atributo-valor. Além disso, a metodologia foi avaliada considerando diferentes valores dos parâmetros que favorecem a identificação de unidades terminológicas unigramas ou bigramas que constituem a raiz das árvores, bem como para realizar a poda dessas árvores, cujos ramos definem os atributos a serem utilizados para descrever os documentos. Os resultados quantitativos obtidos foram bons, mais ainda levando em consideração que são resultados correspondentes ao pior caso. Quanto aos resultados qualitativos, a precisão e o recall obtidos nos diversos experimentos realizados mostram a adequabilidade da nossa proposta.

\subsection{Contribuições}

Como mencionado, a metodologia desenvolvida neste trabalho pode ser aplicada considerando apenas o aspecto sintático dos documentos conjuntamente com um método híbrido de extração de metodologia, ou também con- 
siderando o aspecto semântico por meio da participação do especialista. A idéia por trás da metodologia é considerar seqüências de palavras que foram identificadas por possuirem determinadas características sintáticas, e que são utilizadas com uma certa freqüência, para serem mapeadas como atributos da tabela atributo-valor. Para identificar os termos a serem considerados no início dessas seqüências de palavras, é proposto um método híbrido de extração de terminologias. Após identificados esses termos, cada um deles é utilizado para gerar uma árvore, que tem o termo como raiz, na qual os ramos são constituídos das seqüências de palavras que aparecem no contexto do termo raiz.

A identificação dos termos a serem considerados como raiz das árvores pode ser controlada pelo usuário utilizando dois parâmetros, os quais, na implementação realizada, permitem privilegiar termos unigramas ou bigramas. Após construídas as árvores, o usuário pode definir um limiar de poda para controlar o número de atributos gerados.

Um outro aspecto interessante da metodologia proposta é que ela não necessita de recursos externos de conhecimento do domínio, tais como dicionários de termos, regras semânticas e ontologias do domínio, entre outras. Para ser aplicada, somente é utilizada a informação contida nos documentos. Também, ela pode ser realizada sem nenhuma intervenção do especialista, ainda que nesse caso os resultados, desde o ponto de vista semântico dos atributos encontrados, não serão tão bons quanto os obtidos com a participação do especialista em todas as fases da metodologia. Ainda assim, considerando os experimentos realizados para avaliar a metodologia, pode ser observado que os valores de precisão e recall relacionados aos termos raiz das árvores são razoáveis, considerando que não foi utilizado nenhum conhecimento semântico, o qual é somente fornecido com o auxílio do especialista.

Uma outra contribuição importante deste trabalho é o projeto e implementação do ambiente computacional TP-DISCOVER, no qual está implementada a metodologia proposta. Nesse ambiente, é possível aplicar a metodologia com ou sem a intervenção do especialista. O TP-DISCOVER permite que, a partir de um conjunto de documentos, seja realizado o pré-processamento, a extração de terminologia de interesse, a construção e visualização das árvores, a identificação manual ou automática dos atributos e a construção da tabela atributo-valor. O ambiente é composto por interfaces gráficas amigáveis, nas quais é possível configurar os diversos parâmetros que são utilizados na aplicação da metodologia. 


\subsection{Trabalhos Futuros}

A realização deste trabalho e os resultados obtidos despertaram o nosso interesse para realizar diversos trabalhos futuros, descritos a seguir.

- Nos laudos médicos, geralmente são mapeadas várias conclusões de um dado exame no mesmo laudo. Para os algoritmos de extração de padrões, essas conclusões constituem um atributo especial que está relacionado com a classe do laudo (diagnóstico). Porém, devido ao fato de apresentar várias conclusões, cada laudo deveria ser rotulado com um conjunto de classes em lugar de uma única classe. Linhas mais recentes de pesquisa na área de extração de padrões propõem alguns métodos de classificação a partir de múltiplas classes (Holden \& Freitas, 2008; Blockeel et al., 2002). Assim, pretendemos pesquisar esses métodos com o objetivo de mapear na tabela atributo-valor as conclusões dos laudos. Posteriormente, poderão ser utilizados algoritmos de aprendizado supervisionado para verificar a qualidade dos classificadores induzidos;

- Verificar os agrupamentos obtidos com algoritmos de aprendizado não supervisionado utilizando as tabelas atributo-valor que são geradas com e sem o auxílio do especialista;

- Comparar os resultados obtidos por algoritmos de extração de padrões usando a abordagem proposta e a abordagem bag-of-words;

- Investigar abordagens de construção de novos atributos, i.e., aprendizado construtivo, e verificar o efeito dos modelos induzidos com documentos rotulados, utilizando os novos atributos construídos;

- Utilizar e avaliar a metodologia com outros conjuntos de documentos de outros domínios de conhecimento que possuam as propriedades presentes nas informações não estruturadas de laudos médicos;

- Estender a implementação do TP-DIScover para considerar unidades terminológicas de termos trigramas;

- Avaliar a interação homem-máquina do ambiente TP-Discover com diversos usuários. Implementar as extensões sugeridas e disponibilizar o ambiente como software livre na Internet. 


\section{Referências Bibliográficas}

Aas, K. \& Eikvil, L. (1999). Text categorisation: A survey. Relatório Técnico 941, Norwegian Computing Center. http://citeseer.ist.psu.edu/ aas99text.html. Citado na página 15.

Almeida, G. M. D. B., de Oliveira, L. H. M., \& Aluísio, S. M. (2006). A terminologia na era da informática. Ciência e Cultura, 58(2):42-45. Citado na página 22 .

Bagot, R. E. (1999). Extracció de terminologia: elements per a la construcció d'un SEACUSE (Sistema d'Extracció Automática de Candidats a Unitats de Significació Especialitzada. Tese de Doutorado, Universidade Pompeu Fabra. Citado nas páginas 23, 31, e 32.

Bagot, R. E., Cabré, M. T., \& Vivaldi, J. (1998). Sistemes d'extracció automàtica de (candidats a) termes: estat de la qüestió. Papers de Institut Universitari de Lingüística Aplicada, Universitat Pompeu Fabra, Sèrie Informes. Citado na página 22.

Banerjee, S. \& Pedersen, T. (2003). The design, implementation, and use of the Ngram Statistic Package. In Proceedings of the Fourth International Conference on Intelligent Text Processing and Computational Linguistics, pag. 370-381, Cidade do México, México. Citado na página 70.

Bekhouche, D., Pollet, Y., Grilheres, B., \& Denis, X. (2004). Architecture of a medical information extraction system. In 9th International Conference on Applications of Natural Language to Information Systems, pag. 380-387, Manchester, Reino Unido. Citado na página 19.

Blockeel, H., Bruynooghe, M., Dzeroski, S., Ramon, J., \& Struyf, J. (2002). Hierarchical multi-classification. In Workshop on Multi-Relational Data Mi- 
ning, pag. 21-35. University of Alberta, Edmonton, Canadá. Citado na página 110.

Bourigault, D. (1992). Surface grammatical analysis for the extraction of terminological noun phrases. In Proceedings of the 14th conference on computational linguistics, pag. 977-981, Nova Jérsei, EUA. Citado nas páginas 24 e 25.

Caropreso, M. F., Matwin, S., \& Sebastiani, F. (2001). A learner-independent evaluation of the usefulness of statistical phrases for automated text categorization. In Text Databases and Document Management: Theory and Practice, pag. 78-102. Idea Group Publishing, Pensilvânia, EUA. Citado na página 17.

Chang, C.-H., Kayed, M., Girgis, M. R., \& Shaalan, K. F. (2006). A survey of web information extraction systems. IEEE Transactions on Knowledge and Data Engineering, 18(10):1411-1428. Citado na página 2.

Chapelle, O., Schölkopf, B., \& Zien, A., editors (2006). Semi-Supervised Learning. MIT Press, Massachusetts, EUA. Citado na página 12.

Chen, H., Fuller, S. S., Friedman, C., \& Hersh, W. (2005). Medical Informatics: Knowledge Management and Data Mining in Biomedicine (Operations Research/Computer Science Interfaces). Springer-Verlag New York, Inc., Nova Jérsei, EUA. Citado na página 7.

Cherman, E. A., Lee, H. D., Honorato, D. D. F., Fagundes, J. J., Góes, J. R. N., Coy, C. S. R., , \& Chung, W. F. (2007). Metodologia de mapeamento de laudos médicos para bases de dados: Aplicação em laudos colonoscópicos. In II Congresso da Academia Trinacional de Ciências, pag. 31-40, Paraná, Brasil. Citado na página 8.

Church, K. W. \& Hanks, P. (1989). Word association norms, mutual information, and lexicography. In Proceedings of the 27th. Annual Meeting of the Association for Computational Linguistics, pag. 76-83, Vancouver, Canadá. Citado na página 28.

Cimino, J. J. \& Shortliffe, E. H. (2006). Biomedical Informatics: Computer Applications in Health Care and Biomedicine (Health Informatics). SpringerVerlag New York, Inc., Nova Jérsei, EUA. Citado nas páginas 2, 3, 4, e 7.

da Graça Krieger, M. (2005). Terminologias em construção: procedimentos metodológicos. In VIIII Congresso Internacional da ABECAN, Rio Grande do Sul, Brasil. Citado na página 21. 
Daille, B. (1996). Study and implementation of combined techniques for automatic extraction of terminology. In The Balancing Act: Combining Symbolic and Statistical Approaches to Language, pag. 49-66. The MIT Press, Cambridge, Massachusetts. Citado na página 30.

Damerau, F. J. (1964). A technique for computer detection and correction of spelling errors. Commun. ACM, 7(3):171-176. Citado na página 50.

Dias, G. H. \& Lopes, J. G. P. (2005). Extração Automática de Unidades Polilexicais para o Português, pag. 155-184. Mercado de Letras, São Paulo, Brasil. Citado na página 26.

Diederich, J., Kindermann, J., Leopold, E., \& Paass, G. (2003). Authorship attribution with support vector machines. Applied Intelligence, 19(1-2):109123. Citado na página 17.

Dunning, T. (1993). Accurate methods for the statistics of surprise and coincidence. Computational Linguistics, 19(1):61-74. Citado na página 29.

Fawcett, T. (2006). An introduction to roc analysis. Pattern Recognition Letters, 27(8):861-874. Citado na página 12.

Feldman, R. \& Sanger, J. (2006). The Text Mining Handbook: Advanced Approaches in Analyzing Unstructured Data. Cambridge University Press, Nova Iorque, EUA. Citado nas páginas 1, 11, 16, e 17.

Forman, G. (2003). An extensive empirical study of feature selection metrics for text classification. J. Mach. Learn. Res., 3:1289-1305. Citado na página 16.

Gansner, E. R. \& North, S. C. (2000). An open graph visualization system and its applications to software engineering. Software - Practice and Experience, 30(11):1203-1233. Citado na página 72.

Halkidi, M., Batistakis, Y., \& Vazirgiannis, M. (2002a). Cluster validity methods: Part I. SIGMOD Rec., 31(2):40-45. Citado na página 12.

Halkidi, M., Batistakis, Y., \& Vazirgiannis, M. (2002b). Cluster validity methods: Part II. SIGMOD Rec., 31(3):19-27. Citado na página 12.

Harkema, H., Roberts, I., Gaizauskas, R., \& Hepple, M. (2005). Information extraction from clinical records. In Proceedings of the 4th UK e-Science All Hands Meeting, Nottingham, Reino Unido. Citado na página 19. 
Holden, N. \& Freitas, A. A. (2008). Improving the performance of hierachical classification with swarm intelligence. In Proc. Sixth European Conference on Evolutionary Computation, Machine Learning and Data Mining in Bioinformatics, Nápolis, Itália. Morgan Kaufmann Publishers Inc. in print. Citado na página 110 .

Honorato, D. D. F., Cherman, E. A., Lee, H. D., Monard, M. C., \& Wu, F. C. (2007). Construção de uma representação atributo-valor para extração de conhecimento a partir de informações semi-estruturadas de laudos médicos. In Anais da XXXIII Conferencia Latinoamericana de Informatica, pag. 1-12, San José, Costa Rica. Citado na página 8.

Honorato, D. D. F., Lee, H. D., Monard, M. C., Wu, F. C., Machado, R. B., Neto, A. P., \& Ferrero, C. A. (2005). Uma metodologia para auxiliar no processo de construção de bases de dados. In Anais do V Encontro Nacional de Inteligência Artificial, XXV Congresso da Sociedade Brasileira de Computação, pag. 593-601, Rio Grande do Sul, Brasil. Citado na página 8.

Honorato, D. D. F. \& Monard, M. C. (2008a). Descrição de uma metodologia de mapeamento de informações não estruturadas em uma representação atributo-valor. Relatório Técnico 317, ICMC-USP. http://www.icmc.usp. br/ biblio/BIBLIOTECA/rel_tec/RT_317.pdf. Citado na página 44.

Honorato, D. D. F. \& Monard, M. C. (2008b). Descrição do ambiente computacional TP-DISCOVER para mapear informações não estruturadas em uma tabela atributo-valor. Relatório Técnico 318, ICMC-USP. http://www • i cmc . usp.br/ biblio/BIBLIOTECA/rel_tec/RT_318.pdf. Citado nas páginas 44,52 , e 93.

Hotho, A., Nürnberger, A., \& Paaß, G. (2005). A brief survey of text mining. LDV Forum - GLDV Journal for Computational Linguistics and Language Technology, 20(1):19-62. Citado nas páginas 12 e 15.

Justeson, J. \& Katz, S. (1995). Technical terminology: some linguistic properties and an algorithm for identification in text. Natural Language Engineering, 1(1):9-27. Citado na página 30.

Koster, C. H. \& Seutter, M. (2002). Taming wild phrases. In Proceedings of 25th European Conference on IR Research, pag. 161-176, Pisa, Itália. Citado na página 17.

Kruskal, J. B. (1983). An overview of sequence comparison: Time warps, 
string edits, and macromolecules. SIAM Review, 25(2):201-237. Citado na página 50.

Landauer, T. K., Foltz, P. W., \& Laham, D. (1998). An introduction to latent semantic analysis. Discourse Processes, 25:259-284. Citado na página 16.

Lee, C.-H., Wu, C.-H., \& Yang, H.-C. (2007). Text mining of clinical records for cancer diagnosis. In ICICIC '07: Proceedings of the Second International Conference on Innovative Computing, Information and Control, pag. 172-175, Washington, EUA. Citado na página 18.

Lee, H. D. (2005). Seleção de atributos importantes para a extração de conhecimento de bases de dados. Tese de Doutorado, ICMC-USP, http://www.teses.usp.br/teses/disponiveis/55/55134/ tde-22022006-172219/. Citado na página 16.

Manning, C. D. \& Schtze, H. (1999). Foundations of Statistical Natural Language Processing. The MIT Press, Massachusetts, EUA. Citado na página 28.

Matsubara, E. T., Monard, M. C., \& Prati, R. C. (2007). Exploring unclassified texts using multi-view semi-supervised learning. In Emerging Technologies of Text Mining: Techniques and Applications, pag. 138-160. Idea Group Reference, Nova Iorque, EUA. Citado na página 12.

McCowan, I., Moore, D., \& Fry, M.-J. (2006). Classification of cancer stage from free-text histology reports. In Proceedings IEEE Engineering in Medicine and Biology Conference (EMBC), pag. 5153-5156, Nova Iorque, EUA. Citado na página 18.

McInnes, B. T. (2004). Extending the log-likelihood measure to improve collocation identification. Dissertação de Mestrado, University of Minnesota Duluth. Citado nas páginas 26 e 28.

Mitchell, T. M. (1997). Machine Learning. McGraw-Hill, Nova Iorque, EUA. Citado na página 12 .

Pantel, P. \& Lin, D. (2001). A statistical corpus-based term extractor. In Proceedings of the 14th Biennial Conference of the Canadian Society on Computational Studies of Intelligence: Advances in Artificial Intelligence, pag. 36-46, Londres, Reino Unido. Citado nas páginas 23, 28, e 29.

Pardo, T. A. S. (2006). Senter: Um segmentador sentencial automático para o português do brasil. Relatório Técnico NILC-TR-06-01, ICMC-USP. 
http://www.icmc.usp.br/ taspardo/NILCTR0601-Pardo.pdf. Citado na página 46.

Patry, A. \& Langlais, P. (2005). Corpus-based terminology extraction. In 7th International Conference on Terminology and Knowledge Engineering, pag. 313-321, Copenhague, Dinamarca. Citado na página 30.

Paulo, J. L., Correia, M., Mamede, N. J., \& Hagège, C. (2002). Using morphological, syntactical, and statistical information for automatic term acquisition. In PorTAL '02: Proceedings of the Third International Conference on Advances in Natural Language Processing, pag. 219-228, Londres, Reino Unido. Citado na página 23.

Pavel, S. \& Nolet, D. (2002). Handbook of terminology. Minister of Public Works and Government Services Canada, Québec, Canadá. http://www.bureaudelatraduction.gc.ca/pwgsc_internet/en/ publications/documents/handbook.pdf. Citado na página 21.

Pazienza, M. T., Pennacchiotti, M., \& Zanzotto, F. M. (2005). Terminology extraction: An analysis of linguistic and statistical approaches. In Proceedings of the Nemis 2004 Final Conference, volume 185 of Studies in Fuzziness and Soft Computing, pag. 255-279, Atenas, Grécia. Citado nas páginas 24, 28, e 31 .

Prati, R. C., Batista, G. E. A. P. A., \& Monard, M. C. (2008). Curvas ROC para avaliação de classificadores. Revista IEEE América Latina, 6(2). Citado na página 12 .

Ratnaparkhi, A. (1996). A maximum entropy model for part-of-speech tagging. In Proceedings of the Conference on Empirical Methods in Natural Language Processing, pag. 133-142, Nova Jérsei, EUA. Citado na página 58.

Rezende, S. O., Pugliesi, J. B., Melanda, E. A., \& Paula, M. F. (2003). Mineração de Dados, volume 1 of 1, chapter 12, pag. 307-336. Editora Manole, São Paulo, Brasil. Citado na página 11.

Saad, F. H., de la Iglesia, B., \& Bell, D. G. (2006). A comparison of two document clustering approaches for clustering medical documents. In Proceedings of the 2006 International Conference on Data Mining, pag. 425-431, Las Vegas, EUA. Citado na página 19.

Salton, G. \& Buckley, C. (1987). Term weighting approaches in automatic text retrieval. Relatório técnico, Cornell University, Nova Iorque, EUA. Citado na página 14 . 
Savary, A. \& Jacquemin, C. (2000). Reducing information variation in text. In ELSNET Summer School, pag. 145-181, Ilha Chios, Grécia. Citado nas páginas 25 e 31.

Schmid, H. (1994). Probabilistic part-of-speech tagging using decision trees. In International Conference on New Methods in Language Processing, Manchester, Reino Unido. Citado na página 55.

Scott, S. \& Matwin, S. (1999). Feature engineering for text classification. In ICML '99: Proceedings of the Sixteenth International Conference on Machine Learning, pag. 379-388, Califórnia, EUA. Morgan Kaufmann Publishers Inc. Citado na página 17.

Sebastiani, F. (2002). Machine learning in automated text categorisation. ACM Computing Surveys, 34(1):1-47. Citado nas páginas 15 e 16.

Sebastiani, F. (2006). Classification of text, automatic. In The Encyclopedia of Language and Linguistics, volume 2, pag. 457-463. Elsevier Science Publishers, Amsterdam, Holanda. Citado na página 15.

Slonim, N. \& Tishby, N. (2000). Document clustering using word clusters via the information bottleneck method. In SIGIR '00: Proceedings of the 23rd Annual International ACM SIGIR Conference on Research and development in information retrieval, pag. 208-215, Nova Iorque, EUA. Citado na página 16.

Smadja, F., McKeown, K. R., \& Hatzivassiloglou, V. (1996). Translating collocations for bilingual lexicons: a statistical approach. Computational Linguistics, 22(1):1-38. Citado na página 29.

Soucy, P. \& Mineau, G. W. (2005). Beyond tfidf weighting for text categorization in the vector space model. In IJCAI-05 Proceedings, pag. 1130-1135. Professional Book Center. Citado na página 15.

Spolaôr, N., Lee, H. D., Cherman, E. A., Honorato, D. D. F., Fagundes, J. J., Góes, J. R. N., Coy, C. S. R., \& Chung, W. F. (2007). Um estudo de caso do mapeamento de laudos endoscópicos para bases de dados. In II Congresso da Academia Trinacional de Ciências, pag. 61-70, Paraná, Brasil. Citado na página 8.

Teline, M. F. (2004). Avaliação de métodos de extração automática de terminologia para textos em português. Dissertação de Mestrado, ICMC-USP, http://www.teses.usp.br/teses/disponiveis/55/55134/ tde-25052004-012204/. Citado na página 24. 
Teline, M. F., de B. Almeida, G. M., \& Aluísio, S. M. (2003). Extração manual e automática de terminologia: comparando abordagens e critérios. In Proceedings of the 16th Brazilian Symposium on Computer Graphics and Image Processing, volume 1, pag. 1-12, São Paulo, Brasil. Citado na página 61.

Weiss, S. M., Indurkhya, N., \& Zhang, T. (2005). Text Mining : Predictive Methods for Analyzing Unstructured Information. Springer, Nova Iorque, EUA. Citado nas páginas 1 e 16.

Witschel, H. F. (2005). Terminology extraction and automatic indexing - comparison and qualitative evaluation of methods. In Proceedings of the 7th International conference on Terminology and Knowledge Engineering, pag. 112, Copenhague, Dinamarca. Citado na página 22.

Zhou, X., Han, H., Chankai, I., Prestrud, A., \& Brooks, A. (2006). Approaches to text mining for clinical medical records. In SAC '06: Proceedings of the 2006 ACM Symposium on Applied Computing, pag. 235-239, Nova Iorque, EUA. Citado na página 18.

Zielinski, D. \& Safar, Y. R. (2005). Research meets practice: t-survey 2005 - an online survey on terminology extraction and terminology management. In Proceedings ASLIB 27 - Translating and the Computer, Londres, Inglaterra. Citado na página 23.

Ziviani, N. (2007). Projeto de Algoritmos com Implementações em Java e C++. Thomson, São Paulo, Brasil. Citado na página 75. 
APÊNDICE

Resultados do Processamento da

Seção de Esôfago

As tabelas a seguir são referentes aos resultados descritos para a seção de esôfago, no Capítulo 6.

Tabela A.1: Número de termos raíz e número de atributos identificados usando 500 laudos de treinamento

\begin{tabular}{|c|c|c|c|c|c|c|c|c|}
\hline \multirow{2}{*}{$\begin{array}{c}\text { Doc. } \\
\text { Tr }\end{array}$} & \multirow{2}{*}{ 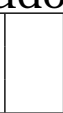 } & \multirow[b]{2}{*}{ Alpha } & \multirow[b]{2}{*}{ Theta } & \multirow{2}{*}{$\begin{array}{c}\text { Número } \\
\text { termos } \\
\text { (raíz) }\end{array}$} & \multicolumn{4}{|c|}{ Número de atributos } \\
\hline & & & & & $0 \%$ & $5 \%$ & $10 \%$ & $20 \%$ \\
\hline 500 & & 100 & 5 & 14 & 235 & $31(13,2 \%)$ & $15(6,4 \%)$ & $10(4,3 \%)$ \\
\hline 500 & $\mathrm{a}$ & 100 & 10 & 11 & 211 & $28(13,3 \%)$ & $15(7,1 \%)$ & $10(4,7 \%)$ \\
\hline 500 & & 100 & 20 & 10 & 161 & $26(16,1 \%)$ & $15(9,3 \%)$ & $10(6,2 \%)$ \\
\hline 500 & & 95 & 5 & 14 & 180 & $27(15,0 \%)$ & $12(6,7 \%)$ & $8(4,4 \%)$ \\
\hline 500 & $\mathrm{~b}$ & 95 & 10 & 10 & 141 & $23(16,3 \%)$ & $12(8,5 \%)$ & $8(5,7 \%)$ \\
\hline 500 & & 95 & 20 & 9 & 106 & $17(16,0 \%)$ & $10(9,4 \%)$ & $8(7,5 \%)$ \\
\hline 500 & & 90 & 5 & 14 & 180 & $27(15,0 \%)$ & $12(6,7 \%)$ & $8(4,4 \%)$ \\
\hline 500 & $\mathrm{c}$ & 90 & 10 & 10 & 141 & $23(16,3 \%)$ & $12(8,5 \%)$ & $8(5,7 \%)$ \\
\hline 500 & & 90 & 20 & 9 & 106 & $17(16,0 \%)$ & $10(9,4 \%)$ & $8(7,5 \%)$ \\
\hline
\end{tabular}


Tabela A.2: Tabela de precisão e recall da lista de termos gerada usando 500 laudos de treinamento

\begin{tabular}{|c|c|c|c|c|c|}
\hline $\begin{array}{c}\text { Doc. } \\
\text { Tr }\end{array}$ & Alpha & Theta & $\begin{array}{c}\text { Termos } \\
\text { Identificados }\end{array}$ & Precisão & Recall \\
\hline 500 & 100 & 5 & 14 & $43 \%$ & $55 \%$ \\
\hline 500 & 100 & 10 & 11 & $55 \%$ & $55 \%$ \\
\hline 500 & 100 & 20 & 10 & $60 \%$ & $55 \%$ \\
\hline 500 & 95 & 5 & 14 & $29 \%$ & $36 \%$ \\
\hline 500 & 95 & 10 & 10 & $40 \%$ & $36 \%$ \\
\hline 500 & 95 & 20 & 9 & $33 \%$ & $27 \%$ \\
\hline 500 & 90 & 5 & 14 & $29 \%$ & $36 \%$ \\
\hline 500 & 90 & 10 & 10 & $40 \%$ & $36 \%$ \\
\hline 500 & 90 & 20 & 9 & $33 \%$ & $27 \%$ \\
\hline
\end{tabular}

Tabela A.3: Taxa de preenchimento para o conjunto $\operatorname{Tr}$ de 500 laudos

\begin{tabular}{|c|c|c|c|c|c|}
\hline \multirow{2}{*}{$\begin{array}{c}\text { Doc. } \\
\text { Tr }\end{array}$} & \multirow{2}{*}{$\begin{array}{l}\text { Alpha/ } \\
\text { Theta }\end{array}$} & \multicolumn{4}{|c|}{ Taxa Preenchimento } \\
\hline & & $0 \%$ & $5 \%$ & $10 \%$ & $20 \%$ \\
\hline 500 & \multirow{3}{*}{$\mathrm{a}$} & 5 & 34,8 & 64,6 & 89,6 \\
\hline 500 & & 5,5 & 37,9 & 64,6 & 89,6 \\
\hline 500 & & 6,9 & 40,3 & 64,6 & 89,6 \\
\hline 500 & \multirow{3}{*}{ b } & 5,3 & 32,4 & 64,5 & 89,8 \\
\hline 500 & & 6,5 & 37,1 & 64,5 & 89,8 \\
\hline 500 & & 7,9 & 46,9 & 74,7 & 89,8 \\
\hline 500 & \multirow{3}{*}{ c } & 5,3 & 32,4 & 64,5 & 89,8 \\
\hline 500 & & 6,5 & 37,1 & 64,5 & 89,8 \\
\hline 500 & & 7,9 & 46,9 & 74,7 & 89,8 \\
\hline
\end{tabular}


Tabela A.4: Garbage gerado a partir do conjunto de 500 laudos de treinamento contendo 2002 frases, usando os limiares 0\%, 5\%, 10\% e 20\%

\begin{tabular}{|c|c|c|c|c|c|}
\hline $\begin{array}{c}\text { Alpha/ } \\
\text { Theta }\end{array}$ & $\begin{array}{c}\text { Número } \\
\text { parcial } \\
0 \%\end{array}$ & $\begin{array}{c}\text { Número } \\
\text { total } \\
0 \%\end{array}$ & $\begin{array}{c}\text { \% processada } \\
\text { parcial / } \\
\text { sem processar }\end{array}$ & $\begin{array}{c}\text { \% processada } \\
\text { parcial }\end{array}$ & $\begin{array}{c}\% \text { sem } \\
\text { processar }\end{array}$ \\
\hline \multirow{3}{*}{$\mathrm{a}$} & 84 & 7 & $4,5 \%$ & $92,3 \%$ & $7,7 \%$ \\
\cline { 2 - 6 } & 84 & 7 & $4,5 \%$ & $92,3 \%$ & $7,7 \%$ \\
\hline \multirow{3}{*}{$\mathrm{b}$} & 83 & 17 & $5,0 \%$ & $83,0 \%$ & $17,0 \%$ \\
\cline { 2 - 6 } & 78 & 18 & $4,8 \%$ & $81,3 \%$ & $18,8 \%$ \\
\cline { 2 - 6 } & 84 & 20 & $5,2 \%$ & $80,8 \%$ & $19,2 \%$ \\
\hline \multirow{3}{*}{$\mathrm{c}$} & 157 & 20 & $8,8 \%$ & $88,7 \%$ & $11,3 \%$ \\
\cline { 2 - 6 } & 78 & 18 & $4,8 \%$ & $81,3 \%$ & $18,8 \%$ \\
\cline { 2 - 6 } & 154 & 20 & $5,2 \%$ & $80,8 \%$ & $19,2 \%$ \\
\hline
\end{tabular}

\begin{tabular}{|c|c|c|c|c|c|}
\hline $\begin{array}{c}\text { Alpha/ } \\
\text { Theta }\end{array}$ & $\begin{array}{c}\text { Número } \\
\text { parcial } \\
5 \%\end{array}$ & $\begin{array}{c}\text { Número } \\
\text { total } \\
5 \%\end{array}$ & $\begin{array}{c}\text { \% processada } \\
\text { parcial / } \\
\text { sem processar }\end{array}$ & $\begin{array}{c}\text { \% processada } \\
\text { parcial }\end{array}$ & $\begin{array}{c}\text { \% sem } \\
\text { processar }\end{array}$ \\
\hline \multirow{3}{*}{ a } & 119 & 26 & $7,2 \%$ & $82,1 \%$ & $17,9 \%$ \\
\cline { 2 - 6 } & 119 & 26 & $7,2 \%$ & $82,1 \%$ & $17,9 \%$ \\
\cline { 2 - 6 } & 126 & 28 & $7,7 \%$ & $81,8 \%$ & $18,2 \%$ \\
\hline \multirow{3}{*}{$\mathrm{b}$} & 116 & 29 & $7,2 \%$ & $80,0 \%$ & $20,0 \%$ \\
\cline { 2 - 6 } & 125 & 29 & $7,7 \%$ & $81,2 \%$ & $18,8 \%$ \\
\cline { 2 - 6 } & 151 & 29 & $9,0 \%$ & $83,9 \%$ & $16,1 \%$ \\
\cline { 2 - 6 } & 116 & 29 & $7,2 \%$ & $80,0 \%$ & $20,0 \%$ \\
\cline { 2 - 6 } & 125 & 29 & $7,7 \%$ & $81,2 \%$ & $18,8 \%$ \\
\hline
\end{tabular}

\begin{tabular}{|c|c|c|c|c|c|}
\hline $\begin{array}{c}\text { Alpha/ } \\
\text { Theta }\end{array}$ & $\begin{array}{c}\text { Número } \\
\text { parcial } \\
10 \%\end{array}$ & $\begin{array}{c}\text { Número } \\
\text { total } \\
10 \%\end{array}$ & $\begin{array}{c}\text { \% processada } \\
\text { parcial / } \\
\text { sem processar }\end{array}$ & $\begin{array}{c}\text { \% processada } \\
\text { parcial }\end{array}$ & $\begin{array}{c}\text { \% sem } \\
\text { processar }\end{array}$ \\
\hline \multirow{3}{*}{$\mathrm{a}$} & 181 & 89 & $13,5 \%$ & $67,0 \%$ & $33,0 \%$ \\
\cline { 2 - 6 } & 181 & 89 & $13,5 \%$ & $67,0 \%$ & $33,0 \%$ \\
\cline { 2 - 6 } & 181 & 89 & $13,5 \%$ & $67,0 \%$ & $33,0 \%$ \\
\hline \multirow{3}{*}{$\mathrm{b}$} & 180 & 88 & $13,4 \%$ & $67,2 \%$ & $32,8 \%$ \\
\cline { 2 - 6 } & 180 & 88 & $13,4 \%$ & $67,2 \%$ & $32,8 \%$ \\
\cline { 2 - 6 } & 180 & 88 & $13,4 \%$ & $67,2 \%$ & $32,8 \%$ \\
\hline \multirow{3}{*}{$\mathrm{c}$} & 180 & 88 & $13,4 \%$ & $67,2 \%$ & $32,8 \%$ \\
\cline { 2 - 6 } & 180 & 88 & $13,4 \%$ & $67,2 \%$ & $32,8 \%$ \\
\cline { 2 - 6 } & 180 & 88 & $13,4 \%$ & $67,2 \%$ & $32,8 \%$ \\
\hline
\end{tabular}

\begin{tabular}{|c|c|c|c|c|c|}
\hline $\begin{array}{c}\text { Alpha/ } \\
\text { Theta }\end{array}$ & $\begin{array}{c}\text { Número } \\
\text { parcial } \\
20 \%\end{array}$ & $\begin{array}{c}\text { Número } \\
\text { total } \\
20 \%\end{array}$ & $\begin{array}{c}\text { \% processada } \\
\text { parcial / } \\
\text { sem processar }\end{array}$ & $\begin{array}{c}\text { \% processada } \\
\text { parcial }\end{array}$ & $\begin{array}{c}\text { \% sem } \\
\text { processar }\end{array}$ \\
\hline \multirow{3}{*}{$\mathrm{a}$} & 28 & 120 & $7,4 \%$ & $18,9 \%$ & $81,1 \%$ \\
\cline { 2 - 6 } & 28 & 120 & $7,4 \%$ & $18,9 \%$ & $81,1 \%$ \\
\cline { 2 - 6 } & 28 & 120 & $7,4 \%$ & $18,9 \%$ & $81,1 \%$ \\
\hline \multirow{3}{*}{$\mathrm{b}$} & 29 & 121 & $7,5 \%$ & $19,3 \%$ & $80,7 \%$ \\
\cline { 2 - 6 } & 29 & 121 & $7,5 \%$ & $19,3 \%$ & $80,7 \%$ \\
\hline \multirow{3}{*}{$\mathrm{c}$} & 29 & 121 & $7,5 \%$ & $19,3 \%$ & $80,7 \%$ \\
\cline { 2 - 6 } & 29 & 121 & $7,5 \%$ & $19,3 \%$ & $80,7 \%$ \\
\cline { 2 - 6 } & 29 & 121 & $7,5 \%$ & $19,3 \%$ & $80,7 \%$ \\
\hline
\end{tabular}


Tabela A.5: Garbage gerado a partir do conjunto de 500 laudos de teste contendo 4009 frases, usando os limiares 0\%, 5\%, 10\% e 20\%

\begin{tabular}{|c|c|c|c|c|c|}
\hline $\begin{array}{c}\text { Alpha/ } \\
\text { Theta }\end{array}$ & $\begin{array}{c}\text { Número } \\
\text { parcial } \\
\text { O\% }\end{array}$ & $\begin{array}{c}\text { Número } \\
\text { total } \\
\text { O\% }\end{array}$ & $\begin{array}{c}\text { \% processada } \\
\text { parcial / } \\
\text { sem processar }\end{array}$ & $\begin{array}{c}\% \text { processada } \\
\text { parcial }\end{array}$ & $\begin{array}{c}\% \text { sem } \\
\text { processar }\end{array}$ \\
\hline \multirow{3}{*}{$\mathrm{a}$} & 198 & 38 & $5,9 \%$ & $83,9 \%$ & $16,1 \%$ \\
\cline { 2 - 6 } & 198 & 38 & $5,9 \%$ & $83,9 \%$ & $16,1 \%$ \\
\cline { 2 - 6 } & 198 & 49 & $6,2 \%$ & $80,2 \%$ & $19,8 \%$ \\
\hline \multirow{3}{*}{$\mathrm{b}$} & 192 & 51 & $6,1 \%$ & $79,0 \%$ & $21,0 \%$ \\
\cline { 2 - 6 } & 191 & 57 & $6,2 \%$ & $77,0 \%$ & $23,0 \%$ \\
\cline { 2 - 6 } & 296 & 57 & $8,8 \%$ & $83,9 \%$ & $16,1 \%$ \\
\hline \multirow{3}{*}{$\mathrm{c}$} & 192 & 51 & $6,1 \%$ & $79,0 \%$ & $21,0 \%$ \\
\cline { 2 - 6 } & 191 & 57 & $6,2 \%$ & $77,0 \%$ & $23,0 \%$ \\
\cline { 2 - 6 } & 296 & 57 & $8,8 \%$ & $83,9 \%$ & $16,1 \%$ \\
\hline
\end{tabular}

\begin{tabular}{|c|c|c|c|c|c|}
\hline $\begin{array}{c}\text { Alpha/ } \\
\text { Theta }\end{array}$ & $\begin{array}{c}\text { Número } \\
\text { parcial } \\
5 \%\end{array}$ & $\begin{array}{c}\text { Número } \\
\text { total } \\
5 \%\end{array}$ & $\begin{array}{c}\text { \% processada } \\
\text { parcial / } \\
\text { sem processar }\end{array}$ & $\begin{array}{c}\text { \% processada } \\
\text { parcial }\end{array}$ & $\begin{array}{c}\% \text { sem } \\
\text { processar }\end{array}$ \\
\hline \multirow{3}{*}{ a } & 228 & 65 & $7,3 \%$ & $77,8 \%$ & $22,2 \%$ \\
\cline { 2 - 6 } & 228 & 65 & $7,3 \%$ & $77,8 \%$ & $22,2 \%$ \\
\cline { 2 - 6 } & 247 & 73 & $8,0 \%$ & $77,2 \%$ & $22,8 \%$ \\
\hline \multirow{3}{*}{$\mathrm{b}$} & 223 & 70 & $7,3 \%$ & $76,1 \%$ & $23,9 \%$ \\
\cline { 2 - 6 } & 245 & 75 & $8,0 \%$ & $76,6 \%$ & $23,4 \%$ \\
\cline { 2 - 6 } & 284 & 75 & $9,0 \%$ & $79,1 \%$ & $20,9 \%$ \\
\hline \multirow{3}{*}{$\mathrm{c}$} & 223 & 70 & $7,3 \%$ & $76,1 \%$ & $23,9 \%$ \\
\cline { 2 - 6 } & 245 & 75 & $8,0 \%$ & $76,6 \%$ & $23,4 \%$ \\
\cline { 2 - 6 } & 284 & 75 & $9,0 \%$ & $79,1 \%$ & $20,9 \%$ \\
\hline
\end{tabular}

\begin{tabular}{|c|c|c|c|c|c|}
\hline $\begin{array}{c}\text { Alpha/ } \\
\text { Theta }\end{array}$ & $\begin{array}{c}\text { Número } \\
\text { parcial } \\
10 \%\end{array}$ & $\begin{array}{c}\text { Número } \\
\text { total } \\
10 \%\end{array}$ & $\begin{array}{c}\text { \% processada } \\
\text { parcial / } \\
\text { sem processar }\end{array}$ & $\begin{array}{c}\text { \% processada } \\
\text { parcial }\end{array}$ & $\begin{array}{c}\% \text { sem } \\
\text { processar }\end{array}$ \\
\hline \multirow{3}{*}{$\mathrm{a}$} & 336 & 73 & $10,2 \%$ & $82,2 \%$ & $17,8 \%$ \\
\cline { 2 - 6 } & 336 & 73 & $10,2 \%$ & $82,2 \%$ & $17,8 \%$ \\
\cline { 2 - 6 } & 336 & 73 & $10,2 \%$ & $82,2 \%$ & $17,8 \%$ \\
\hline \multirow{3}{*}{$\mathrm{b}$} & 334 & 75 & $10,2 \%$ & $81,7 \%$ & $18,3 \%$ \\
\cline { 2 - 6 } & 334 & 75 & $10,2 \%$ & $81,7 \%$ & $18,3 \%$ \\
\cline { 2 - 6 } & 334 & 75 & $10,2 \%$ & $81,7 \%$ & $18,3 \%$ \\
\hline \multirow{3}{*}{$\mathrm{c}$} & 334 & 75 & $10,2 \%$ & $81,7 \%$ & $18,3 \%$ \\
\cline { 2 - 6 } & 334 & 75 & $10,2 \%$ & $81,7 \%$ & $18,3 \%$ \\
\cline { 2 - 6 } & 334 & 75 & $10,2 \%$ & $81,7 \%$ & $18,3 \%$ \\
\hline
\end{tabular}

\begin{tabular}{|c|c|c|c|c|c|}
\hline $\begin{array}{c}\text { Alpha/ } \\
\text { Theta }\end{array}$ & $\begin{array}{c}\text { Número } \\
\text { parcial } \\
20 \%\end{array}$ & $\begin{array}{c}\text { Número } \\
\text { total } \\
20 \%\end{array}$ & $\begin{array}{c}\text { \% processada } \\
\text { parcial / } \\
\text { sem processar }\end{array}$ & $\begin{array}{c}\% \text { processada } \\
\text { parcial }\end{array}$ & $\begin{array}{c}\% \text { sem } \\
\text { processar }\end{array}$ \\
\hline \multirow{3}{*}{$\mathrm{a}$} & 177 & 232 & $10,2 \%$ & $43,3 \%$ & $56,7 \%$ \\
\cline { 2 - 6 } & 177 & 232 & $10,2 \%$ & $43,3 \%$ & $56,7 \%$ \\
\cline { 2 - 6 } & 177 & 232 & $10,2 \%$ & $43,3 \%$ & $56,7 \%$ \\
\hline \multirow{3}{*}{$\mathrm{b}$} & 177 & 232 & $10,2 \%$ & $43,3 \%$ & $56,7 \%$ \\
\cline { 2 - 6 } & 177 & 232 & $10,2 \%$ & $43,3 \%$ & $56,7 \%$ \\
\hline \multirow{3}{*}{$\mathrm{c}$} & 177 & 232 & $10,2 \%$ & $43,3 \%$ & $56,7 \%$ \\
\cline { 2 - 6 } & 177 & 232 & $10,2 \%$ & $43,3 \%$ & $56,7 \%$ \\
\cline { 2 - 6 } & 177 & 232 & $10,2 \%$ & $43,3 \%$ & $56,7 \%$ \\
\hline
\end{tabular}


Tabela A.6: Número de termos raíz e número de atributos identificados usando 1000 laudos de treinamento

\begin{tabular}{|c|c|c|c|c|c|c|c|c|}
\hline \multirow{2}{*}{$\begin{array}{c}\text { Doc. } \\
\text { Tr }\end{array}$} & & \multirow{2}{*}{ Alpha } & \multirow{2}{*}{ Theta } & \multirow{2}{*}{$\begin{array}{c}\text { Número } \\
\text { termos } \\
\text { (raiz) }\end{array}$} & \multicolumn{4}{|c|}{ Número de atributos } \\
\hline & & & & & $0 \%$ & $5 \%$ & $10 \%$ & $20 \%$ \\
\hline 1000 & & 100 & 5 & 13 & 361 & $28(7,8 \%)$ & $13(3,6 \%)$ & $10(2,8 \%)$ \\
\hline 1000 & $\mathrm{a}$ & 100 & 10 & 11 & 316 & $25(7,9 \%)$ & $13(4,1 \%)$ & $10(3,2 \%)$ \\
\hline 1000 & & 100 & 20 & 9 & 137 & $17(12,4 \%)$ & $12(8,8 \%)$ & $10(7,3 \%)$ \\
\hline 1000 & & 95 & 5 & 13 & 270 & $25(9,3 \%)$ & $11(4,1 \%)$ & $8(3,0 \%)$ \\
\hline 1000 & b & 95 & 10 & 10 & 205 & $21(10,2 \%)$ & $11(5,4 \%)$ & $8(3,9 \%)$ \\
\hline 1000 & & 95 & 20 & 8 & 52 & $9(17,3 \%)$ & $9(17,3 \%)$ & $8(15,4 \%)$ \\
\hline 1000 & & 90 & 5 & 13 & 270 & $25(9,3 \%)$ & $11(4,1 \%)$ & $8(3,0 \%)$ \\
\hline 1000 & $\mathrm{c}$ & 90 & 10 & 10 & 205 & $21(10,2 \%)$ & $11(5,4 \%)$ & $8(3,0 \%)$ \\
\hline 1000 & & 90 & 20 & 8 & 52 & $9(17,3 \%)$ & $9(17,3 \%)$ & $8(15,4 \%)$ \\
\hline
\end{tabular}

Tabela A.7: Tabela de precisão e recall da lista de termos gerada usando 1000 laudos de treinamento

\begin{tabular}{|c|c|c|c|c|c|}
\hline $\begin{array}{c}\text { Doc. } \\
\text { Tr }\end{array}$ & Alpha & Theta & $\begin{array}{c}\text { Termos } \\
\text { Identificados }\end{array}$ & Precisão & Recall \\
\hline 1000 & 100 & 5 & 13 & $46 \%$ & $55 \%$ \\
\hline 1000 & 100 & 10 & 11 & $55 \%$ & $55 \%$ \\
\hline 1000 & 100 & 20 & 9 & $56 \%$ & $45 \%$ \\
\hline 1000 & 95 & 5 & 13 & $38 \%$ & $45 \%$ \\
\hline 1000 & 95 & 10 & 10 & $50 \%$ & $45 \%$ \\
\hline 1000 & 95 & 20 & 8 & $38 \%$ & $27 \%$ \\
\hline 1000 & 90 & 5 & 13 & $38 \%$ & $45 \%$ \\
\hline 1000 & 90 & 10 & 10 & $50 \%$ & $45 \%$ \\
\hline 1000 & 90 & 20 & 8 & $38 \%$ & $27 \%$ \\
\hline
\end{tabular}

Tabela A.8: Taxa de preenchimento para o conjunto $\operatorname{Tr}$ de 1000 laudos

\begin{tabular}{|c|c|c|c|c|c|}
\hline \multirow{2}{*}{$\begin{array}{c}\text { Doc. } \\
\text { Tr }\end{array}$} & \multirow{2}{*}{$\begin{array}{l}\text { Alpha/ } \\
\text { Theta }\end{array}$} & \multicolumn{4}{|c|}{ Taxa Preenchimento } \\
\hline & & $0 \%$ & $5 \%$ & $10 \%$ & $20 \%$ \\
\hline 1000 & \multirow{3}{*}{ a } & 3,2 & 37,5 & 72,6 & 90,1 \\
\hline 1000 & & 3,6 & 41,2 & 72,6 & 90,1 \\
\hline 1000 & & 7,4 & 56,7 & 77,3 & 90,1 \\
\hline 1000 & \multirow{3}{*}{ b } & 3,6 & 35,3 & 71,4 & 92,8 \\
\hline 1000 & & 4,5 & 40,9 & 71,4 & 92,8 \\
\hline 1000 & & 14,7 & 83,6 & 83,6 & 92,8 \\
\hline 1000 & \multirow{3}{*}{ 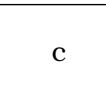 } & 3,6 & 35,3 & 71,4 & 92,8 \\
\hline 1000 & & 4,5 & 40,9 & 71,4 & 92,8 \\
\hline 1000 & & 14,7 & 83,6 & 83,6 & 92,8 \\
\hline
\end{tabular}


Tabela A.9: Garbage gerado a partir do conjunto de 1000 laudos de treinamento contendo 3995 frases, usando os limiares 0\%, 5\%, 10\% e 20\%

\begin{tabular}{|c|c|c|c|c|c|}
\hline $\begin{array}{c}\text { Alpha/ } \\
\text { Theta }\end{array}$ & $\begin{array}{c}\text { Número } \\
\text { parcial } \\
0 \%\end{array}$ & $\begin{array}{c}\text { Número } \\
\text { total } \\
0 \%\end{array}$ & $\begin{array}{c}\text { \% processada } \\
\text { parcial / } \\
\text { sem processar }\end{array}$ & $\begin{array}{c}\% \text { processada } \\
\text { parcial }\end{array}$ & $\begin{array}{c}\% \text { sem } \\
\text { processar }\end{array}$ \\
\hline \multirow{3}{*}{ a } & 157 & 17 & $4,4 \%$ & $90,2 \%$ & $9,8 \%$ \\
\cline { 2 - 6 } & 157 & 17 & $4,4 \%$ & $90,2 \%$ & $9,8 \%$ \\
\cline { 2 - 6 } & 166 & 38 & $5,1 \%$ & $81,4 \%$ & $18,6 \%$ \\
\hline \multirow{3}{*}{$\mathrm{b}$} & 156 & 35 & $4,8 \%$ & $81,7 \%$ & $18,3 \%$ \\
\cline { 2 - 6 } & 165 & 37 & $5,1 \%$ & $81,7 \%$ & $18,3 \%$ \\
\cline { 2 - 6 } & 138 & 204 & $8,6 \%$ & $40,4 \%$ & $59,6 \%$ \\
\hline \multirow{3}{*}{$\mathrm{c}$} & 156 & 35 & $4,8 \%$ & $81,7 \%$ & $18,3 \%$ \\
\cline { 2 - 6 } & 165 & 37 & $5,1 \%$ & $81,7 \%$ & $18,3 \%$ \\
\cline { 2 - 6 } & 138 & 204 & $8,6 \%$ & $40,4 \%$ & $59,6 \%$ \\
\hline
\end{tabular}

\begin{tabular}{|c|c|c|c|c|c|}
\hline $\begin{array}{c}\text { Alpha/ } \\
\text { Theta }\end{array}$ & $\begin{array}{c}\text { Número } \\
\text { parcial } \\
5 \%\end{array}$ & $\begin{array}{c}\text { Número } \\
\text { total } \\
5 \%\end{array}$ & $\begin{array}{c}\text { \% processada } \\
\text { parcial / } \\
\text { sem processar }\end{array}$ & $\begin{array}{c}\text { \% processada } \\
\text { parcial }\end{array}$ & $\begin{array}{c}\% \text { sem } \\
\text { processar }\end{array}$ \\
\hline \multirow{3}{*}{ a } & 267 & 61 & $8,2 \%$ & $81,4 \%$ & $18,6 \%$ \\
\cline { 2 - 6 } & 267 & 61 & $8,2 \%$ & $81,4 \%$ & $18,6 \%$ \\
\cline { 2 - 6 } & 279 & 73 & $8,8 \%$ & $79,3 \%$ & $20,7 \%$ \\
\hline \multirow{3}{*}{ b } & 264 & 64 & $8,2 \%$ & $80,5 \%$ & $19,5 \%$ \\
\cline { 2 - 6 } & 287 & 65 & $8,8 \%$ & $81,5 \%$ & $18,5 \%$ \\
\cline { 2 - 6 } & 168 & 226 & $9,9 \%$ & $42,6 \%$ & $57,4 \%$ \\
\hline \multirow{3}{*}{$\mathrm{c}$} & 264 & 64 & $8,2 \%$ & $80,5 \%$ & $19,5 \%$ \\
\cline { 2 - 6 } & 287 & 65 & $8,8 \%$ & $81,5 \%$ & $18,5 \%$ \\
\cline { 2 - 6 } & 168 & 226 & $9,9 \%$ & $42,6 \%$ & $57,4 \%$ \\
\hline
\end{tabular}

\begin{tabular}{|c|c|c|c|c|c|}
\hline $\begin{array}{c}\text { Alpha/ } \\
\text { Theta }\end{array}$ & $\begin{array}{c}\text { Número } \\
\text { parcial } \\
10 \%\end{array}$ & $\begin{array}{c}\text { Número } \\
\text { total } \\
10 \%\end{array}$ & $\begin{array}{c}\text { \% processada } \\
\text { parcial / } \\
\text { sem processar }\end{array}$ & $\begin{array}{c}\text { \% processada } \\
\text { parcial }\end{array}$ & $\begin{array}{c}\% \text { sem } \\
\text { processar }\end{array}$ \\
\hline \multirow{3}{*}{$\mathrm{a}$} & 331 & 63 & $9,9 \%$ & $84,0 \%$ & $16,0 \%$ \\
\cline { 2 - 6 } & 331 & 63 & $9,9 \%$ & $84,0 \%$ & $16,0 \%$ \\
\cline { 2 - 6 } & 321 & 73 & $9,9 \%$ & $81,5 \%$ & $18,5 \%$ \\
\hline \multirow{3}{*}{$\mathrm{b}$} & 329 & 65 & $9,9 \%$ & $83,5 \%$ & $16,5 \%$ \\
\cline { 2 - 6 } & 329 & 65 & $9,9 \%$ & $83,5 \%$ & $16,5 \%$ \\
\cline { 2 - 6 } & 168 & 226 & $9,9 \%$ & $42,6 \%$ & $57,4 \%$ \\
\hline \multirow{3}{*}{$\mathrm{c}$} & 329 & 65 & $9,9 \%$ & $83,5 \%$ & $16,5 \%$ \\
\cline { 2 - 6 } & 329 & 65 & $9,9 \%$ & $83,5 \%$ & $16,5 \%$ \\
\cline { 2 - 6 } & 168 & 226 & $9,9 \%$ & $42,6 \%$ & $57,4 \%$ \\
\hline
\end{tabular}

\begin{tabular}{|c|c|c|c|c|c|}
\hline $\begin{array}{c}\text { Alpha/ } \\
\text { Theta }\end{array}$ & $\begin{array}{c}\text { Número } \\
\text { parcial } \\
20 \%\end{array}$ & $\begin{array}{c}\text { Número } \\
\text { total } \\
20 \%\end{array}$ & $\begin{array}{c}\text { \% processada } \\
\text { parcial / } \\
\text { sem processar }\end{array}$ & $\begin{array}{c}\text { \% processada } \\
\text { parcial }\end{array}$ & $\begin{array}{c}\text { \% sem } \\
\text { processar }\end{array}$ \\
\hline \multirow{3}{*}{$\mathrm{a}$} & 172 & 223 & $9,9 \%$ & $43,5 \%$ & $56,5 \%$ \\
\cline { 2 - 6 } & 172 & 223 & $9,9 \%$ & $43,5 \%$ & $56,5 \%$ \\
\cline { 2 - 6 } & 172 & 223 & $9,9 \%$ & $43,5 \%$ & $56,5 \%$ \\
\hline \multirow{3}{*}{$\mathrm{b}$} & 169 & 226 & $9,9 \%$ & $42,8 \%$ & $57,2 \%$ \\
\cline { 2 - 6 } & 169 & 226 & $9,9 \%$ & $42,8 \%$ & $57,2 \%$ \\
\cline { 2 - 6 } & 169 & 226 & $9,9 \%$ & $42,8 \%$ & $57,2 \%$ \\
\hline \multirow{3}{*}{$\mathrm{c}$} & 169 & 226 & $9,9 \%$ & $42,8 \%$ & $57,2 \%$ \\
\cline { 2 - 6 } & 169 & 226 & $9,9 \%$ & $42,8 \%$ & $57,2 \%$ \\
\cline { 2 - 6 } & 169 & 226 & $9,9 \%$ & $42,8 \%$ & $57,2 \%$ \\
\hline
\end{tabular}


Tabela A.10: Garbage gerado a partir do conjunto de 1000 laudos de teste contendo 4011 frases, usando os limiares 0\%, 5\%, 10\% e 20\%

\begin{tabular}{|c|c|c|c|c|c|}
\hline $\begin{array}{c}\text { Alpha/ } \\
\text { Theta }\end{array}$ & $\begin{array}{c}\text { Número } \\
\text { parcial } \\
0 \%\end{array}$ & $\begin{array}{c}\text { Número } \\
\text { total } \\
0 \%\end{array}$ & $\begin{array}{c}\text { \% processada } \\
\text { parcial / } \\
\text { sem processar }\end{array}$ & $\begin{array}{c}\% \text { processada } \\
\text { parcial }\end{array}$ & $\begin{array}{c}\% \text { sem } \\
\text { processar }\end{array}$ \\
\hline \multirow{3}{*}{ a } & 198 & 34 & $5,8 \%$ & $85,3 \%$ & $14,7 \%$ \\
\cline { 2 - 6 } & 198 & 34 & $5,8 \%$ & $85,3 \%$ & $14,7 \%$ \\
\cline { 2 - 6 } & 179 & 66 & $6,1 \%$ & $73,1 \%$ & $26,9 \%$ \\
\hline \multirow{3}{*}{$\mathrm{b}$} & 191 & 47 & $5,9 \%$ & $80,3 \%$ & $19,7 \%$ \\
\cline { 2 - 6 } & 193 & 53 & $6,1 \%$ & $78,5 \%$ & $21,5 \%$ \\
\cline { 2 - 6 } & 144 & 224 & $9,2 \%$ & $39,1 \%$ & $60,9 \%$ \\
\hline \multirow{3}{*}{$\mathrm{c}$} & 191 & 47 & $5,9 \%$ & $80,3 \%$ & $19,7 \%$ \\
\cline { 2 - 6 } & 193 & 53 & $6,1 \%$ & $78,5 \%$ & $21,5 \%$ \\
\cline { 2 - 6 } & 144 & 224 & $9,2 \%$ & $39,1 \%$ & $60,9 \%$ \\
\hline
\end{tabular}

\begin{tabular}{|c|c|c|c|c|c|}
\hline $\begin{array}{c}\text { Alpha/ } \\
\text { Theta }\end{array}$ & $\begin{array}{c}\text { Número } \\
\text { parcial } \\
5 \%\end{array}$ & $\begin{array}{c}\text { Número } \\
\text { total } \\
5 \%\end{array}$ & $\begin{array}{c}\text { \% processada } \\
\text { parcial / } \\
\text { sem processar }\end{array}$ & $\begin{array}{c}\text { \% processada } \\
\text { parcial }\end{array}$ & $\begin{array}{c}\% \text { sem } \\
\text { processar }\end{array}$ \\
\hline \multirow{3}{*}{$\mathrm{a}$} & 284 & 65 & $8,7 \%$ & $81,4 \%$ & $18,6 \%$ \\
\cline { 2 - 6 } & 284 & 65 & $8,7 \%$ & $81,4 \%$ & $18,6 \%$ \\
\cline { 2 - 6 } & 286 & 90 & $9,4 \%$ & $76,1 \%$ & $23,9 \%$ \\
\hline \multirow{3}{*}{$\mathrm{b}$} & 281 & 68 & $8,7 \%$ & $80,5 \%$ & $19,5 \%$ \\
\cline { 2 - 6 } & 302 & 74 & $9,4 \%$ & $80,3 \%$ & $19,7 \%$ \\
\cline { 2 - 6 } & 192 & 237 & $10,7 \%$ & $44,8 \%$ & $55,2 \%$ \\
\hline \multirow{3}{*}{$\mathrm{c}$} & 281 & 68 & $8,7 \%$ & $80,5 \%$ & $19,5 \%$ \\
\cline { 2 - 6 } & 302 & 74 & $9,4 \%$ & $80,3 \%$ & $19,7 \%$ \\
\cline { 2 - 6 } & 192 & 237 & $10,7 \%$ & $44,8 \%$ & $55,2 \%$ \\
\hline
\end{tabular}

\begin{tabular}{|c|c|c|c|c|c|}
\hline $\begin{array}{c}\text { Alpha/ } \\
\text { Theta }\end{array}$ & $\begin{array}{c}\text { Número } \\
\text { parcial } \\
10 \%\end{array}$ & $\begin{array}{c}\text { Número } \\
\text { total } \\
10 \%\end{array}$ & $\begin{array}{c}\text { \% processada } \\
\text { parcial / } \\
\text { sem processar }\end{array}$ & $\begin{array}{c}\text { \% processada } \\
\text { parcial }\end{array}$ & $\begin{array}{c}\% \text { sem } \\
\text { processar }\end{array}$ \\
\hline \multirow{3}{*}{$\mathrm{a}$} & 355 & 74 & $10,7 \%$ & $82,8 \%$ & $17,2 \%$ \\
\cline { 2 - 6 } & 355 & 74 & $10,7 \%$ & $82,8 \%$ & $17,2 \%$ \\
\cline { 2 - 6 } & 339 & 90 & $10,7 \%$ & $79,0 \%$ & $21,0 \%$ \\
\hline \multirow{3}{*}{$\mathrm{b}$} & 355 & 74 & $10,7 \%$ & $82,8 \%$ & $17,2 \%$ \\
\cline { 2 - 6 } & 355 & 74 & $10,7 \%$ & $82,8 \%$ & $17,2 \%$ \\
\cline { 2 - 6 } & 192 & 237 & $10,7 \%$ & $44,8 \%$ & $55,2 \%$ \\
\hline \multirow{3}{*}{$\mathrm{c}$} & 355 & 74 & $10,7 \%$ & $82,8 \%$ & $17,2 \%$ \\
\cline { 2 - 6 } & 355 & 74 & $10,7 \%$ & $82,8 \%$ & $17,2 \%$ \\
\cline { 2 - 6 } & 192 & 237 & $10,7 \%$ & $44,8 \%$ & $55,2 \%$ \\
\hline
\end{tabular}

\begin{tabular}{|c|c|c|c|c|c|}
\hline $\begin{array}{c}\text { Alpha/ } \\
\text { Theta }\end{array}$ & $\begin{array}{c}\text { Número } \\
\text { parcial } \\
20 \%\end{array}$ & $\begin{array}{c}\text { Número } \\
\text { total } \\
20 \%\end{array}$ & $\begin{array}{c}\text { \% processada } \\
\text { parcial / } \\
\text { sem processar }\end{array}$ & $\begin{array}{c}\text { \% processada } \\
\text { parcial }\end{array}$ & $\begin{array}{c}\% \text { sem } \\
\text { processar }\end{array}$ \\
\hline \multirow{3}{*}{$\mathrm{a}$} & 194 & 237 & $10,7 \%$ & $45,0 \%$ & $55,0 \%$ \\
\cline { 2 - 6 } & 194 & 237 & $10,7 \%$ & $45,0 \%$ & $55,0 \%$ \\
\cline { 2 - 6 } & 194 & 237 & $10,7 \%$ & $45,0 \%$ & $55,0 \%$ \\
\hline \multirow{3}{*}{$\mathrm{b}$} & 194 & 237 & $10,7 \%$ & $45,0 \%$ & $55,0 \%$ \\
\cline { 2 - 6 } & 194 & 237 & $10,7 \%$ & $45,0 \%$ & $55,0 \%$ \\
\cline { 2 - 6 } & 194 & 237 & $10,7 \%$ & $45,0 \%$ & $55,0 \%$ \\
\cline { 2 - 6 } $\mathrm{c}$ & 194 & 237 & $10,7 \%$ & $45,0 \%$ & $55,0 \%$ \\
\cline { 2 - 6 } & 194 & 237 & $10,7 \%$ & $45,0 \%$ & $55,0 \%$ \\
\cline { 2 - 6 } & 194 & 237 & $10,7 \%$ & $45,0 \%$ & $55,0 \%$ \\
\hline
\end{tabular}


Tabela A.11: Número de termos raíz e número de atributos identificados usando 2000 laudos de treinamento

\begin{tabular}{|c|c|c|c|c|c|c|c|c|}
\hline \multirow{2}{*}{$\begin{array}{c}\text { Doc. } \\
\text { Tr }\end{array}$} & \multirow{2}{*}{ 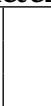 } & \multirow[b]{2}{*}{ Alpha } & \multirow[b]{2}{*}{ Theta } & \multirow{2}{*}{$\begin{array}{c}\text { Número } \\
\text { termos } \\
\text { (raiz) }\end{array}$} & \multicolumn{4}{|c|}{ Número de atributos } \\
\hline & & & & & $0 \%$ & $5 \%$ & $10 \%$ & $20 \%$ \\
\hline 2000 & \multirow{3}{*}{ a } & 100 & 5 & 15 & 602 & $36(6,0 \%)$ & $17(2,8 \%)$ & $14(2,3 \%)$ \\
\hline 2000 & & 100 & 10 & 12 & 532 & $32(6,0 \%)$ & $17(3,2 \%)$ & $14(2,6 \%)$ \\
\hline 2000 & & 100 & 20 & 10 & 245 & $24(9,8 \%)$ & $16(6,5 \%)$ & $14(5,7 \%)$ \\
\hline 2000 & \multirow{3}{*}{$\mathrm{b}$} & 95 & 5 & 16 & 445 & 31 (7,0\%) & 13 (2,9\%) & $11(2,5 \%)$ \\
\hline 2000 & & 95 & 10 & 12 & 340 & $26(7,6 \%)$ & $13(3,8 \%)$ & $11(3,2 \%)$ \\
\hline 2000 & & 95 & 20 & 10 & 100 & $14(14,0 \%)$ & $11(11,0 \%)$ & $11(11,0 \%)$ \\
\hline 2000 & \multirow{3}{*}{ c } & 90 & 5 & 16 & 445 & $31(7,0 \%)$ & $13(2,9 \%)$ & $11(2,5 \%)$ \\
\hline 2000 & & 90 & 10 & 12 & 340 & $26(7,6 \%)$ & $13(3,8 \%)$ & $11(3,2 \%)$ \\
\hline 2000 & & 90 & 20 & 10 & 100 & $14(14,0 \%)$ & $11(11,0 \%)$ & $11(11,0 \%)$ \\
\hline
\end{tabular}

Tabela A.12: Tabela de precisão e recall da lista de termos gerada usando 2000 laudos de treinamento

\begin{tabular}{|c|c|c|c|c|c|}
\hline $\begin{array}{c}\text { Doc. } \\
\text { Tr }\end{array}$ & Alpha & Theta & $\begin{array}{c}\text { Termos } \\
\text { Identificados }\end{array}$ & Precisão & Recall \\
\hline 2000 & 100 & 5 & 15 & $40 \%$ & $55 \%$ \\
\hline 2000 & 100 & 10 & 12 & $50 \%$ & $55 \%$ \\
\hline 2000 & 100 & 20 & 10 & $50 \%$ & $45 \%$ \\
\hline 2000 & 95 & 5 & 16 & $31 \%$ & $45 \%$ \\
\hline 2000 & 95 & 10 & 12 & $42 \%$ & $45 \%$ \\
\hline 2000 & 95 & 20 & 10 & $30 \%$ & $27 \%$ \\
\hline 2000 & 90 & 5 & 16 & $31 \%$ & $45 \%$ \\
\hline 2000 & 90 & 10 & 12 & $42 \%$ & $45 \%$ \\
\hline 2000 & 90 & 20 & 10 & $30 \%$ & $27 \%$ \\
\hline
\end{tabular}

Tabela A.13: Taxa de preenchimento para o conjunto $\operatorname{Tr}$ de 2000 laudos

\begin{tabular}{|c|c|c|c|c|c|}
\hline \multirow{2}{*}{$\begin{array}{c}\text { Doc. } \\
\operatorname{Tr}\end{array}$} & \multirow{2}{*}{$\begin{array}{l}\text { Alpha/ } \\
\text { Theta }\end{array}$} & \multicolumn{4}{|c|}{ Taxa Preenchimento } \\
\hline & & $0 \%$ & $5 \%$ & $10 \%$ & $20 \%$ \\
\hline 2000 & \multirow{3}{*}{ a } & 2,6 & 39,3 & 75,5 & 88,2 \\
\hline 2000 & & 2,8 & 43,4 & 75,5 & 88,2 \\
\hline 2000 & & 5,6 & 55,1 & 79,2 & 88,2 \\
\hline 2000 & \multirow{3}{*}{ b } & 2,8 & 36,6 & 77,8 & 88,8 \\
\hline 2000 & & 3,4 & 42,5 & 77,8 & 88,8 \\
\hline 2000 & & 10 & 71,3 & 88,8 & 88,8 \\
\hline 2000 & \multirow{3}{*}{$\mathrm{c}$} & 2,8 & 36,6 & 77,8 & 88,8 \\
\hline 2000 & & 3,4 & 42,5 & 77,8 & 88,8 \\
\hline 2000 & & 10 & 71,3 & 88,8 & 88,8 \\
\hline
\end{tabular}


Tabela A.14: Garbage gerado a partir do conjunto de 2000 laudos de treinamento contendo 8005 frases, usando os limiares $0 \%, 5 \%, 10 \%$ e $20 \%$

\begin{tabular}{|c|c|c|c|c|c|}
\hline $\begin{array}{c}\text { Alpha/ } \\
\text { Theta }\end{array}$ & $\begin{array}{c}\text { Número } \\
\text { parcial } \\
0 \%\end{array}$ & $\begin{array}{c}\text { Número } \\
\text { total } \\
0 \%\end{array}$ & $\begin{array}{c}\text { \% processada } \\
\text { parcial / } \\
\text { sem processar }\end{array}$ & $\begin{array}{c}\text { \% processada } \\
\text { parcial }\end{array}$ & $\begin{array}{c}\% \text { sem } \\
\text { processar }\end{array}$ \\
\hline \multirow{3}{*}{$\mathrm{a}$} & 290 & 44 & $4,2 \%$ & $86,8 \%$ & $13,2 \%$ \\
\cline { 2 - 6 } & 291 & 44 & $4,2 \%$ & $86,9 \%$ & $13,1 \%$ \\
\cline { 2 - 6 } & 308 & 85 & $4,9 \%$ & $78,4 \%$ & $21,6 \%$ \\
\hline \multirow{3}{*}{$\mathrm{b}$} & 300 & 77 & $4,7 \%$ & $79,6 \%$ & $20,4 \%$ \\
\cline { 2 - 6 } & 319 & 86 & $5,1 \%$ & $78,8 \%$ & $21,2 \%$ \\
\cline { 2 - 6 } & 264 & 426 & $8,6 \%$ & $38,3 \%$ & $61,7 \%$ \\
\hline \multirow{3}{*}{$\mathrm{c}$} & 300 & 77 & $4,7 \%$ & $79,6 \%$ & $20,4 \%$ \\
\cline { 2 - 6 } & 319 & 86 & $5,1 \%$ & $78,8 \%$ & $21,2 \%$ \\
\cline { 2 - 6 } & 264 & 426 & $8,6 \%$ & $38,3 \%$ & $61,7 \%$ \\
\hline
\end{tabular}

\begin{tabular}{|c|c|c|c|c|c|}
\hline $\begin{array}{c}\text { Alpha/ } \\
\text { Theta }\end{array}$ & $\begin{array}{c}\text { Número } \\
\text { parcial } \\
5 \%\end{array}$ & $\begin{array}{c}\text { Número } \\
\text { total } \\
5 \%\end{array}$ & $\begin{array}{c}\text { \% processada } \\
\text { parcial / } \\
\text { sem processar }\end{array}$ & $\begin{array}{c}\text { \% processada } \\
\text { parcial }\end{array}$ & $\begin{array}{c}\% \text { sem } \\
\text { processar }\end{array}$ \\
\hline \multirow{3}{*}{$\mathrm{a}$} & 461 & 109 & $7,1 \%$ & $80,9 \%$ & $19,1 \%$ \\
\cline { 2 - 6 } & 461 & 110 & $7,1 \%$ & $80,7 \%$ & $19,3 \%$ \\
\cline { 2 - 6 } & 463 & 150 & $7,7 \%$ & $75,5 \%$ & $24,5 \%$ \\
\hline \multirow{3}{*}{$\mathrm{b}$} & 443 & 127 & $7,1 \%$ & $77,7 \%$ & $22,3 \%$ \\
\cline { 2 - 6 } & 475 & 138 & $7,7 \%$ & $77,5 \%$ & $22,5 \%$ \\
\cline { 2 - 6 } & 243 & 470 & $8,9 \%$ & $34,1 \%$ & $65,9 \%$ \\
\cline { 2 - 6 } & 443 & 127 & $7,1 \%$ & $77,7 \%$ & $22,3 \%$ \\
\cline { 2 - 6 } & 475 & 138 & $7,7 \%$ & $77,5 \%$ & $22,5 \%$ \\
\hline
\end{tabular}

\begin{tabular}{|c|c|c|c|c|c|}
\hline $\begin{array}{c}\text { Alpha/ } \\
\text { Theta }\end{array}$ & $\begin{array}{c}\text { Número } \\
\text { parcial } \\
10 \%\end{array}$ & $\begin{array}{c}\text { Número } \\
\text { total } \\
10 \%\end{array}$ & $\begin{array}{c}\text { \% processada } \\
\text { parcial / } \\
\text { sem processar }\end{array}$ & $\begin{array}{c}\text { \% processada } \\
\text { parcial }\end{array}$ & $\begin{array}{c}\text { \% sem } \\
\text { processar }\end{array}$ \\
\hline \multirow{3}{*}{$\mathrm{a}$} & 697 & 126 & $10,3 \%$ & $84,7 \%$ & $15,3 \%$ \\
\cline { 2 - 6 } & 697 & 126 & $10,3 \%$ & $84,7 \%$ & $15,3 \%$ \\
\cline { 2 - 6 } & 673 & 150 & $10,3 \%$ & $81,8 \%$ & $18,2 \%$ \\
\hline \multirow{3}{*}{$\mathrm{b}$} & 685 & 138 & $10,3 \%$ & $83,2 \%$ & $16,8 \%$ \\
\cline { 2 - 6 } & 685 & 138 & $10,3 \%$ & $83,2 \%$ & $16,8 \%$ \\
\cline { 2 - 6 } & 353 & 470 & $10,3 \%$ & $42,9 \%$ & $57,1 \%$ \\
\cline { 2 - 6 } $\mathrm{c}$ & 685 & 138 & $10,3 \%$ & $83,2 \%$ & $16,8 \%$ \\
\cline { 2 - 6 } & 685 & 138 & $10,3 \%$ & $83,2 \%$ & $16,8 \%$ \\
\cline { 2 - 6 } & 353 & 470 & $10,3 \%$ & $42,9 \%$ & $57,1 \%$ \\
\hline
\end{tabular}

\begin{tabular}{|c|c|c|c|c|c|}
\hline $\begin{array}{c}\text { Alpha/ } \\
\text { Theta }\end{array}$ & $\begin{array}{c}\text { Número } \\
\text { parcial } \\
20 \%\end{array}$ & $\begin{array}{c}\text { Número } \\
\text { total } \\
20 \%\end{array}$ & $\begin{array}{c}\text { \% processada } \\
\text { parcial / } \\
\text { sem processar }\end{array}$ & $\begin{array}{c}\text { \% processada } \\
\text { parcial }\end{array}$ & $\begin{array}{c}\% \text { sem } \\
\text { processar }\end{array}$ \\
\hline \multirow{3}{*}{$\mathrm{a}$} & 362 & 461 & $10,3 \%$ & $44,0 \%$ & $56,0 \%$ \\
\cline { 2 - 6 } & 362 & 461 & $10,3 \%$ & $44,0 \%$ & $56,0 \%$ \\
\cline { 2 - 6 } & 362 & 461 & $10,3 \%$ & $44,0 \%$ & $56,0 \%$ \\
\hline \multirow{3}{*}{$\mathrm{b}$} & 353 & 470 & $10,3 \%$ & $42,9 \%$ & $57,1 \%$ \\
\cline { 2 - 6 } & 353 & 470 & $10,3 \%$ & $42,9 \%$ & $57,1 \%$ \\
\cline { 2 - 6 } & 353 & 470 & $10,3 \%$ & $42,9 \%$ & $57,1 \%$ \\
\cline { 2 - 6 } $\mathrm{c}$ & 353 & 470 & $10,3 \%$ & $42,9 \%$ & $57,1 \%$ \\
\cline { 2 - 6 } & 353 & 470 & $10,3 \%$ & $42,9 \%$ & $57,1 \%$ \\
\hline
\end{tabular}


Tabela A.15: Garbage gerado a partir do conjunto de 2000 laudos de teste contendo 3998 frases, usando os limiares 0\%, 5\%, 10\% e 20\%

\begin{tabular}{|c|c|c|c|c|c|}
\hline $\begin{array}{c}\text { Alpha/ } \\
\text { Theta }\end{array}$ & $\begin{array}{c}\text { Número } \\
\text { parcial } \\
\text { O\% }\end{array}$ & $\begin{array}{c}\text { Número } \\
\text { total } \\
\text { 0\% }\end{array}$ & $\begin{array}{c}\text { \% processada } \\
\text { parcial / } \\
\text { sem processar }\end{array}$ & $\begin{array}{c}\% \text { processada } \\
\text { parcial }\end{array}$ & $\begin{array}{c}\% \text { sem } \\
\text { processar }\end{array}$ \\
\hline \multirow{3}{*}{$\mathrm{a}$} & 166 & 11 & $4,4 \%$ & $93,8 \%$ & $6,2 \%$ \\
\cline { 2 - 6 } & 167 & 11 & $4,5 \%$ & $93,8 \%$ & $6,2 \%$ \\
\cline { 2 - 6 } & 170 & 27 & $4,9 \%$ & $86,3 \%$ & $13,7 \%$ \\
\hline \multirow{3}{*}{$\mathrm{b}$} & 164 & 19 & $4,6 \%$ & $89,6 \%$ & $10,4 \%$ \\
\cline { 2 - 6 } & 176 & 19 & $4,9 \%$ & $90,3 \%$ & $9,7 \%$ \\
\hline \multirow{3}{*}{$\mathrm{c}$} & 125 & 190 & $7,9 \%$ & $39,7 \%$ & $60,3 \%$ \\
\cline { 2 - 6 } & 164 & 19 & $4,6 \%$ & $89,6 \%$ & $10,4 \%$ \\
\cline { 2 - 6 } & 176 & 19 & $4,9 \%$ & $90,3 \%$ & $9,7 \%$ \\
\hline
\end{tabular}

\begin{tabular}{|c|c|c|c|c|c|}
\hline $\begin{array}{c}\text { Alpha/ } \\
\text { Theta }\end{array}$ & $\begin{array}{c}\text { Número } \\
\text { parcial } \\
5 \%\end{array}$ & $\begin{array}{c}\text { Número } \\
\text { total } \\
5 \%\end{array}$ & $\begin{array}{c}\text { \% processada } \\
\text { parcial / } \\
\text { sem processar }\end{array}$ & $\begin{array}{c}\text { \% processada } \\
\text { parcial }\end{array}$ & $\begin{array}{c}\% \text { sem } \\
\text { processar }\end{array}$ \\
\hline \multirow{3}{*}{$\mathrm{a}$} & 224 & 35 & $6,5 \%$ & $86,5 \%$ & $13,5 \%$ \\
\cline { 2 - 6 } & 224 & 35 & $6,5 \%$ & $86,5 \%$ & $13,5 \%$ \\
\cline { 2 - 6 } & 228 & 52 & $7,0 \%$ & $81,4 \%$ & $18,6 \%$ \\
\hline \multirow{3}{*}{$\mathrm{b}$} & 220 & 39 & $6,5 \%$ & $84,9 \%$ & $15,1 \%$ \\
\cline { 2 - 6 } & 241 & 39 & $7,0 \%$ & $86,1 \%$ & $13,9 \%$ \\
\cline { 2 - 6 } & 124 & 203 & $8,2 \%$ & $37,9 \%$ & $62,1 \%$ \\
\hline \multirow{3}{*}{$\mathrm{c}$} & 220 & 39 & $6,5 \%$ & $84,9 \%$ & $15,1 \%$ \\
\cline { 2 - 6 } & 241 & 39 & $7,0 \%$ & $86,1 \%$ & $13,9 \%$ \\
\cline { 2 - 6 } & 124 & 203 & $8,2 \%$ & $37,9 \%$ & $62,1 \%$ \\
\hline
\end{tabular}

\begin{tabular}{|c|c|c|c|c|c|}
\hline $\begin{array}{c}\text { Alpha/ } \\
\text { Theta }\end{array}$ & $\begin{array}{c}\text { Número } \\
\text { parcial } \\
10 \%\end{array}$ & $\begin{array}{c}\text { Número } \\
\text { total } \\
10 \%\end{array}$ & $\begin{array}{c}\text { \% processada } \\
\text { parcial / } \\
\text { sem processar }\end{array}$ & $\begin{array}{c}\% \text { processada } \\
\text { parcial }\end{array}$ & $\begin{array}{c}\% \text { sem } \\
\text { processar }\end{array}$ \\
\hline \multirow{3}{*}{$\mathrm{a}$} & 342 & 38 & $9,5 \%$ & $90,0 \%$ & $10,0 \%$ \\
\cline { 2 - 6 } & 342 & 38 & $9,5 \%$ & $90,0 \%$ & $10,0 \%$ \\
\cline { 2 - 6 } & 328 & 52 & $9,5 \%$ & $86,3 \%$ & $13,7 \%$ \\
\hline \multirow{3}{*}{$\mathrm{b}$} & 341 & 39 & $9,5 \%$ & $89,7 \%$ & $10,3 \%$ \\
\cline { 2 - 6 } & 341 & 39 & $9,5 \%$ & $89,7 \%$ & $10,3 \%$ \\
\cline { 2 - 6 } & 177 & 203 & $9,5 \%$ & $46,6 \%$ & $53,4 \%$ \\
\cline { 2 - 6 } $\mathrm{c}$ & 341 & 39 & $9,5 \%$ & $89,7 \%$ & $10,3 \%$ \\
\cline { 2 - 6 } & 341 & 39 & $9,5 \%$ & $89,7 \%$ & $10,3 \%$ \\
\hline
\end{tabular}

\begin{tabular}{|c|c|c|c|c|c|}
\hline $\begin{array}{c}\text { Alpha/ } \\
\text { Theta }\end{array}$ & $\begin{array}{c}\text { Número } \\
\text { parcial } \\
20 \%\end{array}$ & $\begin{array}{c}\text { Número } \\
\text { total } \\
20 \%\end{array}$ & $\begin{array}{c}\text { \% processada } \\
\text { parcial / } \\
\text { sem processar }\end{array}$ & $\begin{array}{c}\text { \% processada } \\
\text { parcial }\end{array}$ & $\begin{array}{c}\% \text { sem } \\
\text { processar }\end{array}$ \\
\hline \multirow{3}{*}{$\mathrm{a}$} & 178 & 202 & $9,5 \%$ & $46,8 \%$ & $53,2 \%$ \\
\cline { 2 - 6 } & 178 & 202 & $9,5 \%$ & $46,8 \%$ & $53,2 \%$ \\
\cline { 2 - 6 } & 178 & 202 & $9,5 \%$ & $46,8 \%$ & $53,2 \%$ \\
\hline \multirow{3}{*}{$\mathrm{b}$} & 177 & 203 & $9,5 \%$ & $46,6 \%$ & $53,4 \%$ \\
\cline { 2 - 6 } & 177 & 203 & $9,5 \%$ & $46,6 \%$ & $53,4 \%$ \\
\hline \multirow{3}{*}{$\mathrm{c}$} & 177 & 203 & $9,5 \%$ & $46,6 \%$ & $53,4 \%$ \\
\cline { 2 - 6 } & 177 & 203 & $9,5 \%$ & $46,6 \%$ & $53,4 \%$ \\
\cline { 2 - 6 } & 177 & 203 & $9,5 \%$ & $46,6 \%$ & $53,4 \%$ \\
\hline
\end{tabular}


Tabela A.16: Número de termos raíz e número de atributos identificados usando 4000 laudos de treinamento

\begin{tabular}{|c|c|c|c|c|c|c|c|c|}
\hline \multirow{2}{*}{$\begin{array}{c}\text { Doc. } \\
\operatorname{Tr}\end{array}$} & \multirow{2}{*}{ 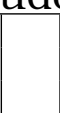 } & \multirow[b]{2}{*}{ Alpha } & \multirow[b]{2}{*}{ Theta } & \multirow{2}{*}{$\begin{array}{c}\text { Número } \\
\text { termos } \\
\text { (raíz) }\end{array}$} & \multicolumn{4}{|c|}{ Número de atributos } \\
\hline & & & & & $0 \%$ & $5 \%$ & $10 \%$ & $20 \%$ \\
\hline 4000 & \multirow{3}{*}{$\mathrm{a}$} & 100 & 5 & 14 & 989 & $33(3,3 \%)$ & $18(1,8 \%)$ & $14(1,4 \%)$ \\
\hline 4000 & & 100 & 10 & 12 & 869 & $30(3,5 \%)$ & $18(2,1 \%)$ & $14(1,6 \%)$ \\
\hline 4000 & & 100 & 20 & 11 & 659 & $28(4,2 \%)$ & $18(2,8 \%)$ & $14(2,1 \%)$ \\
\hline 4000 & \multirow{3}{*}{$\mathrm{b}$} & 95 & 5 & 15 & 748 & $28(3,7 \%)$ & $14(1,9 \%)$ & $11(1,5 \%)$ \\
\hline 4000 & & 95 & 10 & 12 & 555 & $24(4,3 \%)$ & $14(2,5 \%)$ & $11(2,0 \%)$ \\
\hline 4000 & & 95 & 20 & 11 & 432 & $18(4,2 \%)$ & $13(3,0 \%)$ & $11(2,5 \%)$ \\
\hline 4000 & \multirow{3}{*}{$\mathrm{c}$} & 90 & 5 & 15 & 748 & $28(3,7 \%)$ & $14(1,9 \%)$ & $11(1,5 \%)$ \\
\hline 4000 & & 90 & 10 & 12 & 555 & $24(4,3 \%)$ & $14(2,5 \%)$ & $11(2,0 \%)$ \\
\hline 4000 & & 90 & 20 & 11 & 432 & $18(4,2 \%)$ & $13(3,0 \%)$ & $11(2,5 \%)$ \\
\hline
\end{tabular}

Tabela A.17: Tabela de precisão e recall da lista de termos gerada usando 4000 laudos de treinamento

\begin{tabular}{|c|c|c|c|c|c|}
\hline $\begin{array}{c}\text { Doc. } \\
\text { Tr }\end{array}$ & Alpha & Theta & $\begin{array}{c}\text { Termos } \\
\text { Identificados }\end{array}$ & Precisão & Recall \\
\hline 4000 & 100 & 5 & 14 & $43 \%$ & $55 \%$ \\
\hline 4000 & 100 & 10 & 12 & $50 \%$ & $55 \%$ \\
\hline 4000 & 100 & 20 & 11 & $55 \%$ & $55 \%$ \\
\hline 4000 & 95 & 5 & 15 & $33 \%$ & $45 \%$ \\
\hline 4000 & 95 & 10 & 12 & $42 \%$ & $45 \%$ \\
\hline 4000 & 95 & 20 & 11 & $36 \%$ & $36 \%$ \\
\hline 4000 & 90 & 5 & 15 & $33 \%$ & $45 \%$ \\
\hline 4000 & 90 & 10 & 12 & $42 \%$ & $45 \%$ \\
\hline 4000 & 90 & 20 & 11 & $36 \%$ & $36 \%$ \\
\hline
\end{tabular}

Tabela A.18: Taxa de preenchimento para o conjunto $\operatorname{Tr}$ de 4000 laudos

\begin{tabular}{|c|c|c|c|c|c|}
\hline \multirow{2}{*}{$\begin{array}{c}\text { Doc. } \\
\operatorname{Tr}\end{array}$} & \multirow{2}{*}{$\begin{array}{c}\text { Alpha/ } \\
\text { Theta }\end{array}$} & \multicolumn{4}{|c|}{ Taxa Preenchimento } \\
\hline & & $0 \%$ & $5 \%$ & $10 \%$ & $20 \%$ \\
\hline 4000 & \multirow{3}{*}{$\mathrm{a}$} & 1,6 & 42,4 & 71,8 & 87,9 \\
\hline 4000 & & 1,7 & 46 & 71,8 & 87,9 \\
\hline 4000 & & 2,2 & 48,8 & 71,8 & 87,9 \\
\hline 4000 & \multirow{3}{*}{ b } & 1,6 & 39,9 & 72,8 & 88,6 \\
\hline 4000 & & 2,1 & 45,6 & 72,8 & 88,6 \\
\hline 4000 & & 2,5 & 57,8 & 77,2 & 88,6 \\
\hline 4000 & \multirow{3}{*}{ c } & 1,6 & 39,9 & 72,8 & 88,6 \\
\hline 4000 & & 2,1 & 45,6 & 72,2 & 88,6 \\
\hline 4000 & & 2,5 & 57,8 & 77,2 & 88,6 \\
\hline
\end{tabular}


Tabela A.19: Garbage gerado a partir do conjunto de 4000 laudos de treinamento contendo 15990 frases, usando os limiares 0\%, 5\%, 10\% e 20\%

\begin{tabular}{|c|c|c|c|c|c|}
\hline $\begin{array}{c}\text { Alpha/ } \\
\text { Theta }\end{array}$ & $\begin{array}{c}\text { Número } \\
\text { parcial } \\
0 \%\end{array}$ & $\begin{array}{c}\text { Número } \\
\text { total } \\
0 \%\end{array}$ & $\begin{array}{c}\text { \% processada } \\
\text { parcial / } \\
\text { sem processar }\end{array}$ & $\begin{array}{c}\text { \% processada } \\
\text { parcial }\end{array}$ & $\begin{array}{c}\% \text { sem } \\
\text { processar }\end{array}$ \\
\hline \multirow{3}{*}{$\mathrm{a}$} & 646 & 74 & $4,5 \%$ & $89,7 \%$ & $10,3 \%$ \\
\cline { 2 - 6 } & 646 & 75 & $4,5 \%$ & $89,6 \%$ & $10,4 \%$ \\
\cline { 2 - 6 } & 674 & 123 & $5,0 \%$ & $84,6 \%$ & $15,4 \%$ \\
\hline \multirow{3}{*}{$\mathrm{b}$} & 658 & 144 & $5,0 \%$ & $82,0 \%$ & $18,0 \%$ \\
\cline { 2 - 6 } & 698 & 158 & $5,4 \%$ & $81,5 \%$ & $18,5 \%$ \\
\cline { 2 - 6 } & 1273 & 158 & $8,9 \%$ & $89,0 \%$ & $11,0 \%$ \\
\hline \multirow{3}{*}{$\mathrm{c}$} & 658 & 144 & $5,0 \%$ & $82,0 \%$ & $18,0 \%$ \\
\cline { 2 - 6 } & 698 & 158 & $5,4 \%$ & $81,5 \%$ & $18,5 \%$ \\
\cline { 2 - 6 } & 1273 & 158 & $8,9 \%$ & $89,0 \%$ & $11,0 \%$ \\
\hline
\end{tabular}

\begin{tabular}{|c|c|c|c|c|c|}
\hline $\begin{array}{c}\text { Alpha/ } \\
\text { Theta }\end{array}$ & $\begin{array}{c}\text { Número } \\
\text { parcial } \\
5 \%\end{array}$ & $\begin{array}{c}\text { Número } \\
\text { total } \\
5 \%\end{array}$ & $\begin{array}{c}\text { \% processada } \\
\text { parcial / } \\
\text { sem processar }\end{array}$ & $\begin{array}{c}\text { \% processada } \\
\text { parcial }\end{array}$ & $\begin{array}{c}\% \text { sem } \\
\text { processar }\end{array}$ \\
\hline \multirow{3}{*}{$\mathrm{a}$} & 1152 & 222 & $8,6 \%$ & $83,8 \%$ & $16,2 \%$ \\
\cline { 2 - 6 } & 1151 & 224 & $8,6 \%$ & $83,7 \%$ & $16,3 \%$ \\
\cline { 2 - 6 } & 1224 & 250 & $9,2 \%$ & $83,0 \%$ & $17,0 \%$ \\
\hline \multirow{3}{*}{$\mathrm{b}$} & 1120 & 255 & $8,6 \%$ & $81,5 \%$ & $18,5 \%$ \\
\cline { 2 - 6 } & 1204 & 270 & $9,2 \%$ & $81,7 \%$ & $18,3 \%$ \\
\cline { 2 - 6 } & 1396 & 270 & $10,4 \%$ & $83,8 \%$ & $16,2 \%$ \\
\hline \multirow{3}{*}{$\mathrm{c}$} & 1120 & 255 & $8,6 \%$ & $81,5 \%$ & $18,5 \%$ \\
\cline { 2 - 6 } & 1204 & 270 & $9,2 \%$ & $81,7 \%$ & $18,3 \%$ \\
\cline { 2 - 6 } & 1396 & 270 & $10,4 \%$ & $83,8 \%$ & $16,2 \%$ \\
\hline
\end{tabular}

\begin{tabular}{|c|c|c|c|c|c|}
\hline $\begin{array}{c}\text { Alpha/ } \\
\text { Theta }\end{array}$ & $\begin{array}{c}\text { Número } \\
\text { parcial } \\
10 \%\end{array}$ & $\begin{array}{c}\text { Número } \\
\text { total } \\
10 \%\end{array}$ & $\begin{array}{c}\text { \% processada } \\
\text { parcial / } \\
\text { sem processar }\end{array}$ & $\begin{array}{c}\text { \% processada } \\
\text { parcial }\end{array}$ & $\begin{array}{c}\% \text { sem } \\
\text { processar }\end{array}$ \\
\hline \multirow{3}{*}{$\mathrm{a}$} & 1416 & 250 & $10,4 \%$ & $85,0 \%$ & $15,0 \%$ \\
\cline { 2 - 6 } & 1416 & 250 & $10,4 \%$ & $85,0 \%$ & $15,0 \%$ \\
\cline { 2 - 6 } & 1416 & 250 & $10,4 \%$ & $85,0 \%$ & $15,0 \%$ \\
\hline \multirow{3}{*}{$\mathrm{b}$} & 1396 & 270 & $10,4 \%$ & $83,8 \%$ & $16,2 \%$ \\
\cline { 2 - 6 } & 1396 & 270 & $10,4 \%$ & $83,8 \%$ & $16,2 \%$ \\
\cline { 2 - 6 } & 1396 & 270 & $10,4 \%$ & $83,8 \%$ & $16,2 \%$ \\
\hline \multirow{3}{*}{$\mathrm{c}$} & 1396 & 270 & $10,4 \%$ & $83,8 \%$ & $16,2 \%$ \\
\cline { 2 - 6 } & 1396 & 270 & $10,4 \%$ & $83,8 \%$ & $16,2 \%$ \\
\cline { 2 - 6 } & 1396 & 270 & $10,4 \%$ & $83,8 \%$ & $16,2 \%$ \\
\hline
\end{tabular}

\begin{tabular}{|c|c|c|c|c|c|}
\hline $\begin{array}{c}\text { Alpha/ } \\
\text { Theta }\end{array}$ & $\begin{array}{c}\text { Número } \\
\text { parcial } \\
20 \%\end{array}$ & $\begin{array}{c}\text { Número } \\
\text { total } \\
20 \%\end{array}$ & $\begin{array}{c}\text { \% processada } \\
\text { parcial / } \\
\text { sem processar }\end{array}$ & $\begin{array}{c}\% \text { processada } \\
\text { parcial }\end{array}$ & $\begin{array}{c}\% \text { sem } \\
\text { processar }\end{array}$ \\
\hline \multirow{3}{*}{$\mathrm{a}$} & 732 & 936 & $10,4 \%$ & $43,9 \%$ & $56,1 \%$ \\
\cline { 2 - 6 } & 732 & 936 & $10,4 \%$ & $43,9 \%$ & $56,1 \%$ \\
\cline { 2 - 6 } & 732 & 936 & $10,4 \%$ & $43,9 \%$ & $56,1 \%$ \\
\hline \multirow{3}{*}{$\mathrm{b}$} & 718 & 950 & $10,4 \%$ & $43,0 \%$ & $57,0 \%$ \\
\cline { 2 - 6 } & 718 & 950 & $10,4 \%$ & $43,0 \%$ & $57,0 \%$ \\
\hline \multirow{3}{*}{$\mathrm{c}$} & 718 & 950 & $10,4 \%$ & $43,0 \%$ & $57,0 \%$ \\
\cline { 2 - 6 } & 718 & 950 & $10,4 \%$ & $43,0 \%$ & $57,0 \%$ \\
\cline { 2 - 6 } & 718 & 950 & $10,4 \%$ & $43,1 \%$ & $56,9 \%$ \\
\hline
\end{tabular}


Tabela A.20: Garbage gerado a partir do conjunto de 4000 laudos de teste contendo 4013 frases, usando os limiares 0\%, 5\%, 10\% e 20\%

\begin{tabular}{|c|c|c|c|c|c|}
\hline $\begin{array}{c}\text { Alpha/ } \\
\text { Theta }\end{array}$ & $\begin{array}{c}\text { Número } \\
\text { parcial } \\
0 \%\end{array}$ & $\begin{array}{c}\text { Número } \\
\text { total } \\
0 \%\end{array}$ & $\begin{array}{c}\text { \% processada } \\
\text { parcial / } \\
\text { sem processar }\end{array}$ & $\begin{array}{c}\% \text { processada } \\
\text { parcial }\end{array}$ & $\begin{array}{c}\% \text { sem } \\
\text { processar }\end{array}$ \\
\hline \multirow{3}{*}{$\mathrm{a}$} & 170 & 28 & $4,9 \%$ & $85,9 \%$ & $14,1 \%$ \\
\cline { 2 - 6 } & 171 & 28 & $5,0 \%$ & $85,9 \%$ & $14,1 \%$ \\
\cline { 2 - 6 } & 168 & 38 & $5,1 \%$ & $81,6 \%$ & $18,4 \%$ \\
\hline \multirow{3}{*}{$\mathrm{b}$} & 168 & 37 & $5,1 \%$ & $82,0 \%$ & $18,0 \%$ \\
\cline { 2 - 6 } & 169 & 42 & $5,3 \%$ & $80,1 \%$ & $19,9 \%$ \\
\cline { 2 - 6 } & 303 & 52 & $8,8 \%$ & $85,4 \%$ & $14,6 \%$ \\
\hline \multirow{3}{*}{$\mathrm{c}$} & 168 & 37 & $5,1 \%$ & $82,0 \%$ & $18,0 \%$ \\
\cline { 2 - 6 } & 169 & 42 & $5,3 \%$ & $80,1 \%$ & $19,9 \%$ \\
\cline { 2 - 6 } & 303 & 42 & $8,6 \%$ & $87,8 \%$ & $12,2 \%$ \\
\hline
\end{tabular}

\begin{tabular}{|c|c|c|c|c|c|}
\hline $\begin{array}{c}\text { Alpha/ } \\
\text { Theta }\end{array}$ & $\begin{array}{c}\text { Número } \\
\text { parcial } \\
5 \%\end{array}$ & $\begin{array}{c}\text { Número } \\
\text { total } \\
5 \%\end{array}$ & $\begin{array}{c}\text { \% processada } \\
\text { parcial / } \\
\text { sem processar }\end{array}$ & $\begin{array}{c}\text { \% processada } \\
\text { parcial }\end{array}$ & $\begin{array}{c}\% \text { sem } \\
\text { processar }\end{array}$ \\
\hline \multirow{3}{*}{$\mathrm{a}$} & 281 & 50 & $8,2 \%$ & $84,9 \%$ & $15,1 \%$ \\
\cline { 2 - 6 } & 281 & 50 & $8,2 \%$ & $84,9 \%$ & $15,1 \%$ \\
\cline { 2 - 6 } & 304 & 57 & $9,0 \%$ & $84,2 \%$ & $15,8 \%$ \\
\hline \multirow{3}{*}{$\mathrm{b}$} & 271 & 60 & $8,2 \%$ & $81,9 \%$ & $18,1 \%$ \\
\cline { 2 - 6 } & 298 & 63 & $9,0 \%$ & $82,5 \%$ & $17,5 \%$ \\
\cline { 2 - 6 } & 343 & 63 & $10,1 \%$ & $84,5 \%$ & $15,5 \%$ \\
\hline \multirow{3}{*}{$\mathrm{c}$} & 271 & 60 & $8,2 \%$ & $81,9 \%$ & $18,1 \%$ \\
\cline { 2 - 6 } & 298 & 63 & $9,0 \%$ & $82,5 \%$ & $17,5 \%$ \\
\cline { 2 - 6 } & 343 & 63 & $10,1 \%$ & $84,5 \%$ & $15,5 \%$ \\
\hline
\end{tabular}

\begin{tabular}{|c|c|c|c|c|c|}
\hline $\begin{array}{c}\text { Alpha/ } \\
\text { Theta }\end{array}$ & $\begin{array}{c}\text { Número } \\
\text { parcial } \\
10 \%\end{array}$ & $\begin{array}{c}\text { Número } \\
\text { total } \\
10 \%\end{array}$ & $\begin{array}{c}\text { \% processada } \\
\text { parcial / } \\
\text { sem processar }\end{array}$ & $\begin{array}{c}\text { \% processada } \\
\text { parcial }\end{array}$ & $\begin{array}{c}\% \text { sem } \\
\text { processar }\end{array}$ \\
\hline \multirow{3}{*}{$\mathrm{a}$} & 349 & 57 & $10,1 \%$ & $86,0 \%$ & $14,0 \%$ \\
\cline { 2 - 6 } & 349 & 57 & $10,1 \%$ & $86,0 \%$ & $14,0 \%$ \\
\cline { 2 - 6 } & 349 & 57 & $10,1 \%$ & $86,0 \%$ & $14,0 \%$ \\
\hline \multirow{3}{*}{$\mathrm{b}$} & 343 & 63 & $10,1 \%$ & $84,5 \%$ & $15,5 \%$ \\
\cline { 2 - 6 } & 343 & 63 & $10,1 \%$ & $84,5 \%$ & $15,5 \%$ \\
\cline { 2 - 6 } & 343 & 63 & $10,1 \%$ & $84,5 \%$ & $15,5 \%$ \\
\hline \multirow{3}{*}{$\mathrm{c}$} & 343 & 63 & $10,1 \%$ & $84,5 \%$ & $15,5 \%$ \\
\cline { 2 - 6 } & 343 & 63 & $10,1 \%$ & $84,5 \%$ & $15,5 \%$ \\
\cline { 2 - 6 } & 343 & 63 & $10,1 \%$ & $84,5 \%$ & $15,5 \%$ \\
\hline
\end{tabular}

\begin{tabular}{|c|c|c|c|c|c|}
\hline $\begin{array}{c}\text { Alpha/ } \\
\text { Theta }\end{array}$ & $\begin{array}{c}\text { Número } \\
\text { parcial } \\
20 \%\end{array}$ & $\begin{array}{c}\text { Número } \\
\text { total } \\
20 \%\end{array}$ & $\begin{array}{c}\text { \% processada } \\
\text { parcial / } \\
\text { sem processar }\end{array}$ & $\begin{array}{c}\text { \% processada } \\
\text { parcial }\end{array}$ & $\begin{array}{c}\% \text { sem } \\
\text { processar }\end{array}$ \\
\hline \multirow{3}{*}{$\mathrm{a}$} & 192 & 217 & $10,2 \%$ & $46,9 \%$ & $53,1 \%$ \\
\cline { 2 - 6 } & 192 & 217 & $10,2 \%$ & $46,9 \%$ & $53,1 \%$ \\
\cline { 2 - 6 } & 192 & 217 & $10,2 \%$ & $46,9 \%$ & $53,1 \%$ \\
\hline \multirow{3}{*}{$\mathrm{b}$} & 186 & 223 & $10,2 \%$ & $45,5 \%$ & $54,5 \%$ \\
\cline { 2 - 6 } & 186 & 223 & $10,2 \%$ & $45,5 \%$ & $54,5 \%$ \\
\cline { 2 - 6 } & 186 & 223 & $10,2 \%$ & $45,5 \%$ & $54,5 \%$ \\
\hline \multirow{3}{*}{$\mathrm{c}$} & 186 & 223 & $10,2 \%$ & $45,5 \%$ & $54,5 \%$ \\
\cline { 2 - 6 } & 186 & 223 & $10,2 \%$ & $45,5 \%$ & $54,5 \%$ \\
\cline { 2 - 6 } & 186 & 223 & $10,2 \%$ & $45,5 \%$ & $54,5 \%$ \\
\hline
\end{tabular}


APÊNDICE

\section{Resultados do Processamento da Seção de Estômago}

As tabelas a seguir são referentes aos resultados descritos para a seção de estômago, no Capítulo 6.

Tabela B.1: Número de termos raíz e número de atributos identificados usando 500 laudos de treinamento

\begin{tabular}{|c|c|c|c|c|c|c|c|c|}
\hline \multirow[b]{2}{*}{$\begin{array}{c}\text { Doc. } \\
\text { Tr }\end{array}$} & \multirow{2}{*}{ 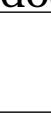 } & \multirow[b]{2}{*}{ Alpha } & \multirow[b]{2}{*}{ Theta } & \multirow{2}{*}{$\begin{array}{c}\text { Número } \\
\text { termos } \\
\text { (raíz) }\end{array}$} & \multicolumn{4}{|c|}{ Número de atributos } \\
\hline & & & & & $0 \%$ & $5 \%$ & $10 \%$ & $20 \%$ \\
\hline 500 & \multirow{3}{*}{ a } & 100 & 5 & 19 & 602 & $52(8,3 \%)$ & $41(6,8 \%)$ & $33(5,5 \%)$ \\
\hline 500 & & 100 & 10 & 15 & 542 & $52(9,6 \%)$ & $41(7,6 \%)$ & $33(6,1 \%)$ \\
\hline 500 & & 100 & 20 & 14 & 532 & $50(9,4$ & $40(7,5 \%)$ & $33(6,2 \%)$ \\
\hline 500 & \multirow{3}{*}{ b } & 95 & 5 & 21 & 590 & $48(8,1 \%)$ & $37(6,3 \%)$ & $30(5,1 \%)$ \\
\hline 500 & & 95 & 10 & 17 & 530 & $48(9,1 \%)$ & $37(7,0 \%)$ & $30(5,7 \%)$ \\
\hline 500 & & 95 & 20 & 16 & 522 & $47(9,0 \%)$ & $37(7,1 \%)$ & $30(5,7 \%)$ \\
\hline 500 & \multirow{3}{*}{$\mathrm{c}$} & 90 & 5 & 21 & 590 & $48(8,1 \%)$ & $37(6,3 \%)$ & $30(5,1 \%)$ \\
\hline 500 & & 90 & 10 & 17 & 530 & $48(9,1 \%)$ & $37(7,0 \%)$ & $30(5,7 \%)$ \\
\hline 500 & & 90 & 20 & 16 & 522 & $47(9,0 \%)$ & $37(7,1 \%)$ & $30(5,7 \%)$ \\
\hline
\end{tabular}


Tabela B.2: Tabela de precisão e recall da lista de termos gerada usando 500 laudos de treinamento

\begin{tabular}{|c|c|c|c|c|c|}
\hline $\begin{array}{c}\text { Doc. } \\
\text { Tr }\end{array}$ & Alpha & Theta & $\begin{array}{c}\text { Termos } \\
\text { Identificados }\end{array}$ & Precisão & Recall \\
\hline 500 & 100 & 5 & 19 & $53 \%$ & $48 \%$ \\
\hline 500 & 100 & 10 & 15 & $60 \%$ & $43 \%$ \\
\hline 500 & 100 & 20 & 14 & $64 \%$ & $43 \%$ \\
\hline 500 & 95 & 5 & 21 & $57 \%$ & $57 \%$ \\
\hline 500 & 95 & 10 & 17 & $65 \%$ & $52 \%$ \\
\hline 500 & 95 & 20 & 16 & $69 \%$ & $52 \%$ \\
\hline 500 & 90 & 5 & 21 & $57 \%$ & $57 \%$ \\
\hline 500 & 90 & 10 & 17 & $65 \%$ & $52 \%$ \\
\hline 500 & 90 & 20 & 16 & $69 \%$ & $52 \%$ \\
\hline
\end{tabular}

Tabela B.3: Taxa de preenchimento para o conjunto $\operatorname{Tr}$ de 500 laudos

\begin{tabular}{|c|c|c|c|c|c|}
\hline Doc. & Alpha/ & \multicolumn{4}{|c|}{ Taxa Preenchimento } \\
\hline $\operatorname{Tr}$ & Theta & $0 \%$ & $5 \%$ & $10 \%$ & $20 \%$ \\
\hline 500 & \multirow{3}{*}{ a } & 4,2 & 43,6 & 53,5 & 63,0 \\
\hline 500 & & 4,6 & 43,6 & 53,5 & 63,0 \\
\hline 500 & & 4,7 & 45,0 & 54,5 & 63,0 \\
\hline 500 & \multirow{3}{*}{ b } & 3,8 & 41,0 & 51,2 & 59,7 \\
\hline 500 & & 4,2 & 41,0 & 51,2 & 59,7 \\
\hline 500 & & 4,2 & 41,8 & 51,2 & 59,7 \\
\hline 500 & \multirow{3}{*}{ c } & 3,8 & 41,0 & 51,2 & 59,7 \\
\hline 500 & & 4,2 & 41,0 & 51,2 & 59,7 \\
\hline 500 & & 4,2 & 41,8 & 51,2 & 59,7 \\
\hline
\end{tabular}


Tabela B.4: Garbage gerado a partir do conjunto de 500 laudos de treinamento contendo 4006 frases, usando os limiares 0\%, 5\%, 10\% e 20\%

\begin{tabular}{|c|c|c|c|c|c|}
\hline $\begin{array}{c}\text { Alpha/ } \\
\text { Theta }\end{array}$ & $\begin{array}{c}\text { Número } \\
\text { parcial } \\
0 \%\end{array}$ & $\begin{array}{c}\text { Número } \\
\text { total } \\
\text { O\% }\end{array}$ & $\begin{array}{c}\text { \% processada } \\
\text { parcial / } \\
\text { sem processar }\end{array}$ & $\begin{array}{c}\% \text { processada } \\
\text { parcial }\end{array}$ & $\begin{array}{c}\text { \% sem } \\
\text { processar }\end{array}$ \\
\hline \multirow{3}{*}{$\mathrm{a}$} & 55 & 41 & $2,4 \%$ & $57,3 \%$ & $42,7 \%$ \\
\cline { 2 - 6 } & 56 & 46 & $2,5 \%$ & $54,9 \%$ & $45,1 \%$ \\
\cline { 2 - 6 } & 56 & 46 & $2,5 \%$ & $54,9 \%$ & $45,1 \%$ \\
\hline \multirow{3}{*}{$\mathrm{b}$} & 59 & 43 & $2,5 \%$ & $57,8 \%$ & $42,2 \%$ \\
\cline { 2 - 6 } & 60 & 48 & $2,7 \%$ & $55,6 \%$ & $44,4 \%$ \\
\cline { 2 - 6 } & 60 & 48 & $2,7 \%$ & $55,6 \%$ & $44,4 \%$ \\
\hline \multirow{3}{*}{$\mathrm{c}$} & 59 & 43 & $2,5 \%$ & $57,8 \%$ & $42,2 \%$ \\
\cline { 2 - 6 } & 60 & 48 & $2,7 \%$ & $55,6 \%$ & $44,4 \%$ \\
\cline { 2 - 6 } & 60 & 48 & $2,7 \%$ & $55,6 \%$ & $44,4 \%$ \\
\hline
\end{tabular}

\begin{tabular}{|c|c|c|c|c|c|}
\hline $\begin{array}{c}\text { Alpha/ } \\
\text { Theta }\end{array}$ & $\begin{array}{c}\text { Número } \\
\text { parcial } \\
5 \%\end{array}$ & $\begin{array}{c}\text { Número } \\
\text { total } \\
5 \%\end{array}$ & $\begin{array}{c}\text { \% processada } \\
\text { parcial / } \\
\text { sem processar }\end{array}$ & $\begin{array}{c}\text { \% processada } \\
\text { parcial }\end{array}$ & $\begin{array}{c}\% \text { sem } \\
\text { processar }\end{array}$ \\
\hline \multirow{3}{*}{$\mathrm{a}$} & 206 & 77 & $7,1 \%$ & $72,8 \%$ & $27,2 \%$ \\
\cline { 2 - 6 } & 206 & 77 & $7,1 \%$ & $72,8 \%$ & $27,2 \%$ \\
\cline { 2 - 6 } & 205 & 78 & $7,1 \%$ & $72,4 \%$ & $27,6 \%$ \\
\hline \multirow{3}{*}{$\mathrm{b}$} & 201 & 86 & $7,2 \%$ & $70,0 \%$ & $30,0 \%$ \\
\cline { 2 - 6 } & 201 & 86 & $7,2 \%$ & $70,0 \%$ & $30,0 \%$ \\
\cline { 2 - 6 } $\mathrm{c}$ & 201 & 86 & $7,2 \%$ & $70,0 \%$ & $30,0 \%$ \\
\cline { 2 - 6 } & 201 & 86 & $7,2 \%$ & $70,0 \%$ & $30,0 \%$ \\
\cline { 2 - 6 } & 201 & 86 & $7,2 \%$ & $70,0 \%$ & $30,0 \%$ \\
\hline
\end{tabular}

\begin{tabular}{|c|c|c|c|c|c|}
\hline $\begin{array}{c}\text { Alpha/ } \\
\text { Theta }\end{array}$ & $\begin{array}{c}\text { Número } \\
\text { parcial } \\
10 \%\end{array}$ & $\begin{array}{c}\text { Número } \\
\text { total } \\
10 \%\end{array}$ & $\begin{array}{c}\text { \% processada } \\
\text { parcial / } \\
\text { sem processar }\end{array}$ & $\begin{array}{c}\text { \% processada } \\
\text { parcial }\end{array}$ & $\begin{array}{c}\% \text { sem } \\
\text { processar }\end{array}$ \\
\hline \multirow{3}{*}{$\mathrm{a}$} & 209 & 101 & $7,7 \%$ & $67,4 \%$ & $32,6 \%$ \\
\cline { 2 - 6 } & 209 & 101 & $7,7 \%$ & $67,4 \%$ & $32,6 \%$ \\
\cline { 2 - 6 } & 207 & 103 & $7,7 \%$ & $66,8 \%$ & $33,2 \%$ \\
\hline \multirow{3}{*}{$\mathrm{b}$} & 203 & 111 & $7,8 \%$ & $64,6 \%$ & $35,4 \%$ \\
\cline { 2 - 6 } & 203 & 111 & $7,8 \%$ & $64,6 \%$ & $35,4 \%$ \\
\cline { 2 - 6 } $\mathrm{c}$ & 203 & 111 & $7,8 \%$ & $64,6 \%$ & $35,4 \%$ \\
\cline { 2 - 6 } & 203 & 111 & $7,8 \%$ & $64,6 \%$ & $35,4 \%$ \\
\cline { 2 - 6 } & 203 & 111 & $7,8 \%$ & $64,6 \%$ & $35,4 \%$ \\
\hline
\end{tabular}

\begin{tabular}{|c|c|c|c|c|c|}
\hline $\begin{array}{c}\text { Alpha/ } \\
\text { Theta }\end{array}$ & $\begin{array}{c}\text { Número } \\
\text { parcial } \\
20 \%\end{array}$ & $\begin{array}{c}\text { Número } \\
\text { total } \\
20 \%\end{array}$ & $\begin{array}{c}\text { \% processada } \\
\text { parcial / } \\
\text { sem processar }\end{array}$ & $\begin{array}{c}\text { \% processada } \\
\text { parcial }\end{array}$ & $\begin{array}{c}\% \text { sem } \\
\text { processar }\end{array}$ \\
\hline \multirow{3}{*}{ a } & 265 & 103 & $9,2 \%$ & $72,0 \%$ & $28,0 \%$ \\
\cline { 2 - 6 } & 265 & 103 & $9,2 \%$ & $72,0 \%$ & $28,0 \%$ \\
\cline { 2 - 6 } & 265 & 103 & $9,2 \%$ & $72,0 \%$ & $28,0 \%$ \\
\hline \multirow{3}{*}{$\mathrm{b}$} & 261 & 111 & $9,3 \%$ & $70,2 \%$ & $29,8 \%$ \\
\cline { 2 - 6 } & 261 & 111 & $9,3 \%$ & $70,2 \%$ & $29,8 \%$ \\
\cline { 2 - 6 } & 261 & 111 & $9,3 \%$ & $70,2 \%$ & $29,8 \%$ \\
\hline \multirow{3}{*}{$\mathrm{c}$} & 261 & 111 & $9,3 \%$ & $70,2 \%$ & $29,8 \%$ \\
\cline { 2 - 6 } & 261 & 111 & $9,3 \%$ & $70,2 \%$ & $29,8 \%$ \\
\cline { 2 - 6 } & 261 & 111 & $9,3 \%$ & $70,2 \%$ & $29,8 \%$ \\
\hline
\end{tabular}


Tabela B.5: Garbage gerado a partir do conjunto de 500 laudos de teste contendo 7966 frases, usando os limiares 0\%, 5\%, 10\% e 20\%

\begin{tabular}{|c|c|c|c|c|c|}
\hline $\begin{array}{c}\text { Alpha/ } \\
\text { Theta }\end{array}$ & $\begin{array}{c}\text { Número } \\
\text { parcial } \\
\text { O\% }\end{array}$ & $\begin{array}{c}\text { Número } \\
\text { total } \\
\text { O\% }\end{array}$ & $\begin{array}{c}\text { \% processada } \\
\text { parcial / } \\
\text { sem processar }\end{array}$ & $\begin{array}{c}\% \text { processada } \\
\text { parcial }\end{array}$ & $\begin{array}{c}\% \text { sem } \\
\text { processar }\end{array}$ \\
\hline \multirow{3}{*}{$\mathrm{a}$} & 206 & 121 & $4,1 \%$ & $63,0 \%$ & $37,0 \%$ \\
\cline { 2 - 6 } & 202 & 125 & $4,1 \%$ & $61,8 \%$ & $38,2 \%$ \\
\cline { 2 - 6 } & 200 & 128 & $4,1 \%$ & $61,0 \%$ & $39,0 \%$ \\
\hline \multirow{3}{*}{$\mathrm{b}$} & 197 & 134 & $4,2 \%$ & $59,5 \%$ & $40,5 \%$ \\
\cline { 2 - 6 } & 193 & 138 & $4,2 \%$ & $58,3 \%$ & $41,7 \%$ \\
\cline { 2 - 6 } & 193 & 138 & $4,2 \%$ & $58,3 \%$ & $41,7 \%$ \\
\hline \multirow{3}{*}{$\mathrm{c}$} & 197 & 134 & $4,2 \%$ & $59,5 \%$ & $40,5 \%$ \\
\cline { 2 - 6 } & 193 & 138 & $4,2 \%$ & $58,3 \%$ & $41,7 \%$ \\
\cline { 2 - 6 } & 193 & 138 & $4,2 \%$ & $58,3 \%$ & $41,7 \%$ \\
\hline
\end{tabular}

\begin{tabular}{|c|c|c|c|c|c|}
\hline $\begin{array}{c}\text { Alpha/ } \\
\text { Theta }\end{array}$ & $\begin{array}{c}\text { Número } \\
\text { parcial } \\
5 \%\end{array}$ & $\begin{array}{c}\text { Número } \\
\text { total } \\
5 \%\end{array}$ & $\begin{array}{c}\text { \% processada } \\
\text { parcial / } \\
\text { sem processar }\end{array}$ & $\begin{array}{c}\text { \% processada } \\
\text { parcial }\end{array}$ & $\begin{array}{c}\% \text { sem } \\
\text { processar }\end{array}$ \\
\hline \multirow{3}{*}{$\mathrm{a}$} & 364 & 166 & $6,7 \%$ & $68,7 \%$ & $31,3 \%$ \\
\cline { 2 - 6 } & 364 & 166 & $6,7 \%$ & $68,7 \%$ & $31,3 \%$ \\
\cline { 2 - 6 } & 361 & 169 & $6,7 \%$ & $68,1 \%$ & $31,9 \%$ \\
\hline \multirow{3}{*}{$\mathrm{b}$} & 352 & 186 & $6,8 \%$ & $65,4 \%$ & $34,6 \%$ \\
\cline { 2 - 6 } & 352 & 186 & $6,8 \%$ & $65,4 \%$ & $34,6 \%$ \\
\cline { 2 - 6 } & 352 & 186 & $6,8 \%$ & $65,4 \%$ & $34,6 \%$ \\
\hline \multirow{3}{*}{$\mathrm{c}$} & 352 & 186 & $6,8 \%$ & $65,4 \%$ & $34,6 \%$ \\
\cline { 2 - 6 } & 352 & 186 & $6,8 \%$ & $65,4 \%$ & $34,6 \%$ \\
\cline { 2 - 6 } & 352 & 186 & $6,8 \%$ & $65,4 \%$ & $34,6 \%$ \\
\hline
\end{tabular}

\begin{tabular}{|c|c|c|c|c|c|}
\hline $\begin{array}{c}\text { Alpha/ } \\
\text { Theta }\end{array}$ & $\begin{array}{c}\text { Número } \\
\text { parcial } \\
10 \%\end{array}$ & $\begin{array}{c}\text { Número } \\
\text { total } \\
10 \%\end{array}$ & $\begin{array}{c}\text { \% processada } \\
\text { parcial / } \\
\text { sem processar }\end{array}$ & $\begin{array}{c}\% \text { processada } \\
\text { parcial }\end{array}$ & $\begin{array}{c}\% \text { sem } \\
\text { processar }\end{array}$ \\
\hline \multirow{3}{*}{$\mathrm{a}$} & 361 & 207 & $7,1 \%$ & $63,6 \%$ & $36,4 \%$ \\
\cline { 2 - 6 } & 361 & 207 & $7,1 \%$ & $63,6 \%$ & $36,4 \%$ \\
\cline { 2 - 6 } & 356 & 212 & $7,1 \%$ & $62,7 \%$ & $37,3 \%$ \\
\hline \multirow{3}{*}{$\mathrm{b}$} & 347 & 229 & $7,2 \%$ & $60,2 \%$ & $39,8 \%$ \\
\cline { 2 - 6 } & 347 & 229 & $7,2 \%$ & $60,2 \%$ & $39,8 \%$ \\
\cline { 2 - 6 } & 347 & 229 & $7,2 \%$ & $60,2 \%$ & $39,8 \%$ \\
\cline { 2 - 6 } $\mathrm{c}$ & 347 & 229 & $7,2 \%$ & $60,2 \%$ & $39,8 \%$ \\
\cline { 2 - 6 } & 347 & 229 & $7,2 \%$ & $60,2 \%$ & $39,8 \%$ \\
\cline { 2 - 6 } & 347 & 229 & $7,2 \%$ & $60,2 \%$ & $39,8 \%$ \\
\hline
\end{tabular}

\begin{tabular}{|c|c|c|c|c|c|}
\hline $\begin{array}{c}\text { Alpha/ } \\
\text { Theta }\end{array}$ & $\begin{array}{c}\text { Número } \\
\text { parcial } \\
20 \%\end{array}$ & $\begin{array}{c}\text { Número } \\
\text { total } \\
20 \%\end{array}$ & $\begin{array}{c}\text { \% processada } \\
\text { parcial / } \\
\text { sem processar }\end{array}$ & $\begin{array}{c}\text { \% processada } \\
\text { parcial }\end{array}$ & $\begin{array}{c}\% \text { sem } \\
\text { processar }\end{array}$ \\
\hline \multirow{3}{*}{$\mathrm{a}$} & 495 & 214 & $8,9 \%$ & $69,8 \%$ & $30,2 \%$ \\
\cline { 2 - 6 } & 495 & 214 & $8,9 \%$ & $69,8 \%$ & $30,2 \%$ \\
\cline { 2 - 6 } & 495 & 214 & $8,9 \%$ & $69,8 \%$ & $30,2 \%$ \\
\hline \multirow{3}{*}{$\mathrm{b}$} & 484 & 231 & $9,0 \%$ & $67,7 \%$ & $32,3 \%$ \\
\cline { 2 - 6 } & 484 & 231 & $9,0 \%$ & $67,7 \%$ & $32,3 \%$ \\
\cline { 2 - 6 } & 484 & 231 & $9,0 \%$ & $67,7 \%$ & $32,3 \%$ \\
\hline \multirow{3}{*}{$\mathrm{c}$} & 484 & 231 & $9,0 \%$ & $67,7 \%$ & $32,3 \%$ \\
\cline { 2 - 6 } & 484 & 231 & $9,0 \%$ & $67,7 \%$ & $32,3 \%$ \\
\cline { 2 - 6 } & 484 & 231 & $9,0 \%$ & $67,7 \%$ & $32,3 \%$ \\
\hline
\end{tabular}


Tabela B.6: Número de termos raíz e número de atributos identificados usando 1000 laudos de treinamento

\begin{tabular}{|c|c|c|c|c|c|c|c|c|}
\hline \multirow{2}{*}{$\begin{array}{c}\text { Doc. } \\
\text { Tr }\end{array}$} & \multirow{2}{*}{ 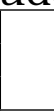 } & \multirow[b]{2}{*}{ Alpha } & \multirow[b]{2}{*}{ Theta } & \multirow{2}{*}{$\begin{array}{c}\text { Número } \\
\text { termos } \\
\text { (raíz) }\end{array}$} & \multicolumn{4}{|c|}{ Número de atributos } \\
\hline & & & & & $0 \%$ & $5 \%$ & $10 \%$ & $20 \%$ \\
\hline 1000 & & 100 & 5 & 21 & 970 & $53(5,5 \%)$ & $37(3,8 \%)$ & $32(3,3 \%)$ \\
\hline 1000 & a & 100 & 10 & 15 & 845 & $53(6,3 \%)$ & $37(4,4 \%)$ & $32(3,8 \%)$ \\
\hline 1000 & & 100 & 20 & 14 & 829 & $52(6,3 \%)$ & $36(4,3 \%)$ & $32(3,9 \%)$ \\
\hline 1000 & & 95 & 5 & 23 & 962 & $50(5,2 \%)$ & $34(3,5 \%)$ & $29(3,0 \%)$ \\
\hline 1000 & $\mathrm{~b}$ & 95 & 10 & 17 & 837 & $50(6,0 \%)$ & $34(4,1 \%)$ & $29(3,5 \%)$ \\
\hline 1000 & & 95 & 20 & 16 & 821 & $49(6,0 \%)$ & $33(4,0 \%)$ & $29(3,5 \%)$ \\
\hline 1000 & & 90 & 5 & 23 & 954 & $49(5,1 \%)$ & $33(3,5 \%)$ & $29(3,0 \%)$ \\
\hline 1000 & $\mathrm{c}$ & 90 & 10 & 17 & 829 & $49(5,9 \%)$ & $33(4,0 \%)$ & $29(3,5 \%)$ \\
\hline 1000 & & 90 & 20 & 16 & 821 & $49(6,0 \%)$ & $33(4,0 \%)$ & $29(3,5 \%)$ \\
\hline
\end{tabular}

Tabela B.7: Tabela de precisão e recall da lista de termos gerada usando 1000 laudos de treinamento

\begin{tabular}{|c|c|c|c|c|c|}
\hline $\begin{array}{c}\text { Doc. } \\
\text { Tr }\end{array}$ & Alpha & Theta & $\begin{array}{c}\text { Termos } \\
\text { Identificados }\end{array}$ & Precisão & Recall \\
\hline 1000 & 100 & 5 & 21 & $48 \%$ & $48 \%$ \\
\hline 1000 & 100 & 10 & 15 & $60 \%$ & $43 \%$ \\
\hline 1000 & 100 & 20 & 14 & $64 \%$ & $43 \%$ \\
\hline 1000 & 95 & 5 & 23 & $52 \%$ & $57 \%$ \\
\hline 1000 & 95 & 10 & 17 & $65 \%$ & $52 \%$ \\
\hline 1000 & 95 & 20 & 16 & $69 \%$ & $52 \%$ \\
\hline 1000 & 90 & 5 & 23 & $52 \%$ & $57 \%$ \\
\hline 1000 & 90 & 10 & 17 & $65 \%$ & $52 \%$ \\
\hline 1000 & 90 & 20 & 16 & $69 \%$ & $52 \%$ \\
\hline
\end{tabular}

Tabela B.8: Taxa de preenchimento para o conjunto Tr de 1000 laudos

\begin{tabular}{|c|c|c|c|c|c|}
\hline \multirow{2}{*}{$\begin{array}{c}\text { Doc. } \\
\text { Tr }\end{array}$} & \multirow{2}{*}{$\begin{array}{c}\text { Alpha/ } \\
\text { Theta }\end{array}$} & \multicolumn{4}{|c|}{ Taxa Preenchimento } \\
\hline & & $0 \%$ & $5 \%$ & $10 \%$ & $20 \%$ \\
\hline 1000 & \multirow{3}{*}{$\mathrm{a}$} & 2,5 & 40,1 & 54,4 & 60,5 \\
\hline 1000 & & 2,8 & 40,1 & 54,4 & 60,5 \\
\hline 1000 & & 2,9 & 40,6 & 55,7 & 60,5 \\
\hline 1000 & \multirow{3}{*}{ b } & 2,2 & 36,8 & 51,0 & 57,0 \\
\hline 1000 & & 2,5 & 36,8 & 51,0 & 57,0 \\
\hline 1000 & & 2,5 & 37,4 & 52,2 & 57,0 \\
\hline 1000 & \multirow{3}{*}{ c } & 2,2 & 37,4 & 52,2 & 57,0 \\
\hline 1000 & & 2,5 & 37,4 & 52,2 & 57,0 \\
\hline 1000 & & 2,5 & 37,4 & 52,2 & 57,0 \\
\hline
\end{tabular}


Tabela B.9: Garbage gerado a partir do conjunto de 1000 laudos de treinamento contendo 7962 frases, usando os limiares 0\%, 5\%, 10\% e 20\%

\begin{tabular}{|c|c|c|c|c|c|}
\hline $\begin{array}{c}\text { Alpha/ } \\
\text { Theta }\end{array}$ & $\begin{array}{c}\text { Número } \\
\text { parcial } \\
0 \%\end{array}$ & $\begin{array}{c}\text { Número } \\
\text { total } \\
0 \%\end{array}$ & $\begin{array}{c}\text { \% processada } \\
\text { parcial / } \\
\text { sem processar }\end{array}$ & $\begin{array}{c}\% \text { processada } \\
\text { parcial }\end{array}$ & $\begin{array}{c}\text { \% sem } \\
\text { processar }\end{array}$ \\
\hline \multirow{3}{*}{ a } & 122 & 89 & $2,7 \%$ & $57,8 \%$ & $42,2 \%$ \\
\cline { 2 - 6 } & 130 & 95 & $2,8 \%$ & $57,8 \%$ & $42,2 \%$ \\
\cline { 2 - 6 } & 126 & 99 & $2,8 \%$ & $56,0 \%$ & $44,0 \%$ \\
\hline \multirow{3}{*}{$\mathrm{b}$} & 124 & 91 & $2,7 \%$ & $57,7 \%$ & $42,3 \%$ \\
\cline { 2 - 6 } & 132 & 97 & $2,9 \%$ & $57,6 \%$ & $42,4 \%$ \\
\cline { 2 - 6 } & 128 & 101 & $2,9 \%$ & $55,9 \%$ & $44,1 \%$ \\
\hline \multirow{3}{*}{$\mathrm{c}$} & 120 & 95 & $2,7 \%$ & $55,8 \%$ & $44,2 \%$ \\
\cline { 2 - 6 } & 128 & 101 & $2,9 \%$ & $55,9 \%$ & $44,1 \%$ \\
\cline { 2 - 6 } & 128 & 101 & $2,9 \%$ & $55,9 \%$ & $44,1 \%$ \\
\hline
\end{tabular}

\begin{tabular}{|c|c|c|c|c|c|}
\hline $\begin{array}{c}\text { Alpha/ } \\
\text { Theta }\end{array}$ & $\begin{array}{c}\text { Número } \\
\text { parcial } \\
5 \%\end{array}$ & $\begin{array}{c}\text { Número } \\
\text { total } \\
5 \%\end{array}$ & $\begin{array}{c}\text { \% processada } \\
\text { parcial / } \\
\text { sem processar }\end{array}$ & $\begin{array}{c}\text { \% processada } \\
\text { parcial }\end{array}$ & $\begin{array}{c}\% \text { sem } \\
\text { processar }\end{array}$ \\
\hline \multirow{3}{*}{$\mathrm{a}$} & 373 & 171 & $6,8 \%$ & $68,6 \%$ & $31,4 \%$ \\
\cline { 2 - 6 } & 373 & 171 & $6,8 \%$ & $68,6 \%$ & $31,4 \%$ \\
\cline { 2 - 6 } & 373 & 172 & $6,8 \%$ & $68,4 \%$ & $31,6 \%$ \\
\hline \multirow{3}{*}{$\mathrm{b}$} & 366 & 194 & $7,0 \%$ & $65,4 \%$ & $34,6 \%$ \\
\cline { 2 - 6 } & 366 & 194 & $7,0 \%$ & $65,4 \%$ & $34,6 \%$ \\
\cline { 2 - 6 } & 363 & 198 & $7,0 \%$ & $64,7 \%$ & $35,3 \%$ \\
\hline \multirow{3}{*}{$\mathrm{c}$} & 363 & 198 & $7,0 \%$ & $64,7 \%$ & $35,3 \%$ \\
\cline { 2 - 6 } & 363 & 198 & $7,0 \%$ & $64,7 \%$ & $35,3 \%$ \\
\cline { 2 - 6 } & 363 & 198 & $7,0 \%$ & $64,7 \%$ & $35,3 \%$ \\
\hline
\end{tabular}

\begin{tabular}{|c|c|c|c|c|c|}
\hline $\begin{array}{c}\text { Alpha/ } \\
\text { Theta }\end{array}$ & $\begin{array}{c}\text { Número } \\
\text { parcial } \\
10 \%\end{array}$ & $\begin{array}{c}\text { Número } \\
\text { total } \\
10 \%\end{array}$ & $\begin{array}{c}\text { \% processada } \\
\text { parcial / } \\
\text { sem processar }\end{array}$ & $\begin{array}{c}\% \text { processada } \\
\text { parcial }\end{array}$ & $\begin{array}{c}\% \text { sem } \\
\text { processar }\end{array}$ \\
\hline \multirow{3}{*}{$\mathrm{a}$} & 470 & 218 & $8,6 \%$ & $68,3 \%$ & $31,7 \%$ \\
\cline { 2 - 6 } & 470 & 218 & $8,6 \%$ & $68,3 \%$ & $31,7 \%$ \\
\cline { 2 - 6 } & 510 & 220 & $9,2 \%$ & $69,9 \%$ & $30,1 \%$ \\
\hline \multirow{3}{*}{$\mathrm{b}$} & 453 & 245 & $8,8 \%$ & $64,9 \%$ & $35,1 \%$ \\
\cline { 2 - 6 } & 453 & 245 & $8,8 \%$ & $64,9 \%$ & $35,1 \%$ \\
\hline \multirow{3}{*}{$\mathrm{c}$} & 488 & 251 & $9,3 \%$ & $66,0 \%$ & $34,0 \%$ \\
\cline { 2 - 6 } & 488 & 251 & $9,3 \%$ & $66,0 \%$ & $34,0 \%$ \\
\cline { 2 - 6 } & 488 & 251 & $9,3 \%$ & $66,0 \%$ & $34,0 \%$ \\
\hline
\end{tabular}

\begin{tabular}{|c|c|c|c|c|c|}
\hline $\begin{array}{c}\text { Alpha/ } \\
\text { Theta }\end{array}$ & $\begin{array}{c}\text { Número } \\
\text { parcial } \\
20 \%\end{array}$ & $\begin{array}{c}\text { Número } \\
\text { total } \\
20 \%\end{array}$ & $\begin{array}{c}\text { \% processada } \\
\text { parcial / } \\
\text { sem processar }\end{array}$ & $\begin{array}{c}\text { \% processada } \\
\text { parcial }\end{array}$ & $\begin{array}{c}\% \text { sem } \\
\text { processar }\end{array}$ \\
\hline \multirow{3}{*}{$\mathrm{a}$} & 510 & 220 & $9,2 \%$ & $69,9 \%$ & $30,1 \%$ \\
\cline { 2 - 6 } & 510 & 220 & $9,2 \%$ & $69,9 \%$ & $30,1 \%$ \\
\cline { 2 - 6 } & 510 & 220 & $9,2 \%$ & $69,9 \%$ & $30,1 \%$ \\
\hline \multirow{3}{*}{$\mathrm{b}$} & 488 & 251 & $9,3 \%$ & $66,0 \%$ & $34,0 \%$ \\
\cline { 2 - 6 } & 488 & 251 & $9,3 \%$ & $66,0 \%$ & $34,0 \%$ \\
\hline \multirow{3}{*}{$\mathrm{c}$} & 488 & 251 & $9,3 \%$ & $66,0 \%$ & $34,0 \%$ \\
\cline { 2 - 6 } & 488 & 251 & $9,3 \%$ & $66,0 \%$ & $34,0 \%$ \\
\cline { 2 - 6 } & 488 & 251 & $9,3 \%$ & $66,0 \%$ & $34,0 \%$ \\
\hline
\end{tabular}


Tabela B.10: Garbage gerado a partir do conjunto de 1000 laudos de teste contendo 7971 frases, usando os limiares 0\%, 5\%, 10\% e 20\%

\begin{tabular}{|c|c|c|c|c|c|}
\hline $\begin{array}{c}\text { Alpha/ } \\
\text { Theta }\end{array}$ & $\begin{array}{c}\text { Número } \\
\text { parcial } \\
0 \%\end{array}$ & $\begin{array}{c}\text { Número } \\
\text { total } \\
0 \%\end{array}$ & $\begin{array}{c}\text { \% processada } \\
\text { parcial / } \\
\text { sem processar }\end{array}$ & $\begin{array}{c}\% \text { processada } \\
\text { parcial }\end{array}$ & $\begin{array}{c}\% \text { sem } \\
\text { processar }\end{array}$ \\
\hline \multirow{3}{*}{$\mathrm{a}$} & 203 & 96 & $3,8 \%$ & $67,9 \%$ & $32,1 \%$ \\
\cline { 2 - 6 } & 205 & 102 & $3,9 \%$ & $66,8 \%$ & $33,2 \%$ \\
\cline { 2 - 6 } & 200 & 112 & $3,9 \%$ & $64,1 \%$ & $35,9 \%$ \\
\hline \multirow{3}{*}{$\mathrm{b}$} & 199 & 104 & $3,8 \%$ & $65,7 \%$ & $34,3 \%$ \\
\cline { 2 - 6 } & 201 & 110 & $3,9 \%$ & $64,6 \%$ & $35,4 \%$ \\
\cline { 2 - 6 } & 196 & 120 & $4,0 \%$ & $62,0 \%$ & $38,0 \%$ \\
\hline \multirow{3}{*}{$\mathrm{c}$} & 194 & 114 & $3,9 \%$ & $63,0 \%$ & $37,0 \%$ \\
\cline { 2 - 6 } & 196 & 120 & $4,0 \%$ & $62,0 \%$ & $38,0 \%$ \\
\cline { 2 - 6 } & 196 & 120 & $4,0 \%$ & $62,0 \%$ & $38,0 \%$ \\
\hline
\end{tabular}

\begin{tabular}{|c|c|c|c|c|c|}
\hline $\begin{array}{c}\text { Alpha/ } \\
\text { Theta }\end{array}$ & $\begin{array}{c}\text { Número } \\
\text { parcial } \\
5 \%\end{array}$ & $\begin{array}{c}\text { Número } \\
\text { total } \\
5 \%\end{array}$ & $\begin{array}{c}\text { \% processada } \\
\text { parcial / } \\
\text { sem processar }\end{array}$ & $\begin{array}{c}\text { \% processada } \\
\text { parcial }\end{array}$ & $\begin{array}{c}\% \text { sem } \\
\text { processar }\end{array}$ \\
\hline \multirow{3}{*}{$\mathrm{a}$} & 341 & 170 & $6,4 \%$ & $66,7 \%$ & $33,3 \%$ \\
\cline { 2 - 6 } & 341 & 170 & $6,4 \%$ & $66,7 \%$ & $33,3 \%$ \\
\cline { 2 - 6 } & 342 & 170 & $6,4 \%$ & $66,8 \%$ & $33,2 \%$ \\
\hline \multirow{3}{*}{$\mathrm{b}$} & 336 & 189 & $6,6 \%$ & $64,0 \%$ & $36,0 \%$ \\
\cline { 2 - 6 } & 336 & 189 & $6,6 \%$ & $64,0 \%$ & $36,0 \%$ \\
\cline { 2 - 6 } & 337 & 189 & $6,6 \%$ & $64,1 \%$ & $35,9 \%$ \\
\hline \multirow{3}{*}{$\mathrm{c}$} & 337 & 189 & $6,6 \%$ & $64,1 \%$ & $35,9 \%$ \\
\cline { 2 - 6 } & 337 & 189 & $6,6 \%$ & $64,1 \%$ & $35,9 \%$ \\
\cline { 2 - 6 } & 337 & 189 & $6,6 \%$ & $64,1 \%$ & $35,9 \%$ \\
\hline
\end{tabular}

\begin{tabular}{|c|c|c|c|c|c|}
\hline $\begin{array}{c}\text { Alpha/ } \\
\text { Theta }\end{array}$ & $\begin{array}{c}\text { Número } \\
\text { parcial } \\
10 \%\end{array}$ & $\begin{array}{c}\text { Número } \\
\text { total } \\
10 \%\end{array}$ & $\begin{array}{c}\text { \% processada } \\
\text { parcial / } \\
\text { sem processar }\end{array}$ & $\begin{array}{c}\text { \% processada } \\
\text { parcial }\end{array}$ & $\begin{array}{c}\% \text { sem } \\
\text { processar }\end{array}$ \\
\hline \multirow{3}{*}{$\mathrm{a}$} & 467 & 214 & $8,5 \%$ & $68,6 \%$ & $31,4 \%$ \\
\cline { 2 - 6 } & 467 & 214 & $8,5 \%$ & $68,6 \%$ & $31,4 \%$ \\
\cline { 2 - 6 } & 519 & 217 & $9,2 \%$ & $70,5 \%$ & $29,5 \%$ \\
\hline \multirow{3}{*}{$\mathrm{b}$} & 455 & 235 & $8,7 \%$ & $65,9 \%$ & $34,1 \%$ \\
\cline { 2 - 6 } & 455 & 235 & $8,7 \%$ & $65,9 \%$ & $34,1 \%$ \\
\cline { 2 - 6 } & 506 & 238 & $9,3 \%$ & $68,0 \%$ & $32,0 \%$ \\
\hline \multirow{3}{*}{$\mathrm{c}$} & 506 & 238 & $9,3 \%$ & $68,0 \%$ & $32,0 \%$ \\
\cline { 2 - 6 } & 506 & 238 & $9,3 \%$ & $68,0 \%$ & $32,0 \%$ \\
\cline { 2 - 6 } & 506 & 238 & $9,3 \%$ & $68,0 \%$ & $32,0 \%$ \\
\hline
\end{tabular}

\begin{tabular}{|c|c|c|c|c|c|}
\hline $\begin{array}{c}\text { Alpha/ } \\
\text { Theta }\end{array}$ & $\begin{array}{c}\text { Número } \\
\text { parcial } \\
20 \%\end{array}$ & $\begin{array}{c}\text { Número } \\
\text { total } \\
20 \%\end{array}$ & $\begin{array}{c}\text { \% processada } \\
\text { parcial / } \\
\text { sem processar }\end{array}$ & $\begin{array}{c}\text { \% processada } \\
\text { parcial }\end{array}$ & $\begin{array}{c}\% \text { sem } \\
\text { processar }\end{array}$ \\
\hline \multirow{3}{*}{$\mathrm{a}$} & 519 & 217 & $9,2 \%$ & $70,5 \%$ & $29,5 \%$ \\
\cline { 2 - 6 } & 519 & 217 & $9,2 \%$ & $70,5 \%$ & $29,5 \%$ \\
\cline { 2 - 6 } & 519 & 217 & $9,2 \%$ & $70,5 \%$ & $29,5 \%$ \\
\hline \multirow{3}{*}{$\mathrm{b}$} & 506 & 238 & $9,3 \%$ & $68,0 \%$ & $32,0 \%$ \\
\cline { 2 - 6 } & 506 & 238 & $9,3 \%$ & $68,0 \%$ & $32,0 \%$ \\
\cline { 2 - 6 } & 506 & 238 & $9,3 \%$ & $68,0 \%$ & $32,0 \%$ \\
\hline \multirow{3}{*}{$\mathrm{c}$} & 506 & 238 & $9,3 \%$ & $68,0 \%$ & $32,0 \%$ \\
\cline { 2 - 6 } & 506 & 238 & $9,3 \%$ & $68,0 \%$ & $32,0 \%$ \\
\cline { 2 - 6 } & 506 & 238 & $9,3 \%$ & $68,0 \%$ & $32,0 \%$ \\
\hline
\end{tabular}


Tabela B.11: Número de termos raíz e número de atributos identificados usando 2000 laudos de treinamento

\begin{tabular}{|c|c|c|c|c|c|c|c|c|}
\hline \multirow{2}{*}{$\begin{array}{c}\text { Doc. } \\
\text { Tr }\end{array}$} & \multirow{2}{*}{ 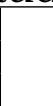 } & \multirow[b]{2}{*}{ Alpha } & \multirow[b]{2}{*}{ Theta } & \multirow{2}{*}{$\begin{array}{c}\text { Número } \\
\text { termos } \\
\text { (raíz) }\end{array}$} & \multicolumn{4}{|c|}{ Número de atributos } \\
\hline & & & & & $0 \%$ & $5 \%$ & $10 \%$ & $20 \%$ \\
\hline 2000 & \multirow{3}{*}{$\mathrm{a}$} & 100 & 5 & 20 & 1548 & $51(3,3 \%)$ & $41(2,6 \%)$ & $35(2,3 \%)$ \\
\hline 2000 & & 100 & 10 & 15 & 1299 & $51(3,9 \%)$ & $41(3,2 \%)$ & $35(2,7 \%)$ \\
\hline 2000 & & 100 & 20 & 14 & 1269 & $49(3,9 \%)$ & $40(3,2 \%)$ & $35(2,8 \%)$ \\
\hline 2000 & \multirow{3}{*}{$\mathrm{b}$} & 95 & 5 & 22 & 1534 & $48(3,1 \%)$ & $38(2,5 \%)$ & $32(2,1 \%)$ \\
\hline 2000 & & 95 & 10 & 17 & 1285 & $48(3,7 \%)$ & $38(3,0 \%)$ & $32(2,5 \%)$ \\
\hline 2000 & & 95 & 20 & 16 & 1255 & $46(3,7 \%)$ & $37(2,9 \%)$ & $32(2,5 \%)$ \\
\hline 2000 & \multirow{3}{*}{$\mathrm{c}$} & 90 & 5 & 22 & 1518 & $47(3,1 \%)$ & $37(2,4 \%)$ & $32(2,1 \%)$ \\
\hline 2000 & & 90 & 10 & 17 & 1269 & $47(3,7 \%)$ & $37(2,9 \%)$ & $32(2,5 \%)$ \\
\hline 2000 & & 90 & 20 & 16 & 1255 & $46(3,7 \%)$ & $37(2,9 \%)$ & $32(2,5 \%)$ \\
\hline
\end{tabular}

Tabela B.12: Tabela de precisão e recall da lista de termos gerada usando 2000 laudos de treinamento

\begin{tabular}{|c|c|c|c|c|c|}
\hline $\begin{array}{c}\text { Doc. } \\
\text { Tr }\end{array}$ & Alpha & Theta & $\begin{array}{c}\text { Termos } \\
\text { Identificados }\end{array}$ & Precisão & Recall \\
\hline 2000 & 100 & 5 & 20 & $50 \%$ & $48 \%$ \\
\hline 2000 & 100 & 10 & 15 & $60 \%$ & $43 \%$ \\
\hline 2000 & 100 & 20 & 14 & $64 \%$ & $43 \%$ \\
\hline 2000 & 95 & 5 & 22 & $55 \%$ & $57 \%$ \\
\hline 2000 & 95 & 10 & 17 & $65 \%$ & $52 \%$ \\
\hline 2000 & 95 & 20 & 16 & $69 \%$ & $52 \%$ \\
\hline 2000 & 90 & 5 & 22 & $55 \%$ & $57 \%$ \\
\hline 2000 & 90 & 10 & 17 & $65 \%$ & $52 \%$ \\
\hline 2000 & 90 & 20 & 16 & $69 \%$ & $52 \%$ \\
\hline
\end{tabular}

Tabela B.13: Taxa de preenchimento para o conjunto $\operatorname{Tr}$ de 2000 laudos

\begin{tabular}{|c|c|c|c|c|c|}
\hline \multirow{2}{*}{$\begin{array}{c}\text { Doc. } \\
\text { Tr }\end{array}$} & \multirow{2}{*}{$\begin{array}{c}\text { Alpha/ } \\
\text { Theta }\end{array}$} & \multicolumn{4}{|c|}{ Taxa Preenchimento } \\
\hline & & $0 \%$ & $5 \%$ & $10 \%$ & $20 \%$ \\
\hline 2000 & \multirow{3}{*}{ a } & 1,7 & 45,1 & 54,5 & 61,2 \\
\hline 2000 & & 2,0 & 45,1 & 54,5 & 61,2 \\
\hline 2000 & & 2,0 & 46,6 & 55,6 & 61,2 \\
\hline 2000 & \multirow{3}{*}{ b } & 1,5 & 42,1 & 51,4 & 58,1 \\
\hline 2000 & & 1,8 & 42,1 & 51,4 & 58,1 \\
\hline 2000 & & 1,8 & 43,5 & 52,5 & 58,1 \\
\hline 2000 & \multirow{3}{*}{ C } & 1,5 & 42,7 & 52,5 & 58,1 \\
\hline 2000 & & 1,8 & 42,7 & 52,5 & 58,1 \\
\hline 2000 & & 1,8 & 43,5 & 52,5 & 58,1 \\
\hline
\end{tabular}


Tabela B.14: Garbage gerado a partir do conjunto de 2000 laudos de treinamento contendo 15911 frases, usando os limiares $0 \%, 5 \%$, 10\% e $20 \%$

\begin{tabular}{|c|c|c|c|c|c|}
\hline $\begin{array}{c}\text { Alpha/ } \\
\text { Theta }\end{array}$ & $\begin{array}{c}\text { Número } \\
\text { parcial } \\
0 \%\end{array}$ & $\begin{array}{c}\text { Número } \\
\text { total } \\
0 \%\end{array}$ & $\begin{array}{c}\text { \% processada } \\
\text { parcial / } \\
\text { sem processar }\end{array}$ & $\begin{array}{c}\text { \% processada } \\
\text { parcial }\end{array}$ & $\begin{array}{c}\% \text { sem } \\
\text { processar }\end{array}$ \\
\hline \multirow{3}{*}{ a } & 250 & 151 & $2,5 \%$ & $62,3 \%$ & $37,7 \%$ \\
\cline { 2 - 6 } & 253 & 170 & $2,7 \%$ & $59,8 \%$ & $40,2 \%$ \\
\cline { 2 - 6 } & 239 & 185 & $2,7 \%$ & $56,4 \%$ & $43,6 \%$ \\
\hline \multirow{3}{*}{$\mathrm{b}$} & 255 & 153 & $2,6 \%$ & $62,5 \%$ & $37,5 \%$ \\
\cline { 2 - 6 } & 258 & 172 & $2,7 \%$ & $60,0 \%$ & $40,0 \%$ \\
\cline { 2 - 6 } & 243 & 188 & $2,7 \%$ & $56,4 \%$ & $43,6 \%$ \\
\hline \multirow{3}{*}{$\mathrm{c}$} & 240 & 169 & $2,6 \%$ & $58,7 \%$ & $41,3 \%$ \\
\cline { 2 - 6 } & 243 & 188 & $2,7 \%$ & $56,4 \%$ & $43,6 \%$ \\
\cline { 2 - 6 } & 243 & 188 & $2,7 \%$ & $56,4 \%$ & $43,6 \%$ \\
\hline
\end{tabular}

\begin{tabular}{|c|c|c|c|c|c|}
\hline $\begin{array}{c}\text { Alpha/ } \\
\text { Theta }\end{array}$ & $\begin{array}{c}\text { Número } \\
\text { parcial } \\
5 \%\end{array}$ & $\begin{array}{c}\text { Número } \\
\text { total } \\
5 \%\end{array}$ & $\begin{array}{c}\text { \% processada } \\
\text { parcial / } \\
\text { sem processar }\end{array}$ & $\begin{array}{c}\text { \% processada } \\
\text { parcial }\end{array}$ & $\begin{array}{c}\% \text { sem } \\
\text { processar }\end{array}$ \\
\hline \multirow{3}{*}{$\mathrm{a}$} & 716 & 423 & $7,2 \%$ & $62,9 \%$ & $37,1 \%$ \\
\cline { 2 - 6 } & 716 & 423 & $7,2 \%$ & $62,9 \%$ & $37,1 \%$ \\
\cline { 2 - 6 } & 713 & 427 & $7,2 \%$ & $62,5 \%$ & $37,5 \%$ \\
\hline \multirow{3}{*}{$\mathrm{b}$} & 680 & 480 & $7,3 \%$ & $58,6 \%$ & $41,4 \%$ \\
\cline { 2 - 6 } & 680 & 480 & $7,3 \%$ & $58,6 \%$ & $41,4 \%$ \\
\cline { 2 - 6 } & 677 & 484 & $7,3 \%$ & $58,3 \%$ & $41,7 \%$ \\
\hline \multirow{3}{*}{$\mathrm{c}$} & 676 & 484 & $7,3 \%$ & $58,3 \%$ & $41,7 \%$ \\
\cline { 2 - 6 } & 676 & 484 & $7,3 \%$ & $58,3 \%$ & $41,7 \%$ \\
\cline { 2 - 6 } & 677 & 484 & $7,3 \%$ & $58,3 \%$ & $41,7 \%$ \\
\hline
\end{tabular}

\begin{tabular}{|c|c|c|c|c|c|}
\hline $\begin{array}{c}\text { Alpha/ } \\
\text { Theta }\end{array}$ & $\begin{array}{c}\text { Número } \\
\text { parcial } \\
10 \%\end{array}$ & $\begin{array}{c}\text { Número } \\
\text { total } \\
10 \%\end{array}$ & $\begin{array}{c}\text { \% processada } \\
\text { parcial / } \\
\text { sem processar }\end{array}$ & $\begin{array}{c}\text { \% processada } \\
\text { parcial }\end{array}$ & $\begin{array}{c}\% \text { sem } \\
\text { processar }\end{array}$ \\
\hline \multirow{3}{*}{$\mathrm{a}$} & 953 & 428 & $8,7 \%$ & $69,0 \%$ & $31,0 \%$ \\
\cline { 2 - 6 } & 953 & 428 & $8,7 \%$ & $69,0 \%$ & $31,0 \%$ \\
\cline { 2 - 6 } & 947 & 434 & $8,7 \%$ & $68,6 \%$ & $31,4 \%$ \\
\hline \multirow{3}{*}{$\mathrm{b}$} & 916 & 486 & $8,8 \%$ & $65,3 \%$ & $34,7 \%$ \\
\cline { 2 - 6 } & 916 & 486 & $8,8 \%$ & $65,3 \%$ & $34,7 \%$ \\
\cline { 2 - 6 } & 910 & 492 & $8,8 \%$ & $64,9 \%$ & $35,1 \%$ \\
\hline \multirow{3}{*}{$\mathrm{c}$} & 910 & 492 & $8,8 \%$ & $64,9 \%$ & $35,1 \%$ \\
\cline { 2 - 6 } & 910 & 492 & $8,8 \%$ & $64,9 \%$ & $35,1 \%$ \\
\cline { 2 - 6 } & 910 & 492 & $8,8 \%$ & $64,9 \%$ & $35,1 \%$ \\
\hline
\end{tabular}

\begin{tabular}{|c|c|c|c|c|c|}
\hline $\begin{array}{c}\text { Alpha/ } \\
\text { Theta }\end{array}$ & $\begin{array}{c}\text { Número } \\
\text { parcial } \\
20 \%\end{array}$ & $\begin{array}{c}\text { Número } \\
\text { total } \\
20 \%\end{array}$ & $\begin{array}{c}\text { \% processada } \\
\text { parcial / } \\
\text { sem processar }\end{array}$ & $\begin{array}{c}\text { \% processada } \\
\text { parcial }\end{array}$ & $\begin{array}{c}\% \text { sem } \\
\text { processar }\end{array}$ \\
\hline \multirow{3}{*}{$\mathrm{a}$} & 1042 & 434 & $9,3 \%$ & $70,6 \%$ & $29,4 \%$ \\
\cline { 2 - 6 } & 1042 & 434 & $9,3 \%$ & $70,6 \%$ & $29,4 \%$ \\
\cline { 2 - 6 } & 1042 & 434 & $9,3 \%$ & $70,6 \%$ & $29,4 \%$ \\
\hline \multirow{3}{*}{$\mathrm{b}$} & 1003 & 492 & $9,4 \%$ & $67,1 \%$ & $32,9 \%$ \\
\cline { 2 - 6 } & 1003 & 492 & $9,4 \%$ & $67,1 \%$ & $32,9 \%$ \\
\cline { 2 - 6 } & 1003 & 492 & $9,4 \%$ & $67,1 \%$ & $32,9 \%$ \\
\hline \multirow{3}{*}{$\mathrm{c}$} & 1003 & 492 & $9,4 \%$ & $67,1 \%$ & $32,9 \%$ \\
\cline { 2 - 6 } & 1003 & 492 & $9,4 \%$ & $67,1 \%$ & $32,9 \%$ \\
\cline { 2 - 6 } & 1003 & 492 & $9,4 \%$ & $67,1 \%$ & $32,9 \%$ \\
\hline
\end{tabular}


Tabela B.15: Garbage gerado a partir do conjunto de 2000 laudos de teste contendo 8003 frases, usando os limiares 0\%, 5\%, 10\% e 20\%

\begin{tabular}{|c|c|c|c|c|c|}
\hline $\begin{array}{c}\text { Alpha/ } \\
\text { Theta }\end{array}$ & $\begin{array}{c}\text { Número } \\
\text { parcial } \\
0 \%\end{array}$ & $\begin{array}{c}\text { Número } \\
\text { total } \\
0 \%\end{array}$ & $\begin{array}{c}\text { \% processada } \\
\text { parcial / } \\
\text { sem processar }\end{array}$ & $\begin{array}{c}\% \text { processada } \\
\text { parcial }\end{array}$ & $\begin{array}{c}\% \text { sem } \\
\text { processar }\end{array}$ \\
\hline \multirow{3}{*}{$\mathrm{a}$} & 219 & 94 & $3,9 \%$ & $70,0 \%$ & $30,0 \%$ \\
\cline { 2 - 6 } & 216 & 102 & $4,0 \%$ & $67,9 \%$ & $32,1 \%$ \\
\cline { 2 - 6 } & 212 & 111 & $4,0 \%$ & $65,6 \%$ & $34,4 \%$ \\
\hline \multirow{3}{*}{$\mathrm{b}$} & 221 & 97 & $4,0 \%$ & $69,5 \%$ & $30,5 \%$ \\
\cline { 2 - 6 } & 218 & 105 & $4,0 \%$ & $67,5 \%$ & $32,5 \%$ \\
\cline { 2 - 6 } & 214 & 114 & $4,1 \%$ & $65,2 \%$ & $34,8 \%$ \\
\hline \multirow{3}{*}{$\mathrm{c}$} & 217 & 106 & $4,0 \%$ & $67,2 \%$ & $32,8 \%$ \\
\cline { 2 - 6 } & 214 & 114 & $4,1 \%$ & $65,2 \%$ & $34,8 \%$ \\
\cline { 2 - 6 } & 214 & 114 & $4,1 \%$ & $65,2 \%$ & $34,8 \%$ \\
\hline
\end{tabular}

\begin{tabular}{|c|c|c|c|c|c|}
\hline $\begin{array}{c}\text { Alpha/ } \\
\text { Theta }\end{array}$ & $\begin{array}{c}\text { Número } \\
\text { parcial } \\
5 \%\end{array}$ & $\begin{array}{c}\text { Número } \\
\text { total } \\
5 \%\end{array}$ & $\begin{array}{c}\text { \% processada } \\
\text { parcial / } \\
\text { sem processar }\end{array}$ & $\begin{array}{c}\text { \% processada } \\
\text { parcial }\end{array}$ & $\begin{array}{c}\% \text { sem } \\
\text { processar }\end{array}$ \\
\hline \multirow{3}{*}{ a } & 344 & 226 & $7,1 \%$ & $60,4 \%$ & $39,6 \%$ \\
\cline { 2 - 6 } & 344 & 226 & $7,1 \%$ & $60,4 \%$ & $39,6 \%$ \\
\cline { 2 - 6 } & 345 & 227 & $7,1 \%$ & $60,3 \%$ & $39,7 \%$ \\
\hline \multirow{3}{*}{$\mathrm{b}$} & 330 & 249 & $7,2 \%$ & $57,0 \%$ & $43,0 \%$ \\
\cline { 2 - 6 } & 330 & 249 & $7,2 \%$ & $57,0 \%$ & $43,0 \%$ \\
\cline { 2 - 6 } & 329 & 252 & $7,3 \%$ & $56,6 \%$ & $43,4 \%$ \\
\hline \multirow{3}{*}{$\mathrm{c}$} & 328 & 252 & $7,2 \%$ & $56,6 \%$ & $43,4 \%$ \\
\cline { 2 - 6 } & 328 & 252 & $7,2 \%$ & $56,6 \%$ & $43,4 \%$ \\
\cline { 2 - 6 } & 329 & 252 & $7,3 \%$ & $56,6 \%$ & $43,4 \%$ \\
\hline
\end{tabular}

\begin{tabular}{|c|c|c|c|c|c|}
\hline $\begin{array}{c}\text { Alpha/ } \\
\text { Theta }\end{array}$ & $\begin{array}{c}\text { Número } \\
\text { parcial } \\
10 \%\end{array}$ & $\begin{array}{c}\text { Número } \\
\text { total } \\
10 \%\end{array}$ & $\begin{array}{c}\text { \% processada } \\
\text { parcial / } \\
\text { sem processar }\end{array}$ & $\begin{array}{c}\text { \% processada } \\
\text { parcial }\end{array}$ & $\begin{array}{c}\% \text { sem } \\
\text { processar }\end{array}$ \\
\hline \multirow{3}{*}{$\mathrm{a}$} & 461 & 229 & $8,6 \%$ & $66,8 \%$ & $33,2 \%$ \\
\cline { 2 - 6 } & 461 & 229 & $8,6 \%$ & $66,8 \%$ & $33,2 \%$ \\
\cline { 2 - 6 } & 461 & 230 & $8,6 \%$ & $66,7 \%$ & $33,3 \%$ \\
\hline \multirow{3}{*}{$\mathrm{b}$} & 446 & 252 & $8,7 \%$ & $63,9 \%$ & $36,1 \%$ \\
\cline { 2 - 6 } & 446 & 252 & $8,7 \%$ & $63,9 \%$ & $36,1 \%$ \\
\cline { 2 - 6 } & 444 & 255 & $8,7 \%$ & $63,5 \%$ & $36,5 \%$ \\
\hline \multirow{3}{*}{$\mathrm{c}$} & 444 & 255 & $8,7 \%$ & $63,5 \%$ & $36,5 \%$ \\
\cline { 2 - 6 } & 444 & 255 & $8,7 \%$ & $63,5 \%$ & $36,5 \%$ \\
\cline { 2 - 6 } & 444 & 255 & $8,7 \%$ & $63,5 \%$ & $36,5 \%$ \\
\hline
\end{tabular}

\begin{tabular}{|c|c|c|c|c|c|}
\hline $\begin{array}{c}\text { Alpha/ } \\
\text { Theta }\end{array}$ & $\begin{array}{c}\text { Número } \\
\text { parcial } \\
20 \%\end{array}$ & $\begin{array}{c}\text { Número } \\
\text { total } \\
20 \%\end{array}$ & $\begin{array}{c}\text { \% processada } \\
\text { parcial / } \\
\text { sem processar }\end{array}$ & $\begin{array}{c}\text { \% processada } \\
\text { parcial }\end{array}$ & $\begin{array}{c}\% \text { sem } \\
\text { processar }\end{array}$ \\
\hline \multirow{3}{*}{$\mathrm{a}$} & 514 & 230 & $9,3 \%$ & $69,1 \%$ & $30,9 \%$ \\
\cline { 2 - 6 } & 514 & 230 & $9,3 \%$ & $69,1 \%$ & $30,9 \%$ \\
\cline { 2 - 6 } & 514 & 230 & $9,3 \%$ & $69,1 \%$ & $30,9 \%$ \\
\hline \multirow{3}{*}{$\mathrm{b}$} & 497 & 255 & $9,4 \%$ & $66,1 \%$ & $33,9 \%$ \\
\cline { 2 - 6 } & 497 & 255 & $9,4 \%$ & $66,1 \%$ & $33,9 \%$ \\
\hline \multirow{3}{*}{$\mathrm{c}$} & 497 & 255 & $9,4 \%$ & $66,1 \%$ & $33,9 \%$ \\
\cline { 2 - 6 } & 497 & 255 & $9,4 \%$ & $66,1 \%$ & $33,9 \%$ \\
\cline { 2 - 6 } & 497 & 255 & $9,4 \%$ & $66,1 \%$ & $33,9 \%$ \\
\hline
\end{tabular}


Tabela B.16: Número de termos raíz e número de atributos identificados usando 4000 laudos de treinamento

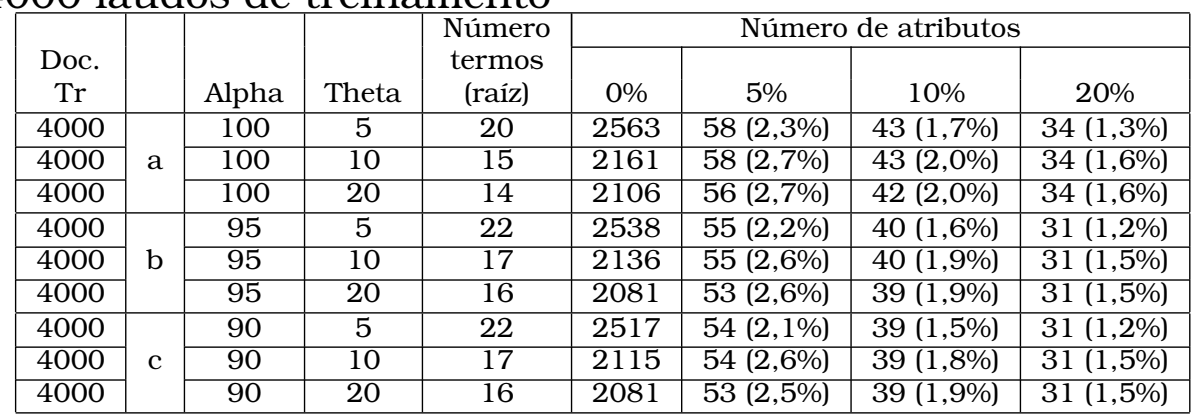

Tabela B.17: Tabela de precisão e recall da lista de termos gerada usando 4000 laudos de treinamento

\begin{tabular}{|c|c|c|c|c|c|}
\hline $\begin{array}{c}\text { Doc. } \\
\text { Tr }\end{array}$ & Alpha & Theta & $\begin{array}{c}\text { Termos } \\
\text { Identificados }\end{array}$ & Precisão & Recall \\
\hline 4000 & 100 & 5 & 20 & $50 \%$ & $48 \%$ \\
\hline 4000 & 100 & 10 & 15 & $60 \%$ & $43 \%$ \\
\hline 4000 & 100 & 20 & 14 & $64 \%$ & $43 \%$ \\
\hline 4000 & 95 & 5 & 22 & $55 \%$ & $57 \%$ \\
\hline 4000 & 95 & 10 & 17 & $65 \%$ & $52 \%$ \\
\hline 4000 & 95 & 20 & 16 & $69 \%$ & $52 \%$ \\
\hline 4000 & 90 & 5 & 22 & $55 \%$ & $57 \%$ \\
\hline 4000 & 90 & 10 & 17 & $65 \%$ & $52 \%$ \\
\hline 4000 & 90 & 20 & 16 & $69 \%$ & $52 \%$ \\
\hline
\end{tabular}

Tabela B.18: Taxa de preenchimento para o conjunto Tr de 4000 laudos

\begin{tabular}{|c|c|c|c|c|c|}
\hline \multirow{2}{*}{$\begin{array}{c}\text { Doc. } \\
\operatorname{Tr}\end{array}$} & \multirow{2}{*}{$\begin{array}{c}\text { Alpha/ } \\
\text { Theta }\end{array}$} & \multicolumn{4}{|c|}{ Taxa Preenchimento } \\
\hline & & $0 \%$ & $5 \%$ & $10 \%$ & $20 \%$ \\
\hline 4000 & \multirow{3}{*}{$\mathrm{a}$} & 1,1 & 41,0 & 53,1 & 63,0 \\
\hline 4000 & & 1,2 & 41,0 & 53,1 & 63,0 \\
\hline 4000 & & 1,3 & 42,1 & 54,1 & 63,0 \\
\hline 4000 & \multirow{3}{*}{ b } & 0,9 & 38,1 & 50,0 & 59,9 \\
\hline 4000 & & 1,1 & 38,1 & 50,0 & 59,9 \\
\hline 4000 & & 1,1 & 39,2 & 51,0 & 59,9 \\
\hline 4000 & \multirow{3}{*}{ c } & 1,0 & 38,5 & 51,0 & 59,9 \\
\hline 4000 & & 1,1 & 38,5 & 51,0 & 59,9 \\
\hline 4000 & & 1,1 & 39,2 & 51,0 & 50,9 \\
\hline
\end{tabular}


Tabela B.19: Garbage gerado a partir do conjunto de 4000 laudos de treinamento contendo 31867 frases, usando os limiares 0\%, 5\%, 10\% e 20\%

\begin{tabular}{|c|c|c|c|c|c|}
\hline $\begin{array}{c}\text { Alpha/ } \\
\text { Theta }\end{array}$ & $\begin{array}{c}\text { Número } \\
\text { parcial } \\
0 \%\end{array}$ & $\begin{array}{c}\text { Número } \\
\text { total } \\
0 \%\end{array}$ & $\begin{array}{c}\text { \% processada } \\
\text { parcial / } \\
\text { sem processar }\end{array}$ & $\begin{array}{c}\text { \% processada } \\
\text { parcial }\end{array}$ & $\begin{array}{c}\text { \% sem } \\
\text { processar }\end{array}$ \\
\hline \multirow{3}{*}{ a } & 510 & 325 & $2,6 \%$ & $61,1 \%$ & $38,9 \%$ \\
\cline { 2 - 6 } & 517 & 359 & $2,7 \%$ & $59,0 \%$ & $41,0 \%$ \\
\cline { 2 - 6 } & 487 & 390 & $2,8 \%$ & $55,5 \%$ & $44,5 \%$ \\
\hline \multirow{3}{*}{$\mathrm{b}$} & 523 & 332 & $2,7 \%$ & $61,2 \%$ & $38,8 \%$ \\
\cline { 2 - 6 } & 529 & 366 & $2,8 \%$ & $59,1 \%$ & $40,9 \%$ \\
\cline { 2 - 6 } & 496 & 400 & $2,8 \%$ & $55,4 \%$ & $44,6 \%$ \\
\hline \multirow{3}{*}{$\mathrm{c}$} & 490 & 366 & $2,7 \%$ & $57,2 \%$ & $42,8 \%$ \\
\cline { 2 - 6 } & 496 & 400 & $2,8 \%$ & $55,4 \%$ & $44,6 \%$ \\
\cline { 2 - 6 } & 496 & 400 & $2,8 \%$ & $55,4 \%$ & $44,6 \%$ \\
\hline
\end{tabular}

\begin{tabular}{|c|c|c|c|c|c|}
\hline $\begin{array}{c}\text { Alpha/ } \\
\text { Theta }\end{array}$ & $\begin{array}{c}\text { Número } \\
\text { parcial } \\
5 \%\end{array}$ & $\begin{array}{c}\text { Número } \\
\text { total } \\
5 \%\end{array}$ & $\begin{array}{c}\text { \% processada } \\
\text { parcial / } \\
\text { sem processar }\end{array}$ & $\begin{array}{c}\text { \% processada } \\
\text { parcial }\end{array}$ & $\begin{array}{c}\% \text { sem } \\
\text { processar }\end{array}$ \\
\hline \multirow{3}{*}{$\mathrm{a}$} & 1411 & 866 & $7,1 \%$ & $62,0 \%$ & $38,0 \%$ \\
\cline { 2 - 6 } & 1411 & 866 & $7,1 \%$ & $62,0 \%$ & $38,0 \%$ \\
\cline { 2 - 6 } & 1411 & 870 & $7,2 \%$ & $61,9 \%$ & $38,1 \%$ \\
\hline \multirow{3}{*}{$\mathrm{b}$} & 1344 & 977 & $7,3 \%$ & $57,9 \%$ & $42,1 \%$ \\
\cline { 2 - 6 } & 1344 & 977 & $7,3 \%$ & $57,9 \%$ & $42,1 \%$ \\
\cline { 2 - 6 } & 1340 & 985 & $7,3 \%$ & $57,6 \%$ & $42,4 \%$ \\
\hline \multirow{3}{*}{$\mathrm{c}$} & 1337 & 985 & $7,3 \%$ & $57,6 \%$ & $42,4 \%$ \\
\cline { 2 - 6 } & 1337 & 985 & $7,3 \%$ & $57,6 \%$ & $42,4 \%$ \\
\cline { 2 - 6 } & 1340 & 985 & $7,3 \%$ & $57,6 \%$ & $42,4 \%$ \\
\hline
\end{tabular}

\begin{tabular}{|c|c|c|c|c|c|}
\hline $\begin{array}{c}\text { Alpha/ } \\
\text { Theta }\end{array}$ & $\begin{array}{c}\text { Número } \\
\text { parcial } \\
10 \%\end{array}$ & $\begin{array}{c}\text { Número } \\
\text { total } \\
10 \%\end{array}$ & $\begin{array}{c}\text { \% processada } \\
\text { parcial / } \\
\text { sem processar }\end{array}$ & $\begin{array}{c}\text { \% processada } \\
\text { parcial }\end{array}$ & $\begin{array}{c}\% \text { sem } \\
\text { processar }\end{array}$ \\
\hline \multirow{3}{*}{$\mathrm{a}$} & 1894 & 871 & $8,7 \%$ & $68,5 \%$ & $31,5 \%$ \\
\cline { 2 - 6 } & 1894 & 871 & $8,7 \%$ & $68,5 \%$ & $31,5 \%$ \\
\cline { 2 - 6 } & 1886 & 880 & $8,7 \%$ & $68,2 \%$ & $31,8 \%$ \\
\hline \multirow{3}{*}{$\mathrm{b}$} & 1821 & 984 & $8,8 \%$ & $64,9 \%$ & $35,1 \%$ \\
\cline { 2 - 6 } & 1821 & 984 & $8,8 \%$ & $64,9 \%$ & $35,1 \%$ \\
\cline { 2 - 6 } & 1808 & 998 & $8,8 \%$ & $64,4 \%$ & $35,6 \%$ \\
\hline \multirow{3}{*}{$\mathrm{c}$} & 1808 & 998 & $8,8 \%$ & $64,4 \%$ & $35,6 \%$ \\
\cline { 2 - 6 } & 1808 & 998 & $8,8 \%$ & $64,4 \%$ & $35,6 \%$ \\
\cline { 2 - 6 } & 1808 & 998 & $8,8 \%$ & $64,4 \%$ & $35,6 \%$ \\
\hline
\end{tabular}

\begin{tabular}{|c|c|c|c|c|c|}
\hline $\begin{array}{c}\text { Alpha/ } \\
\text { Theta }\end{array}$ & $\begin{array}{c}\text { Número } \\
\text { parcial } \\
20 \%\end{array}$ & $\begin{array}{c}\text { Número } \\
\text { total } \\
20 \%\end{array}$ & $\begin{array}{c}\text { \% processada } \\
\text { parcial / } \\
\text { sem processar }\end{array}$ & $\begin{array}{c}\text { \% processada } \\
\text { parcial }\end{array}$ & $\begin{array}{c}\% \text { sem } \\
\text { processar }\end{array}$ \\
\hline \multirow{3}{*}{$\mathrm{a}$} & 2085 & 880 & $9,3 \%$ & $70,3 \%$ & $29,7 \%$ \\
\cline { 2 - 6 } & 2085 & 880 & $9,3 \%$ & $70,3 \%$ & $29,7 \%$ \\
\cline { 2 - 6 } & 2085 & 880 & $9,3 \%$ & $70,3 \%$ & $29,7 \%$ \\
\hline \multirow{3}{*}{$\mathrm{b}$} & 2002 & 998 & $9,4 \%$ & $66,7 \%$ & $33,3 \%$ \\
\cline { 2 - 6 } & 2002 & 998 & $9,4 \%$ & $66,7 \%$ & $33,3 \%$ \\
\cline { 2 - 6 } & 2002 & 998 & $9,4 \%$ & $66,7 \%$ & $33,3 \%$ \\
\hline \multirow{3}{*}{$\mathrm{c}$} & 2002 & 998 & $9,4 \%$ & $66,7 \%$ & $33,3 \%$ \\
\cline { 2 - 6 } & 2002 & 998 & $9,4 \%$ & $66,7 \%$ & $33,3 \%$ \\
\cline { 2 - 6 } & 2002 & 998 & $9,4 \%$ & $66,7 \%$ & $33,3 \%$ \\
\hline
\end{tabular}


Tabela B.20: Garbage gerado a partir do conjunto de 4000 laudos de teste contendo 7961 frases, usando os limiares 0\%, 5\%, 10\% e 20\%

\begin{tabular}{|c|c|c|c|c|c|}
\hline $\begin{array}{c}\text { Alpha/ } \\
\text { Theta }\end{array}$ & $\begin{array}{c}\text { Número } \\
\text { parcial } \\
\text { O\% }\end{array}$ & $\begin{array}{c}\text { Número } \\
\text { total } \\
0 \%\end{array}$ & $\begin{array}{c}\text { \% processada } \\
\text { parcial / } \\
\text { sem processar }\end{array}$ & $\begin{array}{c}\% \text { processada } \\
\text { parcial }\end{array}$ & $\begin{array}{c}\% \text { sem } \\
\text { processar }\end{array}$ \\
\hline \multirow{3}{*}{$\mathrm{a}$} & 197 & 86 & $3,6 \%$ & $69,6 \%$ & $30,4 \%$ \\
\cline { 2 - 6 } & 208 & 88 & $3,7 \%$ & $70,3 \%$ & $29,7 \%$ \\
\cline { 2 - 6 } & 200 & 97 & $3,7 \%$ & $67,3 \%$ & $32,7 \%$ \\
\hline \multirow{3}{*}{$\mathrm{b}$} & 196 & 90 & $3,6 \%$ & $68,5 \%$ & $31,5 \%$ \\
\cline { 2 - 6 } & 207 & 92 & $3,8 \%$ & $69,2 \%$ & $30,8 \%$ \\
\cline { 2 - 6 } & 199 & 101 & $3,8 \%$ & $66,3 \%$ & $33,7 \%$ \\
\hline \multirow{3}{*}{$\mathrm{c}$} & 188 & 99 & $3,6 \%$ & $65,5 \%$ & $34,5 \%$ \\
\cline { 2 - 6 } & 199 & 101 & $3,8 \%$ & $66,3 \%$ & $33,7 \%$ \\
\cline { 2 - 6 } & 199 & 101 & $3,8 \%$ & $66,3 \%$ & $33,7 \%$ \\
\hline
\end{tabular}

\begin{tabular}{|c|c|c|c|c|c|}
\hline $\begin{array}{c}\text { Alpha/ } \\
\text { Theta }\end{array}$ & $\begin{array}{c}\text { Número } \\
\text { parcial } \\
5 \%\end{array}$ & $\begin{array}{c}\text { Número } \\
\text { total } \\
5 \%\end{array}$ & $\begin{array}{c}\text { \% processada } \\
\text { parcial / } \\
\text { sem processar }\end{array}$ & $\begin{array}{c}\text { \% processada } \\
\text { parcial }\end{array}$ & $\begin{array}{c}\% \text { sem } \\
\text { processar }\end{array}$ \\
\hline \multirow{3}{*}{ a } & 368 & 206 & $7,2 \%$ & $64,1 \%$ & $35,9 \%$ \\
\cline { 2 - 6 } & 368 & 206 & $7,2 \%$ & $64,1 \%$ & $35,9 \%$ \\
\cline { 2 - 6 } & 365 & 209 & $7,2 \%$ & $63,6 \%$ & $36,4 \%$ \\
\hline \multirow{3}{*}{$\mathrm{b}$} & 345 & 237 & $7,3 \%$ & $59,3 \%$ & $40,7 \%$ \\
\cline { 2 - 6 } & 345 & 237 & $7,3 \%$ & $59,3 \%$ & $40,7 \%$ \\
\cline { 2 - 6 } & 340 & 242 & $7,3 \%$ & $58,4 \%$ & $41,6 \%$ \\
\hline \multirow{3}{*}{$\mathrm{c}$} & 340 & 242 & $7,3 \%$ & $58,4 \%$ & $41,6 \%$ \\
\cline { 2 - 6 } & 340 & 242 & $7,3 \%$ & $58,4 \%$ & $41,6 \%$ \\
\cline { 2 - 6 } & 340 & 242 & $7,3 \%$ & $58,4 \%$ & $41,6 \%$ \\
\hline
\end{tabular}

\begin{tabular}{|c|c|c|c|c|c|}
\hline $\begin{array}{c}\text { Alpha/ } \\
\text { Theta }\end{array}$ & $\begin{array}{c}\text { Número } \\
\text { parcial } \\
10 \%\end{array}$ & $\begin{array}{c}\text { Número } \\
\text { total } \\
10 \%\end{array}$ & $\begin{array}{c}\text { \% processada } \\
\text { parcial / } \\
\text { sem processar }\end{array}$ & $\begin{array}{c}\text { \% processada } \\
\text { parcial }\end{array}$ & $\begin{array}{c}\text { \% sem } \\
\text { processar }\end{array}$ \\
\hline \multirow{3}{*}{$\mathrm{a}$} & 482 & 211 & $8,7 \%$ & $69,6 \%$ & $30,4 \%$ \\
\cline { 2 - 6 } & 482 & 211 & $8,7 \%$ & $69,6 \%$ & $30,4 \%$ \\
\cline { 2 - 6 } & 477 & 216 & $8,7 \%$ & $68,8 \%$ & $31,2 \%$ \\
\hline \multirow{3}{*}{$\mathrm{b}$} & 457 & 243 & $8,8 \%$ & $65,3 \%$ & $34,7 \%$ \\
\cline { 2 - 6 } & 457 & 243 & $8,8 \%$ & $65,3 \%$ & $34,7 \%$ \\
\cline { 2 - 6 } & 449 & 251 & $8,8 \%$ & $64,1 \%$ & $35,9 \%$ \\
\hline \multirow{3}{*}{$\mathrm{c}$} & 449 & 251 & $8,8 \%$ & $64,1 \%$ & $35,9 \%$ \\
\cline { 2 - 6 } & 449 & 251 & $8,8 \%$ & $64,1 \%$ & $35,9 \%$ \\
\cline { 2 - 6 } & 449 & 251 & $8,8 \%$ & $64,1 \%$ & $35,9 \%$ \\
\hline
\end{tabular}

\begin{tabular}{|c|c|c|c|c|c|}
\hline $\begin{array}{c}\text { Alpha/ } \\
\text { Theta }\end{array}$ & $\begin{array}{c}\text { Número } \\
\text { parcial } \\
20 \%\end{array}$ & $\begin{array}{c}\text { Número } \\
\text { total } \\
20 \%\end{array}$ & $\begin{array}{c}\text { \% processada } \\
\text { parcial / } \\
\text { sem processar }\end{array}$ & $\begin{array}{c}\text { \% processada } \\
\text { parcial }\end{array}$ & $\begin{array}{c}\% \text { sem } \\
\text { processar }\end{array}$ \\
\hline \multirow{3}{*}{$\mathrm{a}$} & 522 & 216 & $9,3 \%$ & $70,7 \%$ & $29,3 \%$ \\
\cline { 2 - 6 } & 522 & 216 & $9,3 \%$ & $70,7 \%$ & $29,3 \%$ \\
\cline { 2 - 6 } & 522 & 216 & $9,3 \%$ & $70,7 \%$ & $29,3 \%$ \\
\hline \multirow{3}{*}{$\mathrm{b}$} & 494 & 251 & $9,4 \%$ & $66,3 \%$ & $33,7 \%$ \\
\cline { 2 - 6 } & 494 & 251 & $9,4 \%$ & $66,3 \%$ & $33,7 \%$ \\
\cline { 2 - 6 } & 494 & 251 & $9,4 \%$ & $66,3 \%$ & $33,7 \%$ \\
\hline \multirow{3}{*}{$\mathrm{c}$} & 494 & 251 & $9,4 \%$ & $66,3 \%$ & $33,7 \%$ \\
\cline { 2 - 6 } & 494 & 251 & $9,4 \%$ & $66,3 \%$ & $33,7 \%$ \\
\cline { 2 - 6 } & 494 & 251 & $9,4 \%$ & $66,3 \%$ & $33,7 \%$ \\
\hline
\end{tabular}

